RODRIGO VIDONSCKY PINTO

\begin{abstract}
Análise da modelagem utilizada para a simulação computacional do desempenho de um tubo de calor utilizando nanofluidos em seu interior
\end{abstract}


Análise da modelagem utilizada para a simulação computacional do desempenho de um tubo de calor utilizando nanofluidos em seu interior

Dissertação apresentada à Escola Politécnica da Universidade de São Paulo para obtenção do título de Mestre em Ciências

Orientador: Prof. Dr. Flávio Augusto Sanzovo Fiorelli 


\section{Análise da modelagem utilizada para a simulação computacional do desempenho de um tubo de calor utilizando nanofluidos em seu interior}

Dissertação apresentada à Escola Politécnica da Universidade de São Paulo para obtenção do título de Mestre em Ciências

Área de Concentração: Energia e Fluidos

Orientador: Prof. Dr. Flávio Augusto Sanzovo Fiorelli 
exemplar foi revisado e corrigido em relação à versão original, sob responsabilidade única do autor e com a anuência de seu orientador.

São Paulo, de de

Assinatura do autor:

Assinatura do orientador:

Pinto, Rodrigo Vidonscky

Análise da modelagem utilizada para a simulação computacional do desempenho de um tubo de calor utilizando nanofluidos em seu interior / R. V. Pinto -- versão corr. -- São Paulo, 2016.

$$
175 \mathrm{p} \text {. }
$$

Dissertação (Mestrado) - Escola Politécnica da Universidade de São Paulo. Departamento de Engenharia Mecânica.

1.NANOPARTÍCULAS (SIMULAÇÃO COMPUTACIONAL)

2.TERMODINÂMICA (RESISTENCIA) 3.ENGENHARIA TÉRMICA 4.MÉTODO DOS ELEMENTOS FINITOS I.Universidade de São Paulo. Escola

Politécnica. Departamento de Engenharia Mecânica Il.t. 


\section{AGRADECIMENTOS}

Gostaria de agradecer primeiramente aos meus pais, sem os quais não teria sido possível ter o tempo e a tranquilidade necessários para a elaboração deste trabalho. Agradeço também aos meus familiares e amigos, por contribuírem fornecendo o apoio necessário e o incentivo que precisei em todos os momentos.

Gostaria também de agradecer ao Prof. Dr. Flávio Augusto Sanzovo Fiorelli, meu orientador, o qual fez tudo que estava ao seu alcance para me ajudar em diversos momentos ao longo deste programa de mestrado, e sem o qual, este trabalho também não teria se tornado realidade.

Gostaria também de agradecer à Universidade de São Paulo e a todo o departamento de Engenharia Mecânica da Escola Politécnica da Universidade de São Paulo, por fornecerem a estrutura necessária para que a maior parte das atividades do meu mestrado pudesse ser cumprida sem grandes perturbações.

Em especial, gostaria de agradecer aos Profs. Drs. Alberto Hernandez Neto e Marcos de Mattos Pimenta, os quais participaram da pré-banca de qualificação deste trabalho e forneceram uma grande ajuda apontando os principais problemas que existiam no momento da qualificação.

Por fim, também gostaria de agradecer ao Conselho Nacional de Desenvolvimento Científico e Tecnológico (CNPq) por ter apoiado o desenvolvimento deste trabalho, permitindo assim a conclusão do mesmo em um tempo adequado. 
A natureza não nos faz crescer

Apenas em forças e tamanho.

À medida que este templo se amplia,

Amplia-se dentro dele o espaço reservado

Pra alma e pra inteligência.

William Shakespeare 


\section{RESUMO}

A aplicação de nanofluidos em tubos de calor em geral apresenta resultados experimentais satisfatórios em estudos buscando obter uma redução na resistência térmica do tubo de calor. No entanto, os estudos computacionais existentes associando tubos de calor e nanofluidos apresentam resultados conflitantes e carecem de uma discussão mais aprofundada a respeito da validade dos modelos utilizados para a representação computacional do comportamento de um nanofluido em tubo de calor, especialmente utilizando materiais e fluidos não convencionais como nanotubos de carbono ou etilenoglicol. Assim, o presente estudo busca avaliar a exatidão e a precisão obtida em uma série de simulações computacionais utilizando diferentes equações disponíveis na literatura para a modelagem de um nanofluido em um tubo de calor por meio da comparação com dados experimentais da literatura. Esta modelagem utiliza o método dos volumes finitos e permite determinar o efeito da variação dos modelos de propriedades e da concentração volumétrica de um nanofluido nos campos de temperaturas e nas resistências térmicas resultantes das simulações. Os resultados obtidos apresentam concordância com o comportamento esperado do ponto de vista qualitativo, mas falham em representar quantitativamente o comportamento da seção do evaporador dos tubos de calor estudados, apresentando variações máximas entre $1,5 \%$ e $23,9 \%$ em relação às temperaturas medidas experimentalmente. Isso pode ser justificado pelo fato de que a modelagem do fenômeno de ebulição de um nanofluido é mais complexa do que a modelagem utilizada atualmente em simulações computacionais. Essa consideração possui suporte na literatura e cria possibilidades para pesquisas futuras.

Palavras-Chave: Tubos de calor. Nanofluidos. Nanotubos de carbono. Etilenoglicol. Análise computacional. 


\begin{abstract}
Application of nanofluids in heat pipes usually presents satisfactory experimental results in studies seeking to reduce the thermal resistance of the heat pipe. However, the existing computational studies connecting heat pipes and nanofluids present conflicting results and lack a deeper discussion regarding the validity of the models currently used for the computational representation of the behavior of a nanofluid in a heat pipe, especially using unusual materials and fluids, like carbon nanotubes or ethylene glycol. Thus, the present study seek to analyze the accuracy and the precision obtained in a set of computational simulations using pre-established equations for the modeling of a nanofluid in a heat pipe by using a direct comparison with existing experimental data. This modeling uses the finite volume method and permits to determine the effect of the variation of the properties models and the volume fraction of a nanofluid in the resulting temperature fields and the thermal resistances of the simulations. The obtained results show agreement with the expected behavior qualitatively, but fail to represent the phenomenon quantitatively, presenting maximum variations between 1,5\% and 23,9\% comparing to the experimentally measured average temperatures. This is justified by the hypothesis that the ebullition phenomenon modeling is more complex than the modeling currently used for computational simulations. This hypothesis is supported by the literature and creates possibilities for future researches.
\end{abstract}

Keywords: Heat Pipes. Nanofluids. Carbon Nanotubes. Etyhlene Glycol. Computational Analysis. 


\section{LISTA DE FIGURAS}

Figura 1. Esquema de funcionamento de um tubo de calor (Chi, 1976)

Figura 2. Tipos de matrizes porosas no interior de um tubo de calor 14

Figura 3. Termosifão bifásico fechado (adaptada de Thermal-Fluids 15 Central, 2010-2011)

Figura 4. Tubo de calor oscilante (OHP) (adaptada de Fasula, 2009) 15

Figura 5. Perfil de temperaturas de um tubo de calor contendo água 17 para uma potência térmica de 24 W (adaptada de Zerbini, 1984)

Figura 6. Perfil de temperaturas de um tubo de calor contendo água para uma potência térmica de 37 W (adaptada de Zerbini, 1984)

Figura 7. Perfil de temperaturas de um tubo de calor contendo água para uma potência térmica de 49 W (adaptada de Zerbini, 1984)

Figura 8. Intensificação da condutividade térmica de nanofluidos contendo etilenoglicol e partículas de diferentes óxidos (Xie et al., 2011)

Figura 9. Intensificação da condutividade térmica de nanofluidos contendo etilenoglicol e partículas diversas (Xie et al., 2011)

Figura 10. Intensificação da condutividade térmica de nanofluidos contendo etilenoglicol e $\mathrm{ZnO}$ - Comparação entre modelos da literatura (Yu et al., 2009)

Figura 11. Amostra de nanofluido contendo nanotubos de carbono a concentração mássica de 1\% (Liu e Lu, 2009)

Figura 12. Perfis de temperaturas na parede do tubo de calor (Liu e Lu, 2009)

Figura 13. Coeficiente de transferência de calor por evaporação em função da quantidade de calor inserida no tubo de calor para diferentes concentrações mássicas de nanopartículas 
(Liu e Lu, 2009)

Figura 14. Resistência térmica do tubo de calor em função da quantidade de calor inserida no tubo de calor para diferentes concentrações mássicas de nanopartículas (Liu e Lu, 2009)

Figura 15. Intensificação da condutividade térmica de nanofluidos contendo etilenoglicol (Putra et al., 2012)

Figura 16. Perfis de temperatura de tubos de calor contendo fluidosbase e nanofluidos de diferentes composições (Putra et al., 2012)

Figura 17. Coeficientes de transferência de calor por evaporação obtidos na seção do evaporador de tubos de calor contendo fluidos-base e nanofluidos de diferentes composições (Putra et al., 2012)

Figura 18. Comparação entre os perfis de temperaturas da parede de um termosifão bifásico fechado contendo água, obtidos experimentalmente e computacionalmente (adaptada de Asmaie et al., 2013)

Figura 19. Comparação entre os perfis de temperaturas da parede de um termosifão bifásico fechado contendo nanofluido, obtidos experimentalmente e computacionalmente (adaptada de Asmaie et al., 2013)

Figura 20. Efeito da concentração mássica de nanopartículas no perfil de temperaturas de um termosifão bifásico fechado (adaptada de Asmaie et al., 2013)

Figura 21. Perfis de temperaturas na parede de um tubo de calor contendo nanofluidos compostos por água e Al203 para diferentes concentrações de nanopartículas (Shafahi et al., 2010)

Figura 22. Perfis de temperaturas na parede de um tubo de calor contendo nanofluidos compostos por água e TiO2 para diferentes concentrações de nanopartículas (Shafahi et al., 2010) 
Figura 23. Perfis de temperaturas na parede de um tubo de calor contendo nanofluidos compostos por água e $\mathrm{CuO}$ para diferentes concentrações de nanopartículas (Shafahi et al., 2010)

Figura 24. Resistência térmica de tubos de calor contendo diferentes nanofluidos, para concentrações entre $1 \%$ e $4 \%$ de nanopartículas. (Shafahi et al., 2010)

Figura 25. Perfis de temperatura de um tubo de calor contendo nanofluidos compostos por água e $\mathrm{Al} 203$ em diferentes concentrações (adaptada de Gavtash et al., 2012)

Figura 26. Resistência térmica de um tubo de calor contendo um nanofluido composto por água e Al203 em função da concentração de nanopartículas (adaptada de Gavtash et al., 2012)

Figura 27. Perfis de temperatura de um tubo de calor contendo nanofluidos compostos por diferentes nanopartículas (adaptada de Gavtash et al., 2012)

Figura 28. Resistência térmica do tubo de calor contendo nanofluidos compostos por nanopartículas de condutividade térmica distinta (adaptada de Gavtash et al., 2012)

Figura 29. Perfis de temperatura da parede de um tubo de calor contendo água deionizada e nanofluidos em diferentes concentrações de nanopartículas (adaptada de Huminic e Huminic, 2009)

Figura 30. Resistência térmica do tubo de calor contendo nanofluidos em diferentes concentrações volumétricas (adaptada de Huminic e Huminic, 2009)

Figura 31. Trecho da malha computacional construída para a 80 simulação do tubo de calor de estudo de Zerbini (1984)

Figura 32. Trecho da malha computacional construída para a avaliação do tubo de calor do estudo de Liu e Lu (2009) Seção do condensador

Figura 33. Trecho da malha computacional construída para a 
avaliação do tubo de calor do estudo de Putra et al. (2012)

Figura 34. Valor da função de Reynolds utilizada para a determinação

da permeabilidade de matrizes porosas contendo aberturas retangulares (adaptada de Chi, 1976)

Figura 35. Representação das condições de contorno aplicadas na transição entre a seção do evaporador e a seção adiabática

Figura 36. Representação das condições de contorno aplicadas na transição entre a seção do condensador e a seção adiabática

Figura 37. Comparação entre o perfil de temperaturas obtido experimentalmente no trabalho de Zerbini (1984) e o perfil de temperaturas obtido computacionalmente pelo CFX para $\dot{Q}=24 W$

Figura 38. Comparação entre o perfil de temperaturas obtido experimentalmente no trabalho de Zerbini (1984) e o perfil de temperaturas obtido computacionalmente pelo CFX para $\dot{Q}=37 \mathrm{~W}$

Figura 39. Comparação entre o perfil de temperaturas obtido experimentalmente no trabalho de Zerbini (1984) e o perfil de temperaturas obtido computacionalmente pelo CFX para $\dot{Q}=49 \mathrm{~W}$

Figura 40. Comparação entre os perfis de temperaturas obtidos experimentalmente no trabalho de Liu e $\mathrm{Lu}$ (2009) e os perfis de temperaturas obtidos computacionalmente pelo CFX para diferentes potências térmicas inseridas na seção do evaporador

Figura 41. Comparação entre o perfil de temperaturas obtido experimentalmente no trabalho de Putra et al. (2012) e o perfil de temperaturas obtido computacionalmente pelo CFX para água como fluido de trabalho

Figura 42. Comparação entre o perfil de temperaturas obtido experimentalmente no trabalho de Putra et al. (2012) e o perfil de temperaturas obtido computacionalmente pelo 
CFX para água como fluido de trabalho - detalhe da seção do evaporador e seção adiabática

Figura 43. Comparação entre o perfil de temperaturas obtido experimentalmente no trabalho de Putra et al. (2012) e o perfil de temperaturas obtido computacionalmente pelo CFX para etilenoglicol como fluido de trabalho - detalhe da seção do evaporador e seção adiabática

Figura 44. Comparação entre os perfis de temperaturas experimentais e computacionais do tubo de calor de Liu e Lu (2009) contendo água e um nanofluido composto por água e nanotubos de carbono - $\dot{Q}=10 \mathrm{~W}$

Figura 45. Comparação entre os perfis de temperaturas experimentais e computacionais do tubo de calor de Liu e Lu (2009) contendo água e um nanofluido composto por água e nanotubos de carbono $-\dot{Q}=40 \mathrm{~W}$

Figura 46. Comparação entre os perfis de temperaturas experimentais e computacionais do tubo de calor de Liu e Lu (2009) contendo água e um nanofluido composto por água e nanotubos de carbono $-\dot{Q}=70 \mathrm{~W}$

Figura 47. Comparação entre os perfis de temperaturas experimentais e computacionais do tubo de calor de Liu e Lu (2009) contendo água e um nanofluido composto por água e nanotubos de carbono $-\dot{Q}=80 \mathrm{~W}$

Figura 48. Comparação entre os as condutividades térmicas obtidas utilizando correlações da literatura e os dados fornecidos por Putra et. al (2012) para o nanofluido composto por etilenoglicol e óxido de zinco

Figura 49. Comparação entre os perfis de temperaturas experimentais e computacionais do tubo de calor de Putra et. al (2012) contendo água, etilenoglicol e um nanofluido composto por etilenoglicol e óxido de zinco

Figura 50. Análise de sensibilidade da potência térmica do tubo de 
calor de Zerbini (1984) contendo água para $\dot{Q}=37 \mathrm{~W} \pm$ $5,1 \%$

Figura 51. Análise de sensibilidade da potência térmica do tubo de calor de Liu e Lu (2009) contendo água para $\dot{Q}=40 \mathrm{~W} \pm$ $4 \%$

Figura 52. Análise de sensibilidade da potência térmica do tubo de calor de Liu e Lu (2009) contendo água para $\dot{Q}=70 \mathrm{~W} \pm$ $4 \%$

Figura 53. Análise de sensibilidade da potência térmica do tubo de calor de Putra et al. (2012) contendo água para $\dot{Q}=$ $30 W \pm 2 \%$

Figura 54. Intensificação proporcional obtida para a condutividade térmica dos nanofluidos estudados

Figura 55. Análise de sensibilidade da concentração volumétrica de nanopartículas do nanofluido do tubo de calor de Liu e Lu (2009) contendo um nanofluido composto por água e nanotubos de carbono para $\varphi=1 \%$

Figura 56. Análise de sensibilidade da concentração volumétrica de nanopartículas do nanofluido do tubo de calor de Liu e Lu (2009) contendo um nanofluido composto por água e nanotubos de carbono para $\varphi=2 \%$

Figura 57. Análise de sensibilidade da concentração volumétrica de nanopartículas do nanofluido do tubo de calor de Liu e Lu (2009) contendo um nanofluido composto por água e nanotubos de carbono para $\varphi=5 \%$

Figura 58. Análise de sensibilidade da concentração volumétrica de nanopartículas do nanofluido do tubo de calor de Liu e Lu (2009) contendo um nanofluido composto por água e nanotubos de carbono para $\varphi=6 \%$

Figura 59. Análise de sensibilidade da concentração volumétrica de nanopartículas do nanofluido do tubo de calor de Liu e Lu (2009) contendo um nanofluido composto por água e nanotubos de carbono para $\varphi=9 \%$ 
Figura 60. Análise de sensibilidade da concentração volumétrica de nanopartículas do nanofluido do tubo de calor de Liu e $\mathrm{Lu}$ (2009) contendo um nanofluido composto por água e nanotubos de carbono para $\varphi=10 \%$

Figura 61. Resistências térmicas obtidas por meio de 10 148 aproximações lineares inseridas entre as resistências térmicas obtidas para os casos DTMax e DTMin no tubo de calor de Liu e Lu (2009) para $\dot{Q}=70 \mathrm{~W}$

Figura 62. Análise de sensibilidade da concentração volumétrica de nanopartículas do nanofluido do tubo de calor de Putra et al. (2012) contendo um nanofluido composto por etilenoglicol e óxido de zinco para $\varphi=1 \%$

Figura 63. Análise de sensibilidade da concentração volumétrica de 149 nanopartículas do nanofluido do tubo de calor de Putra et al. (2012) contendo um nanofluido composto por etilenoglicol e óxido de zinco para $\varphi=2 \%$

Figura 64. Análise de sensibilidade da concentração volumétrica de 149 nanopartículas do nanofluido do tubo de calor de Putra et al. (2012) contendo um nanofluido composto por etilenoglicol e óxido de zinco para $\varphi=5 \%$

Figura 65. Análise de sensibilidade da concentração volumétrica de 150 nanopartículas do nanofluido do tubo de calor de Putra et al. (2012) contendo um nanofluido composto por etilenoglicol e óxido de zinco para $\varphi=6 \%$

Figura 66. Análise de sensibilidade da concentração volumétrica de 150 nanopartículas do nanofluido do tubo de calor de Putra et al. (2012) contendo um nanofluido composto por etilenoglicol e óxido de zinco para $\varphi=9 \%$

Figura 67. Análise de sensibilidade da concentração volumétrica de nanopartículas do nanofluido do tubo de calor de Putra et al. (2012) contendo um nanofluido composto por etilenoglicol e óxido de zinco para $\varphi=10 \%$

Figura 68. Representação esquemática do balanço de energia feito na 
parede da seção do evaporador do tubo de calor de Zerbini (1984)

Figura 69. Representação esquemática do balanço de energia feito na parede da seção do condensador do tubo de calor de Putra et al. (2012) 


\section{LISTA DE TABELAS}

Tabela 1. Efeito da presença de nanopartículas dispersas na 8 condutividade térmica em um fluido-base (adaptada de Saidur et al., 2011)

Tabela 2. Dimensões representativas do tubo de calor utilizado em Zerbini (1984)

Tabela 3. Modelos de viscosidade apresentados em Mishra et al (2014)

Tabela 4. Descrição dos modelos de viscosidade apresentados em 30 Mishra et al. (2014)

Tabela 5. Dimensões utilizadas no tubo de calor do estudo de Liu e Lu (2009)

Tabela 6. Dimensões utilizadas no tubo de calor do estudo de Putra 58 et al. (2012)

Tabela 7. Dimensões do tubo de calor utilizado em Huminic e 74 Huminic (2009)

Tabela 8. Seleção dos casos experimentais a serem estudados

Tabela 9. Condições de contorno térmicas adotadas para as interações com meio externo para o trabalho de Zerbini (1984)

Tabela 10. Parâmetros $\eta$ provenientes da análise de balanço de 103 energia adotados para o trabalho de Zerbini (1984)

Tabela 11. Condições de contorno térmicas adotadas para os 103 processos de evaporação e condensação para o trabalho de Zerbini (1984)

Tabela 12. Condições de contorno hidrodinâmicas adotadas para os 104 processos de evaporação e condensação para o trabalho de Zerbini (1984)

Tabela 13. Condutividade térmica do nanofluido contendo nanotubos de carbono do estudo de Liu e Lu (2009) e de fluidos comparativos

Tabela 14. Viscosidade absoluta do nanofluido contendo nanotubos de 
carbono do estudo de Liu e Lu (2009) e de fluidos comparativos

Tabela 15. Condições de contorno térmicas adotadas para as interações com meio externo adotadas para o trabalho de Liu e Lu (2009)

Tabela 16. Parâmetros $\eta$ provenientes da análise de balanço de 108 energia adotados para o trabalho de Liu e Lu (2009)

Tabela 17. Condições de contorno térmicas adotadas para os 108 processos de evaporação e condensação para o trabalho de Liu e Lu (2009)

Tabela 18. Condições de contorno hidrodinâmicas adotadas para os 109 processos de evaporação e condensação para o trabalho de Liu e Lu (2009)

Tabela 19 Condutividade térmica do nanofluido contendo etilenoglicol e ZnO do estudo de Putra et al. (2012) e de fluidos comparativos

Tabela 20. Viscosidade absoluta do nanofluido contendo etilenoglicol e ZnO do estudo de Putra et. al (2012) e de fluidos comparativos

Tabela 21. Condições de contorno térmicas adotadas para as interações com meio externo para o trabalho de Putra et al. (2012)

Tabela 22. Parâmetros $\eta$ provenientes da análise de balanço de 114 energia adotados para o trabalho de Putra et al. (2012)

Tabela 23. Condições de contorno térmicas adotadas para os processos de evaporação e condensação no trabalho de Putra et al. (2012)

Tabela 24. Condições de contorno hidrodinâmicas adotadas nos processos de evaporação e condensação para o trabalho de Putra et al. (2012)

Tabela 25. Resistências térmicas obtidas experimentalmente e 118 computacionalmente para o tubo de calor de Zerbini (1984) 
Tabela 26. Comparação entre os perfis de temperaturas do tubo de calor de Liu e Lu (2009) contendo água para diferentes potências térmicas inseridas

Tabela 27. Resistências térmicas obtidas experimentalmente e 121 computacionalmente para o tubo de calor de Liu e $\mathrm{Lu}$ (2009) contendo água

Tabela 28. Resistências térmicas obtidas experimentalmente e computacionalmente para o tubo de calor de Putra et al. (2012) contendo água

Tabela 29. Resistências térmicas obtidas experimentalmente e 125 computacionalmente para o tubo de calor de Putra et al. (2012) contendo etilenoglicol

Tabela 30. Resistências térmicas obtidas experimentalmente e computacionalmente para o tubo de calor de Liu e $\mathrm{Lu}$ (2009) contendo um nanofluido composto por água e nanotubos de carbono

Tabela 31. Resistências térmicas obtidas experimentalmente e computacionalmente para o tubo de calor de Putra et al. (2012) contendo água, etilenoglicol e um nanofluido composto por etilenoglicol e óxido de zinco

Tabela 32. Valores das incertezas associadas à potência térmica de cada tubo de calor

Tabela 33. Conjunto de propriedades dos nanofluidos contendo água e nanotubos de carbono para diferentes concentrações volumétricas de nanopartículas

Tabela 34. Conjunto de propriedades dos nanofluidos contendo etilenoglicol e óxido de zinco para diferentes concentrações volumétricas de nanopartículas

Tabela 35. Resistências térmicas do tubo de calor de Liu e Lu (2009) contendo nanofluidos compostos por água e nanotubos de carbono em diferentes concentrações volumétricas

Tabela 36. Resistências térmicas do tubo de calor de Putra et al. (2012) contendo nanofluidos compostos por etilenoglicol e 
óxido de zinco em diferentes concentrações volumétricas

Tabela 37. Resultados obtidos para a análise da porcentagem de calor conduzido pela parede do tubo de calor da seção do evaporador para a seção adiabática

Tabela 38. Resultados obtidos para a análise da porcentagem de calor retirado pela condição de contorno da seção do condensador do tubo de calor de Putra et al. (2012) 


\section{LISTA DE ABREVIATURAS E SIGLAS}

Ad. Seção adiabática

AL Aproximação linear

AR Razão de aspecto

CFD Fluidodinâmica computacional

CNT Nanotubo de carbono

Cond. Seção do condensador

Comp. Computacional

DNP 2,4-Dinitrofenol

DTMax Desempenho térmico máximo

DTMin Desempenho térmico mínimo

EG Etilenoglicol

Evap. Seção do Evaporador

Exp. Experimental

H-C Hamilton e Crosser

OHP Tubos de calor oscilatórios

PHP Tubos de calor pulsantes

QUICK Interpolação Quadrática "Upstream" para Cinemática Convectiva

RMS Raiz do valor quadrático médio

SIMPLE Método Semi-Implícito para Equações Acopladas pela Pressão

VOF Esquema de advecção "Volume de Fluido" 


\section{LISTA DE SÍMBOLOS}

$\mathbf{A}^{\prime}$

A

B

AR

$\mathrm{C}_{\mathbf{j}}$

$\mathbf{C}_{\mathbf{p}}$

$\mathbf{C}_{\mathrm{v}}$

d

D

$f_{l} \operatorname{Re}_{\mathbf{I}}$

$\mathbf{h}_{\text {Iv }}$

$\mathbf{k}$

$\mathbf{k}_{11}^{\mathrm{C}}$

$\mathbf{k}_{33}^{\mathrm{C}}$

K

L

M

n

N

$\mathbf{N}^{\prime}$

P

$\mathbf{Q}$

$\mathbf{r}$

$\mathbf{R}$

$\mathbf{R}_{\mathbf{k}}$

S

$\mathbf{T}$

t

$\mathbf{u}$

$\mathbf{v}$

w

y

Parâmetro utilizado para o cálculo da viscosidade de gases orgânicos Área $\left[\mathrm{m}^{2}\right]$

Parâmetro utilizado no modelo de Jeffrey (1973)

Razão de aspecto

Constantes utilizadas no modelo de Chow

Calor específico a pressão constante [ J/kg.K]

Calor específico a volume constante[ J/kg.K]

Diâmetro [m]

Índice fractal

Função do número de Reynolds para o cálculo da permeabilidade de uma matriz porosa composta por sulcos retangulares

Entalpia líquido-vapor $[\mathrm{kJ} / \mathrm{kg}]$

Condutividade térmica $[\mathrm{W} / \mathrm{m} . \mathrm{K}]$

Parâmetro utilizado no modelo de Nan

Parâmetro utilizado no modelo de Nan

Permeabilidade $\left[\mathrm{m}^{2}\right]$

Comprimento $[\mathrm{m}]$

Massa molecular [u]

Fator de forma da nanopartícula

Número de malha das matrizes porosas compostas por telas [ $\left.\mathrm{mm}^{-1}\right]$

Grau da aproximação polinomial do modelo de Chow

Pressão [Pa]

Potência térmica [W]

Coordenada radial $[\mathrm{m}]$

Raio [m]

Constante utilizada no cálculo do raio de Kapitza

Termo fonte [W]

Temperatura $\left[{ }^{\circ} \mathrm{C}\right.$ ou $\left.\mathrm{K}\right]$

Espessura da matriz porosa [m]

Velocidade na direção axial [m/s]

Velocidade na direção radial [m/s]

Largura dos sulcos retangulares de uma matriz porosa [m]

Distância entre dois elementos no método dos volumes finitos [m] 
Y Dimensão axial do tubo de calor [m]

\section{Letras gregas}

\begin{tabular}{|c|c|}
\hline$\alpha^{\prime}$ & $\begin{array}{l}\text { Razão entre a condutividade térmica da nanocamada formada ao redor } \\
\text { da nanopartícula e a condutividade térmica da nanopartícula } \\
\text { Raio de Kapitza [m] }\end{array}$ \\
\hline$\alpha$ & $\begin{array}{l}\text { Razão entre as condutividades térmica da nanopartícula e do fluido- } \\
\text { base }\end{array}$ \\
\hline$\beta_{1}$ & $\begin{array}{l}\text { Razão entre a espessura da nanocamada formada ao redor da } \\
\text { nanopartícula e o raio da nanopartícula }\end{array}$ \\
\hline$\beta_{11}$ & Parâmetro utilizado no modelo de Nan \\
\hline$\beta_{33}$ & Parâmetro utilizado no modelo de Nan \\
\hline $\boldsymbol{\delta}$ & Profundidade dos sulcos retangulares de uma matriz porosa [m] \\
\hline$\Delta$ & Parâmetro auxiliar utilizado no modelo de Murshed \\
\hline$\varepsilon$ & Porosidade \\
\hline$\Lambda$ & Resistência térmica $[\mathrm{K} / \mathrm{W}]$ \\
\hline $\boldsymbol{\mu}$ & Viscosidade absoluta [Pa.s] \\
\hline$\xi$ & Coeficiente de Einstein \\
\hline $\boldsymbol{\rho}$ & Massa específica $\left[\mathrm{kg} / \mathrm{m}^{3}\right]$ \\
\hline $\mathbf{Y}$ & Parâmetro auxiliar usado no modelo de Brenner e Condiff \\
\hline$\varphi$ & Concentração volumétrica de nanopartículas no nanofluido \\
\hline$\varphi \mathrm{m}$ & Concentração volumétrica máxima de nanopartículas \\
\hline$\Psi$ & Esfericidade da nanopartícula \\
\hline
\end{tabular}

\section{Subscritos}

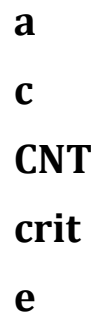

a

CNT

e
Aglomerados de nanopartículas

Condensador

Nanotubos de Carbono

Crítica

Evaporador 


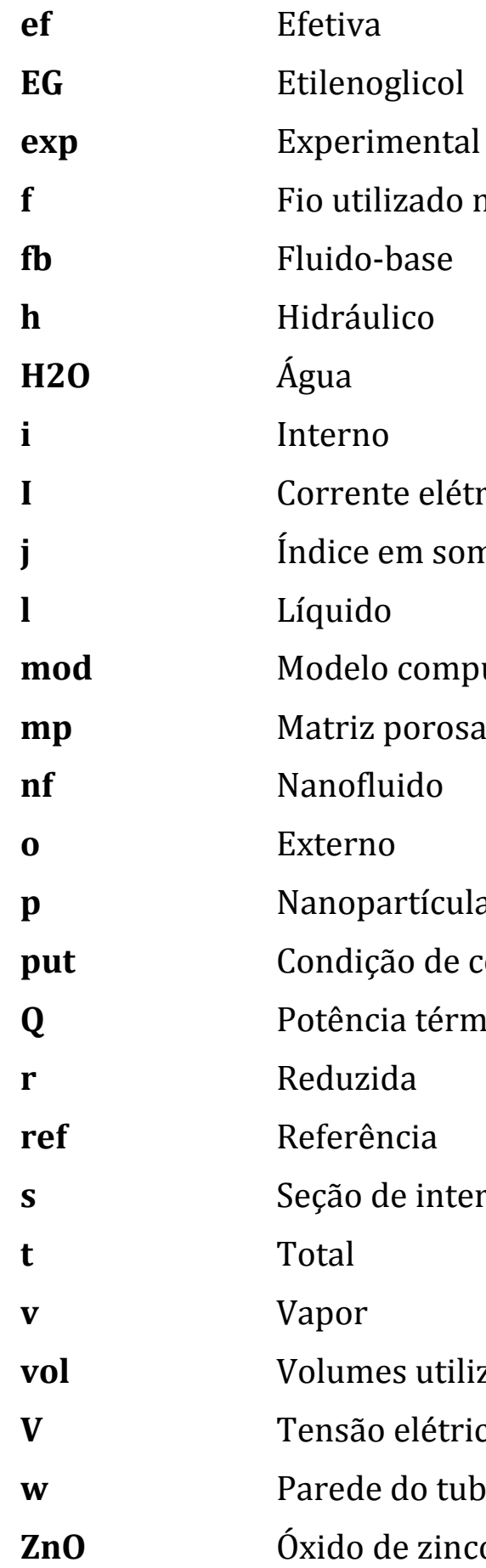

Outros

\%Err Margem de erro 


\section{SUMÁRIO}

1. INTRODUÇÃO E OBJETIVOS.

$\begin{array}{lll}1.1 & \text { Objetivos } & 10\end{array}$

2. REVISÃO DA LITERATURA 12

$\begin{array}{lll}2.1 & \text { Tubos de calor } & 12\end{array}$

$2.2 \quad$ Nanofluidos 23

2.2.1 Nanofluidos contendo nanotubos de carbono 24

2.2.1.1 Propriedades de nanofluidos contendo nanotubos de carbono 28

2.2.2 Nanofluidos baseados em etilenoglicol 37

2.2.2.1 Propriedades de nanofluidos contendo etilenoglicol 41

$2.3 \quad$ Tubos de calor contendo nanofluidos 47

2.3.1 Tubos de calor contendo nanofluidos com nanotubos de carbono 52

2.3.2 Tubos de calor contendo nanofluidos baseados em etilenoglicol $\quad 57$

2.4 Estudos analíticos sobre tubos de calor contendo nanofluidos 62

3. METODOLOGIA 78

$\begin{array}{lll}3.1 & \text { Seleção dos casos a serem estudados } & 78\end{array}$

$\begin{array}{lll}3.2 & \text { Construção do modelo computacional } & 78\end{array}$

$\begin{array}{lll}\text { 3.2.1 } & \text { Malha computacional } & 79\end{array}$

3.2.2. Materiais e suas propriedades físicas 83

3.2.3 Configuração dos modelos computacionais 92

$\begin{array}{lll}\text { 3.2.3.1 Zerbini (1984) } & 101\end{array}$

3.2.3.2 Liu e Lu (2009) 104

$\begin{array}{lll}\text { 3.2.3.3 Putra et al. (2012) } & 109\end{array}$

4. RESULTADOS 116

4.1 Validação preliminar do modelo computacional para água e

4.1.1 Zerbini (1984) 116

4.1.2 Liu e Lu (2009) 119

$\begin{array}{lll}\text { 4.1.3 Putra et al. (2012) } & 121\end{array}$ 
4.2 Aplicação dos nanofluidos no modelo computacional 125

4.2.1 Nanofluidos contendo nanotubos de carbono (Liu e Lu, 2009) 125

4.2.2 Nanofluidos baseados em etilenoglicol (Putra et al., 2012) 130

$4.3 \quad$ Análises de sensibilidade 134

4.3.1 Potência térmica inserida - Água 134

4.3.2 Concentração volumétrica de nanopartículas nos nanofluidos $\quad 139$

5. DISCUSSÃO E CONCLUSÕES 153

$\begin{array}{lll}5.1 & \text { Discussão } & 153\end{array}$

$\begin{array}{lll}5.2 & \text { Conclusões } & 160\end{array}$

6. REFERÊNCIAS 163

APÊNDICE A - ANALISE DA CONSERVAÇÃO DA ENERGIA NA PAREDE DO TUBO

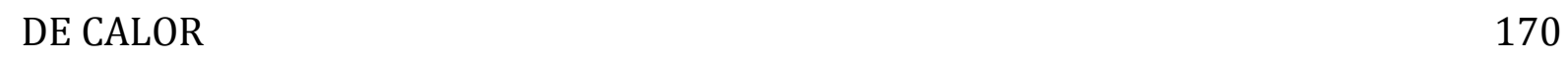

APÊNDICE B - ANALISE DA CONSERVAÇÃO DA ENERGIA NO TUBO DE CALOR DE PUTRA ET AL. (2012) 


\section{INTRODUÇÃO E OBJETIVOS}

Uma das grandes preocupações provenientes da recente evolução tecnológica mundial consiste no desenvolvimento e na fabricação de máquinas e sistemas cada vez mais confiáveis e eficientes.

No que diz respeito às máquinas e sistemas que têm como principal finalidade o controle térmico de um determinado objeto, espaço ou organismo, tais como um sistema de climatização ou um trocador de calor, este desenvolvimento tem relação direta com a busca por componentes capazes de diminuírem o consumo energético por meio de técnicas que possibilitem efeitos como a intensificação da transferência de calor.

Além disso, a miniaturização recorrente dos componentes de máquinas fabricados industrialmente fez com que os dispositivos dissipadores de calor tivessem que obter taxas de transferência de calor por unidade de área cada vez maiores, para que o calor fornecido por um componente pudesse ser dissipado em um volume compacto, como um computador portátil. Para isso, são adotadas práticas conhecidas da teoria de transferência de calor, como a utilização de tubos de calor ("heat pipes") e o desenvolvimento de fluidos de trabalho com melhores propriedades térmicas, tais como os nanofluidos.

Um tubo de calor consiste em um tubo de material condutor, contendo um material poroso de formato anular e um fluido de trabalho confinados em seu interior. Este material poroso recobre a superfície interior do tubo ao longo de todo o seu comprimento, enquanto o fluido de trabalho preenche o espaço vazio no interior do material poroso na forma de líquido saturado e o restante do interior do tubo de calor na forma de vapor saturado.

Este tubo é construído de forma a operar como uma bomba de calor passiva, extraindo calor de uma parte quente, conduzindo este calor ao longo de sua estrutura (sem precisar consumir energia para isso) e rejeitando este calor para uma parte fria. Este calor é responsável pelo processo de mudança de fase do fluido de trabalho no interior do tubo de calor, o que permite a obtenção de altos coeficientes de transferência de calor.

Por sua vez, um nanofluido é obtido a partir da mistura de um fluido-base, tal como água, óleo ou etilenoglicol, e nanopartículas de um material sólido, dispersas em suspensão no fluido-base. Uma ampla gama de materiais sólidos pode ser utilizada na 
composição de um nanofluido, como por exemplo, metais (como o cobre), óxidos (como o óxido de cobre) ou mesmo estruturas carbônicas (como diamante ou nanotubos de carbono).

Estas partículas possuem um tamanho médio inferior a $100 \mathrm{~nm}$ e são dispersas de maneira uniforme, de forma a permanecerem em suspensão de forma estável no fluido. Alguns nanofluidos típicos são a mistura de etilenoglicol com nanopartículas de cobre e a mistura de água com nanopartículas de óxido de cobre, entre outros.

As propriedades térmicas (como a condutividade térmica) obtidas com a dispersão destas nanopartículas no fluido são consideravelmente superiores às propriedades originais do fluido-base em relação à transferência de calor. Como exemplo, podemos mencionar a revisão realizada por Saidur et al. (2011), que sumariza uma grande quantidade de estudos experimentais realizados com nanofluidos, apresentados na tabela parcialmente reproduzida abaixo, relacionando a condutividade térmica de um fluido-base com a condutividade térmica de um nanofluido contendo este mesmo fluido-base e uma determinada nanopartícula dispersa nele.

Tabela 1 - Efeito da presença de nanopartículas dispersas na condutividade térmica em um fluido-base (adaptada de Saidur et al., 2011)

\begin{tabular}{ccccc}
\hline Fluido-base & Nanopartícula & $\begin{array}{c}\text { Tamanho médio } \\
\text { da } \\
\text { nanopartícula }\end{array}$ & $\begin{array}{c}\text { Fração } \\
\text { volumétrica }\end{array}$ & $\begin{array}{c}\text { Aumento da } \\
\text { condutividade } \\
\text { térmica }\end{array}$ \\
\hline Água & Cobre & $100 \mathrm{~nm}$ & $7,5 \%$ & $78 \%$ \\
\hline Água & Prata & $60-80 \mathrm{~nm}$ & $0,001 \%$ & $17 \%$ \\
\hline Água & $\begin{array}{c}\text { Óxido de } \\
\text { Alumínio }\end{array}$ & $13 \mathrm{~nm}$ & $4,3 \%$ & $30 \%$ \\
\hline Água & $\begin{array}{c}\text { Óxido de } \\
\text { Alumínio }\end{array}$ & $68 \mathrm{~nm}$ & $5 \%$ & $21 \%$ \\
\hline Água & Óxido de Cobre & $36 \mathrm{~nm}$ & $3,4 \%$ & $12 \%$ \\
\hline Etilenoglicol & Cobre & $10 \mathrm{~nm}$ & $0,3 \%$ & $40 \%$ \\
\hline
\end{tabular}

Estudos experimentais mostram que a aplicação de nanofluidos em tubos de calor em geral apresenta resultados satisfatórios em termos de intensificação da troca de calor, e levam a crer que esta aplicação possui perspectivas excelentes. As propriedades obtidas por meio da elaboração desses nanofluidos permitem uma 
intensificação bastante significativa na transferência de calor que ocorre no fenômeno de mudança de fase existente no interior de tubos de calor.

A revisão publicada por Liu e Li (2012) apresenta os resultados experimentais obtidos para a combinação de tubos de calor e nanofluidos aplicada a diferentes tipos e formatos de tubos de calor, diferentes nanofluidos compostos com diferentes concentrações e formados com múltiplas combinações entre fluidos-base, tamanhos e materiais das nanopartículas.

Ao todo foram analisadas quarenta configurações diferentes nesta revisão, e, desses casos, somente quatro deles apresentaram um desempenho inferior ao obtido utilizando somente o fluido-base como fluido de trabalho no tubo de calor. Em alguns dos casos positivos, a resistência térmica do tubo de calor utilizando um nanofluido foi reduzida a menos da metade da resistência térmica original. Isto significa que, para uma mesma diferença de temperatura, uma quantidade de calor superior ao dobro da quantidade original pode ser transferida por este tubo de calor.

Este comportamento, associado à ausência de estudos analíticos específicos sobre estes equipamentos, leva a crer que há espaço para o desenvolvimento de técnicas analíticas para a avaliação da eficiência térmica destes equipamentos com uma precisão significativa.

No campo da pesquisa analítica, a busca por técnicas simples e eficazes para a determinação das características físicas dos processos de mecânica de fluidos e transferência de calor em equipamentos tem por objetivo a redução dos custos de operação destes componentes e a subsequente viabilização comercial das máquinas contendo estes componentes.

Neste nicho, o estudo computacional das características térmicas e hidrodinâmicas destes equipamentos por meio das técnicas modernas, tais como os programas de fluidodinâmica computacional baseados em métodos numéricos, permite que seja possível otimizar um determinado equipamento de forma a obter uma eficiência máxima para cada aplicação prática que exista interesse.

Ao lidarmos especificamente com nanofluidos aplicados a tubos de calor, os estudos computacionais existentes associando estes dois conceitos ainda são razoavelmente raros e focados em aplicações práticas limitadas. Isso indica a necessidade de uma análise mais aprofundada a respeito da modelagem utilizada para a simulação computacional do nanofluido, das correlações utilizadas para a avaliação das 
propriedades do nanofluido nesta modelagem, tais como condutividade térmica e da viscosidade, e da utilização de nanofluidos envolvendo materiais mais recentes, tais como nanotubos de carbono, ou materiais utilizados em aplicações não convencionais, tais como etilenoglicol.

\subsection{Objetivos}

0 presente estudo busca primariamente avaliar a validade do modelo proposto por Mahjoub e Matabroshan (2008) e utilizado por Gavtash et al. (2012) para a simulação computacional de um tubo de calor contendo um nanofluido. Esta avaliação consiste em uma análise dos resultados obtidos por meio da aplicação deste modelo na simulação computacional de diferentes tubos de calor avaliados experimentalmente na literatura contendo fluidos de trabalho diferentes e, adicionalmente, dois tipos de nanofluidos. Os nanofluidos selecionados para este trabalho consistem em aplicações que obtiveram resultados experimentais significativos na literatura recente: nanofluidos utilizando água como fluido-base e contendo nanopartículas de nanotubos de carbono e nanofluidos utilizando etilenoglicol como fluido-base.

Como segunda contribuição, espera-se determinar a influência da caracterização das propriedades dos nanofluidos selecionados em uma simulação computacional de um tubo de calor contendo estes nanofluidos. Para isso, será realizada uma análise paramétrica envolvendo a variação dos modelos das propriedades selecionadas dos nanofluidos. Espera-se que a comparação direta dos resultados obtidos contendo nanofluidos caracterizados por equacionamentos diferentes com os dados experimentais existentes permita determinar a relevância de cada propriedade na modelagem do comportamento de um nanofluido e a validade de cada um destes equacionamentos na determinação das propriedades físicas associadas aos nanofluidos em simulações computacionais.

Por fim, também serão avaliados os efeitos da variação da concentração volumétrica de nanopartículas, de forma a determinar a influência dessa variação no comportamento térmico do sistema. Espera-se que o comportamento da variação deste parâmetro no modelo siga a tendência experimental da literatura, que indica a existência de um valor intermediário de concentração de nanopartículas para o qual o 
desempenho do sistema atinge um valor de máximo, a partir do qual os efeitos viscosos passam a ser mais dominantes do que a intensificação obtida no desempenho térmico. 


\section{REVISÃO DA LITERATURA}

\subsection{Tubos de calor}

Um tubo de calor consiste em um dispositivo concebido de forma a realizar o transporte de calor de um ponto para o outro sem necessitar de energia, funcionando como uma bomba de calor passiva. 0 princípio de funcionamento de um tubo de calor foi concebido por R. S. Gaugler em 1944, que imaginou o conceito de um dispositivo fechado no qual um fluido sofreria processos de evaporação e condensação e se movimentaria de um ponto para outro sem consumir energia para isso. Este dispositivo se tornou mais difundido publicamente a partir dos experimentos publicados por Grover et al. (1964), que obtiveram tubos de calor com alta eficiência no transporte de calor e aplicações bem definidas.

Esta tecnologia está baseada nos processos de mudança de fase de uma substância, responsáveis por altos coeficientes de transferência de calor, e na movimentação do fluido tanto na fase líquida, causada pelo efeito de capilaridade das estruturas porosas, como na fase gasosa, causada por efeitos de diferença de pressão.

Um tubo de calor é composto de três seções principais, mostradas na Figura 1: um evaporador (em contato com a região da qual se deseja retirar calor), uma seção adiabática e um condensador (em contato com a região que dissipará o calor para a região fria). Na sua forma convencional, utiliza-se um tubo fechado preenchido ao longo de toda sua extensão por uma estrutura porosa anular responsável pelo transporte do fluido no estado líquido.

É possível observar na Figura 1 o funcionamento do tubo de calor, onde o calor proveniente da aplicação é fornecido à região do evaporador e transmitido pela estrutura do tubo de calor de forma quase ideal ao fluido de trabalho, promovendo a evaporação do fluido de trabalho. No condensador, o fluido de trabalho transfere calor para a região de rejeição de calor e passa por um processo de condensação, depositando-se ao longo da matriz porosa anular que recobre as paredes do tubo de calor. A movimentação do vapor do evaporador para o condensador é devida à diferença de pressão resultante dos processos de mudança de fase que ocorrem no evaporador e no condensador, atravessando a seção adiabática praticamente sem transferir calor. 0 retorno do líquido do condensador para o evaporador se dá através da matriz porosa, que possui micro cavidades que permitem a formação de uma diferença de pressão 
capilar entre as extremidades do tubo de calor, responsável pelo transporte do fluido de trabalho no estado líquido do condensador até o evaporador. Assim, o fluido na forma líquida realimenta a seção do evaporador, completando o ciclo.

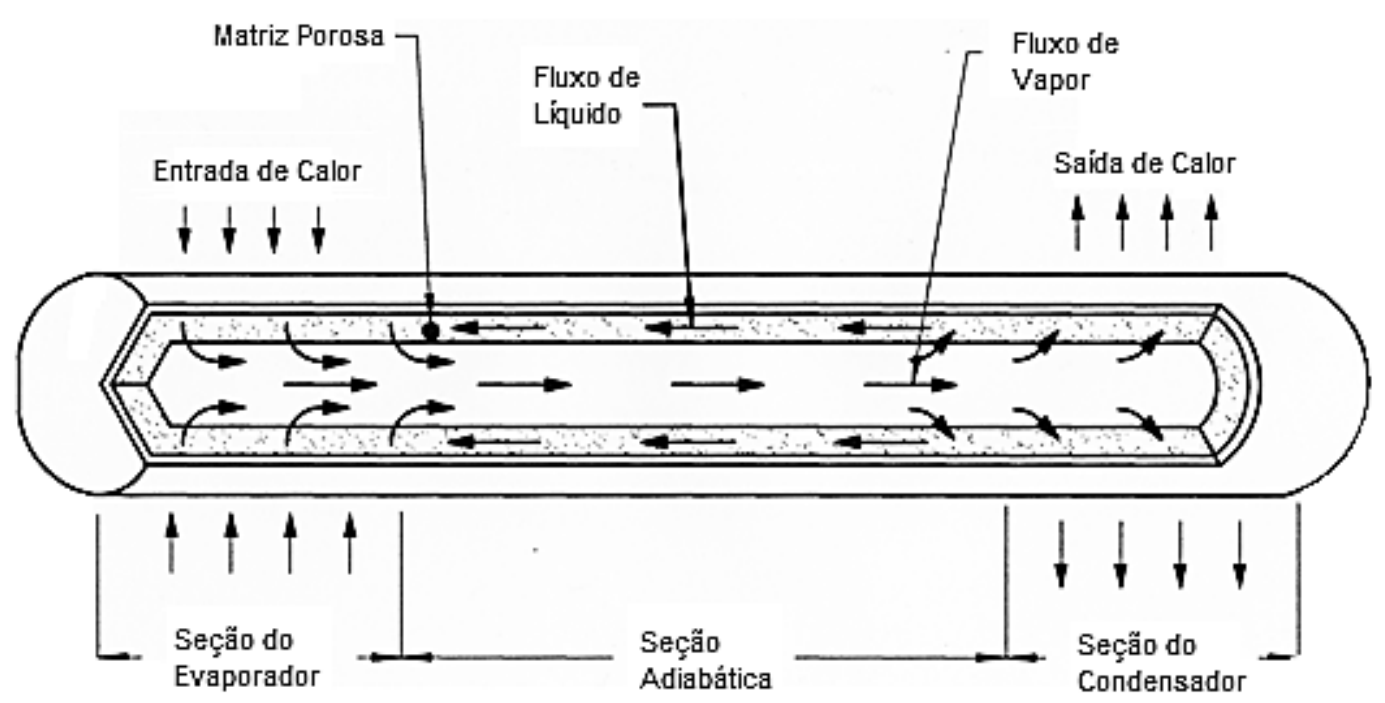

Figura 1. Esquema de funcionamento de um tubo de calor (adaptada de Chi, 1976)

Os tubos de calor podem apresentar configurações diferentes no que diz respeito à matriz porosa. Esta estrutura deve propiciar a formação de uma diferença de pressão por capilaridade que seja capaz de manter um fluxo adequado de líquido condensado retornando ao evaporador. Ao mesmo tempo, deve ser permeável de forma a permitir que o fluxo de vapor condensado seja admitido ao longo da interface líquido-vapor, e deve possuir uma condutividade térmica tal que o calor proveniente da aplicação seja recebido pelo fluido de trabalho e transmitido novamente ao ambiente na quantidade necessária para a operação correta do tubo de calor. Em geral, a matriz porosa é constituída por estruturas contendo telas de malha, fibras finas de vidro, metais sinterizados ou sulcos axiais estreitos. A Figura 2 mostra algumas vistas em corte contendo algumas das configurações possíveis para a construção de matrizes porosas no interior de tubos de calor. 


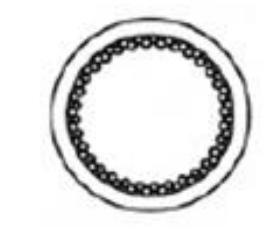

Metal Sinterizado

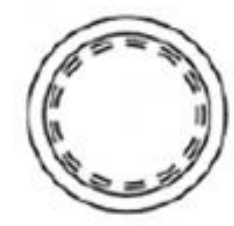

Malha de Tela

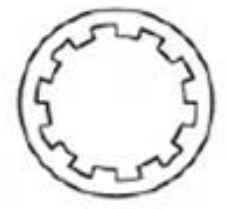

Sulcos Axiais

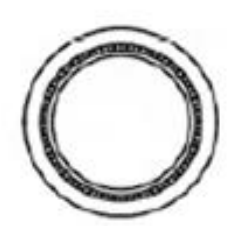

Fibras Finas

Figura 2. Tipos de matrizes porosas no interior de um tubo de calor (adaptada de Chi, 1976)

Existem também tubos de calor construídos sem a presença de matrizes porosas. Os tubos de calor do tipo termosifões bifásicos fechados (Fig. 3) utilizam a força gravitacional como forma a garantir o retorno do fluido condensado para a seção do evaporador sem a necessidade de bombeamento capilar. Ao mesmo tempo, a tensão superficial do líquido ao longo da parede do tubo de calor garante que o filme de líquido acompanhe a parede do tubo ao longo de toda sua extensão. Os tubos de calor também podem apresentar diversas variações do ponto de vista construtivo. Por exemplo, existem tubos de calor que possuem mais de um ponto de aquecimento ou resfriamento, como mostrado na Figura 4. Nestes casos, o tubo possui dimensões internas capilares, de forma a produzir pulsos de vapor ao longo do líquido. 0 fluido então sofre evaporação e condensação continuamente, o que provoca a movimentação oscilatória do fluido em ambas as fases ao longo do tubo de calor. Esses tubos de calor são conhecidos como tubos de calor oscilatórios (OHP) ou pulsantes (PHP) (Fasula, 2009). 


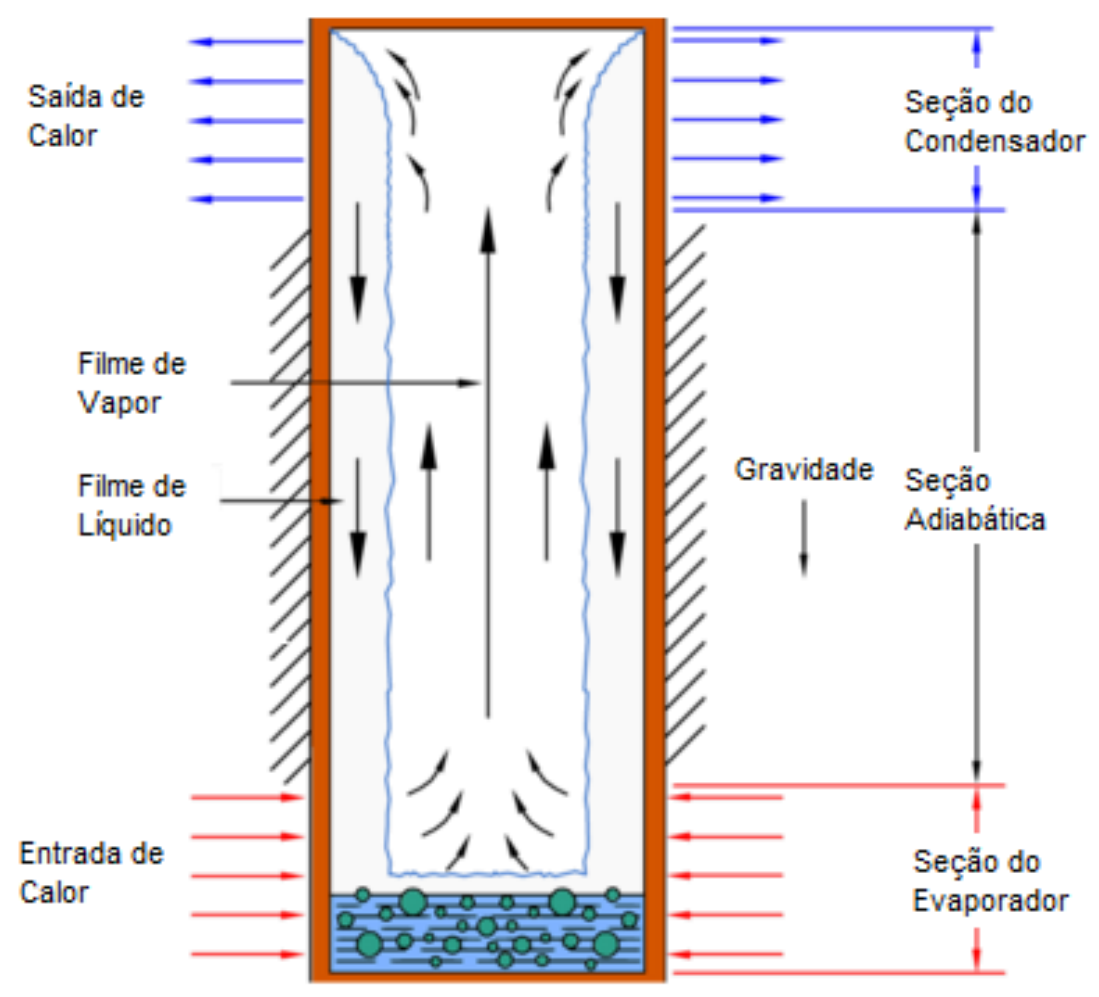

Figura 3. Termosifão bifásico fechado (adaptada de www.thermalfluidscentral.org)

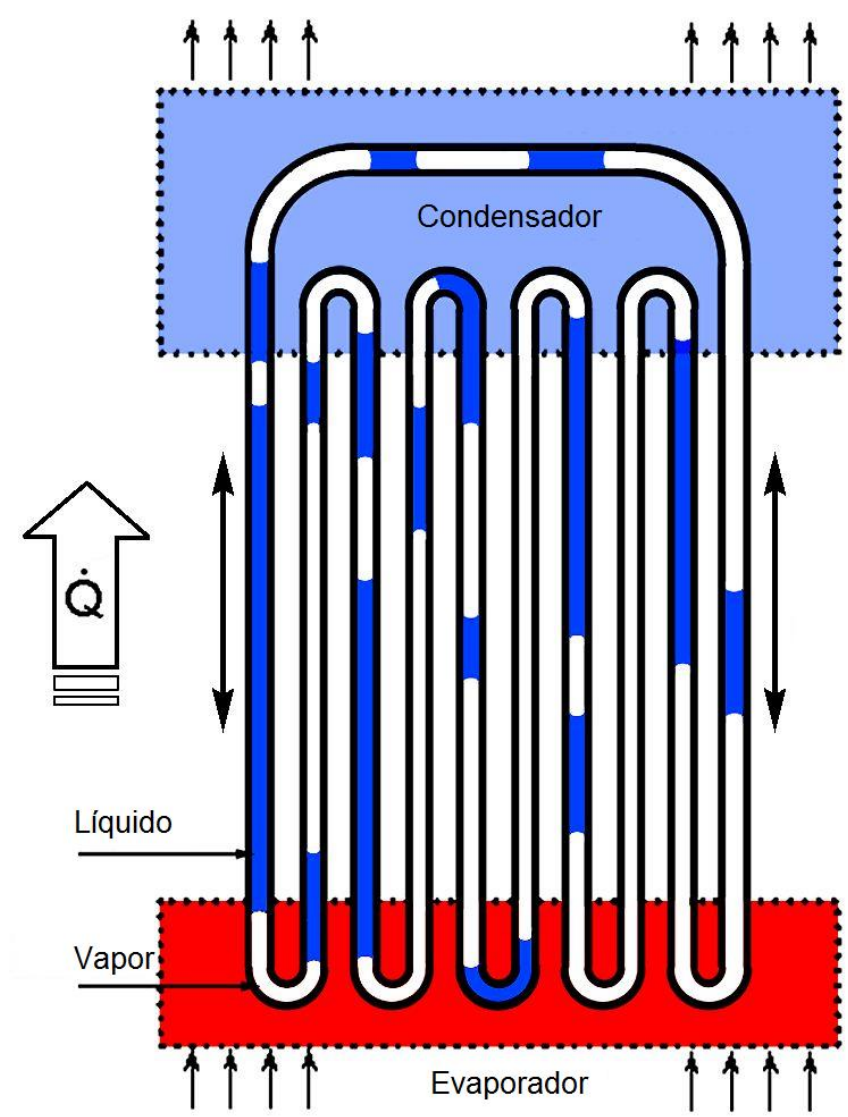

Figura 4. Tubo de calor oscilante (OHP) (adaptada de Fasula, 2009) 
No que tange aos fluidos de trabalho utilizados em um tubo de calor, Wallin (2012) mostra que a sua escolha corresponde a selecionar um material cujas propriedades sejam capazes de atingir as especificações impostas pelo problema e pelas características construtivas do tubo de calor. Assim, em geral, as seguintes características são observadas na seleção de um fluido de trabalho para o tubo de calor:

compatibilidade com os materiais da parede e da matriz porosa do tubo de calor;

> boa estabilidade térmica (ausência de efeitos prejudiciais à integridade da substância em altas ou baixas temperaturas, tais como decomposição);

- molhabilidade do fluido em relação as paredes e a matriz porosa do tubo de calor;

níveis de pressão de vapor adequados para a faixa de temperaturas de operação;

altos valores de entalpia de vaporização;

$>$ alta condutividade térmica;

baixas viscosidades nas fases líquido e vapor;

alta tensão superficial.

É possível encontrar os mais diferentes fluidos de trabalho sendo utilizados na fabricação de tubos de calor, desde hélio líquido em aplicações trabalhando em temperaturas muito baixas, próximas do zero absoluto, até prata líquida em aplicações para temperaturas muito altas, geralmente acima de $2000{ }^{\circ} \mathrm{C}$. Devido à alta disponibilidade e às boas propriedades térmicas nas faixas mais comuns de utilização, o fluido de trabalho mais utilizado em um tubo de calor é a água.

A modelagem do comportamento térmico de um tubo de calor contendo fluidos de trabalho convencionais já possui uma quantidade significativa de trabalhos envolvendo soluções analíticas e experimentais.

No campo experimental, o trabalho de Zerbini (1984) analisou tubos de calor em temperaturas moderadas, avaliando os limites de operação e valores para a condutividade térmica efetiva de um tubo de calor contendo água. O tubo de calor avaliado neste estudo foi construído a partir de um tubo com paredes de cobre contendo uma matriz porosa composta por telas de malha fabricadas em bronze. As dimensões representativas deste tubo podem ser observadas na Tabela 2. 
Este tubo de calor foi montado em uma bancada experimental e instrumentado de forma a determinar os perfis de temperatura e a condutividade térmica equivalente dos tubos de calor para diversas potências térmicas inseridas na seção do evaporador. As Figuras 5 a 7 reproduzem os perfis obtidos para as potências térmicas de 24 W, 37 W e $49 \mathrm{~W}$, respectivamente.

Tabela 2. Dimensões representativas do tubo de calor utilizado em Zerbini (1984)

\begin{tabular}{c|c}
\hline Comprimento $(\mathrm{mm})$ & 700 \\
\hline Evaporador $(\mathrm{mm})$ & 100 \\
\hline Condensador $(\mathrm{mm})$ & 100 \\
\hline Diâmetro externo $(\mathrm{mm})$ & 25,4 \\
\hline Espessura da parede $(\mathrm{mm})$ & 3,2 \\
\hline Diâmetro da câmara de vapor $(\mathrm{mm})$ & 17 \\
\hline Permeabilidade da matriz porosa $\left(\mathrm{m}^{2}\right)$ & $2,38.10^{-10}$ \\
\hline Raio de curvatura mínimo do menisco $(\mathrm{m})$ & $6,35.10^{-5}$ \\
\hline
\end{tabular}

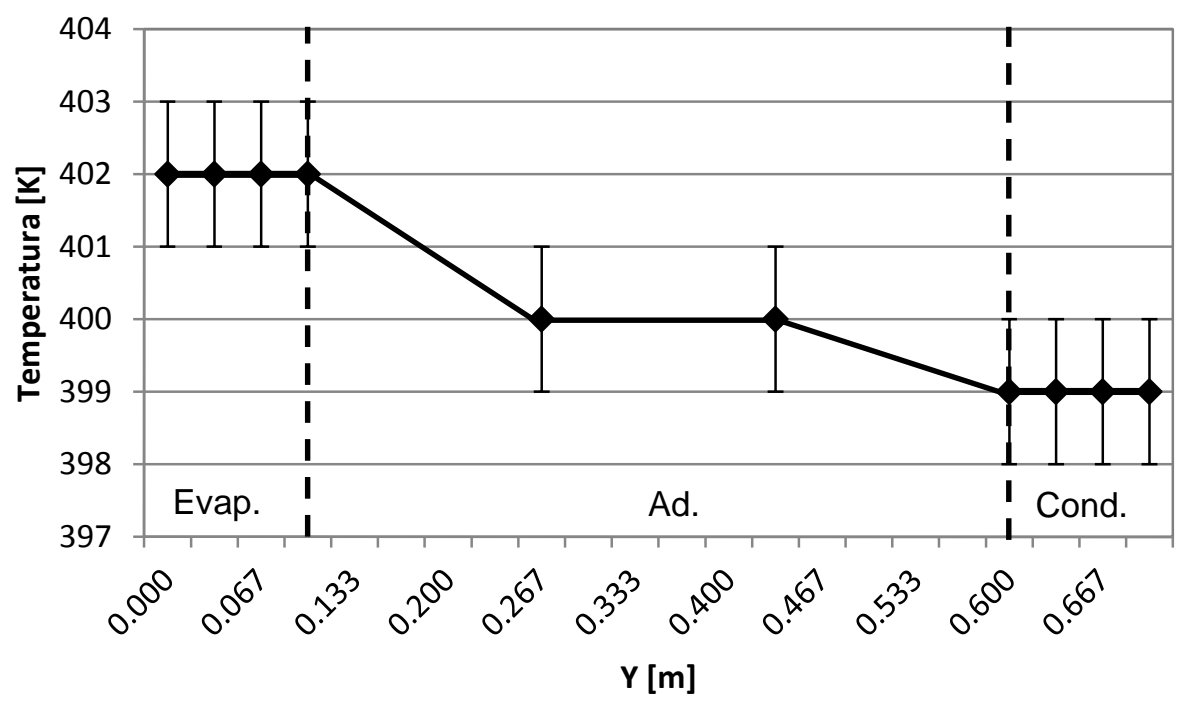

Figura 5. Perfil de temperaturas de um tubo de calor contendo água para uma potência térmica de $24 \mathrm{~W}$ (adaptada de Zerbini, 1984) 


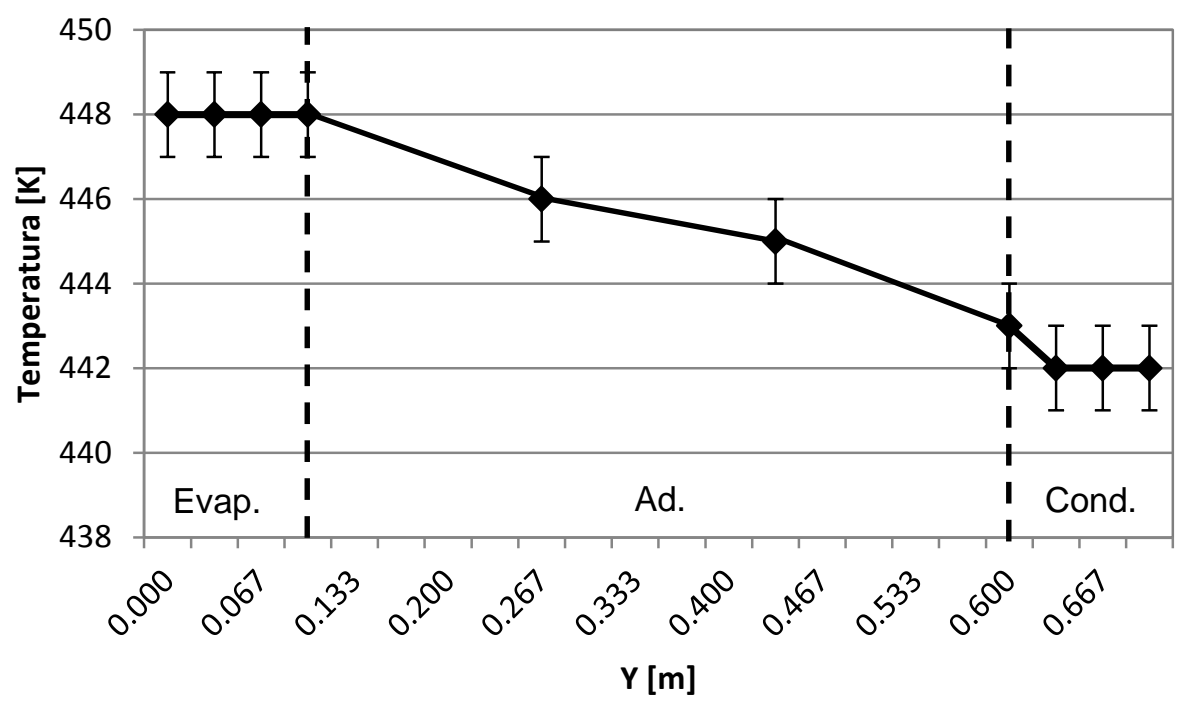

Figura 6. Perfil de temperaturas de um tubo de calor contendo água para uma potência térmica de 37 W (adaptada de Zerbini, 1984)

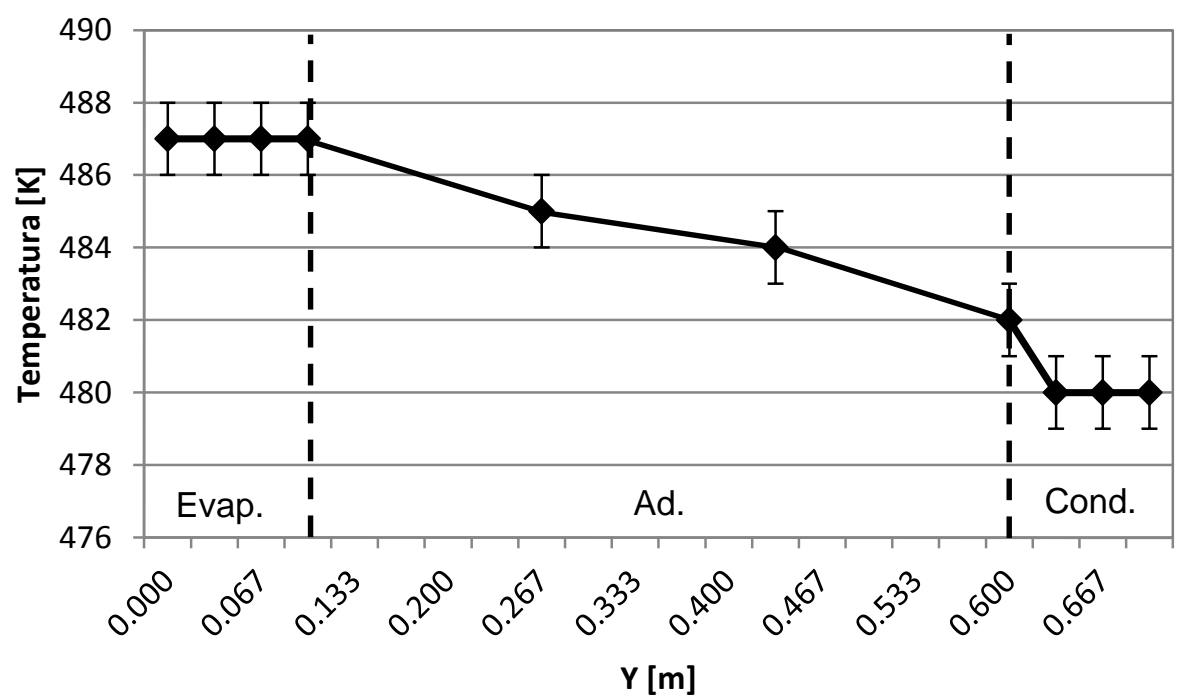

Figura 7. Perfil de temperaturas de um tubo de calor contendo água para uma potência térmica de 49 W (adaptada de Zerbini, 1984)

Estes perfis de temperatura mostram que a diferença de temperatura entre o evaporador e o condensador aumenta com o aumento da potência térmica inserida no evaporador, o que sugere que a resistência térmica possui um valor similar em todos os casos. Além disso, observa-se que o aumento na potência térmica inserida faz com que a temperatura média de todo o tubo de calor aumente de forma considerável (cerca de 85 $\mathrm{K}$ para $25 \mathrm{~W}$ a mais). 
Também são reportados aumentos na condutividade térmica equivalente do tubo de calor de até 27 vezes em relação a uma barra de cobre puro. Observou-se também que o valor da condutividade térmica equivalente do tubo de calor aumenta com o aumento da potência fornecida ao tubo de calor. Os erros experimentais agregados aos resultados obtidos neste estudo foram estimados por propagação e assumem valor máximo igual a $15 \%$.

Entre os trabalhos numéricos disponíveis na literatura, Mahjoub e Matabroshan (2008) propuseram uma solução para o escoamento do fluido de trabalho ao longo de todo o tubo de calor na qual as equações de conservação da massa, da energia e da quantidade de movimento foram utilizadas em conjunto com o método dos volumes finitos aplicado a coordenadas cilíndricas, utilizando o software FLUENT para obter a solução do sistema de equações resultantes.

O modelo matemático utilizado pelos autores dividiu o tubo de calor utilizando as 3 seções mencionadas anteriormente: evaporador, adiabática e condensador. Considerou-se que o escoamento ocorre em regime permanente, incompressível e laminar, e que o escoamento apresenta simetria angular. Além disso, admitiu-se que o fluido da região de vapor não entra em contato com o fluido da região porosa do tubo de calor.

As equações que governam a conservação da massa, da quantidade de movimento e da energia na região de vapor no interior do tubo de calor, respectivamente, são as seguintes:

$$
\begin{gathered}
\frac{\partial u_{v}}{\partial z}+\frac{\partial v_{v}}{\partial r}+\frac{v_{v}}{r}=0 \\
\rho_{v}\left(u_{v} \frac{\partial u_{v}}{\partial z}+v_{v} \frac{\partial v_{v}}{\partial r}\right)=-\frac{\partial P_{v}}{\partial z}+\mu_{v}\left(\frac{1}{r} \frac{\partial}{\partial r}\left[r \frac{\partial u_{v}}{\partial r}\right]+\frac{\partial^{2} u_{v}}{\partial z^{2}}\right) \\
\rho_{v}\left(u_{v} \frac{\partial v_{v}}{\partial z}+v_{v} \frac{\partial v_{v}}{\partial r}\right)=-\frac{\partial P_{v}}{\partial r}+\mu_{v}\left(\frac{1}{r} \frac{\partial}{\partial r}\left[r \frac{\partial v_{v}}{\partial r}\right]+\frac{\partial^{2} v_{v}}{\partial z^{2}}\right) \\
\rho_{v} c_{p, v}\left(u_{v} \frac{\partial T_{v}}{\partial z}+v_{v} \frac{\partial T_{v}}{\partial r}\right)=k_{v}\left(\frac{1}{r} \frac{\partial}{\partial r}\left[r \frac{\partial T_{v}}{\partial z}\right]+\frac{\partial^{2} T_{v}}{\partial z^{2}}\right)+S
\end{gathered}
$$


Na região da matriz porosa do tubo de calor, as equações de conservação da quantidade de movimento e da energia para o fluido no estado líquido se baseiam na lei de Darcy:

$$
\begin{gathered}
\rho_{l}\left(u_{l} \frac{\partial u_{l}}{\partial z}+v_{l} \frac{\partial v_{l}}{\partial r}\right)=-\frac{\partial P_{l}}{\partial z}+\mu_{l}\left(\frac{1}{r} \frac{\partial}{\partial r}\left[r \frac{\partial u_{l}}{\partial r}\right]+\frac{\partial^{2} u_{l}}{\partial z^{2}}\right)-\frac{\mu_{l} \cdot u_{l}}{K_{z}} \\
\rho_{l}\left(u_{l} \frac{\partial v_{l}}{\partial z}+v_{l} \frac{\partial v_{l}}{\partial r}\right)=-\frac{\partial P_{l}}{\partial r}+\mu_{l}\left(\frac{1}{r} \frac{\partial}{\partial r}\left[r \frac{\partial v_{l}}{\partial r}\right]+\frac{\partial^{2} v_{l}}{\partial z^{2}}\right)-\frac{\mu_{l} \cdot v_{l}}{K_{r}} \\
\rho_{l} c_{p, l}\left(u_{l} \frac{\partial T_{l}}{\partial z}+v_{l} \frac{\partial T_{l}}{\partial r}\right)=\frac{k_{e f}}{\varepsilon}\left(\frac{1}{r} \frac{\partial}{\partial r}\left[r \frac{\partial T_{l}}{\partial z}\right]+\frac{\partial^{2} T_{l}}{\partial z^{2}}\right)+S
\end{gathered}
$$

Onde $k_{e f}$ representa a condutividade térmica efetiva da matriz porosa preenchida com líquido. Neste artigo, esta condutividade é obtida através da seguinte relação entre a condutividade do líquido $k l$, a condutividade da matriz porosa $k_{m p}$ e a porosidade da matriz porosa $\varepsilon$, extraída de Faghri, 1995:

$$
k_{e f}=\frac{k_{l}\left[\left(k_{l}+k_{m p}\right)-(1-\varepsilon)\left(k_{l}-k_{m p}\right)\right]}{\left(k_{l}+k_{m p}\right)+(1-\varepsilon)\left(k_{l}-k_{m p}\right)}
$$

Por fim, nas paredes de um tubo de calor, a equação da condução de calor em coordenadas cilíndricas assume a seguinte forma:

$$
k_{w}\left(\frac{1}{r} \frac{\partial}{\partial r}\left[r \frac{\partial T_{w}}{\partial z}\right]+\frac{\partial^{2} T_{w}}{\partial z^{2}}\right)=0
$$

As condições de contorno adotadas para a solução do problema foram as seguintes:

- na região da interface líquido-vapor, a mudança de fase do fluido tem por consequência a formação de quantidade de movimento, responsável pela sucção de fluido de uma das regiões que compõem a interface e pela expulsão deste fluido para a outra região que compõe a interface. Para a representação deste fenômeno, é necessária a introdução de velocidades de sucção e de expulsão na interface líquido-vapor contendo os seguintes valores na fase de vapor: 


$$
\begin{gathered}
V_{e, v}=\frac{\dot{Q_{e}}}{2 \pi R_{i} L_{e} \rho_{v} h_{l v}} \\
V_{a}=0 \\
V_{c, v}=-\frac{\dot{Q}_{c}}{2 \pi R_{i} L_{c} \rho_{v} h_{l v}}
\end{gathered}
$$

e na fase de líquido:

$$
\begin{gathered}
V_{e, l}=-\frac{\dot{Q_{e}}}{2 \pi R_{i} L_{e} \rho_{v} h_{l v}} \\
V_{a}=0 \\
V_{c, l}=\frac{\dot{Q}_{c}}{2 \pi R_{i} L_{c} \rho_{v} h_{l v}}
\end{gathered}
$$

- também é necessário introduzir o efeito térmico causado pelo calor latente de vaporização decorrente dos processos de mudança de fase no modelo. Desta forma, são introduzidos uma fonte e um sumidouro de calor nas seções do evaporador e do condensador, cujas intensidades correspondem a:

$$
\begin{gathered}
S_{e}=-\frac{\dot{Q}_{e}}{\pi\left(\left(R_{i}+t\right)^{2}-R_{i}^{2}\right) L_{e}} \\
S_{a}=0 \\
S_{c}=\frac{\dot{Q}_{c}}{\pi\left(\left(R_{i}+t\right)^{2}-R_{i}{ }^{2}\right) L_{c}}
\end{gathered}
$$

- na interface entre a parede do tubo de calor e a matriz porosa, a condição de contorno referente a condução de calor entre as duas regiões é representada pela Equação [19]: 


$$
k_{e f} \frac{\partial T_{l}}{\partial r}=k_{w} \frac{\partial T_{w}}{\partial r}
$$

- na superfície externa das paredes do tubo de calor, são aplicadas as condições de contorno referentes à introdução do calor obtido da aplicação pelo evaporador e à dissipação deste calor para o ambiente realizada pelo condensador. Desta forma, temos que:

$$
\begin{gathered}
\text { Evaporador: } \frac{\partial T_{w}}{\partial r}=\frac{\dot{Q_{e}}}{2 \pi R_{o} L_{e}} \\
\text { Adiabática: } \frac{\partial T_{w}}{\partial r}=0 \\
\text { Condensador: } \frac{\partial T_{w}}{\partial r}=-\frac{\dot{Q_{e}}}{2 \pi R_{o} L_{c}}
\end{gathered}
$$

- por fim, em todas as regiões apresentadas, a região da borda longitudinal do tubo de calor apresenta a condição de contorno equivalente a uma parede adiabática. Assim:

$$
\begin{aligned}
& u=v=0 \\
& \frac{\partial T}{\partial z}=0
\end{aligned}
$$

A solução das equações anteriores utilizando um tubo de calor de material e dimensões especificadas, contendo um fluido de trabalho (água destilada) cujas propriedades físicas foram fornecidas, forneceu os perfis de temperatura e velocidades e com isso, foi possível calcular o valor da resistência térmica total do tubo de calor, variando as condições de condutividade térmica da parede do tubo de calor, porosidade da matriz porosa, calor inserido no tubo de calor, diâmetro e comprimento do tubo de calor.

Os resultados obtidos mostraram que a resistência térmica de um tubo de calor convencional possui relação diretamente proporcional com a porosidade da matriz porosa e inversamente proporcional com a condutividade térmica da parede do tubo de 
calor e com o diâmetro do tubo de calor. Além disso, verificou-se que o comprimento do tubo de calor possui uma influência pequena no valor da sua resistência térmica.

\subsection{Nanofluidos}

Um nanofluido é obtido a partir da mistura de um fluido-base, tal como água, óleo ou etilenoglicol, e uma quantidade significativa de partículas de dimensões nanométricas de um material sólido, dispersas em suspensão no fluido-base. Uma ampla gama de materiais sólidos pode ser utilizada na composição de um nanofluido, como por exemplo, metais (como o cobre), óxidos (como o óxido de cobre) ou mesmo estruturas carbônicas (como diamante ou nanotubos de carbono). Estas partículas possuem um tamanho médio inferior a 100 nanômetros e são dispersas de maneira uniforme, de forma a permanecerem em suspensão estável ao longo do fluido. Alguns nanofluidos típicos são a mistura de etilenoglicol com nanopartículas de cobre e a mistura de água com nanopartículas de óxido de cobre, entre outros (Kakaç e Pramuanjaroenkij, 2009).

As propriedades destes nanofluidos são dependentes de parâmetros vinculados às características do fluido-base (tais como propriedades físicas), às características das nanopartículas (tais como geometria, dimensões e propriedades físicas) e às interações existentes entre as nanopartículas e o fluido-base (tais como concentrações e efeitos de interface).

A utilização de nanofluidos possui relação direta com a obtenção destas propriedades, uma vez que a introdução de nanopartículas permite que seja possível obter propriedades térmicas significativamente melhores. Assim, a simples substituição do fluido de trabalho utilizado em uma aplicação qualquer por um nanofluido poderia representar um aumento considerável na transferência de calor que ocorre em um equipamento.

Por exemplo, a introdução de nanofluidos em geral propicia um aumento significativo na condutividade térmica do fluido. Este efeito isoladamente já resulta em um aumento na transferência de calor de um determinado sistema, tornando o estudo dos nanofluidos relevante para a maior parte das aplicações industriais envolvendo transferência de calor, pois a introdução de nanofluidos permite obter um aumento na transferência de calor total de um sistema sem que para isso sejam necessárias quaisquer alterações na configuração dos dispositivos trocadores de calor utilizados. 
Mesmo uma pequena quantidade de nanopartículas é capaz de aumentar significativamente a condutividade térmica de um fluido-base, uma vez que a maior parte dos sólidos possui uma condutividade térmica muito maior do que a maioria dos líquidos utilizados como fluido-base. Além disso, a introdução de partículas de tamanho nanométrico permite a obtenção de uma condutividade térmica maior do que a condutividade térmica esperada de uma simples mistura de partículas sólidas e um fluido, obtida a partir da média ponderada entre as condutividades térmicas do fluidobase e da nanopartícula, devido a existência de efeitos que ocorrem somente nesta escala de comprimento. Desta forma, uma grande quantidade de trabalhos tem sido desenvolvida recentemente de forma a levar em consideração diferentes mecanismos de interação entre partículas de fluido e nanopartículas sólidas, permitindo assim que as propriedades térmicas de um nanofluido (como a condutividade térmica) pudessem ser determinadas analiticamente com uma precisão significativa.

A seleção dos materiais utilizados para a fabricação de nanofluidos tem sido estudada extensivamente, de forma que é possível observar nanofluidos compostos por materiais cada vez mais modernos. As pesquisas feitas com alguns destes materiais tem obtido resultados bastante atrativos no que diz respeito às possíveis aplicações de nanofluidos. Dentre os resultados obtidos utilizando estes materiais, destacam-se a utilização de nanotubos de carbono, os quais permitem altas taxas de intensificação da condutividade térmica (Xie et al., 2003) e a utilização de fluidos-base tais como o etilenoglicol, que possuem uma condutividade térmica menor que a água, uma vez que diversos trabalhos (Xie et al., 2003, Xie et al., 2011, Liu et al., 2005) mostram que a intensificação na condutividade térmica obtida por meio da introdução de nanopartículas em fluidos com menor condutividade térmica é proporcionalmente mais alta do que a obtida em nanofluidos compostos por fluidos-base com maior condutividade térmica.

\subsubsection{Nanofluidos contendo nanotubos de carbono}

Os trabalhos experimentais utilizando nanotubos de carbono como nanopartículas na constituição de um nanofluido têm apresentado resultados altamente satisfatórios no que diz respeito à intensificação da condutividade térmica e da transferência de calor por convecção. 
Um dos motivos é a alta condutividade térmica dos nanotubos de carbono (até $6000 \mathrm{~W} / \mathrm{m} . \mathrm{K}$ para nanotubos de carbono de parede simples e até $3000 \mathrm{~W} / \mathrm{m} . \mathrm{K}$ para nanotubos de carbono de parede múltipla). No entanto, a intensificação da transferência de calor por convecção é ainda maior do que a intensificação esperada pela simples intensificação da condutividade térmica.

O estudo de Ding et. al (2006) atribuiu esta intensificação a diversos mecanismos que ocorrem em escala microscópica no nanofluido. Em resumo, é possível listar os seguintes fatores associados à intensificação da transferência de calor em um nanofluido contendo nanotubos de carbono:

- a intensificação simples da condutividade térmica causada pela simples mistura de partículas com maior condutividade térmica ao fluido-base;

- o rearranjo das nanopartículas ao longo do nanofluido, causado pelas taxas de cisalhamento não uniformes ao longo da secção transversal do escoamento;

- a indução de um aumento extra na condutividade térmica, causada pelas tensões dinâmicas de cisalhamento formadas ao longo do escoamento do fluido;

- a redução da camada limite térmica ao longo do escoamento, causada pela presença de nanopartículas;

- a alta razão de aspecto existente nas partículas de nanotubos de carbono, o que aumenta a área de contato do fluido-base com os nanotubos de carbono.

Ainda nesse estudo, a condutividade térmica obtida com a adição de nanotubos de carbono superou a condutividade térmica da água para todas as concentrações pesquisadas, e a intensificação máxima obtida representou um aumento de mais de $350 \%$ no coeficiente de transferência de calor por convecção em relação ao fluido-base, para um arranjo contendo 0,25\% em massa de goma arábica e 0,5\% em massa de nanotubos de carbono.

Além disso, verificou-se que a intensificação da transferência de calor possui relação direta com a distância percorrida pelo fluido ao longo da seção de testes, aumentando até uma distância para a qual se obtém intensificação máxima, e depois diminuindo progressivamente.

Por fim, também é dado destaque neste estudo à natureza hidrofóbica das moléculas de nanotubos de carbono, tornando-as propensas a sofrerem aglomeração ou precipitação, o que gera a necessidade do uso de substâncias químicas dispersantes ou 
técnicas de quebra e dispersão para a utilização destas nanopartículas em estudos experimentais ou aplicações práticas.

0 uso de substâncias dispersantes (tais como laurato de sódio, dodecilbenzenossulfonato de sódio ou goma arábica) e de técnicas de quebra e dispersão (tais como a ultrassonificação e a aplicação de tensões de cisalhamento elevadas) com o objetivo de evitar a formação de aglomerados ou precipitados pode ser observado neste e em outros estudos envolvendo nanofluidos contendo nanotubos de carbono (Wen e Ding. 2004, Rashidi e Nezamabad, 2011, Ong e Walwekar, 2013).

O estudo de Wen e Ding (2004) indicou que existe uma dependência proporcional da condutividade térmica efetiva de um nanofluido contendo nanotubos de carbono com a temperatura deste nanofluido. Esta dependência, no entanto, ocorre de forma nãolinear. Além disso, este estudo mostrou que os modelos utilizados para a previsão das características físicas de misturas contendo partículas de tamanho milimétrico ou micrométrico não são capazes de estimar o aumento da condutividade térmica do nanofluido. 0 artigo ainda apontou o agrupamento dos nanotubos, formando uma estrutura de rede de nanotubos de carbono, como uma possível razão para o aumento superior da condutividade térmica obtido com os nanofluidos.

O trabalho de Rashmi et al. (2013) comparou resultados experimentais e analíticos para o comportamento da intensificação da transferência de calor em um escoamento laminar de um nanofluido contendo nanotubos de carbono ao longo de um trocador de calor de tubos concêntricos. Os resultados obtidos experimentalmente mostram intensificações na faixa entre $4 \%$ e $125 \%$, e os resultados computacionais apresentaram uma boa concordância com estes valores. Para a condutividade térmica, a introdução de nanotubos de carbono também levou a uma intensificação significativa. Esta intensificação é justificada pela presença do movimento browniano de partículas nas escalas molecular e nanométrica. Já para a massa específica, não foram observadas diferenças perceptíveis entre soluções contendo goma arábica e nanofluidos contendo nanotubos de carbono. Para a viscosidade, observou-se que o nanofluido contendo nanotubos de carbono apresentou um comportamento aproximadamente newtoniano para diversas faixas de temperatura. No que diz respeito à transferência de calor total, a presença das nanopartículas foi responsável por uma intensificação significativa, e este resultado pôde ser reproduzido por um modelo computacional com uma boa aproximação em relação aos resultados experimentais obtidos. 
Rashidi e Nezamabad (2011) realizaram um trabalho experimental voltado para a determinação do coeficiente de transferência de calor de nanofluidos contendo nanotubos de carbono de parede múltipla para diferentes valores de concentração volumétrica de partículas. Os resultados obtidos neste estudo mostram que a intensificação da transferência de calor depende diretamente da concentração de nanotubos de carbono ao longo do nanofluido e do número de Reynolds.

Ong e Walwekar (2013) realizaram estudos para determinar a relação entre as propriedades físicas de nanofluidos contendo nanotubos de carbono e a concentração volumétrica das nanopartículas presentes neste nanofluido. Os resultados mostram uma intensificação entre $69 \%$ e $250 \%$ na condutividade térmica obtida com o nanofluido, e entre $9 \%$ e $67 \%$ na taxa de transferência de calor. A viscosidade dos nanofluidos apresenta valores significativamente maiores do que a viscosidade da água sem nanopartículas, e ocorre um aumento na viscosidade com o aumento da concentração do nanofluido. Para a massa específica, os nanofluidos apresentam valores levemente maiores que a água.

Xie et al. (2003) mediram a condutividade térmica de nanofluidos compostos por nanopartículas de nanotubos de carbono. Foram obtidos resultados mostrando uma intensificação na condutividade térmica de até 19,6\% em relação à água. Este artigo também obteve resultados que comprovam que a intensificação da condutividade térmica é mais acentuada quando a condutividade térmica do fluido-base é menor. É observado também que a intensificação da transferência de calor sempre é maior utilizando nanotubos de carbono do que utilizando alumina na composição de um nanofluido.

Xie et al. (2011) propuseram uma discussão sobre a intensificação obtida na condutividade térmica de diferentes nanofluidos, entre eles os que utilizam nanotubos de carbono como nanopartículas. Entre as conclusões apresentadas, observou-se que a condutividade térmica dos nanofluidos depende diretamente de parâmetros tais como a concentração volumétrica de nanopartículas no nanofluido, da temperatura de trabalho, das condutividades térmicas dos componentes do nanofluido, entre outros parâmetros. 0 artigo mostra que nanofluidos contendo nanotubos de carbono sofrem influência direta da temperatura de trabalho, e essa influência é justificada pela agregação cinética das nanopartículas de nanotubos de carbono. Além disso, novamente é observado um 
aumento maior na condutividade térmica destes nanofluidos quando compostos por fluidos-base de condutividade térmica menor.

Nestes dois estudos (Xie et al., 2003 e Xie et al., 2011), são destacados os efeitos prejudiciais que podem ser causados pela adição de surfactantes ao longo do nanofluido na intensificação obtida na condutividade térmica. Assim, uma metodologia é descrita para a obtenção de nanofluidos contendo nanotubos de carbono sem substâncias

químicas surfactantes, adequadamente dispersos e livres de agregados. Esta metodologia envolve a introdução de grupos hidrofílicos na superfície dos nanotubos e a sonificação do nanofluido (Xie et al., 2003) ou o corte dos nanotubos de carbono em dimensões otimizadas (Xie et al., 2011).

\subsubsection{Propriedades de nanofluidos contendo nanotubos de carbono}

A determinação correta das propriedades dos nanofluidos é um aspecto chave na simulação do comportamento físico deste nanofluido, uma vez que as equações que governam a movimentação dinâmica e a transferência de calor em um fluido contêm estas propriedades como parâmetros. Desta maneira, existem trabalhos específicos com o objetivo de elaborar modelos matemáticos que permitam a representação correta do comportamento das principais propriedades físicas de um nanofluido contendo nanotubos de carbono.

As principais propriedades a serem discutidas são a massa específica, a viscosidade absoluta, o calor específico e a condutividade térmica, sendo que esta última possui destaque por ter relação direta com a transferência de calor do sistema.

Para a determinação da massa específica de um nanofluido contendo nanotubos de carbono, em geral, os modelos adotados na literatura se baseiam nos modelos utilizados para a determinação da massa específica de misturas contendo partículas microscópicas, assumindo assim que a massa específica de um nanofluido possui valor equivalente à massa específica de uma mistura simples contendo um fluido e partículas sólidas. 0 equacionamento que define a massa específica de uma destas misturas é a regra das misturas, apresentada em diversos estudos contendo dispersões sólidolíquido, como Pak e Cho (1998), para um líquido qualquer contendo partículas sólidas em dispersão ao longo deste líquido. 0 mesmo equacionamento possui referências nos 
trabalhos de Shafahi et al. (2010), Gavtash et al. (2012) e Rashidi e Nezamabad (2011), e pode ser escrito da seguinte forma:

$$
\rho_{n f}=\rho_{n p} \varphi+\rho_{f b}(1-\varphi)
$$

Onde $\varphi$ corresponde à concentração volumétrica de nanopartículas ao longo do nanofluido. Os índices $n f$, $n p$ e $f b$ correspondem, respectivamente, a "nanofluido", "nanopartícula" e "fluido-base".

Já para a determinação da viscosidade absoluta, existem diversos modelos que buscam representar o comportamento desta propriedade em nanofluidos, relacionandoa com a resistência dos nanofluidos ao escoamento.

Estes modelos possuem como parâmetros principais:

- a concentração volumétrica de nanopartículas ao longo do nanofluido;

- a razão de aspecto das nanopartículas;

- o raio das nanopartículas;

- a viscosidade original do fluido-base.

O trabalho de Mishra et al. (2014) buscou reunir diversos dos modelos existentes para o cálculo desta viscosidade em diferentes tipos de nanofluidos. Nesse artigo também é discutida a influência de diversas características dos nanofluidos na viscosidade, tais como o tamanho e o formato das nanopartículas, a temperatura, a concentração volumétrica e o pH, entre outras características. Esta influência pode ser verificada a partir dos experimentos referidos ao longo do artigo.

Os modelos apresentados neste estudo consistem em aproximações para diferentes situações nas quais uma ou mais destas características possui influência direta na determinação da viscosidade do nanofluido. Uma tabela reunindo todos os modelos apresentados e as características associadas a estes modelos foi elaborada pelo autor, e os modelos de interesse para o presente estudo foram extraídos e podem ser observados nas Tabelas 3 e 4 . 
Tabela 3. Modelos de viscosidade apresentados em Mishra et al. (2014)

\begin{tabular}{ccc}
\hline Autor do Modelo & Equação Característica & Equação \\
\hline Einstein & $\mu_{n f}=\mu_{f b}(1+2,5 \varphi)$ & {$[26]$} \\
\hline Nielsen & $\mu_{n f}=(1+1,5 \varphi) e^{\frac{\varphi}{\left(1-\varphi_{m}\right) \mu_{f b}}}$ & {$[27]$} \\
\hline Batchelor & $\mu_{n f}=\mu_{f b}\left(1+2,5 \varphi+6,5 \varphi^{2}\right)$ & {$[28]$} \\
\hline Brinkman & $\mu_{n f}=\mu_{f b}(1+\varphi)^{2,5}$ & {$[29]$} \\
\hline Nguyen et al. & $\mu_{n f}=\mu_{f b}\left(2,1275-0,0215 . T+0,000277 . T^{2}\right)$ & {$[30]$} \\
\hline Pak e Cho & $\mu_{n f}=\mu_{f b}\left(1+39,11 \varphi+533,9 \varphi^{2}\right)$ & {$[31]$} \\
\hline
\end{tabular}

Tabela 4. Descrição dos modelos de viscosidade apresentados em Mishra et al. (2014)

\begin{tabular}{ccc}
\hline Autor do Modelo & Equação & Descrição \\
\hline Einstein & {$[26]$} & $\begin{array}{r}\text { Utilizado em dispersões uniformes contendo partículas } \\
\text { esféricas com baixa concentração volumétrica. }\end{array}$ \\
\hline Nielsen & {$[27]$} & Lei de potência válida para dispersões com concentração \\
valumétrica maior que 0,02.
\end{tabular}

A variável $\varphi_{m}$ na Equação [27] representa a concentração volumétrica máxima de empacotamento das nanopartículas, acima da qual o escoamento do nanofluido não se torna mais possível. Esta concentração pode ser determinada experimentalmente, e seu valor normalmente varia entre 0,495 e 0,54.

0 artigo ainda destaca que nenhum modelo é capaz de prever a viscosidade de um nanofluido sob quaisquer condições, e que os valores obtidos podem variar de acordo com as condições do experimento. 
0 trabalho de Halelfadl et al. (2013) apresenta resultados experimentais obtidos a partir da análise de nanofluidos contendo especificamente nanotubos de carbono de parede múltipla. São estudados os efeitos da concentração volumétrica de partículas e da temperatura na viscosidade destes nanofluidos.

A partir do resultado experimental, o trabalho busca apresentar modelos teóricos previamente desenvolvidos de forma a observar a comparação dos valores obtidos experimentalmente com a previsão feita por estes modelos.

Além dos modelos de Einstein (Eq. [26]), Brinkman (Eq. [29]) e Batchelor (Eq. [28]) apresentados anteriormente, o trabalho apresenta mais três modelos. 0 primeiro deles é o modelo de Krieger-Dougherty. Este modelo é utilizado em dispersões com alta concentração volumétrica de partículas ao longo do nanofluido, e prevê a viscosidade de suspensões de dispersões uniformes e não-coloidais com bastante eficiência. A equação que define este modelo é:

$$
\mu_{n f}=\left(1-\frac{\varphi}{\varphi_{m}}\right)^{-\xi \varphi_{m}}
$$

Onde o coeficiente $\xi$ é chamado de coeficiente de Einstein e possui valor igual a 2,5 .

O segundo modelo apresentado foi desenvolvido por Maron e Pierce, e apresenta uma forma funcional bastante semelhante. A equação que define este modelo é:

$$
\mu_{n f}=\left(1-\frac{\varphi}{\varphi_{m}}\right)^{-2}
$$

Segundo os autores, esta equação pode ser usada para prever a viscosidade relativa de suspensões contendo fibras, tornando o valor de $\varphi_{\mathrm{m}}$ como sendo dependente da razão de aspecto dessas fibras. Um valor de 0,0361 foi utilizado para a concentração máxima de partículas, levando em consideração a razão de aspecto dos nanotubos de carbono utilizados neste experimento.

0 terceiro modelo apresentado é o modelo de Brenner e Condiff. Este modelo é utilizado geralmente para situações onde existem partículas não-esféricas, pois considera os efeitos de forma na determinação da viscosidade. Para o caso de nanotubos 
de carbono, este modelo é aplicável para concentrações volumétricas até $1 /(\mathrm{AR})^{2}$, onde $A R$ corresponde a razão de aspecto dos nanotubos de carbono. Este modelo é definido pelas seguintes equações:

$$
\mu_{n f}=(1+\Upsilon \varphi)
$$

Com

$$
\Upsilon=\frac{0,312 \cdot A R}{\ln (2 \cdot A R)-1,5}+2-\frac{0,5}{\ln (2 \cdot A R)-1,5}-\frac{1,872}{A R}
$$

0 artigo ainda expõe uma correção para a concentração volumétrica de partículas na presença de aglomerados de nanopartículas. A concentração de aglomerados pode ser descrita como:

$$
\varphi_{a}=\varphi\left(\frac{R_{a}}{R_{p}}\right)^{3-D}
$$

Onde $R_{a}$ corresponde ao raio dos aglomerados de partículas, $R_{p}$ corresponde ao raio da nanopartícula e o índice $D$ corresponde a um índice fractal, capaz de representar as estruturas dos aglomerados. 0 trabalho define que, para nanotubos de carbono, os valores de $D$ variam entre 1,5 e 2,45, sendo que geralmente um valor de 2,1 é utilizado.

Os modelos apresentados neste artigo são válidos para nanofluidos contendo nanotubos de carbono com baixas concentrações volumétricas de nanopartículas. A diferença entre os valores experimentais e os modelos aumenta com o aumento da concentração volumétrica de partículas. 0 modelo de Maron-Pierce obteve os melhores resultados na comparação com os dados experimentais deste estudo.

No que diz respeito ao calor específico de nanofluidos, O'Hanley et al. (2012) apresenta duas correlações capazes de prever esta propriedade de um nanofluido. A primeira correlação se baseia numa ponderação volumétrica dos calores específicos do fluido-base e da nanopartícula, similar à teoria utilizada para misturas de gases ideais para a determinação da massa específica em nanofluidos. A equação que define essa correlação é: 


$$
c_{p, n f}=\varphi c_{p, n p}+(1-\varphi) c_{p, f b}
$$

A segunda correlação se baseia na hipótese de que ocorre equilíbrio térmico entre as nanopartículas e o fluido-base ao redor destas partículas. Esta correlação utiliza a definição de massa específica apresentada anteriormente e a definição formal de calor especifico de forma a obter a seguinte expressão:

$$
\mathrm{c}_{p, n f}=\frac{\varphi\left(\rho \mathrm{c}_{p}\right)_{n p}+(1-\varphi)\left(\rho \mathrm{c}_{p}\right)_{f b}}{\varphi \rho_{n p}+(1-\varphi) \rho_{f b}}
$$

Os resultados obtidos neste estudo mostram que a utilização da segunda correlação estima melhor os resultados experimentais obtidos utilizando nanofluidos composto por água/alumina, água/sílica e água/CuO, enquanto que a primeira correlação em geral superestima os valores de calor específico na maioria dos casos pesquisados.

Xuan e Roetzel (2000) também utilizaram em seu estudo uma forma adaptada da Eq. [38] para a determinação do calor específico de um nanofluido genérico, possibilitando assim o cálculo da taxa de transferência de calor ao longo deste nanofluido. Rashmi et al. (2013), na elaboração de seu modelo computacional, também utilizaram uma forma adaptada da Eq. [38] para a determinação do calor específico de um nanofluido contendo nanotubos de carbono.

No que se refere à condutividade térmica, uma grande quantidade de estudos e modelos foi proposta para a determinação desta propriedade em nanofluidos, uma vez que ela tem relação direta com a transferência de calor do sistema. Considerando o foco deste capítulo como sendo a utilização de nanofluidos contendo nanotubos de carbono, somente os artigos contendo a avaliação desta propriedade nestes nanofluidos serão apresentados. Discussões adicionais a respeito da avaliação desta propriedade para nanofluidos contendo composições diferentes podem ser encontradas em Das (2008), Kakaç e Pramuanjaroenkij (2009) e Lee et al. (2010).

O estudo de Lamas et al. (2014) apresenta uma análise estatística dos modelos existentes para a determinação da condutividade térmica em nanofluidos contendo nanotubos de carbono, de forma a selecionar as variáveis de maior importância para 
essa determinação. Dentre os modelos apresentados pelos autores foram selecionados três modelos de interesse para o presente estudo.

O primeiro modelo apresentado para a previsão da condutividade térmica é o modelo de Hamilton e Crosser. Este modelo considera que o nanofluido possui uma distribuição estatisticamente homogênea de partículas não esféricas ao longo do fluidobase, e que as partículas não interagem umas com as outras. Neste modelo, são utilizadas as equações fundamentais de Maxwell (1873) para a condutividade térmica de dispersões de partículas microscópicas, introduzindo um fator empírico n, responsável pela variação da geometria das partículas dispersas. Este modelo pode ser representado pela seguinte equação:

$$
\mathrm{k}_{n f}=\frac{\mathrm{k}_{n p}+(n-1) \mathrm{k}_{f b}-(n-1)\left(\mathrm{k}_{f b}-\mathrm{k}_{n p}\right) \varphi}{\mathrm{k}_{n p}+(n-1) \mathrm{k}_{f b}+\left(\mathrm{k}_{f b}-\mathrm{k}_{n p}\right) \varphi}
$$

Onde o parâmetro $n$ representa o fator de forma da nanopartícula e pode ser representado como:

$$
\mathrm{n}=\frac{3}{\psi}
$$

Nessa equação, o parâmetro $\psi$ representa a esfericidade da nanopartícula e pode ser definido como a razão entre a área superficial de uma esfera de volume equivalente ao volume da nanopartícula e a área superficial real da nanopartícula. Para partículas de esfericidade igual a 1 (ou seja, partículas perfeitamente esféricas), a equação que define o modelo de Hamilton e Crosser se reduz ao modelo fundamental proposto por Maxwell (1873).

Este modelo de Hamilton e Crosser também foi mencionado nos trabalhos de Wen e Ding (2004), Xie et al. (2003) e Liu et al. (2005), e os resultados obtidos apresentaram uma concordância significativa com os dados experimentais para concentrações baixas de nanofluidos.

O segundo modelo apresentado para a previsão da condutividade térmica é o modelo de Nan. Este modelo é baseado na teoria de dispersão múltipla, e considera a presença de uma resistência térmica na interface entre as nanopartículas e o fluido-base. A equação que descreve este modelo tem a seguinte forma: 


$$
\mathrm{k}_{n f}=\mathrm{k}_{f b} \frac{3+\varphi\left(\beta_{11}+\beta_{33}\right)}{3-\varphi \beta_{11}}
$$

Os parâmetros $\beta_{11}$ e $\beta_{33}$ podem ser definidos como:

$$
\begin{gathered}
\beta_{11}=\frac{2\left(k_{11}^{C}+\mathrm{k}_{f b}\right)}{k_{11}^{C}+\mathrm{k}_{f b}} \\
\beta_{33}=\frac{k_{33}^{C}}{\mathrm{k}_{f b}}-1
\end{gathered}
$$

E os parâmetros $k_{11}^{C}$ e $k_{33}^{C}$ podem ser definidos, respectivamente, como sendo as condutividades térmicas nos eixos transversal e longitudinal da resistência térmica interfacial entre as nanopartículas e o fluido-base. As equações que definem estes parâmetros são:

$$
\begin{aligned}
& k_{11}^{C}=\frac{\mathrm{k}_{n p}}{1+\frac{2 \alpha_{k} \mathrm{k}_{n p}}{d_{p} \mathrm{k}_{f b}}} \\
& k_{33}^{C}=\frac{\mathrm{k}_{n p}}{1+\frac{2 \alpha_{k} \mathrm{k}_{n p}}{L_{p} \mathrm{k}_{f b}}}
\end{aligned}
$$

Onde $d_{p}$ e $L_{p}$ compreendem, respectivamente, o diâmetro e o comprimento de um nanotubo de carbono e $\alpha_{k}$ é o raio de Kapitza, definido como:

$$
\alpha_{k}=R_{k} \mathrm{k}_{f b}
$$

Onde $R_{k}$ é uma constante de valor igual a $8 \cdot 10^{-8} \mathrm{~m}^{2} \mathrm{~K} / \mathrm{W}$.

Este modelo também foi mencionado no trabalho de Wen e Ding (2004), embora os resultados obtidos na aplicação deste modelo não tenham obtido boa concordância com os resultados experimentais. 
O terceiro modelo apresentado corresponde ao modelo de Xue. Esse modelo também é baseado na equação de dispersão de Maxwell (1873), e considera a distribuição de partículas de forma análoga à existente em um material compósito. A equação que define este modelo é a seguinte:

$$
\mathrm{k}_{n f}=\mathrm{k}_{f b} \frac{1-\varphi+2 \varphi\left(\frac{\mathrm{k}_{n p}}{\mathrm{k}_{n p}-\mathrm{k}_{f b}}\right) \ln \left(\frac{\mathrm{k}_{n p}+\mathrm{k}_{f b}}{2 \mathrm{k}_{f b}}\right)}{1-\varphi+2 \varphi\left(\frac{\mathrm{k}_{f b}}{\mathrm{k}_{n p}-\mathrm{k}_{f b}}\right) \ln \left(\frac{\mathrm{k}_{n p}+\mathrm{k}_{f b}}{2 \mathrm{k}_{f b}}\right)}
$$

No entanto, a condutividade térmica possui relação direta somente com a concentração volumétrica de partículas, e a razão de aspecto das partículas é desconsiderada no cálculo da Equação [47], o que não condiz com a literatura.

Os autores concluem ao final deste estudo que estes modelos apresentados ainda apresentam diferenças significativas entre si, e desconsideram efeitos importantes como da geometria dos nanotubos de carbono. Além disso, o efeito da temperatura é visto pelos modelos como prejudicial, enquanto os resultados experimentais mostram o contrário.

Por sua vez, no estudo de Liu et al. (2005) foram realizados experimentos utilizando nanofluidos compostos por etilenoglicol e óleo sintético como fluido-base e nanotubos de carbono de parede múltipla como nanopartículas. Para ambos os casos, observou-se um aumento na condutividade térmica com a introdução das nanopartículas, sendo que o aumento foi maior para o nanofluido contendo óleo sintético, que apresentava uma condutividade térmica inicial menor. Os resultados obtidos mostram também que o aumento da condutividade térmica é maior para nanofluidos contendo concentrações volumétricas de nanopartículas maiores.

$\mathrm{O}$ autor ainda apresenta três modelos com a finalidade de compará-los com os resultados obtidos. 0 primeiro modelo consiste no modelo de dispersão de Maxwell (1873) para suspensões contendo partículas de dimensões microscópicas. Este modelo possui uma concordância baixa com os resultados experimentais envolvendo nanofluidos.

O segundo modelo apresentado consiste no modelo de Hamilton e Crosser para dispersões contendo partículas de formato não-esférico. Este modelo já foi apresentado pela Equação [39]. 
O terceiro modelo apresentado é o modelo de Jeffrey (1973), que realizou um estudo para dispersões contendo uma concentração volumétrica pequena de partículas esféricas. A equação que define a condutividade térmica deste modelo é escrita na forma de uma série infinita e possui a seguinte forma:

$$
\mathrm{k}_{n f}=\mathrm{k}_{f b}\left[1+3 \mathrm{~B} \varphi+\left(3 B^{2}+\frac{3 B^{3}}{4}+\frac{9 B^{3}}{16} \frac{\alpha+2}{2 \alpha+3}+\frac{3 B^{4}}{64}+\cdots\right) \varphi^{2}\right]
$$

E os parâmetros $\alpha$ e $B$ podem ser escritos como:

$$
\begin{gathered}
\alpha=\frac{\mathrm{k}_{n p}}{\mathrm{k}_{f b}} \\
\mathrm{~B}=\frac{(\alpha-1)}{(\alpha-2)}
\end{gathered}
$$

\subsubsection{Nanofluidos baseados em etilenoglicol}

Da mesma forma que os nanofluidos contendo nanotubos de carbono, os nanofluidos contendo etilenoglicol como fluido-base vem recebendo uma atenção crescente nas pesquisas recentes por dois motivos principais.

O primeiro motivo consiste na obtenção de um nanofluido cuja intensificação na condutividade térmica e na transferência de calor global é proporcionalmente mais significativa do que a intensificação obtida com o uso de água. Isto ocorre devido à menor condutividade térmica do etilenoglicol. Estudos como os de Xie et al. (2003), Xie et al. (2011) e Liu et al. (2005) demonstram que fluidos de menor condutividade térmica em geral sofrem intensificações mais significativas na sua capacidade de transferir calor com a introdução de nanopartículas.

O segundo motivo está relacionado à aplicação de etilenoglicol em radiadores automotivos. 0 etilenoglicol possui um ponto de fusão mais baixo do que a água, e, portanto, pode ser utilizado como aditivo em regiões do mundo de frio intenso, nas quais a água presente no radiador do automóvel pode congelar. No entanto, uma consequência da adição de etilenoglicol é a redução da condutividade térmica total dessa mistura de fluidos. Com a adição de nanopartículas a esta mistura, este efeito pode 
sofrer uma compensação. Este efeito foi estudado mais detalhadamente em Peyghambarzadeh et al. (2011).

Desta forma, os estudos experimentais utilizando nanofluidos contendo etilenoglicol buscam determinar quais são os aspectos na composição do nanofluido que influenciam o aumento da condutividade térmica e a intensificação da transferência de calor, e buscam quantificar as propriedades físicas que servem de parâmetros para o cálculo da transferência de calor ao longo destes nanofluidos.

0 estudo de Xie et al. (2011) mostra que a concentração volumétrica de diferentes tipos de partículas em nanofluidos utilizando etilenoglicol (EG) como fluidobase possui influência direta na intensificação da condutividade térmica do nanofluido. As Figuras 8 e 9 extraídas deste estudo mostram que, mesmo para diferentes tipos de nanopartículas, o aumento da concentração volumétrica de nanopartículas causa uma intensificação na condutividade térmica de um fluido.

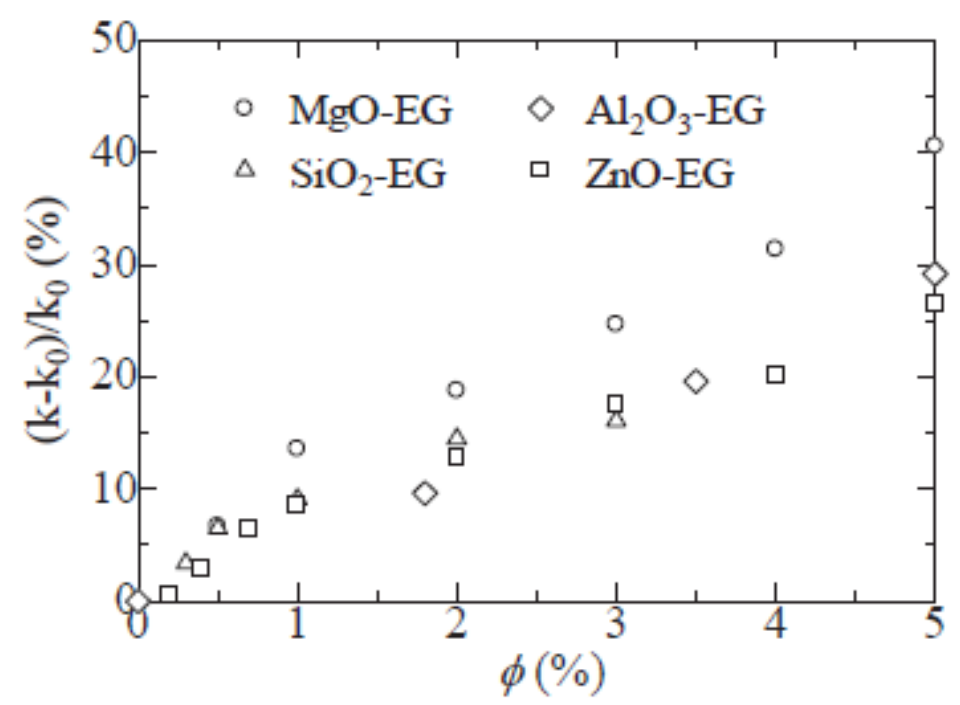

Figura 8. Intensificação da condutividade térmica de nanofluidos contendo etilenoglicol e partículas de diferentes óxidos (Xie et al., 2011) Obs.: 0 valor de $\mathrm{k}_{0}$ corresponde à condutividade térmica do fluido-base neste caso. 


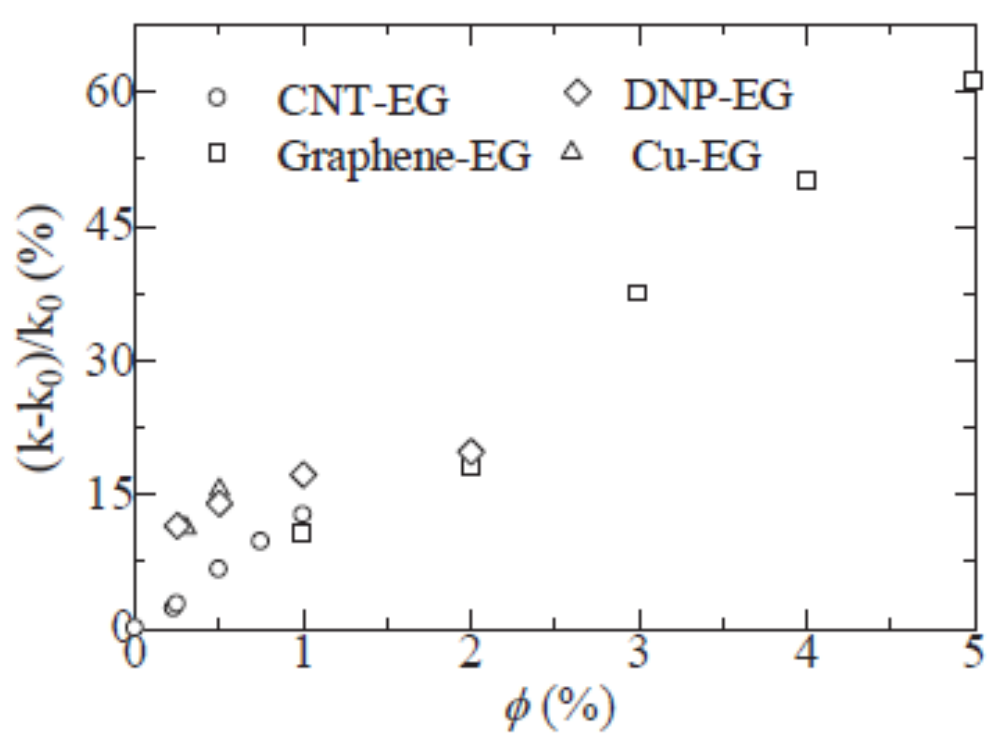

Figura 9. Intensificação da condutividade térmica de nanofluidos contendo etilenoglicol e partículas diversas (Xie et al., 2011) Obs.: $\mathrm{O}$ valor de $\mathrm{k}_{0}$ corresponde à condutividade térmica do fluido-base neste caso.

A relevância de outros parâmetros para a intensificação da condutividade térmica de um nanofluido é discutida ao longo do trabalho de Xie et al. (2011). Estes parâmetros consistem na temperatura, no tamanho das partículas, no pré-tratamento do nanofluido, no pH do nanofluido e na adição de surfactantes. Estes parâmetros possuem pouca relevância no presente estudo, e podem ser verificados no artigo original.

0 trabalho de Suganthi et al. (2014) apresenta experimentos utilizando nanofluidos compostos por $\mathrm{ZnO}$ e etilenoglicol, obtendo resultados referentes à intensificação da condutividade térmica e ao comportamento da viscosidade.

Observou-se que a presença de nanopartículas de $\mathrm{ZnO}$ foi responsável por quebrar as ligações intermoleculares existentes entre as moléculas de etilenoglicol, e isso foi responsável por uma diminuição na viscosidade do nanofluido. Este comportamento não condiz com o comportamento usual dos nanofluidos encontrado na literatura, e é atribuído ao grau de dispersão das nanopartículas obtido neste experimento. A temperatura do nanofluido foi observada como sendo um fator influente da determinação da viscosidade, reduzindo-a de forma exponencial. Um modelo empírico dependente da temperatura e da concentração volumétrica de nanopartículas foi proposto para a determinação da viscosidade. 
O comportamento da condutividade térmica se mostrou aproximadamente linear, obtendo um aumento máximo de cerca de 34\%. Um modelo empírico foi proposto de forma a correlacionar a condutividade térmica do nanofluido com a concentração volumétrica das nanopartículas. É observado que o modelo proposto se aproxima do modelo de Hamilton e Crosser, descrito pela Equação [39]. No entanto, a condutividade obtida é maior que a prevista por Hamilton-Crosser. Isto é justificado devido à microconvecção induzida pelo movimento browniano de partículas, ao arranjo ordenado das partículas ao longo do nanofluido, à formação de camadas de aglomerados de nanopartículas e ao transporte de calor por meio da mecânica molecular de partículas. 0 aumento da temperatura neste caso possui um efeito negativo na condutividade térmica, reduzindo o efeito obtido pela introdução das nanopartículas.

Os modelos propostos são validos somente para misturas de etilenoglicol e óxido de zinco. Novamente, é possível observar que a adição de um fluido com maior condutividade térmica (água) teve por consequência a obtenção de uma intensificação menos acentuada na condutividade térmica do nanofluido.

O estudo de Garg. et al. (2008) baseia-se na determinação experimental da condutividade térmica e da viscosidade de nanofluidos contendo etilenoglicol e partículas de cobre. Obteve-se uma intensificação máxima na condutividade térmica de cerca de $12 \%$, para uma solução contendo uma concentração volumétrica de partículas de $2 \%$.

A condutividade térmica obtida neste trabalho foi comparada com a condutividade prevista pelo modelo proposto por Maxwell (1873) e com os resultados experimentais obtidos por Lee et al. (1999) para um nanofluido contendo nanopartículas de óxido de cobre dispersas em etilenoglicol. Observou-se que o modelo de Maxwell (1873) subestima a intensificação na condutividade térmica, e que a intensificação obtida é mais acentuada utilizando cobre puro.

Para a viscosidade, houve uma comparação dos resultados obtidos com o modelo proposto por Einstein e com os resultados experimentais obtidos por Prasher et al. (2006) para um nanofluido contendo partículas de alumina dispersas em propilenoglicol. Observou-se que o modelo de Einstein subestima consideravelmente o valor da viscosidade, e que o aumento na viscosidade obtido pelos dois nanofluidos é bastante similar. 
Desta forma, conclui-se neste estudo que, devido ao aumento mais intenso na viscosidade do que na condutividade térmica, a utilização destes nanofluidos não seria indicada, a menos em situações em que as configurações do problema permitissem um aproveitamento considerável do aumento da condutividade térmica.

\subsubsection{Propriedades de nanofluidos contendo etilenoglicol}

Os modelos utilizados para a determinação das propriedades de nanofluidos contendo etilenoglicol possuem algumas semelhanças com os modelos apresentados para a avaliação das propriedades de nanofluidos contendo nanotubos de carbono.

Como primeira consideração a ser feita, é importante observar que a determinação da massa específica de um nanofluido feita em Pak e Cho (1998) e referida em Shafahi et al. (2010) e Gavtash et al. (2012) possui um caráter amplo, incluindo nanofluidos com uma ampla gama de composições. Desta forma, por considerar um líquido qualquer contendo partículas sólidas em dispersão ao longo deste líquido, é possível utilizar a mesma formulação para a determinação da massa específica de nanofluidos contendo etilenoglicol. Assim, a Equação [25] continua a ser válida e pode servir de referência ao presente estudo para o cálculo da massa específica destes nanofluidos.

Analogamente, o mesmo ocorre na determinação do calor específico, uma vez que os estudos de O’Hanley et al. (2012) e Xuan e Roetzel (2000) também se referem a nanofluidos genéricos. Assim, as Equações [37] e [38] também podem ser usadas para a determinação do calor específico de nanofluidos contendo etilenoglicol.

No que diz respeito a viscosidade, diversos estudos vem sendo desenvolvidos com a finalidade de determinar esta propriedade especificamente para nanofluidos contendo etilenoglicol.

O estudo de Sundar et al. (2014) utilizou nanofluidos contendo partículas de $\mathrm{Al}_{2} \mathrm{O}_{3}$ dispersas em soluções contendo diferentes proporções de água e etilenoglicol em temperaturas moderadas e concentrações volumétricas de partículas entre 0,3\% e 1,5\%. Observou-se que a viscosidade aumenta com o aumento da concentração volumétrica de partículas, mas decresce com o aumento da temperatura do nanofluido.

Os modelos apresentados no trabalho são similares aos modelos apresentados anteriormente por Mishra et al. (2014). Novamente são apresentados os modelos de 
Einstein (Equação [26]), Brinkman (Equação [29]) e Batchelor (Equação [28]) como alternativas para o cálculo da viscosidade do nanofluido.

O estudo de Pastoriza-Gallego et al. (2014) buscou determinar valores para a viscosidade e para a condutividade térmica de nanofluidos contendo etilenoglicol e nanopartículas de ZnO. Observou-se que o valor da viscosidade possui relação diretamente proporcional com a concentração volumétrica de partículas e inversamente proporcional com a temperatura. 0 tamanho das nanopartículas utilizadas também possui relação direta com a viscosidade, sendo que os nanofluidos contendo partículas menores apresentaram valores maiores para a viscosidade. Isso mostra que a viscosidade dos nanofluidos é diretamente proporcional ao grau de aglomeração entre as nanopartículas do nanofluido.

O estudo mostra, a partir da determinação da taxa de cisalhamento do fluido, que este nanofluido apresenta um comportamento newtoniano.

$\mathrm{O}$ autor ainda apresenta modelos com a finalidade de correlacionar os resultados experimentais obtidos com equações propostas na literatura. 0 primeiro modelo apresentado é o modelo de Chow. Este modelo é válido para nanofluidos contendo partículas esféricas de tamanho similar e pode ser descrito a partir de uma expansão polinomial que tem a seguinte forma:

$$
\mu_{n f}=\mu_{f b}\left(1+\sum_{j=1}^{N^{\prime}} C_{j} \varphi^{j}\right)
$$

Onde $N^{\prime}$ representa o grau da aproximação polinomial desejada e os valores de $C_{j}$ correspondem a constantes determinadas para cada caso. Para o caso estudado, determinou-se que a aproximação polinomial linear fornecia uma aproximação suficiente, e assim, foi fixado o valor de $N^{\prime}=1$. Desta forma, para as duas amostras pesquisadas neste trabalho, os valores determinados para a constante $C_{1}$ foram de 7,7 e 15,6, para as amostras contendo partículas maiores e menores, respectivamente.

O segundo modelo apresentado neste trabalho é o modelo de Krieger e Dougherty, o qual já foi apresentado e previamente discutido. A equação que define este modelo é a Equação [32]. Adicionalmente, uma segunda correlação baseada neste 
modelo foi proposta de forma a levar em consideração a formação de agregados de partículas estáveis. Esta correlação possui o seguinte formato:

$$
\mu_{n f}=\mu_{f b}\left[1-\frac{\varphi}{0,605}\left(\frac{R_{a}}{R_{p}}\right)^{1,2}\right]^{-1,5125}
$$

Nesta correlação, as variáveis $R_{a}$ e $R_{p}$ correspondem aos raios do aglomerado de nanopartículas e das nanopartículas individuais. Segundo Pastoriza-Gallego et al. (2014), esta correlação apresenta melhores resultados em situações nas quais a aglomeração das nanopartículas possui uma importância maior na determinação da viscosidade. Isto ocorre em situações onde o tamanho das partículas utilizadas é pequeno, tal como no estudo mencionado.

Já para a avaliação da condutividade térmica, em geral os parâmetros que influenciam diretamente a condutividade do nanofluido são a condutividade térmica do fluido-base, a condutividade térmica da nanopartícula, a concentração volumétrica de nanopartículas e a razão de aspecto das nanopartículas. Estes parâmetros são recorrentes ao longo dos modelos apresentados, e possuem uma influência significativa no valor final da condutividade térmica.

O estudo de Kwak e Kim (2005) teve por objetivo a determinação das propriedades de nanofluidos contendo etilenoglicol e partículas de CuO. Em especial, as propriedades pesquisadas consistem na viscosidade e na condutividade térmica. No que diz respeito à condutividade térmica, dois modelos capazes de preverem o comportamento desta propriedade foram propostos. 0 primeiro modelo apresentado consiste no modelo de Hamilton e Crosser, o qual já foi apresentado anteriormente e pode ser definido pela Equação [39].

Um segundo modelo apresentado no trabalho consiste no modelo de Wasp. Este modelo pode ser utilizado para a determinação da condutividade térmica de misturas entre líquidos e partículas sólidas e pode ser representado pela seguinte equação:

$$
k_{n f}=k_{f b} \frac{\alpha+2-2 \varphi(1-\alpha)}{\alpha+2+\varphi(1-\alpha)}
$$


0 valor de $\alpha$ é definido pela Equação [49] e corresponde à razão entre as condutividades térmicas da nanopartícula e do fluido-base. De acordo com o estudo, este modelo subestima a intensificação obtida na condutividade térmica do nanofluido.

O estudo de Eastman et al. (2001) utilizou nanofluidos contendo nanopartículas de cobre e etilenoglicol. Os resultados mostram que a condutividade térmica do nanofluido aumenta de acordo com o aumento da concentração volumétrica de nanopartículas. 0 estudo buscou comparar os resultados obtidos experimentalmente com o modelo proposto por Hamilton e Crosser, definido pela Equação [39]. No entanto, os resultados obtidos superam as previsões feitas pelo modelo. 0 trabalho justifica que esta diferença pode ter ocorrido devido a ausência da influência do tamanho das partículas na condutividade térmica do nanofluido no modelo de Hamilton e Crosser.

O trabalho de Liu et. al (2005) lidou com nanofluidos contendo nanopartículas de nanotubos de carbono e utilizou etilenoglicol e óleo sintético como fluidos-base. Desta forma, as equações apresentadas neste trabalho, correspondente aos modelos de Hamilton e Crosser (Equação [39]) e Jeffrey (Equação [48]) também serão avaliados para a aplicação estudada envolvendo nanofluidos contendo etilenoglicol como fluidobase.

$\mathrm{O}$ estudo de Yu et al. (2009) buscou determinar a condutividade térmica e a viscosidade em nanofluidos contendo etilenoglicol e ZnO. Observou-se que a condutividade térmica possui relação direta com a concentração volumétrica de nanopartículas e com a temperatura. Dos modelos utilizados para a determinação da condutividade térmica, o primeiro modelo consiste na combinação dos modelos de Maxwell e Hamilton e Crosser. A aplicação deste modelo pode ser observada por meio da utilização da Equação [39].

O segundo modelo apresentado consiste no modelo de Chen et al. Este modelo busca utilizar o mecanismo de aglomeração de partículas de forma a explicar o aumento na condutividade térmica. A equação que define este modelo possui o seguinte formato:

$$
\mathrm{k}_{n f}=\mathrm{k}_{f b} \frac{\mathrm{k}_{a}-2 \mathrm{k}_{f b}+2 \varphi_{a}\left(\mathrm{k}_{f b}-\mathrm{k}_{a}\right)}{\mathrm{k}_{a}+2 \mathrm{k}_{f b}+\varphi_{a}\left(\mathrm{k}_{f b}-\mathrm{k}_{a}\right)}
$$

Sendo que $k_{a}$ e $\varphi_{a}$ correspondem à condutividade térmica equivalente do aglomerado de nanopartículas e a concentração volumétrica efetiva de aglomerados de 
nanopartículas. Esta concentração volumétrica pode ser calculada por meio da expressão a seguir:

$$
\varphi_{a}=\varphi\left(\frac{\mathrm{R}_{a}}{\mathrm{R}_{n p}}\right)^{3-D}
$$

Onde o valor de $D$ é usualmente definido como sendo igual a 1,8.

$O$ valor de $k_{a}$ pode ser definido por meio do modelo de Bruggeman. Este modelo é utilizado para determinar a condutividade térmica de misturas sólido-líquido contendo aglomerados de partículas. 0 modelo pode ser descrito pela equação:

$$
\begin{aligned}
\mathrm{k}_{a}=0,25 \mathrm{k}_{f b}\left\{\left(3 \varphi_{a}-1\right) \frac{\mathrm{k}_{n p}}{\mathrm{k}_{f b}}+\left(3\left(1-\varphi_{a}\right)-1\right)\right. \\
\left.+\left[\left(\left(3 \varphi_{a}-1\right) \frac{\mathrm{k}_{n p}}{\mathrm{k}_{f b}}+\left(3\left(1-\varphi_{a}\right)-1\right)\right)^{\frac{1}{2}}+8 \frac{\mathrm{k}_{n p}}{\mathrm{k}_{f b}}\right]\right\}
\end{aligned}
$$

A partir da comparação entre os modelos, pode-se observar que o modelo de Hamilton e Crosser obteve uma aproximação significativamente boa em relação aos resultados experimentais. Esta aproximação pode ser observada na Fig. 10, extraída de Yu et al. (2009): 


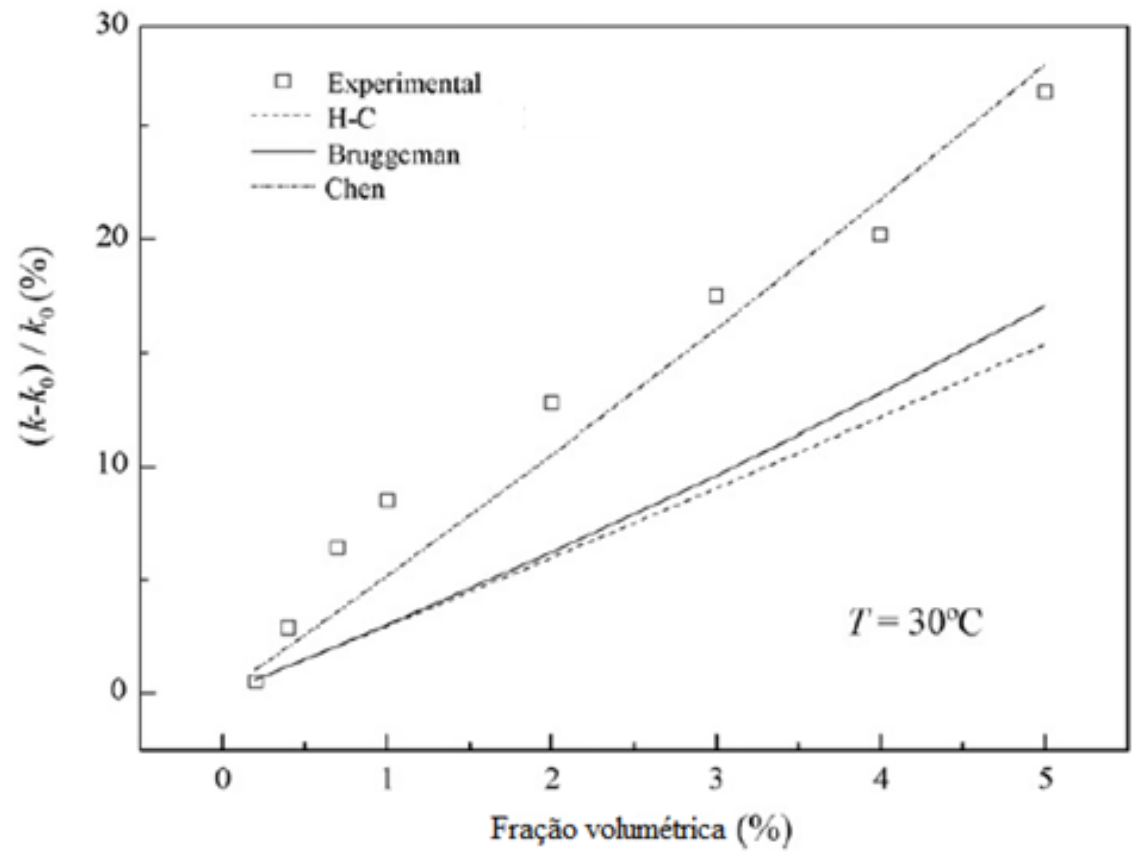

Figura 10. Intensificação da condutividade térmica de nanofluidos contendo etilenoglicol e ZnO - Comparação entre modelos da literatura (Yu et al., 2009)

O estudo de Sundar et al. (2014) também verificou a validade de diferentes modelos utilizados para a avaliação da condutividade térmica de nanofluidos. Os modelos de Maxwell, Hamilton e Crosser e Bruggeman são utilizados de forma a avaliar os resultados experimentais obtidos. Estes modelos podem ser observados nas Equações [39] e [56].

Em sequência, são propostos novos modelos para a avaliação da condutividade térmica. 0 modelo de Murshed et al. é baseado no modelo de Bruggeman, desconsiderando, no entanto, o efeito dos aglomerados de nanopartículas. Este modelo possui o seguinte formato:

$$
\mathrm{k}_{n f}=0,25\left((3 \varphi-1) \mathrm{k}_{n p}+\left((2-3 \varphi) \mathrm{k}_{f b}\right)\right)+\frac{\mathrm{k}_{f b}}{4} \sqrt{\Delta}
$$

Sendo $\Delta$ definido como:

$$
\Delta=\left[(3 \varphi-1)^{2}\left(\frac{\mathrm{k}_{n p}}{\mathrm{k}_{f b}}\right)^{2}+(2-3 \varphi)^{2}+2\left(2+9 \varphi+9 \varphi^{2}\right)\left(\frac{\mathrm{k}_{n p}}{\mathrm{k}_{f b}}\right)\right]
$$


Em seguida, o modelo de Yu e Choi é apresentado como uma alternativa para o cálculo da condutividade térmica de um nanofluido genérico. 0 modelo é definido pela seguinte equação:

$$
\mathrm{k}_{n f}=\mathrm{k}_{f b}\left[\frac{\mathrm{k}_{n p}+2 \mathrm{k}_{f b}+2 \varphi\left(\mathrm{k}_{n p}-\mathrm{k}_{f b}\right)\left(1+\beta_{1}\right)^{3}}{\mathrm{k}_{n p}+2 \mathrm{k}_{f b}-\varphi\left(\mathrm{k}_{n p}-\mathrm{k}_{f b}\right)\left(1+\beta_{1}\right)^{3}}\right]
$$

0 parâmetro $\beta_{1}$ é definido como sendo a razão entre a espessura da nanocamada formada ao redor da nanopartícula e o raio da nanopartícula, e geralmente possui valor igual a 0,1 .

Por fim, o estudo de Pastoriza-Gallego et al. (2014) já mencionado anteriormente também analisa as correlações existentes na literatura para a determinação da condutividade térmica de nanofluidos contendo etilenoglicol. Os modelos de Maxwell, Hamilton e Crosser e Jeffrey são mencionados novamente. Estes modelos podem ser revistos nas Equações [39] e [48] do presente trabalho.

Uma alternativa é proposta com o modelo de Turian et al., utilizado para a determinação da condutividade térmica de dispersões contendo sílica, alumina, carbono, entre outras partículas. 0 modelo consiste em uma aproximação logarítmica que busca corrigir as imprecisões que ocorrem no modelo de Maxwell (1873) para casos envolvendo o uso de nanofluidos contendo partículas de alta condutividade térmica. A equação que define esse modelo possui a seguinte forma:

$$
\mathrm{k}_{n f}=\mathrm{k}_{f b}{ }^{\varphi} \mathrm{k}_{n p}{ }^{1-\varphi}
$$

\subsection{Tubos de calor contendo nanofluidos}

O estudo da aplicação de nanofluidos contendo as mais diferentes composições no interior de tubos de calor já possui uma importância considerável, que pode ser verificada pelo grande número de trabalhos existentes na literatura. Estes trabalhos buscam aliar os efeitos de intensificação da condutividade térmica e da transferência de calor global obtidos por meio dos nanofluidos com os mecanismos de mudança de fase e bombeamento passivo existentes no interior de tubos de calor. Desta forma, o objetivo 
destes estudos é obter um equipamento capaz de transportar calor ao longo de distâncias significativas de forma bastante eficiente e sem precisar introduzir energia no sistema para tanto.

Os trabalhos envolvendo estes dois conceitos são numerosos, e, consequentemente, já existem análises críticas englobando uma grande quantidade destes trabalhos. 0 trabalho de Liu e Li (2012) busca sintetizar o resultado obtido em diversos destes trabalhos, de forma a observar o efeito das principais características dos nanofluidos na resistência térmica de diversos tipos de tubos de calor.

Ao todo foram verificados 38 diferentes estudos nessa revisão. Estes trabalhos compreendem experimentos feitos com cinco tipos diferentes de tubos de calor:

- tubos de calor contendo matrizes porosas compostas por microssulcos;

- tubos de calor contendo matrizes porosas compostas por telas;

- tubos de calor contendo matrizes porosas compostas por metal sinterizado;

- tubos de calor oscilatórios;

- termosifões bifásicos fechados.

Os nanofluidos utilizados nestas aplicações incluem misturas compostas por água (mais comum), etanol ou acetona (menos comuns), e uma grande diversidade de tipos de nanopartículas, como partículas metálicas ( $\mathrm{Au}, \mathrm{Ag}$, $\mathrm{Ni}$, etc.), óxidos $\left(\mathrm{Al}_{2} \mathrm{O}_{3}, \mathrm{CuO}, \mathrm{TiO}_{2}\right.$, etc.), ou mesmo partículas orgânicas (diamante, CNT, etc.).

Destes 38 trabalhos, é possível observar que somente quatro deles apresentaram resultados insatisfatórios. Em geral, estes resultados insatisfatórios estão ligados à escolha inadequada de materiais para a construção do tubo de calor ou para a elaboração do nanofluido, à instabilidade do nanofluido utilizado, causando uma tendência de aglomeração das partículas e consequente desmembramento do nanofluido, e à elaboração inadequada de nanofluidos contendo estruturas complexas, como nanotubos de carbono. Por outro lado, estudos utilizando termosifões bifásicos fechados ou matrizes porosas compostas por metal sinterizado obtiveram reduções máximas na resistência térmica global do tubo de calor na ordem de $80-90 \%$. Estes resultados representam um avanço bastante significativo na tecnologia de tubos de calor.

Os resultados comparativos apresentados pela revisão ainda mostram que, para tubos de calor contendo matrizes porosas compostas por micro canais, todos os nanofluidos aplicados (contendo concentrações de nanopartículas otimizadas) 
obtiveram resultados positivos para qualquer quantidade de calor aplicada ao tubo de calor, aumentando assim a quantidade máxima de calor que pode ser removido por este dispositivo. 0 mesmo ocorreu para tubos de calor contendo matrizes porosas compostas por telas. Isto se deve a três principais razões decorrentes da introdução de nanopartículas ao fluido: o aumento da condutividade térmica do fluido, a diminuição do ângulo de contato entre o fluido e as superfícies sólidas e o aumento da pressão capilar no interior do tubo de calor.

Para os casos envolvendo tubos de calor contendo matrizes porosas compostas por metal sinterizado, tubos de calor oscilatórios e termosifões bifásicos fechados, houve resultados positivos e negativos, ainda que os negativos tenham ocorrido em número consideravelmente menor.

Para os tubos de calor oscilatórios, a intensificação obtida justifica-se pelo aumento da condutividade térmica e pela intensificação das oscilações causadas pela introdução de nanopartículas.

Para termosifões bifásicos fechados, a discussão a respeito da intensificação consiste na observação do comportamento do nanofluido em condições de ebulição em piscina. Este comportamento, dependendo das condições do problema, pode causar como consequência um aumento ou uma diminuição do coeficiente de transferência de calor, uma vez que o mecanismo de ebulição nestes casos depende também da superfície na qual o fluido está inserido e da estabilidade do fluido utilizado.

Adicionalmente, o trabalho ainda discute a existência de uma concentração volumétrica ótima de nanopartículas. Esta concentração seria decorrente da indução de uma maior força capilar ao longo da matriz porosa, decorrente do aumento da concentração volumétrica de nanopartículas. Este aumento possui um limite, no qual existe o equilíbrio entre o aumento da pressão capilar e o aumento das forças de arrasto, decorrentes do consequente aumento da viscosidade e da massa específica do nanofluido causado pelo aumento da concentração volumétrica de partículas.

Em sequência, Buschmann (2013) realizou uma revisão semelhante, analisando os resultados experimentais recentes envolvendo termosifões, tubos de calor convencionais e tubos de calor oscilatórios contendo nanofluidos em seu interior. Ao todo foram verificados 38 trabalhos experimentais (sendo que alguns destes trabalhos estão presentes também no trabalho de Liu e Li (2012)) e quatro estudos envolvendo a modelagem destes dispositivos. Novamente, foram obtidos resultados positivos e 
negativos na avaliação do desempenho de tubos de calor dos cinco tipos diferentes de tubos de calor apresentados anteriormente, contendo 51 tipos diferentes de nanofluidos, compostos por nanopartículas já mencionadas anteriormente, e por fluidos-base tais como etilenoglicol, R-11 (triclorofluorometano) e outros compostos orgânicos.

O estudo ainda avalia a influência de parâmetros como a taxa de preenchimento do tubo de calor, o ângulo de inclinação em relação a horizontal do tubo de calor, a temperatura de operação, a utilização de fluidos-base diferentes e as características físicas e geométricas das partículas que compõem o nanofluido. A concentração volumétrica das nanopartículas recebe destaque, por ser uma propriedade amplamente conhecida como sendo responsável por boa parte do desempenho térmico de um nanofluido. Torna-se evidente a presença de um valor ótimo para a concentração, acima do qual ocorre um decréscimo na eficiência térmica do nanofluido.

O estudo ainda destaca que o comportamento dos nanofluidos contendo nanotubos de carbono se diferencia do comportamento usualmente observado em outros nanofluidos por serem partículas com razão de aspecto alta, e que esta razão de aspecto pode fazer com que o comportamento da intensificação da transferência de calor nestes nanofluidos seja provocado por mecanismos térmicos diferentes. Estes nanofluidos também podem apresentar dificuldades de manterem a estabilidade, o que pode ocasionar reduções no desempenho térmico do tubo de calor como um todo.

Em geral, o resultado obtido pela maioria dos trabalhos mostra uma diminuição no valor da resistência térmica total do tubo de calor com a introdução das nanopartículas. Esta redução possui dependência direta com as características do nanofluido, com o calor inserido no sistema, com o ângulo de inclinação da aplicação e com a razão de preenchimento do tubo de calor.

Ao descrever os mecanismos que possibilitam o aumento da eficiência térmica na utilização de nanofluidos, o autor destaca o aumento da condutividade térmica, o aumento do fluxo de calor crítico, o aumento na frequência de formação de bolhas na seção do evaporador, o aumento da área de transferência de calor no interior da matriz porosa e a formação de uma camada porosa de nanopartículas ao longo do evaporador.

O mecanismo cuja influência se mostra mais significativa no desempenho térmico do tubo de calor contendo nanofluidos consiste na formação de uma camada porosa composta de nanopartículas acumuladas na superfície do evaporador. Estas 
nanopartículas, por não sofrerem ebulição juntamente com o fluido-base, se conectam a superfície de aquecimento ao longo do sítio de nucleação de bolhas, causando a modificação desta superfície. Observa-se também que a deposição de nanopartículas altera a molhabilidade da superfície de aquecimento, alterando o ângulo de contato do fluido com a superfície, diminuindo a densidade de sítios de nucleação de bolhas e podendo consequentemente intensificar ou deteriorar o fenômeno de ebulição, de acordo com a formação de capilaridade ou entupimento nos novos sítios de nucleação.

Em geral, esta camada se mostra responsável pela diminuição da temperatura do evaporador, aumentando desta forma o desempenho do tubo de calor como um todo. No entanto os efeitos de deposição podem ser contrabalançados pela diminuição da rugosidade causada pelo atrito decorrente do escoamento dos nanofluidos, o que, em longo prazo, deteriora a transferência de calor por ebulição.

Em contraponto, observou-se que, na maioria dos estudos apresentados, a adição de nanofluidos tem pouco ou nenhum efeito sobre a temperatura do condensador. Isto está de acordo com a hipótese apresentada neste estudo de que as nanopartículas não são transportadas pela fase de vapor em um tubo de calor, permanecendo primariamente na seção do evaporador.

0 estudo ainda discute as situações para as quais houve redução da eficiência térmica do sistema. Esta redução é justificada para alguns casos como decorrente da aglomeração e deposição de partículas ao longo do tubo de calor, dos efeitos adversos causados pelas nanopartículas na evaporação dentro do tubo de calor e das interações formadas entre as superfícies do tubo de calor e os nanofluidos.

0 estudo de Sureshkumar et al. (2013) também busca fazer uma revisão dos trabalhos contendo tubos de calor e nanofluidos. 0 estudo mostra que em diversos trabalhos foi possível obter uma melhoria na eficiência térmica e uma redução na resistência térmica destes tubos de calor com a introdução de nanofluidos. Nestes estudos, foram utilizadas todas as configurações de tubos de calor propostas anteriormente, em nanofluidos utilizando água ou etilenoglicol como fluido-base e uma ampla variedade de nanopartículas já mencionadas anteriormente.

Observou-se que para os 21 estudos pesquisados ao longo desta revisão, somente dois deles apresentaram resultados negativos, compreendendo uma redução no desempenho térmico do tubo de calor com a introdução dos nanofluidos. Este efeito foi justificado por conta de fenômenos tais como o depósito de nanopartículas ao longo da 
superfície do tubo de calor, uma vez que a configuração formada por estas partículas depositadas pode também prejudicar a formação da ebulição no evaporador.

Observou-se o efeito de parâmetros tais como a natureza, a geometria e a concentração volumétrica das nanopartículas utilizadas ao longo do nanofluido, o ângulo de inclinação do tubo de calor com a horizontal, a molhabilidade do nanofluido ao longo da matriz porosa na eficiência térmica do sistema, a razão de preenchimento do tubo de calor e a quantidade de calor inserida no sistema. 0 aumento da condutividade térmica é tido como tendo uma importância elevada na obtenção de uma maior eficiência térmica nestes casos. Novamente, é dado destaque à formação de uma camada de revestimento formada na matriz porosa existente na região do evaporador, uma vez que esta camada aumenta a área de evaporação, a molhabilidade superficial e a pressão capilar formada ao longo da matriz porosa, aumentando desta forma o desempenho global do tubo de calor. Os trabalhos experimentais apresentados neste estudo obtiveram reduções máximas na resistência térmica do sistema na ordem de $80 \%$.

A utilização de modelos preditivos para as propriedades como o modelo de Batchelor (Equação [28]) obteve estimativas subestimadas para os valores da viscosidade e da condutividade térmica. No campo dos modelos teóricos, foi possível determinar a existência de uma concentração ótima de nanopartículas. Na aplicação destes modelos, observa-se também a possibilidade de redução de tamanho do tubo de calor sem perda de eficiência.

\subsubsection{Tubos de calor contendo nanofluidos com nanotubos de carbono}

As aplicações de nanofluidos contendo nanotubos de carbono em sua composição em tubos de calor ainda são bastante restritas e usualmente se restringem a aplicações utilizando termosifões fechados bifásicos. Por exemplo, é possível observar estes termosifões contendo nanotubos de carbono em estudos como Xue et al. (2006), Liu et al. (2010b) e Shanbedi et al. (2012). No entanto, estes termosifões possuem limitações de posicionamento, uma vez que precisam da gravidade para realizar o retorno do condensado para a seção do evaporador. Ademais, a modelagem destes termosifões é complexa, devido aos efeitos relativos ao escoamento bifásico existentes na interface líquido-vapor de um termosifão. Desta forma, o presente estudo irá manter o enfoque nos tubos de calor convencionais, contendo matrizes porosas. 
Neste campo, destaca-se o estudo de Liu e Lu (2009), envolvendo a pesquisa do desempenho térmico de tubos de calor contendo microcanais axiais, utilizando como fluido de trabalho um nanofluido utilizando água como fluido-base e contendo partículas de nanotubos de carbono dispersas em suspensão. Este estudo realizou experimentos em três níveis de pressão $(7,45 ; 12,38$ e 19,97 $\mathrm{kPa})$ de forma a observar o efeito da introdução dos nanotubos de carbono no desempenho térmico do tubo de calor. Foram utilizados como parâmetros a variação da concentração mássica de nanotubos de carbono e a variação da pressão, de forma a observar o efeito destes parâmetros na determinação dos coeficientes de transferência de calor na seção do evaporador e na seção do condensador.

Foram utilizados nanotubos de carbono com diâmetro médio de $15 \mathrm{~nm}$ e comprimento variando entre 5 e $15 \mu \mathrm{m}$. 0 valor do $\mathrm{pH}$ do nanofluido foi determinado como sendo 6,5. A concentração mássica de nanotubos de carbono sofreu variações na faixa entre $1 \%$ e $2,5 \%$, correspondendo a uma variação na concentração volumétrica entre $0,25 \%$ e $0,8 \%$. A Figura 11 reproduzida de Liu e Lu (2009) mostra uma foto feita por microscopia eletrônica de uma amostra deste estudo contendo concentração mássica de $1 \%$.

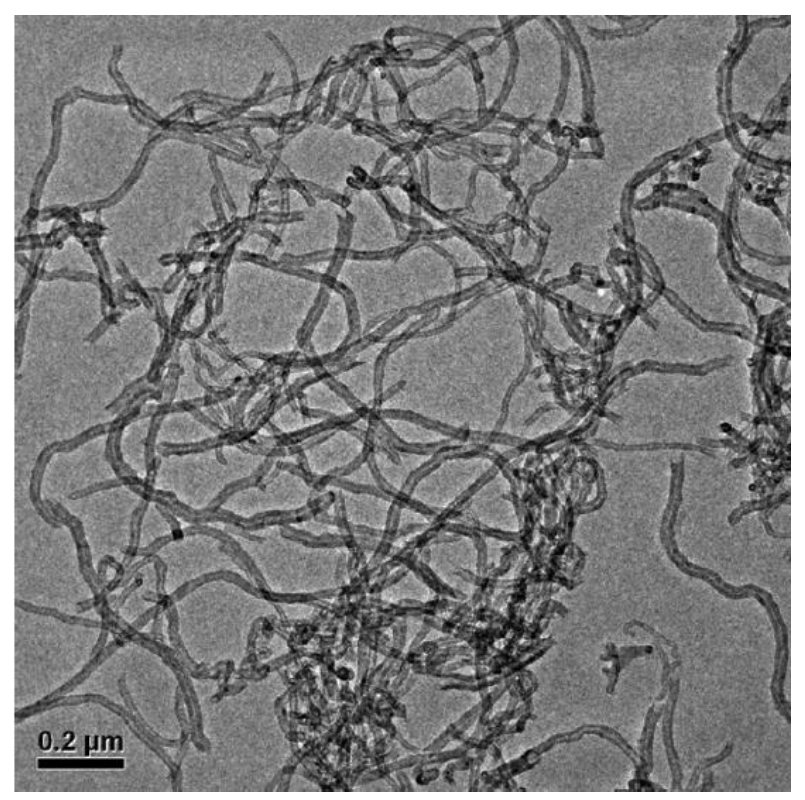

Figura 11. Amostra de nanofluido contendo nanotubos de carbono a concentração mássica de 1\% (Liu e Lu, 2009) 
Utilizou-se um tubo de calor feito de cobre contendo sulcos retangulares na parede interior do tubo de calor. Estes sulcos são responsáveis pelo retorno do fluido condensado à seção do evaporador. 0 tubo de calor foi utilizado na posição horizontal neste estudo. As dimensões do tubo de calor podem ser verificadas na Tabela 5.

Tabela 5. Dimensões utilizadas no tubo de calor do estudo de Liu e Lu (2009)

\begin{tabular}{cc}
\hline Comprimento & $350 \mathrm{~mm}$ \\
\hline Diâmetro externo & $8 \mathrm{~mm}$ \\
\hline Espessura da parede & $0,6 \mathrm{~mm}$ \\
\hline Altura do sulco & $0,2 \mathrm{~mm}$ \\
\hline Largura do sulco & $0,25 \mathrm{~mm}$ \\
\hline Número de sulcos & 60 \\
\hline Comprimento do evaporador & $100 \mathrm{~mm}$ \\
\hline Comprimento da seção adiabática & $100 \mathrm{~mm}$ \\
\hline Comprimento do condensador & $150 \mathrm{~mm}$ \\
\hline
\end{tabular}

A seção do evaporador foi aquecida por meio de uma resistência elétrica (fluxo de calor constante), enquanto a seção do condensador foi resfriada por meio de uma corrente de água a temperatura constante. A pressão foi controlada de forma a se permanecer em um patamar constante ao longo de cada experimento. As temperaturas de saturação definidas para as pressões estudadas $(7,45 ; 12,38$ e 19,97 kPa) são de 40 ${ }^{\circ} \mathrm{C}, 50{ }^{\circ} \mathrm{C}$ e $60^{\circ} \mathrm{C}$, respectivamente.

Observou-se a partir do balanço de energia que mais de $96 \%$ do calor emitido pelo aquecedor elétrico foi removido na seção do condensador, o que indica que a conservação da energia é respeitada. As incertezas obtidas neste estudo são de 0,2 K para as temperaturas, 0,5\% para as pressões e 4\% para os fluxos de calor medidos.

A Figura 12, adaptada de Liu e Lu (2009), mostra os perfis de temperatura obtidos na parede externa do tubo de calor para situações utilizando água ou o nanofluido contendo uma concentração mássica de 2\%. Foram definidas como condições do experimento uma pressão de 7,45 $\mathrm{kPa}$ e uma quantidade de calor introduzida no evaporador como variando entre $10 \mathrm{~W}$ e $80 \mathrm{~W}$.

É possível perceber a partir da Fig. 12 que, para pequenas quantidades de calor introduzidas no tubo de calor, o efeito da introdução das nanopartículas praticamente 
não afeta o perfil de temperaturas, enquanto que, para maiores quantidades de calor, a introdução dos nanofluidos reduz consideravelmente a diferença média de temperatura entre as seções do evaporador e do condensador do tubo de calor. Este efeito é mais pronunciado na seção do evaporador do que na seção do condensador.

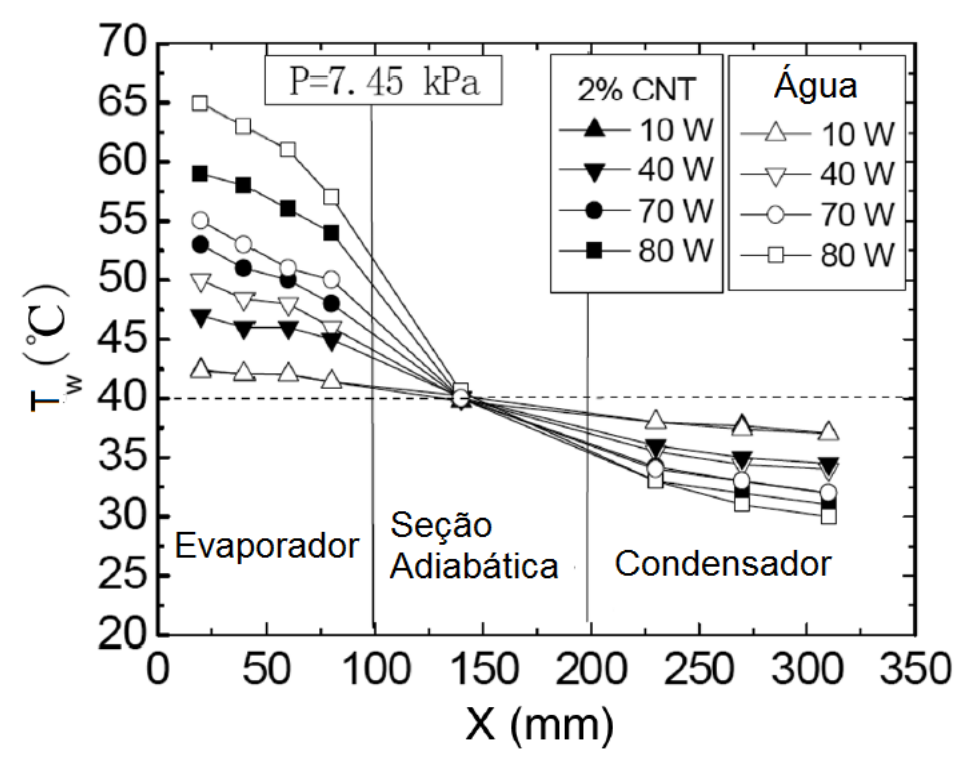

Figura 12. Perfis de temperaturas na parede do tubo de calor (Liu e Lu, 2009)

Em sequencia, é possível observar a partir da Fig. 13 extraída do mesmo trabalho o comportamento do coeficiente de transferência de calor por evaporação obtido na seção do evaporador com a variação da concentração mássica do nanofluido.

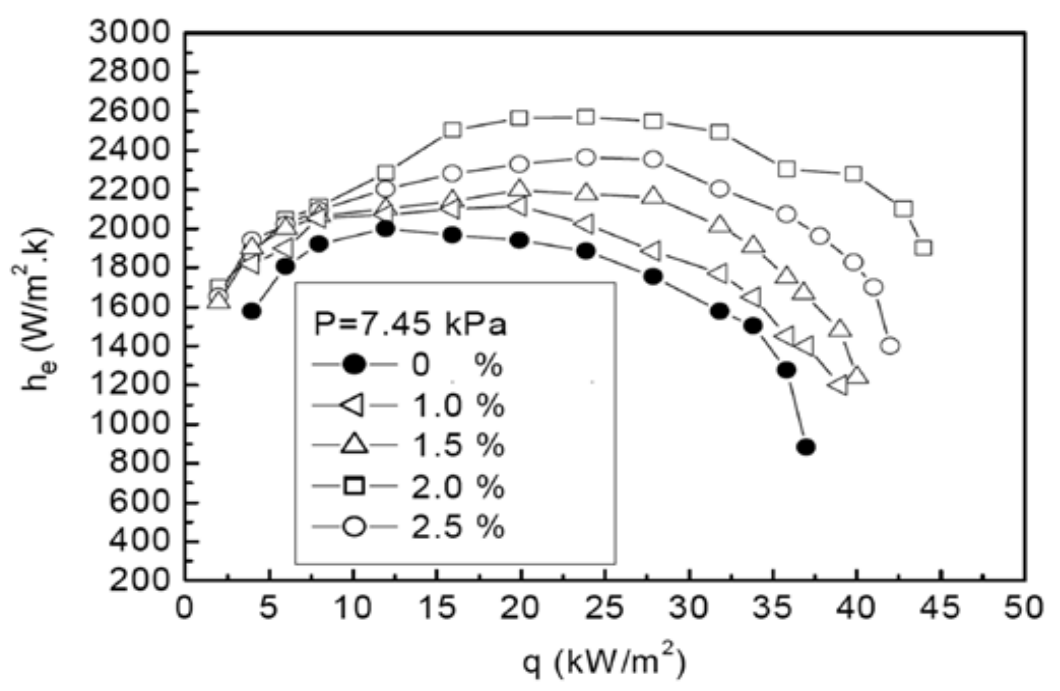

Figura 13. Coeficiente de transferência de calor por evaporação em função da quantidade de calor inserida no tubo de calor para diferentes concentrações mássicas de nanopartículas (Liu e Lu, 2009) 
É possível verificar que o aumento da concentração de nanopartículas ao longo do nanofluido possui o efeito de intensificar o coeficiente de transferência de calor por evaporação. No entanto, este coeficiente atinge um nível ótimo para a concentração mássica de $2 \%$, a partir do qual o coeficiente de transferência de calor sofre uma diminuição.

Além disso, para todas as concentrações pesquisadas, existe um fluxo de calor inserido para o qual o coeficiente de transferência de calor é máximo. Isto ocorre devido à transição entre a convecção natural imposta ao fluido e a ebulição nucleada, a qual, para níveis muito altos de calor inserido, pode representar uma condição denominada dryout, na qual a seção do evaporador passa a apresentar falta de fluido no estado líquido, seja pela formação de uma camada de fluido na forma de vapor na interface sólido-líquido, ou seja pela insuficiência de retorno do fluido condensado na matriz porosa, causada pela limitação da pressão capilar formada no material poroso, prejudicando desta forma a transferência de calor nesta seção.

0 estudo justifica a intensificação obtida na transferência de calor por meio de quatro razões principais. A primeira é a intensificação da condutividade térmica obtida com a introdução das nanopartículas de nanotubos de carbono, o que por si só é capaz de intensificar a transferência de calor global do sistema. A segunda razão é o aumento da massa específica provocado pela introdução das nanopartículas de nanotubos de carbono, a qual é responsável por uma maior transferência de calor por convecção. A terceira razão é a diminuição do ângulo de contato entre o fluido e a superfície sólida obtido com a introdução dos nanofluidos, o que é responsável por um aumento na pressão capilar de bombeamento no interior do tubo de calor. A quarta razão é a formação de turbulência em nanoescala (decorrente do movimento browniano das nanopartículas) ao longo do nanofluido.

0 valor da resistência térmica também foi levantado por meio da seguinte equação:

$$
\Lambda=\frac{\left(\bar{T}_{e}-\bar{T}_{c}\right)}{Q}
$$


Onde $\bar{T}_{e}$ e $\bar{T}_{c}$ foram as temperaturas médias do evaporador e do condensador, respectivamente, levantadas experimentalmente. 0 resultado obtido para uma pressão fixa em 7,45 $\mathrm{kPa}$, comparando o experimento contendo o nanofluido com concentração mássica igual a $2 \%$ com o caso base (contendo somente água) pode ser observado na Fig. 14.

É possível perceber que, para quantidades pequenas de calor inserido no sistema, a resistência térmica praticamente não sofre alterações com a introdução das nanopartículas. Com o aumento da quantidade de calor inserido, o efeito das nanopartículas se torna evidente, e permite a obtenção de resistências térmicas menores para todo o intervalo de potências estudado. Novamente é observada a presença do dryout, cujo efeito é menos pronunciado e atrasado na presença das nanopartículas.

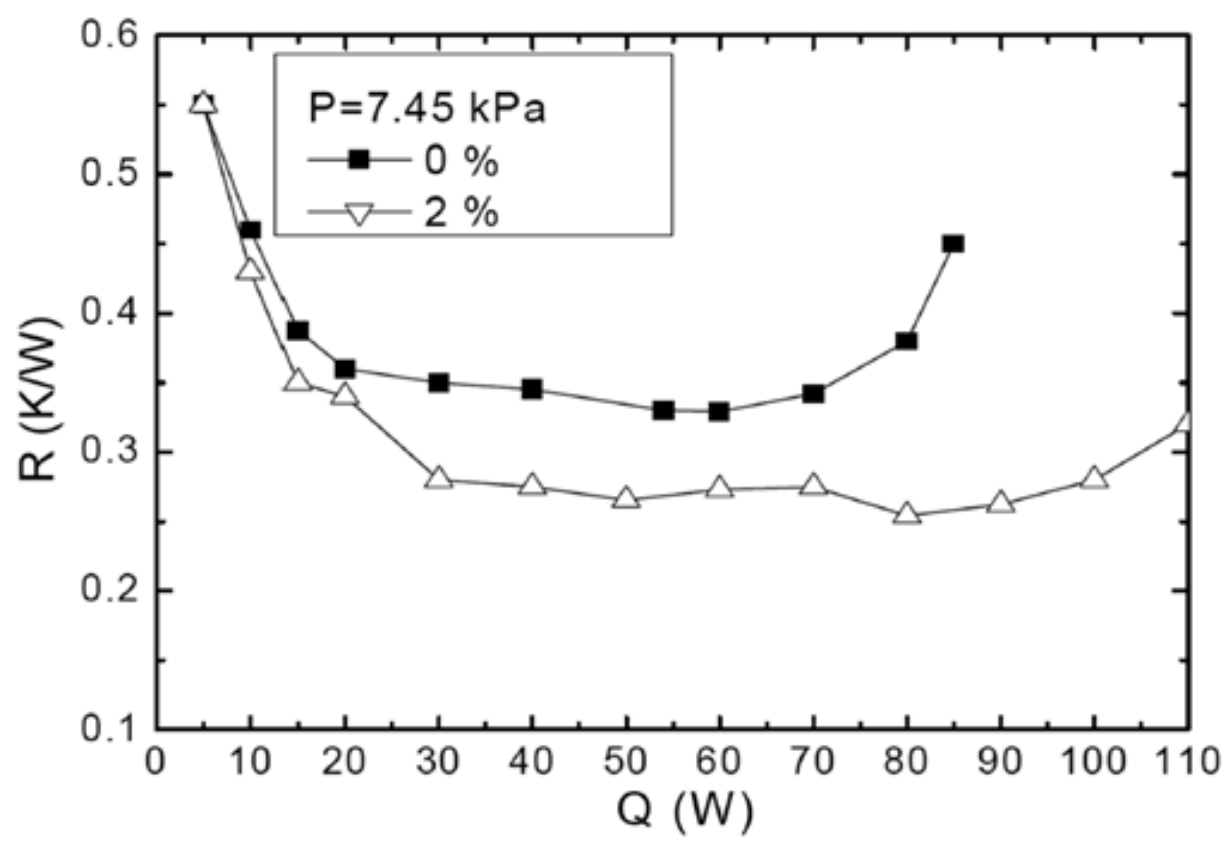

Figura 14. Resistência térmica do tubo de calor em função da quantidade de calor inserida no tubo de calor para diferentes concentrações mássicas de nanopartículas (Liu e Lu, 2009)

\subsubsection{Tubos de calor contendo nanofluidos baseados em etilenoglicol}

A utilização de etilenoglicol como o fluido-base de um nanofluido em um tubo de calor em geral está associada a aplicações que requerem baixo ponto de fusão do 
nanofluido. Por exemplo, a patente US 4,036,286 (Anderson e Waters, 1977) envolve a utilização de tubos de calor contendo misturas de etilenoglicol e água em suportes aplicados a regiões de permafrost, nas quais a temperatura média do solo pode atingir valores significativamente inferiores a $0^{\circ} \mathrm{C}$.

Entretanto, como a condutividade térmica do etilenoglicol é de aproximadamente $0,25 \mathrm{~W} / \mathrm{m} . \mathrm{K}$ à temperatura ambiente e a condutividade térmica da água é de aproximadamente $0,6 \mathrm{~W} / \mathrm{m} . \mathrm{K}$ à temperatura ambiente, ocorre uma redução de cerca de $58 \%$ na condutividade térmica do fluido de trabalho ao realizar esta substituição direta, e isso pode afetar diretamente o desempenho do tubo de calor. Assim, a aplicação de nanopartículas pode compensar esta redução.

Os estudos envolvendo tubos de calor e nanofluidos contendo etilenoglicol puro ainda são poucos e envolvem uma quantidade limitada de nanopartículas aplicadas a estes nanofluidos.

0 estudo de Putra et al. (2012) busca relacionar a intensificação obtida no desempenho térmico de um tubo de calor contendo matrizes porosas compostas por telas e nanofluidos compostos por água ou etilenoglicol como fluido-base e nanopartículas de $\mathrm{Al}_{2} \mathrm{O}_{3}, \mathrm{TiO}_{2}$ e $\mathrm{ZnO}$ em diferentes concentrações volumétricas.

Para a construção do tubo de calor deste estudo, foram utilizados tubos retos de cobre contendo matrizes porosas compostas por malhas de tela de aço inoxidável com as dimensões indicadas na Tabela 6.

Tabela 6. Dimensões utilizadas no tubo de calor do estudo de Putra et al. (2012)

\begin{tabular}{cc}
\hline Dimensão & Valor \\
\hline Comprimento & $200 \mathrm{~mm}$ \\
\hline Diâmetro externo & $8 \mathrm{~mm}$ \\
\hline Espessura da parede & $0,3 \mathrm{~mm}$ \\
\hline Diâmetro da câmara de vapor & $7 \mathrm{~mm}$ \\
\hline Diâmetro dos fios da tela & $5,65 \mu \mathrm{m}$ \\
\hline Número de malha & $67,42 \mathrm{~mm}^{-1}$ \\
\hline Comprimento do evaporador & $60 \mathrm{~mm}^{-1}$ \\
\hline Comprimento da seção adiabática & $80 \mathrm{~mm}$ \\
\hline Comprimento do condensador & $60 \mathrm{~mm}$ \\
\hline
\end{tabular}


A utilização das nanopartículas listadas permitiu a obtenção de intensificações significativas na condutividade térmica dos nanofluidos resultantes. A Figura 15, extraída e adaptada do trabalho dos autores, mostra a razão entre as condutividades térmicas dos nanofluidos resultantes e a condutividade térmica do etilenoglicol, medida experimentalmente neste estudo, em função da concentração volumétrica de nanopartículas utilizada.

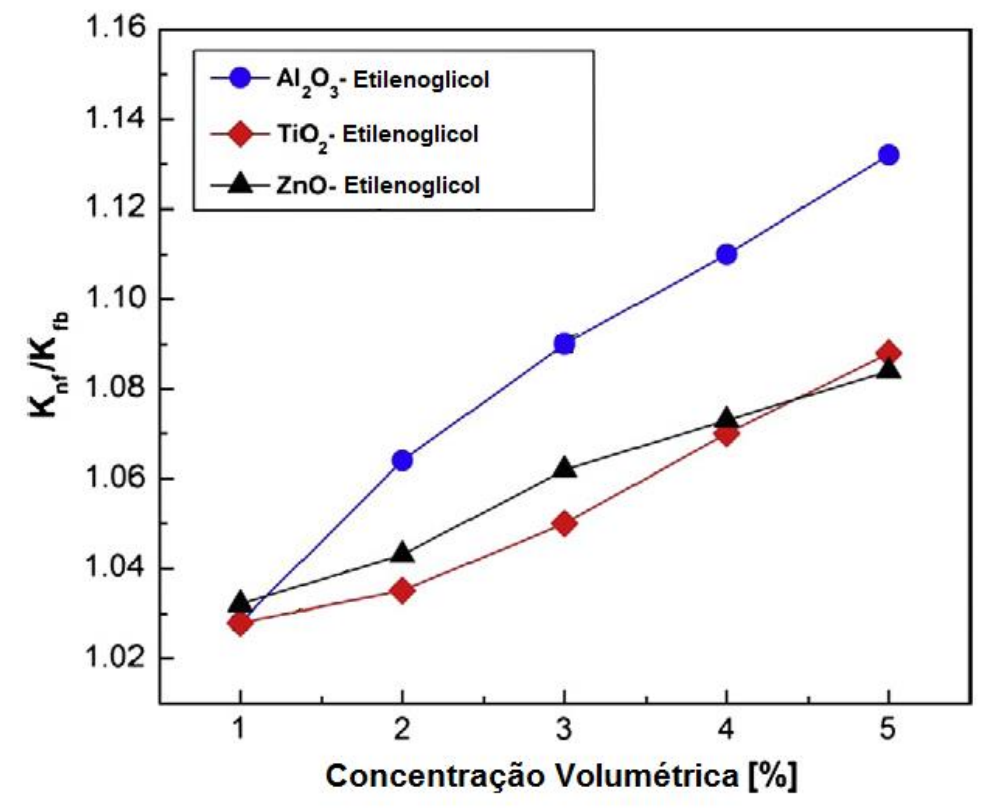

Figura 15. Intensificação da condutividade térmica de nanofluidos contendo etilenoglicol (Putra et al., 2012)

É possível observar o comportamento térmico obtido no tubo de calor para uma potência inserida de $30 \mathrm{~W}$ com a introdução dos nanofluidos por meio dos perfis de temperaturas associados aos diferentes casos, apresentados na Fig. 16. 


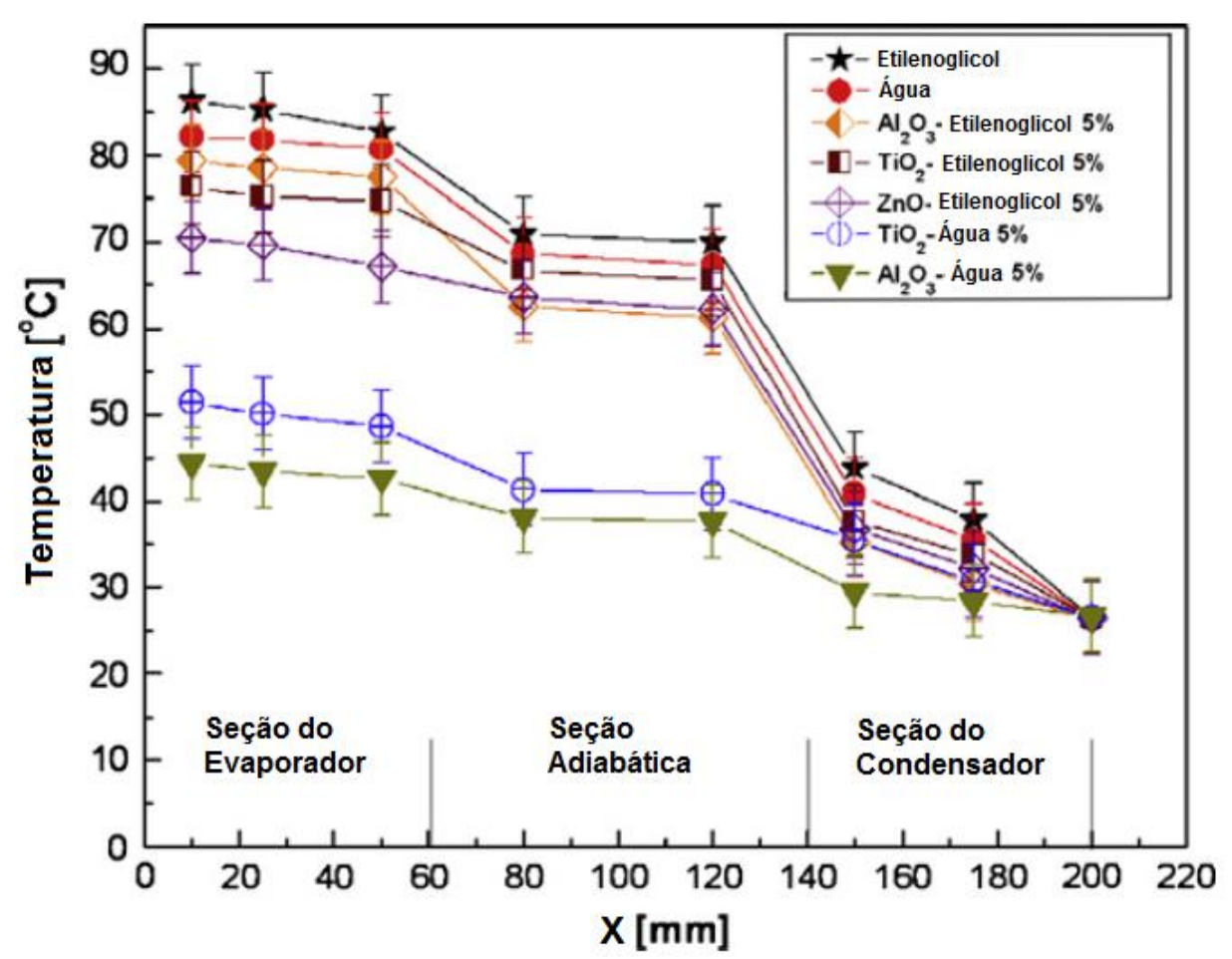

Figura 16. Perfis de temperatura de tubos de calor contendo fluidos-base e nanofluidos de diferentes composições (Putra et al., 2012)

É possível perceber que a utilização de qualquer composição de nanofluidos permite a obtenção de uma redução perceptível na temperatura máxima obtida na seção do evaporador. Isto significa que, para uma mesma quantidade de calor introduzida no sistema, os nanofluidos são capazes de transferir o calor de forma mais eficiente ao longo do tubo de calor do que os fluidos-base sem adição de nanopartículas. Assim, a introdução de nanofluidos representa uma redução na resistência térmica global do tubo de calor como um todo.

Além disso, o perfil de temperaturas mostra que na extremidade do tubo de calor correspondente ao final da seção do condensador a temperatura permanece constante e igual a aproximadamente $25{ }^{\circ} \mathrm{C}$. Isto ocorre devido às condições experimentais, nas quais um reservatório de fluido nesta temperatura é mantido acoplado ao final da seção do condensador.

A Figura 17 mostra a variação do coeficiente de transferência de calor por evaporação na seção do evaporador de acordo com o fluido de trabalho utilizado no tubo de calor e com a quantidade de calor inserida na seção do evaporador do tubo de calor. 


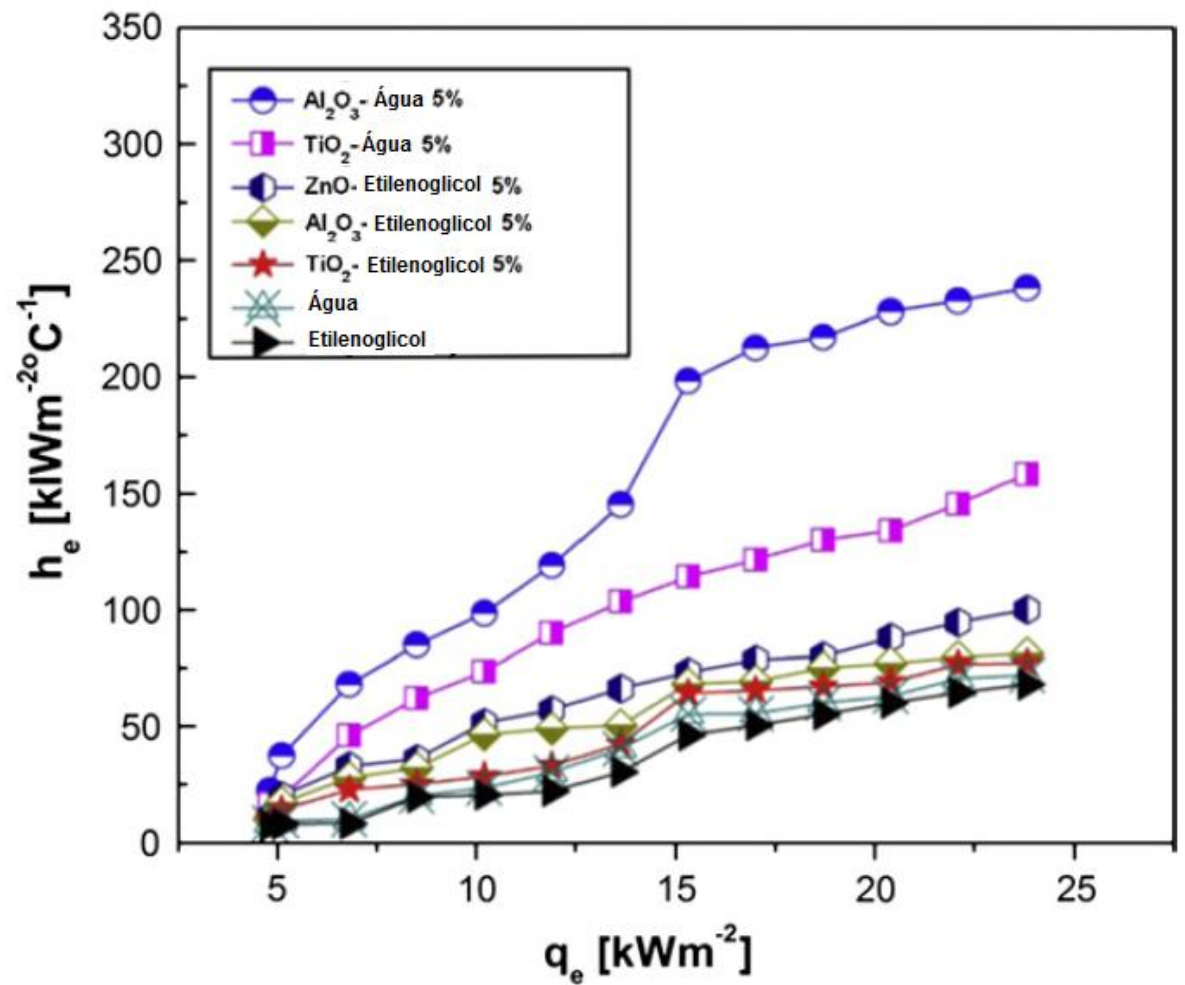

Figura 17. Coeficientes de transferência de calor por evaporação obtidos na seção do evaporador de tubos de calor contendo fluidos-base e nanofluidos de diferentes composições (Putra et al., 2012)

É possível perceber que o comportamento obtido para este coeficiente assemelha-se ao comportamento da condutividade térmica, o que permite afirmar que estes valores possuem relação direta entre si.

Com isso, foi possível determinar os valores da resistência térmica dos tubos de calor estudados para diferentes quantidades de calor introduzidas no tubo de calor e diferentes fluidos de trabalho. Neste estudo, a determinação da resistência térmica deste tubo de calor foi feita através da diferença de temperaturas entre a temperatura média da seção do evaporador e a temperatura média da seção adiabática da seguinte forma:

$$
\Lambda=\frac{\left(\overline{T_{e}}-\overline{T_{a}}\right)}{Q}
$$

Conclui-se ao fim deste estudo ainda que a utilização de nanofluidos foi responsável pela formação de uma camada fina na superfície da matriz porosa, e esta camada possibilitou a melhoria do transporte capilar ao longo do tubo de calor, o que 
permitiu a obtenção de uma transferência de calor ainda mais intensa do que a esperada pela simples intensificação da condutividade térmica.

\subsection{Estudos analíticos e computacionais sobre tubos de calor contendo nanofluidos}

As análises computacionais utilizando métodos numéricos são uma ferramenta muito útil na elaboração de modelos para a previsão das características térmicas e hidrodinâmicas de um sistema fluidotérmico. Estas análises permitem a solução de problemas com geometrias e condições de contorno complexas, ao mesmo tempo em que fornecem soluções aproximadas para problemas de engenharia com uma boa precisão e a um custo relativamente baixo, o que é interessante do ponto de vista comercial.

No que diz respeito ao problema estudado, a maior parte dos estudos publicados possui caráter experimental. Isto ocorre devido à dificuldade de simular um tubo de calor computacionalmente, uma vez que este equipamento, mesmo sendo conceitualmente simples, envolve processos de mudança de fase e de transporte capilar de fluidos, o que torna o equacionamento utilizado para a previsão das características térmicas e hidrodinâmicas no interior do tubo de calor significativamente mais complexo. Esta complexidade torna necessária uma maior precisão na construção da grade computacional que representa o problema e uma atenção maior ao método de solução utilizado para a discretização das equações que governam os fenômenos no interior do tubo de calor. Assim, poucos artigos de caráter analítico ou computacional lidam com tubos de calor e nanofluidos simultaneamente.

Uma análise computacional de um termosifão bifásico fechado contendo nanofluidos compostos por CuO e água foi desenvolvida por Asmaie et al. (2013). Nesta análise, são considerados os efeitos do escoamento bifásico, incluindo uma representação da mudança de fase que ocorre no interior do termosifão bifásico fechado.

Para isso, o estudo considerou um termosifão dimensionalmente semelhante ao termosifão estudado em Liu et al. (2010a), de forma a poder comparar os resultados computacionais com soluções obtidas experimentalmente. Considerou-se que o escoamento ao longo do tubo de calor ocorre em regime laminar, sem a presença de 
reações químicas. 0 equacionamento considera a presença de múltiplas fases escoando simultaneamente, e os fenômenos de evaporação e condensação são introduzidos por meio de um esquema de advecção denominado Volume de Fluido (VOF, do inglês volume of fluid), de forma a modelar corretamente a interação que ocorre nas interfaces. Ao longo do escoamento, são utilizadas as equações de conservação da massa, da energia e da quantidade de movimento, adaptadas para a utilização do esquema VOF.

As propriedades físicas dos nanofluidos foram calculadas por meio das correlações propostas pela literatura. A massa específica do nanofluido é determinada pela equação proposta por Pak e Cho (1998), Equação [25]. A viscosidade do nanofluido é determinada pela expressão de Einstein, Equação [26]. O calor específico do nanofluido é determinado por meio da expressão proposta em Xuan e Roetzel (2000), correspondente a uma forma adaptada da Equação [38], combinada com a Equação [25]. Para a determinação da condutividade térmica do nanofluido, o artigo utiliza o modelo proposto por Yu e Choi, Equação [59], de forma a considerar a formação de uma nanocamada ao redor das nanopartículas, a qual influencia diretamente o valor da condutividade térmica. Neste caso, o parâmetro $\beta_{1}$ é definido como sendo 0,1 , em concordância com o apresentado em Sundar et al. (2014).

O software utilizado para a discretização e solução das equações de conservação foi o ANSYS Fluent 12.1, utilizando o algoritmo SIMPLEC para resolver o acoplamento entre a pressão e a velocidade nas equações de conservação da quantidade de movimento. Utilizou-se ainda o esquema QUICK para a discretização das equações de conservação.

A grade computacional utilizada para a solução do problema consiste em uma grade bidimensional contendo 94400 elementos de formato quadrilátero. Foram aplicadas as condições de contorno usuais existentes no interior de um termosifão bifásico fechado.

Como resultados, foi possível obter os campos de temperatura ao longo de todo o termosifão bifásico fechado e os coeficientes médios de transferência de calor no interior do termosifão.

É possível observar uma comparação com os resultados experimentais de Liu et al. (2010a) obtidos utilizando água e nanofluidos a partir das Figs. 18 e 19 reproduzidas de Asmaie et al. (2013). 


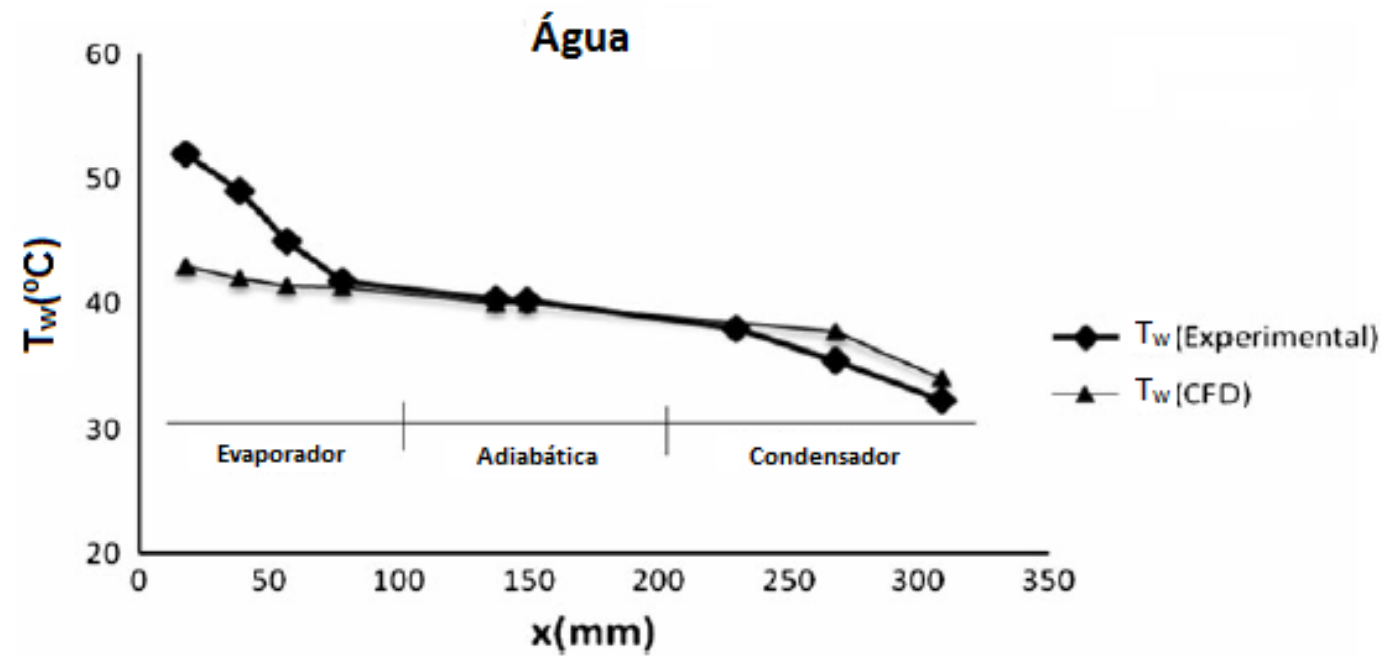

Figura 18. Comparação entre os perfis de temperaturas da parede de um termosifão bifásico fechado contendo água, obtidos experimentalmente e computacionalmente (adaptada de Asmaie et al., 2013)

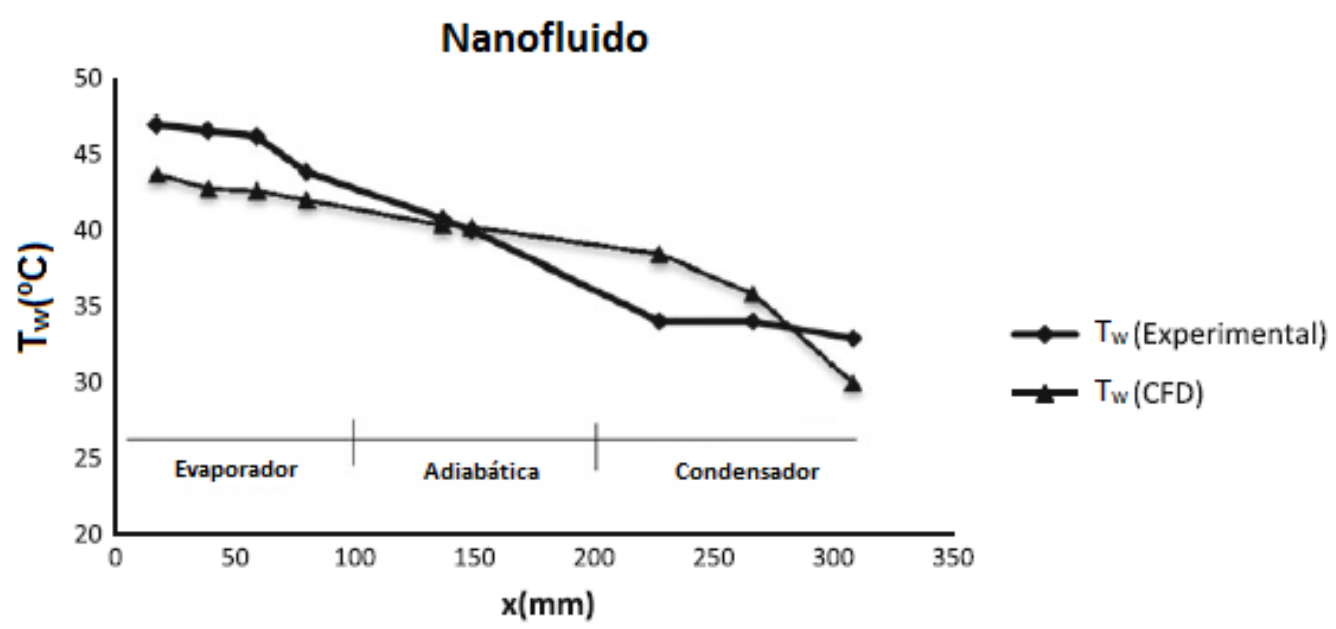

Figura 19. Comparação entre os perfis de temperaturas da parede de um termosifão bifásico fechado contendo nanofluido, obtidos experimentalmente e computacionalmente (adaptada de Asmaie et al., 2013)

É possível observar que o comportamento do termosifão possui uma representação computacional melhor do comportamento experimental na seção adiabática e na seção do condensador. No entanto, ao estimar a temperatura máxima de um termosifão contando água, o modelo subestima em quase $18 \%$ o valor da temperatura. Para o termosifão contendo nanofluido, esta diferença atinge cerca de 7\%. 
Em seguida foram obtidos resultados correspondentes aos perfis de temperatura e aos coeficientes de transferência de calor para diferentes quantidades de calor inserido na seção do evaporador. 0 comportamento obtido mostra que, quanto maior a quantidade de calor inserido, maior a diferença de temperatura no interior do tubo de calor. Além disso, é possível identificar que os coeficientes de transferência de calor sofrem um aumento significativo com a inserção das nanopartículas no fluido de trabalho.

Também foram obtidos resultados relacionando os coeficientes de transferência de calor por evaporação e por condensação, obtidos experimentalmente e computacionalmente. Foi possível perceber que o modelo computacional subestima os coeficientes de transferência de calor para todo o domínio estudado, exceto nas bordas do problema, onde a previsão se aproxima bastante dos resultados experimentais.

Por fim, é importante mencionar que o estudo verificou a influência da concentração mássica de nanopartículas do nanofluido no perfil de temperaturas obtido ao longo do termosifão. 0 estudo de Liu et al. (2010a) apresenta a concentração mássica de $1 \%$ como sendo a concentração ótima para a intensificação da transferência de calor. No estudo de Asmaie et al.(2013), são estudados os perfis de temperatura obtidos para concentrações mássicas de 0,1\%, 0,5\% e 1\%. A Figura 19, extraída de Asmaie et al. (2013), mostra o comportamento dos perfis de temperatura para estas concentrações mássicas.

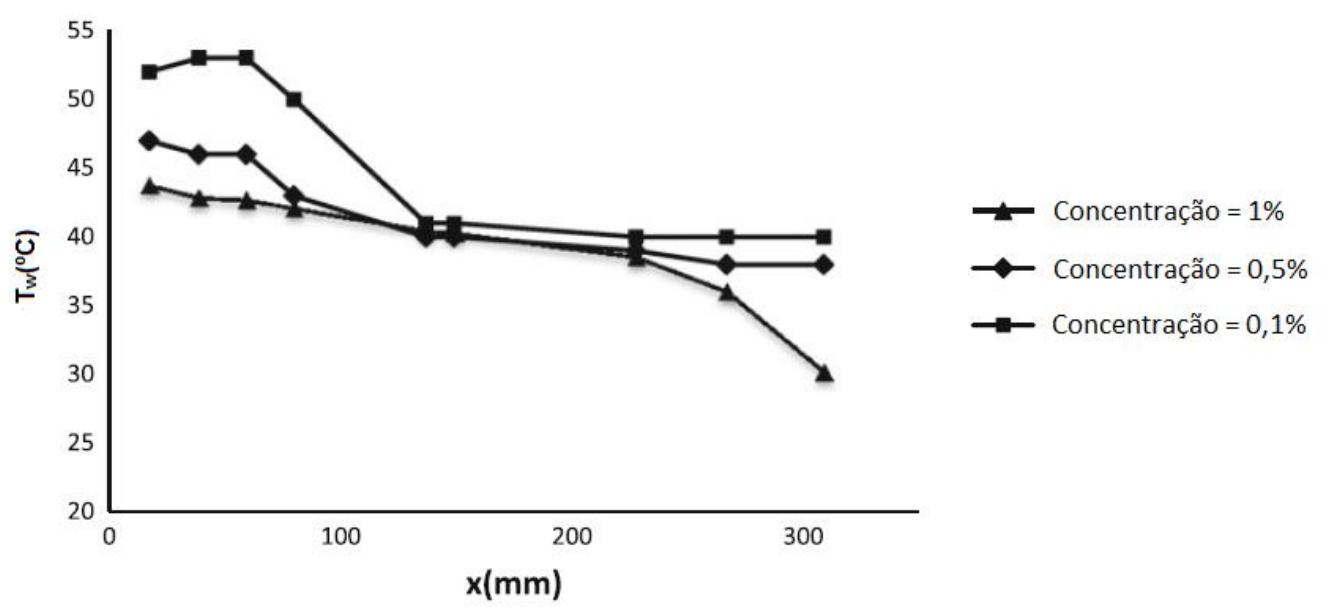

Figura 20. Efeito da concentração mássica de nanopartículas no perfil de temperaturas de um termosifão bifásico fechado (adaptada de Asmaie et al., 2013) 
Verificou-se que a temperatura máxima obtida diminui com o aumento da concentração volumétrica de nanopartículas. A temperatura média do evaporador também cai 19,6\% com a alteração da concentração mássica de 0,1\% para 1\%.

Em seguida, o estudo analítico de Shafahi et al. (2010) busca realizar uma análise numérica bidimensional de forma a determinar o desempenho de um tubo de calor cilíndrico utilizando nanofluidos. São utilizadas três nanopartículas diferentes na composição dos nanofluidos estudados $\left(\mathrm{Al}_{2} \mathrm{O}_{3}, \mathrm{CuO}\right.$ e $\left.\mathrm{TiO}_{2}\right)$, de forma a determinar os efeitos da concentração mássica de nanopartículas e do tamanho destas nanopartículas contidas no nanofluido no desempenho global da transferência de calor deste tubo de calor, buscando desta forma determinar uma concentração ótima de nanopartículas de forma a obter a máxima transferência de calor de um nanofluido.

As equações utilizadas para a representação dos campos de velocidades e temperaturas consistem nas equações da conservação da massa, energia e quantidade de movimento apresentadas em Mahjoub e Matabroshan (2008). No entanto, a equação que governa a conservação da quantidade de movimento possui uma pequena alteração de forma a introduzir uma função geométrica para a estrutura da matriz porosa.

Para a solução destas equações, o estudo de Shafahi et al. (2010) propôs que a integração das equações de conservação fosse realizada de forma analítica, sujeita a condições de contorno pré-determinadas e dependentes das propriedades físicas do tubo de calor e do nanofluido utilizado. Esta análise é proveniente de um trabalho realizado por Zhu e Vafai (1999).

Nesta análise, para o cálculo da pressão na região de líquido é necessária a determinação da massa específica e da viscosidade do nanofluido. A massa específica do nanofluido é determinada por meio da expressão proposta por Pak e Cho (1998), Equação [25]. Já a viscosidade é determinada pelo modelo de Brinkman, Equação [29]. Adicionalmente, para o cálculo da distribuição de temperatura ao longo do tubo de calor, é necessário determinar o valor da condutividade térmica equivalente da matriz porosa do tubo de calor. Esta condutividade pode ser determinada pela Equação [8] e depende diretamente do valor da condutividade térmica do fluido de trabalho utilizado, o que, neste caso, corresponde a condutividade térmica do nanofluido. Para a determinação da condutividade térmica do nanofluido, é utilizado o modelo de Yu e Choi, Equação [59]. Uma correção é feita sobre o valor da condutividade térmica das nanopartículas de 
forma a introduzir o efeito da formação de uma nanocamada ao redor da nanopartícula. Esta correção possui a seguinte forma:

$$
\mathrm{k}_{n p}{ }^{\prime}=\mathrm{k}_{n p} \frac{\left[2\left(1-\alpha^{\prime}\right)++\left(1+\beta_{1}\right)^{3}\left(1-2 \alpha^{\prime}\right) \alpha^{\prime}\right]}{-\left(1-\alpha^{\prime}\right)+\left(1+\beta_{1}\right)^{3}\left(1-2 \alpha^{\prime}\right)}
$$

Onde $\alpha^{\prime}$ corresponde a:

$$
\alpha^{\prime}=\frac{k_{n c}}{\mathrm{k}_{n p}}
$$

E $\mathrm{k}_{\mathrm{nc}}$ corresponde a condutividade térmica da nanocamada formada ao redor da nanopartícula.

São obtidos resultados por meio da integração das equações para um tubo de calor de comprimento total igual a $89 \mathrm{~cm}$, sendo $20 \mathrm{~cm}$ correspondentes a seção do condensador, $60 \mathrm{~cm}$ correspondentes a seção do evaporador e $9 \mathrm{~cm}$ de seção adiabática. 0 raio externo deste tubo de calor possui 9,55 $\mathrm{mm}$, o raio interno possui 9,4 $\mathrm{mm}$ e o raio da câmara de vapor corresponde a 8,65 $\mathrm{mm}$.

Um dos resultados apresentados neste estudo é o perfil de temperaturas obtido na parede do tubo de calor contendo diferentes nanofluidos. São apresentados os perfis de temperatura para diferentes concentrações de nanopartículas nas Figuras 20 a 22.

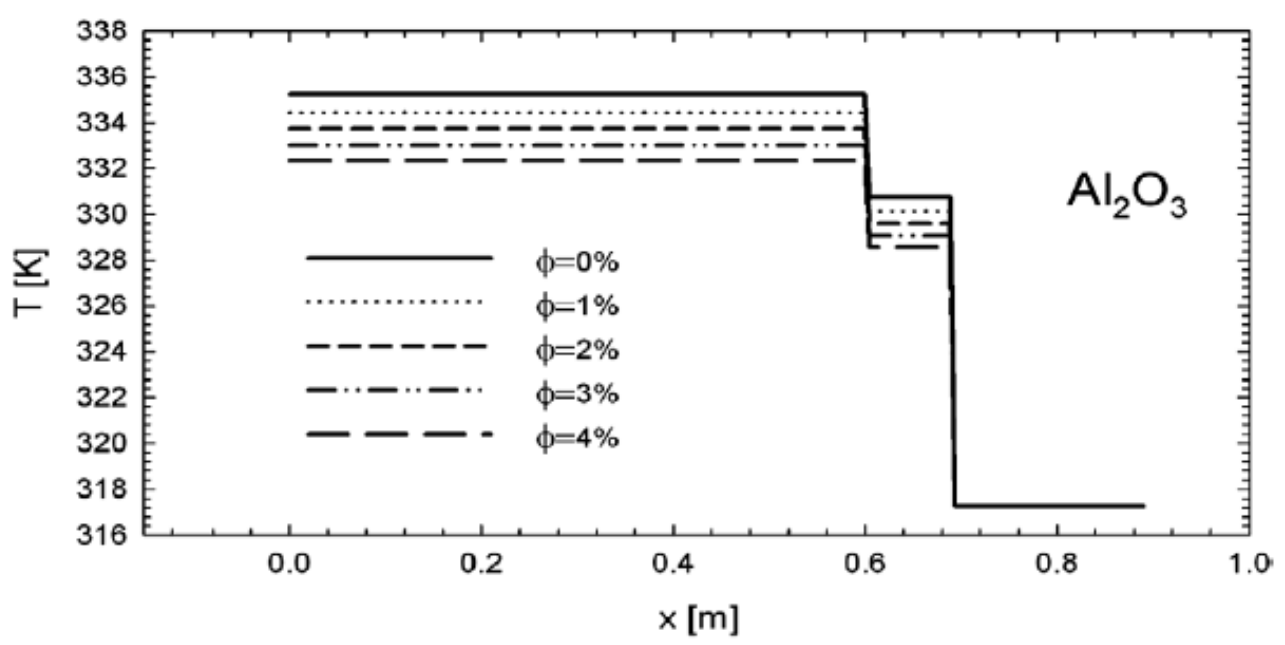

Figura 21. Perfis de temperaturas na parede de um tubo de calor contendo nanofluidos compostos por água e $\mathrm{Al}_{2} \mathrm{O}_{3}$ para diferentes concentrações de nanopartículas (Shafahi et al., 2010) 


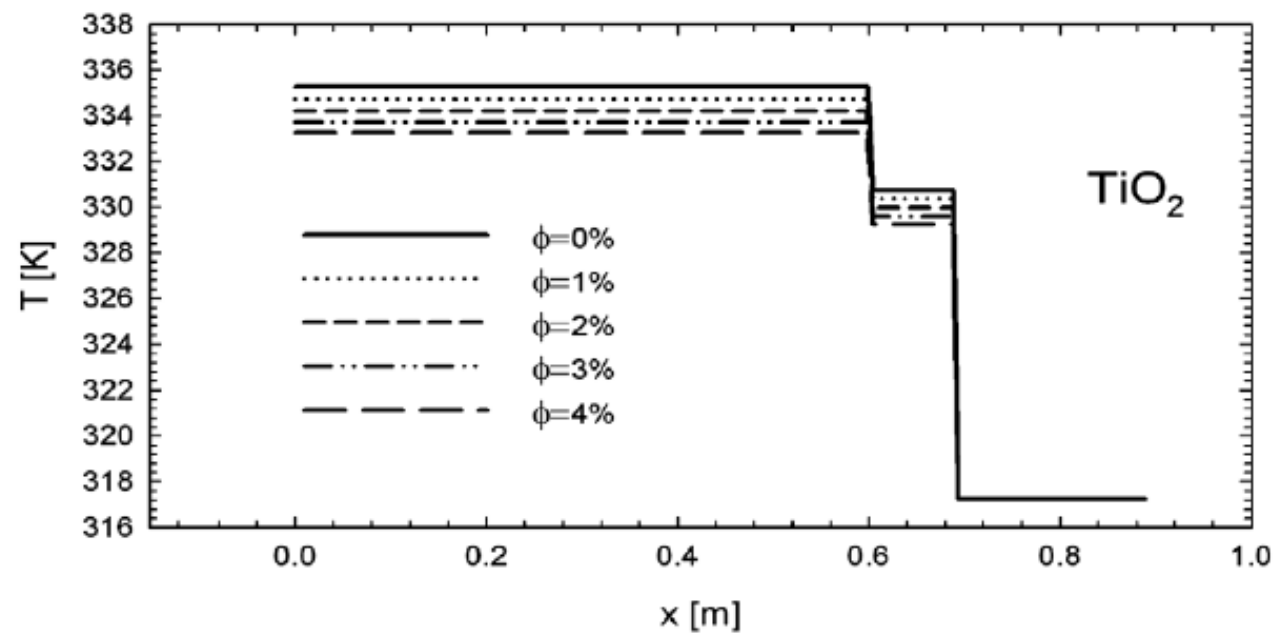

Figura 22. Perfis de temperaturas na parede de um tubo de calor contendo nanofluidos compostos por água e $\mathrm{TiO}_{2}$ para diferentes concentrações de nanopartículas (Shafahi et al., 2010)

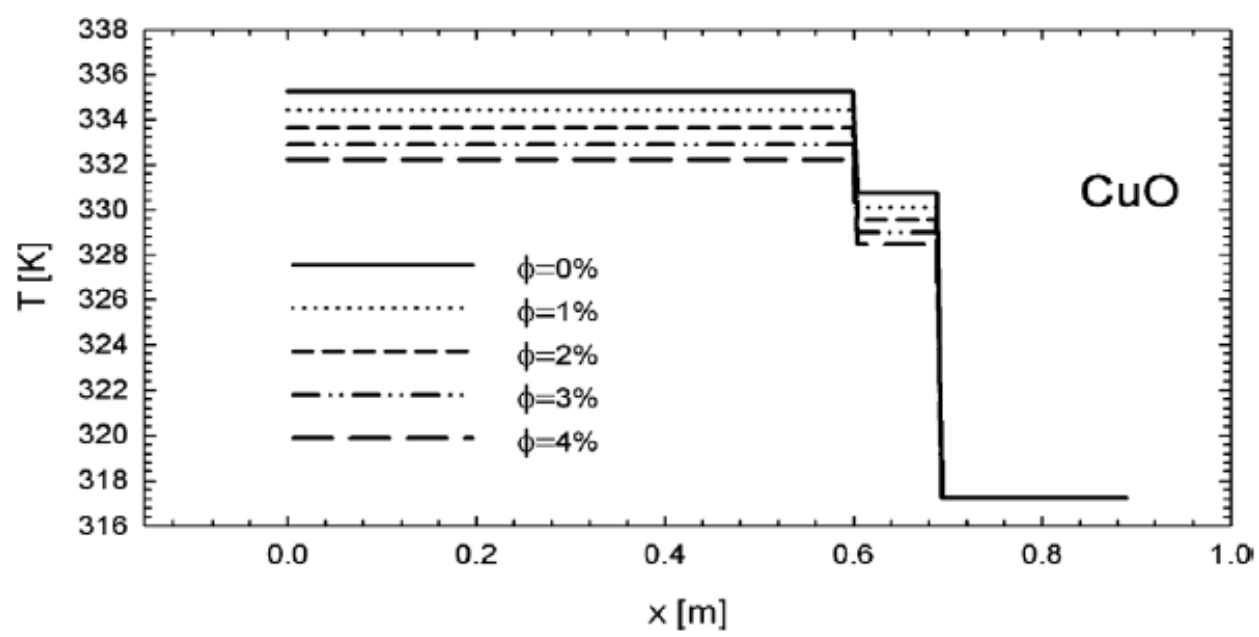

Figura 23. Perfis de temperaturas na parede de um tubo de calor contendo nanofluidos compostos por água e $\mathrm{CuO}$ para diferentes concentrações de nanopartículas (Shafahi et al., 2010)

É possível perceber claramente a influência dos nanofluidos nos perfis de temperatura, uma vez que qualquer concentração de nanofluidos resulta em um impacto positivo no desempenho térmico do tubo de calor, diminuindo a temperatura máxima do sistema. Para todos os nanofluidos estudados, também é possível perceber que, quanto maior a concentração de nanopartículas, maior é a redução das temperaturas do evaporador. Adicionalmente, é possível perceber que a utilização deste modelo mantém 
a temperatura do condensador invariável com a variação da concentração de nanopartículas.

O efeito da concentração de partículas na resistência térmica total do tubo de calor também é analisado neste estudo. Este efeito pode ser observado na Fig. 24, através de gráficos normalizados em relação à resistência térmica de um tubo de calor contendo somente água.

Pode-se perceber que a resistência térmica é reduzida para todos os casos nos quais ocorre a introdução de nanofluidos. Além disso, o aumento na concentração das nanopartículas reduz a resistência global do tubo de calor de cerca de 7\% para até cerca de $25 \%$.
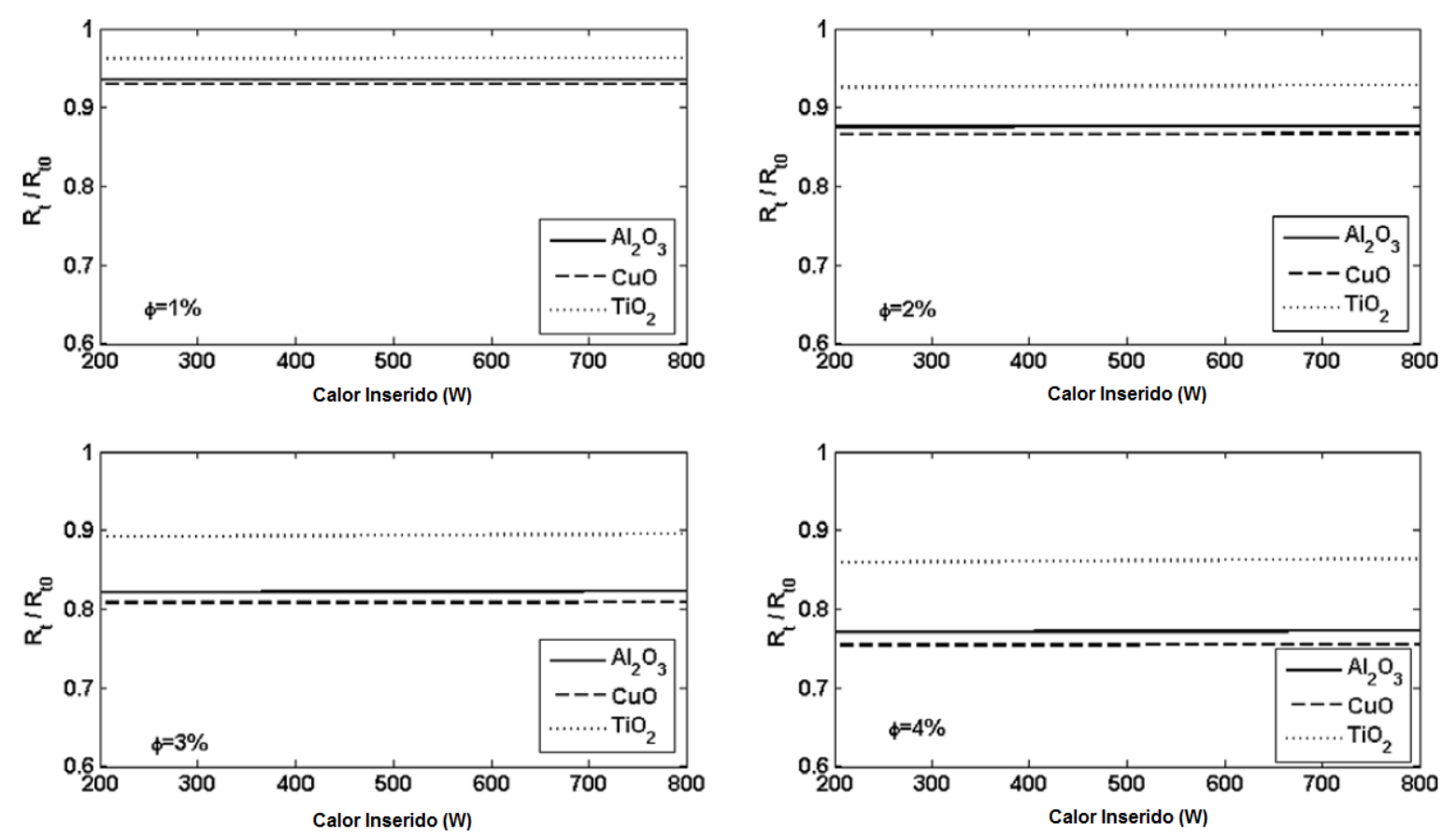

Figura 24. Resistência térmica de tubos de calor contendo diferentes nanofluidos, para concentrações entre 1\% e 4\% de nanopartículas. (Shafahi et al., 2010)

Em sequência, o estudo de Gavtash et al. (2012) busca simular computacionalmente o desempenho térmico de tubos de calor cilíndricos contendo nanofluidos, utilizando um programa comercial de fluidodinâmica computacional. São utilizados nanofluidos contendo água como fluido-base e três nanopartículas diferentes $\left(\mathrm{Cu}, \mathrm{Al}_{2} \mathrm{O}_{3}\right.$ e $\left.\mathrm{TiO}_{2}\right)$, de forma a avaliar o efeito da concentração volumétrica e do tamanho das nanopartículas utilizadas na composição do nanofluido no desempenho térmico e na resistência térmica do tubo de calor. 
Esta simulação baseou-se na construção de um modelo computacional bidimensional, uma vez que ocorre simetria na direção angular de um tubo de calor. Foram utilizadas as equações de conservação da massa, da energia e da quantidade de movimento expostas por Mahjoub e Matabroshan (2008) em condições de regime permanente e aplicadas separadamente sobre cada seção no interior do tubo de calor, isto é, não ocorre mistura ou interferência entre as fases líquida e vapor no interior do tubo de calor. Estas equações encontram-se explícitas no presente estudo, e correspondem às Equações [1] a [4] para a câmara de vapor e às Equações [1], [5], [6] e [7] para a região da matriz porosa. Além disso, considera-se que os fluidos escoam de forma incompressível e que o regime de escoamento permanece laminar ao longo de todo o tubo de calor.

Desta forma, o programa computacional utiliza o algoritmo SIMPLE para discretizar as equações diferenciais apresentadas para cada elemento definido pela grade computacional construída para a geometria do problema. Para representar as condições de contorno existentes no problema, são utilizadas as Equações [9] a [24], tal como no estudo de Mahjoub e Matabroshan (2008). No entanto, para a determinação da condutividade térmica da matriz porosa, utiliza-se a Equação [8] associada ao modelo de Yu e Choi, Equação [59], utilizando ainda a correção da condutividade térmica correspondente às Equações [63] e [64] do presente estudo, de forma a considerar a condutividade térmica da nanocamada formada ao redor da nanopartícula.

Para a determinação da massa específica e da viscosidade dos nanofluidos utilizados, novamente são utilizadas as expressões propostas por Pak e Cho (1998) e por Brinkman, Equações [25] e [29]. É importante destacar que nenhum comentário foi feito a respeito dos valores do calor específico e da entalpia de vaporização do nanofluido. Isso leva a crer que os valores utilizados são propriedades do fluido-base sem nanopartículas, o que neste caso corresponde à água.

0 tubo de calor estudado é um tubo de cobre de comprimento de 1,0 m e diâmetro externo de 33,5 mm. As seções do evaporador e do condensador possuem comprimentos respectivamente de $200 \mathrm{~mm}$ e $250 \mathrm{~mm}$. A parede do tubo de calor e a matriz porosa possuem espessuras respectivamente iguais a 4,07 $\mathrm{mm}$ e 3,7 mm. Nenhuma informação é dada a respeito das características da matriz porosa utilizada neste estudo. 
Com essa geometria, foi possível construir uma grade computacional contendo 43611 nós para a discretização do domínio. A temperatura de trabalho do tubo de calor é definida como sendo $338 \mathrm{~K}$, para a qual a pressão de trabalho corresponde a 25,03 kPa. Por fim, a quantidade de calor inserida no sistema corresponde a $450 \mathrm{~W}$.

Para a avaliação dos resultados obtidos, é feita a determinação da resistência térmica do tubo de calor em cada caso utilizando a Equação [61]. As temperaturas médias do evaporador e do condensador são definidas como sendo a média entre as temperaturas mínima e máxima obtidas em cada uma destas seções.

Para a avaliação do efeito da concentração volumétrica de nanopartículas no desempenho do tubo de calor, foram utilizados nanofluidos contendo diferentes concentrações de $\mathrm{Al}_{2} \mathrm{O}_{3}$. Os perfis de temperatura da região da parede do tubo de calor foram levantados para esta avaliação e podem ser observados na Fig. 25.

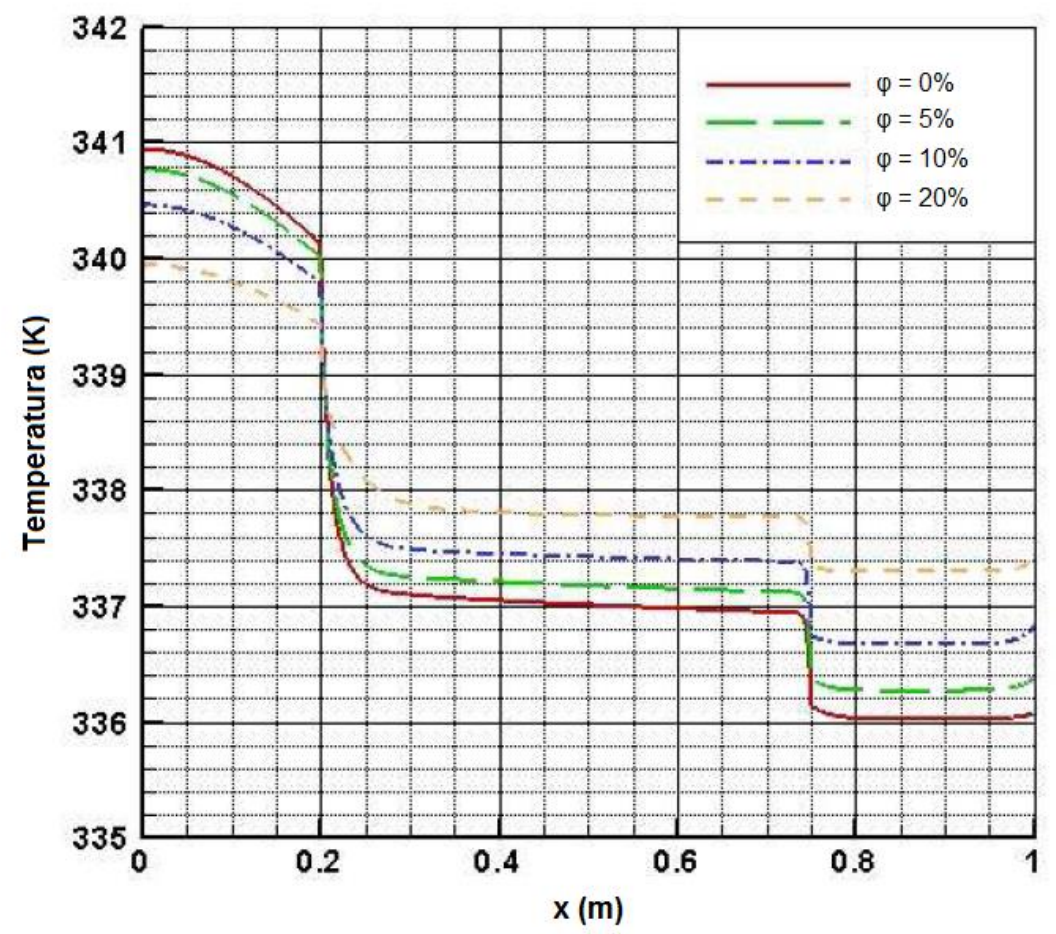

Figura 25. Perfis de temperatura de um tubo de calor contendo nanofluidos compostos por água e $\mathrm{Al}_{2} \mathrm{O}_{3}$ em diferentes concentrações (adaptada de Gavtash et al., 2012)

É possível perceber, como esperado, que o aumento da concentração de nanopartículas faz com que a temperatura máxima obtida no tubo de calor diminua, assim como a amplitude de temperaturas obtida ao longo de todo o tubo de calor. Este 
comportamento é justificado pelos autores como decorrente do aumento da condutividade térmica da matriz porosa causado pela introdução dos nanofluidos.

Como consequência, a resistência térmica do tubo de calor também sofre um decréscimo com o aumento da concentração volumétrica. Este decréscimo pode ser observado na Fig. 26.

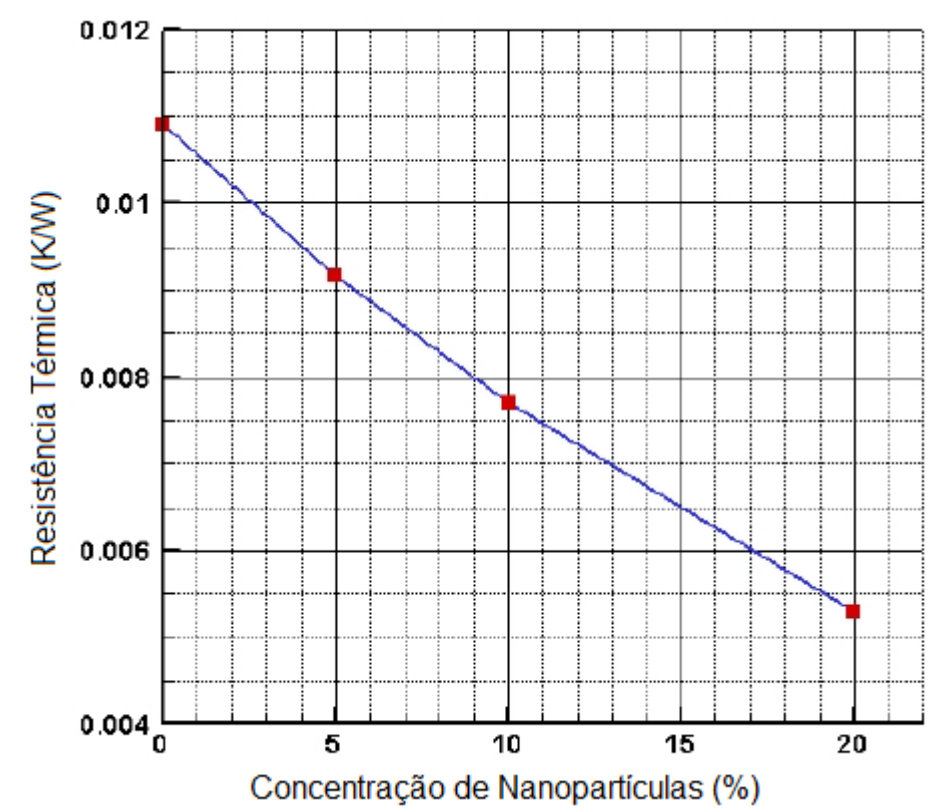

Figura 26. Resistência térmica de um tubo de calor contendo um nanofluido composto por água e $\mathrm{Al}_{2} \mathrm{O}_{3}$ em função da concentração de nanopartículas (adaptada de Gavtash et al., 2012)

Na sequência, são avaliados os efeitos do tamanho das nanopartículas no perfil de temperaturas e na resistência térmica do tubo de calor estudado. Observou-se que para partículas menores o perfil de temperaturas apresenta uma temperatura máxima menor e uma amplitude de temperaturas menor ao longo do tubo de calor. Consequentemente, a resistência térmica do tubo de calor também é reduzida nesta situação.

Por fim, são avaliados os efeitos do uso de nanofluidos contendo diferentes nanopartículas. Neste caso, a condutividade térmica da nanopartícula utilizada possui influência direta no desempenho térmico do tubo de calor. Para isso, foram estudados nanofluidos contendo concentrações e tamanhos de nanopartículas idênticos e iguais a $10 \%$ e $50 \mathrm{~nm}$. 
As Figuras 27 e 28 mostram o comportamento dos perfis de temperatura e da resistência térmica para os nanofluidos contendo diferentes nanopartículas e para as condutividades térmicas associadas a estas nanopartículas.

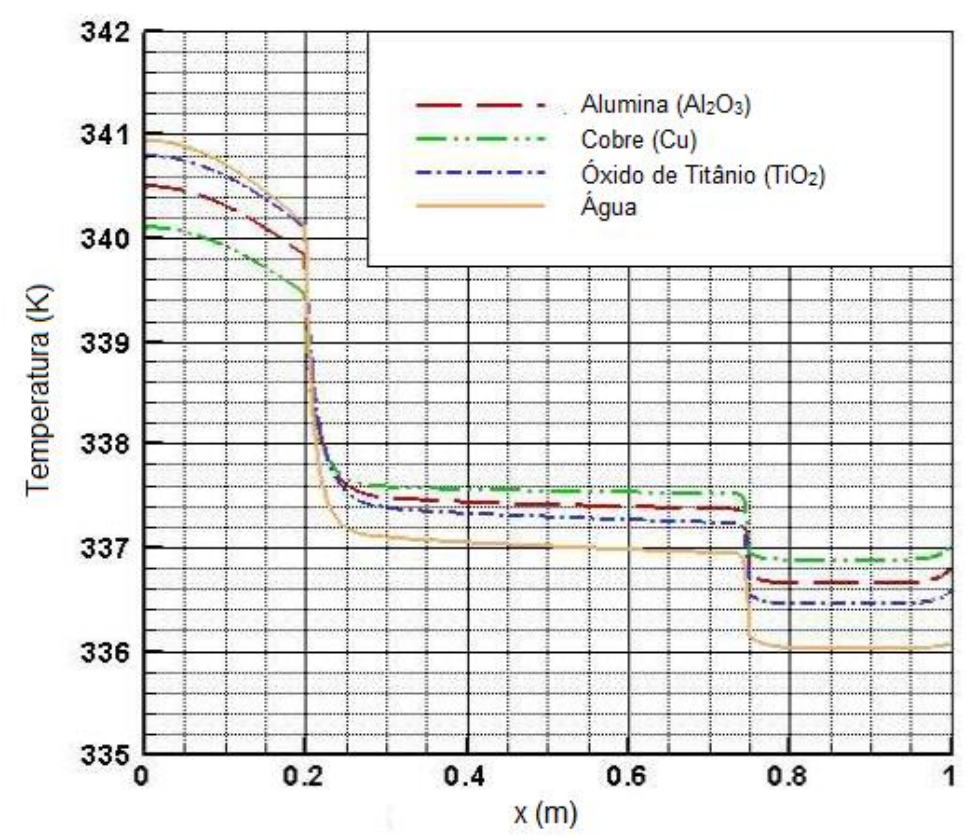

Figura 27. Perfis de temperatura de um tubo de calor contendo nanofluidos compostos por diferentes nanopartículas (adaptada de Gavtash et al., 2012)

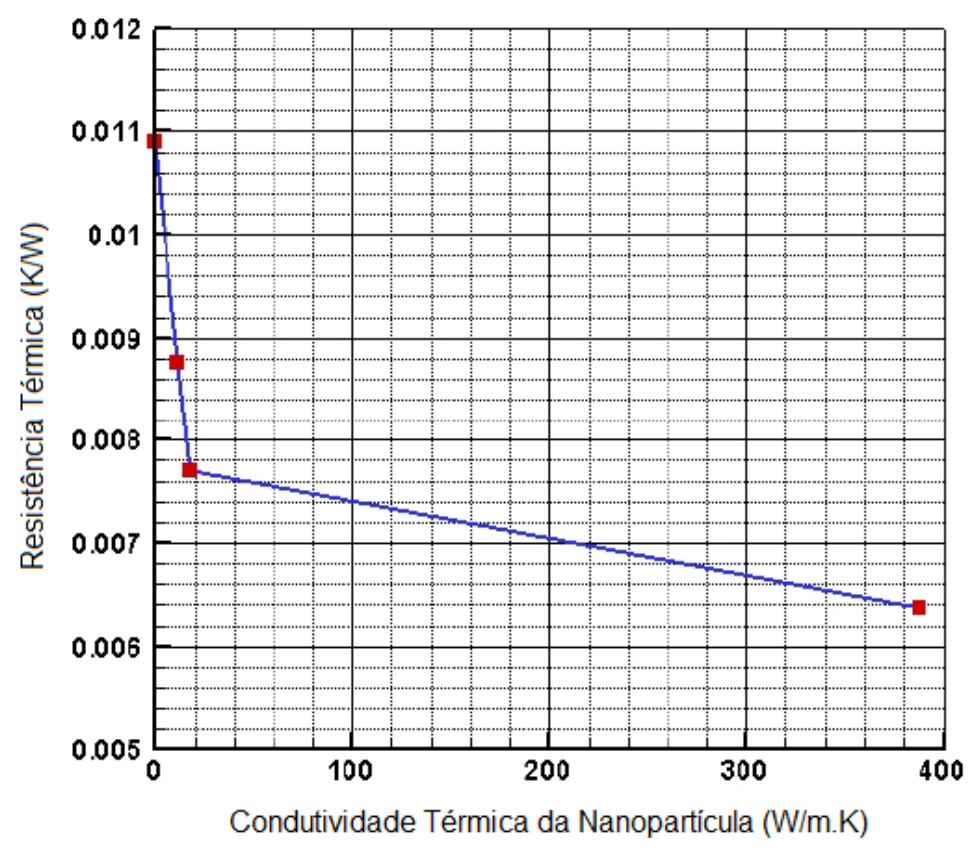

Figura 28. Resistência térmica do tubo de calor contendo nanofluidos compostos por nanopartículas de condutividade térmica distinta (adaptada de Gavtash et al., 2012) 
É possível perceber que a presença de nanopartículas influencia diretamente o comportamento da resistência térmica do tubo de calor. Além disso, nos níveis mais baixos de condutividade, ocorre uma queda bastante significativa da resistência térmica da nanopartícula para um pequeno aumento na condutividade térmica.

Por fim, este estudo ainda conclui que a relação entre a massa específica e a viscosidade do nanofluido causa a presença de uma concentração volumétrica de nanopartículas considerada crítica, para a qual os efeitos viscosos passam a superar os efeitos do aumento de massa específica e as tensões de cisalhamento passam a causar queda de pressão capilar ao longo da estrutura porosa do tubo de calor, ainda que este efeito não tenha sido observado.

Por fim, o estudo de Huminic e Huminic (2009) consiste na avaliação do desempenho térmico de tubos de calor contendo nanofluidos compostos por água e nanopartículas de $\mathrm{CuO}$ por meio de uma simulação computacional. São levantadas soluções para os perfis de temperatura e pressão, considerando o escoamento como sendo permanente e incompressível ao longo das regiões de líquido e vapor de um tubo de calor. Para isso, são realizadas a discretização e a solução do sistema de equações que governam a conservação da massa, da energia e da quantidade de movimento no interior do tubo de calor. Neste estudo, o tubo de calor utilizado possui as dimensões apresentadas na Tabela 7 .

Tabela 7. Dimensões do tubo de calor utilizado em Huminic e Huminic (2009)

\begin{tabular}{c|c}
\hline Dimensão & Valor \\
\hline Comprimento $(\mathrm{mm})$ & 200 \\
\hline Evaporador $(\mathrm{mm})$ & 25 \\
\hline Condensador $(\mathrm{mm})$ & 60 \\
\hline Diâmetro externo (mm) & 8,9 \\
\hline Espessura da parede (mm) & 0,15 \\
\hline Diâmetro da câmara de vapor $(\mathrm{mm})$ & 7,1 \\
\hline
\end{tabular}

Esta geometria do tubo de calor foi elaborada computacionalmente por meio de um programa de desenho técnico. A partir da geometria, foi possível elaborar uma grade 
computacional. Esta grade foi elaborada de forma a representar o domínio bidimensional a partir de uma grade tridimensional. Isso foi possível adotando simetria na direção angular do tubo de calor. A grade resultante foi obtida contendo 33089 nós e 26800 elementos, sendo posteriormente importada para o programa de análise ANSYS CFX.

As condições de contorno aplicadas ao modelo computacional consistem na introdução e remoção de calor do tubo de calor. Estas condições referem-se às Equações [20] a [22]. Adicionalmente, são acrescentadas as condições de contorno correspondentes à movimentação do fluido decorrente da difusão causada no interior do tubo de calor pelos processos de mudança de fase que ocorrem nas seções do evaporador e do condensador. Estas condições referem-se às Equações [10] a [15] do presente estudo.

Adicionalmente, foram admitidas as hipóteses de que o escoamento permanece laminar e incompressível ao longo de todo o tubo de calor. Considerou-se também que a temperatura e a pressão de saturação do fluido estudado são respectivamente iguais a 0,123 bar e 323,15 K. A quantidade de calor inserido na seção do evaporador corresponde a $30 \mathrm{~W}$ e os nanofluidos estudados apresentam três níveis de concentração volumétrica: $0 \%$, 2\% e 4\%. Não são apresentados os modelos utilizados para a avaliação das propriedades dos nanofluidos neste estudo. Foram obtidos valores para as velocidades nas interfaces de $-9,407.10^{-4} \mathrm{~m} / \mathrm{s}$ para a região de líquido e 3,832 m/s para a região de vapor.

Para a convergência do sistema, adotou-se como critérios a redução da soma dos resíduos para valores menores que $10^{-4}$ e a variação das temperaturas no tubo de calor menores que $0,5 \%$ da temperatura total para os passos finais da obtenção da solução.

Foram obtidos perfis de temperaturas para a parede do tubo de calor contendo água deionizada e nanofluidos compostos por água e nanopartículas de CuO nas concentrações volumétricas de 2\% e 4\%. Este perfil pode ser observado na Fig. 29.

É possível perceber, neste estudo, que o comportamento do tubo de calor contendo nanofluidos apresenta diferenças consideráveis em relação aos estudos previamente considerados, uma vez que a introdução das nanopartículas faz com que a temperatura máxima obtida no evaporador do tubo de calor seja bastante superior do que a temperatura obtida utilizando somente o fluido-base. No entanto, a amplitude de 
temperatura obtida no interior do tubo de calor foi menor para os casos utilizando nanofluidos.

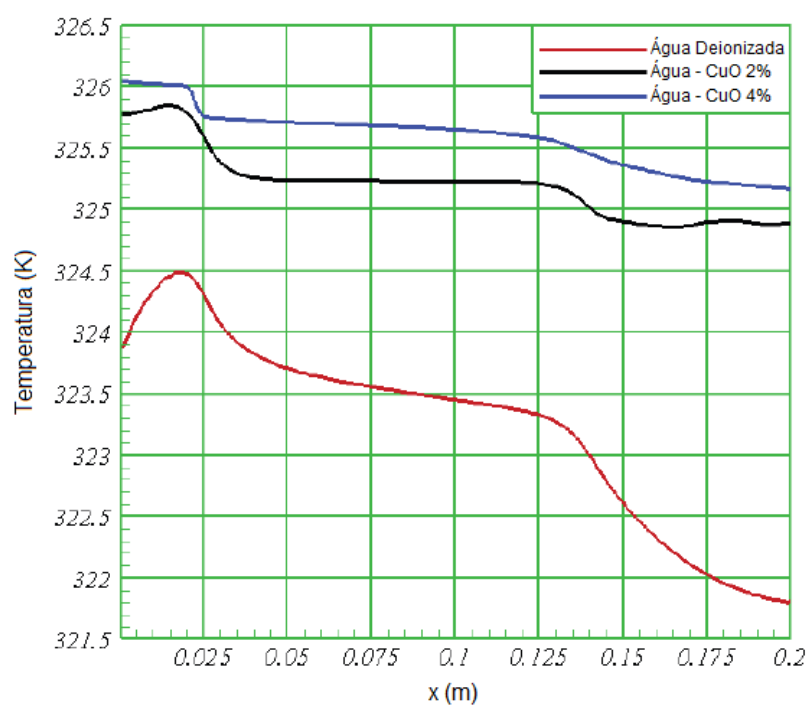

Figura 29. Perfis de temperatura da parede de um tubo de calor contendo água deionizada e nanofluidos em diferentes concentrações de nanopartículas (adaptada de Huminic e Huminic, 2009)

Adicionalmente, foi elaborado um gráfico mostrando o comportamento da resistência térmica no interior do tubo de calor em função da concentração volumétrica de nanopartículas ao longo do nanofluido. Este gráfico pode ser observado na Fig. 30.

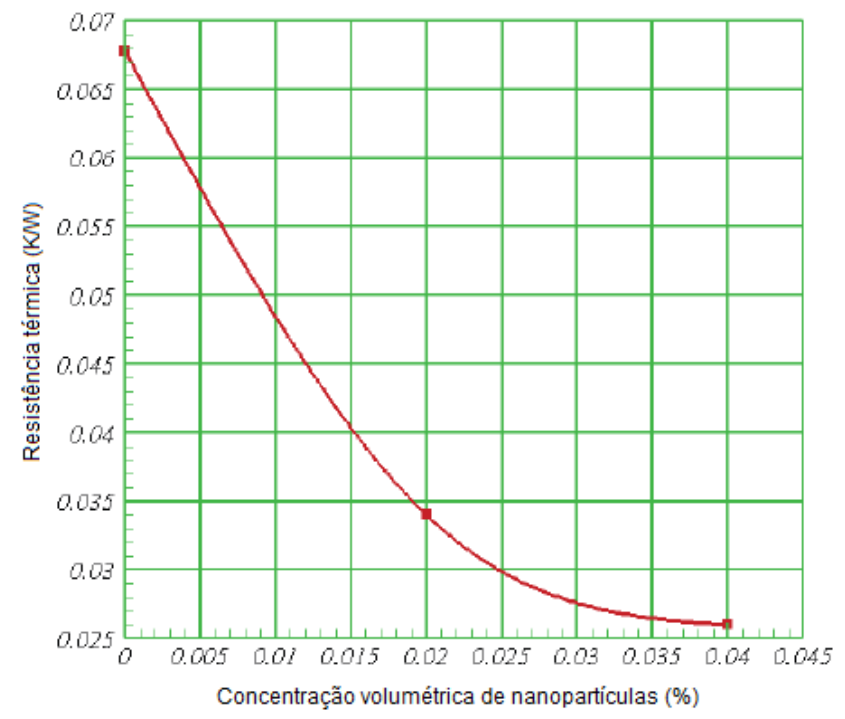

Figura 30. Resistência térmica do tubo de calor contendo nanofluidos em diferentes concentrações volumétricas (adaptada de Huminic e Huminic, 2009) 
A Figura 30 mostra um comportamento similar ao observado nos demais trabalhos da literatura, uma vez que o aumento da concentração volumétrica de nanopartículas ao longo do nanofluido causa uma diminuição na resistência térmica global do tubo de calor. 


\section{METODOLOGIA}

\subsection{Seleção dos casos a serem estudados}

A abrangência de uma análise depende diretamente da variedade de situações que se deseja representar. Espera-se que o modelo computacional seja capaz de representar o comportamento esperado em uma quantidade significativa de casos. Em contraponto, uma quantidade mais limitada de casos permite que seja possível aprofundar melhor as análises a serem realizadas. Tendo isso em mente, foram escolhidas as configurações experimentais representadas na Tab. 8 para serem avaliadas computacionalmente no presente estudo:

Tabela 8. Seleção dos casos experimentais a serem estudados

\begin{tabular}{|c|c|c|}
\hline Estudo Experimental & Fluido de Trabalho & Potência Térmica Inserida \\
\hline \multirow{3}{*}{ Zerbini (1984) } & \multirow{3}{*}{ Água } & $24 \mathrm{~W}$ \\
\hline & & $37 \mathrm{~W}$ \\
\hline & & 49W \\
\hline \multirow{8}{*}{ Liu e Lu (2009) } & \multirow{4}{*}{ Água } & $10 \mathrm{~W}$ \\
\hline & & $40 \mathrm{~W}$ \\
\hline & & $70 W$ \\
\hline & & 80W \\
\hline & \multirow{4}{*}{$\begin{array}{l}\text { Nanofluido } \\
\text { Água + CNT }\end{array}$} & $10 \mathrm{~W}$ \\
\hline & & $40 \mathrm{~W}$ \\
\hline & & 70W \\
\hline & & 80W \\
\hline \multirow{3}{*}{ Putra et al. (2012) } & Água & $30 \mathrm{~W}$ \\
\hline & Etilenoglicol (EG) & $30 \mathrm{~W}$ \\
\hline & Nanofluido EG+ZnO & $30 \mathrm{~W}$ \\
\hline
\end{tabular}

\subsection{Construção do modelo computacional}

Para a realização de simulações computacionais envolvendo mecânica de fluidos e transferência de calor, é necessário utilizar programas de fluidodinâmica computacional 
(CFD) para elaborar um modelo representativo do problema físico a ser solucionado e representar corretamente os campos de temperatura e velocidade existentes no tubo de calor através de gráficos, tabelas, campos de vetores ou superfícies isométricas. 0 pacote computacional selecionado para esta finalidade no presente trabalho foi o ANSYS, devido à disponibilidade e ao fato de fornecer ferramentas para a introdução das propriedades dos nanofluidos.

O primeiro passo na construção de um modelo computacional consiste na criação de uma malha computacional, para que seja possível obter uma representação geométrica do problema real a ser solucionado por meio de um domínio discretizado, no qual as equações de conservação serão aplicadas.

\subsubsection{Malha computacional}

Para a construção da malha, o software selecionado foi o ICEM CFD. Este software permite a criação de malhas bidimensionais e grades tridimensionais, e possui uma série de ferramentas que auxiliam na construção e na avaliação da qualidade de uma malha ou grade computacional. Optou-se pela construção de somente metade da malha e bidimensional, uma vez que existe axissimetria ao longo de todo o tubo de calor.

Foram construídas ao todo três malhas computacionais bidimensionais, de forma a representar os tubos de calor utilizados nos estudos previamente apresentados (Zerbini, 1984; Liu e Lu, 2009; Putra et al., 2012).

A primeira malha elaborada corresponde a uma representação do tubo de calor utilizado no estudo experimental de Zerbini (1984). Esta malha possui o objetivo de obter uma validação preliminar do modelo computacional criado, uma vez que representa o funcionamento de um tubo de calor simples contendo água.

As dimensões do tubo calor utilizado no trabalho de Zerbini (1984) foram apresentadas na Tabela 2. Estas dimensões foram utilizadas na construção de uma geometria bidimensional. A partir desta geometria, utilizou-se a rotina automática de construção de malha computacional baseada na geometria do problema, contida no ICEM CFD. Esta rotina permitiu a construção de uma malha computacional baseada em quadriláteros, cujo tamanho pode ser definido através do número de subdivisões desejado para cada seção do tubo de calor. 
Para obter elementos contendo dimensões com uma precisão alta o suficiente para representar o problema físico, mas reduzida de forma a não tornar o problema computacionalmente complexo demais, as menores dimensões utilizadas na malha computacional foram fixadas na ordem de décimo de milímetro (correspondente a 10\% da menor ordem de grandeza obtida no modelo). Desta forma, as regiões correspondentes à parede do tubo de cobre foram divididas em 16 partes iguais, as regiões correspondentes à matriz porosa foram divididas em 8 partes iguais e a região correspondente à câmara de vapor foi dividida em 50 partes iguais. As seções do evaporador e do condensador foram divididas em 80 partes iguais e a seção adiabática foi dividida em 400 partes iguais. A região correspondente à matriz porosa foi dividida em três partes iguais, de forma a separar as partes da matriz porosa contidas em cada uma das três seções existentes no tubo de calor (evaporador, condensador e adiabática). Todos os elementos receberam $100 \%$ na avaliação de qualidade realizada pelo ICEM CFD. A malha resultante para este caso contem 41440 elementos.

A Figura 31 mostra parte da seção do condensador do tubo de calor, de forma a representar a malha computacional obtida, que se repete ao longo de todo o comprimento do tubo de calor. Nessa figura, as cores branca, verde e vermelha correspondem, respectivamente à câmara de vapor, à matriz porosa e à parede do tubo de calor.

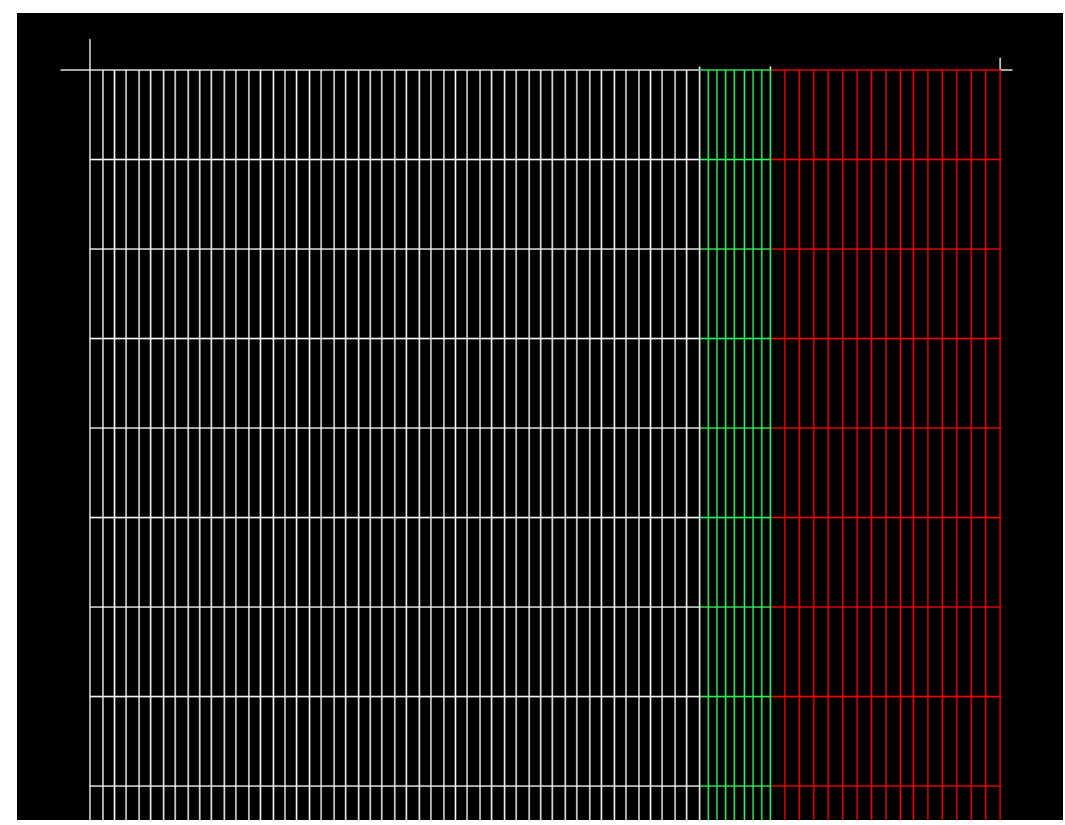

Figura 31. Trecho da malha computacional construída para a simulação do tubo de calor de estudo de Zerbini (1984) 
Em seguida, foi elaborada uma segunda malha computacional para representar o tubo de calor contendo nanotubos de carbono apresentado no estudo de Liu e Lu (2009). As dimensões do tubo de calor utilizado neste estudo foram apresentadas na Tabela 5. Com estas dimensões, foi possível elaborar uma geometria bidimensional computacional representando este tubo de calor. A partir desta geometria, utilizou-se novamente a rotina automática de construção de malha computacional baseada na geometria do problema, contida no ICEM CFD, para a elaboração de uma malha computacional composta por quadriláteros.

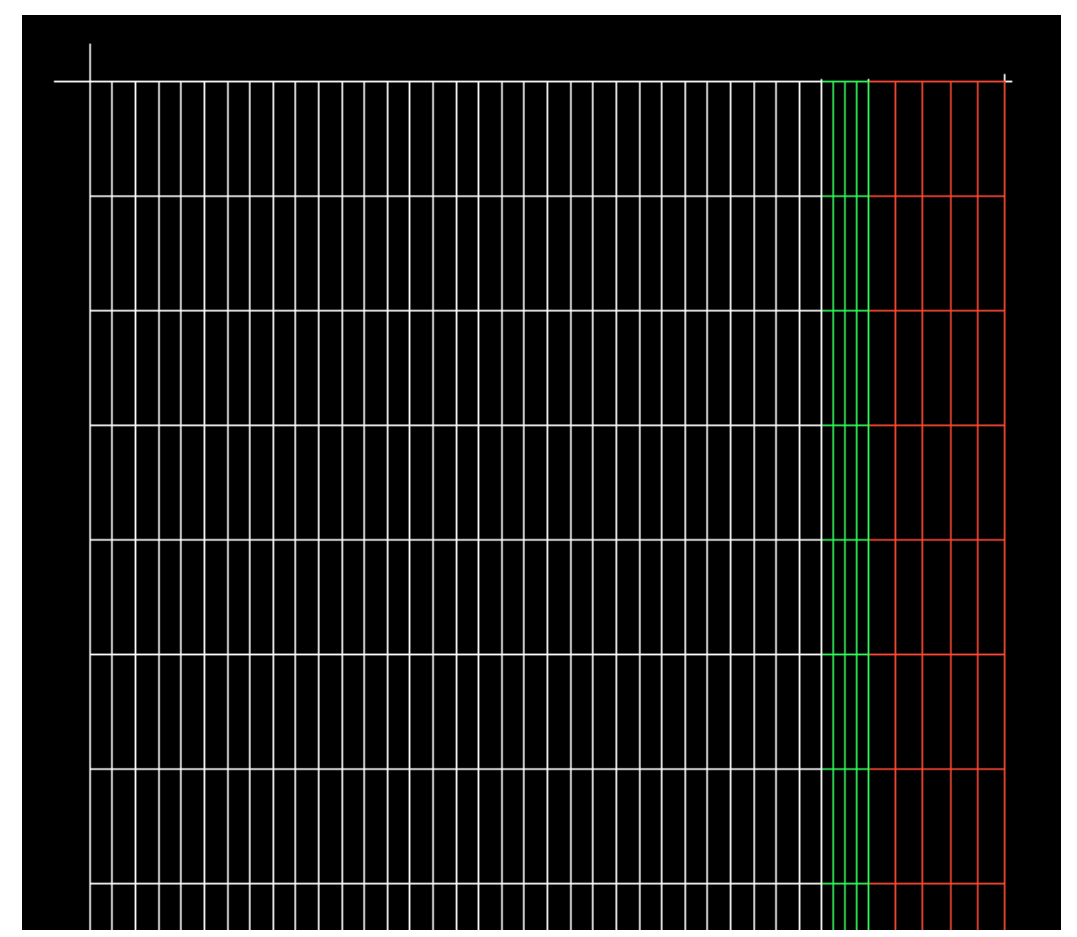

Figura 32. Trecho da malha computacional construída para a avaliação do tubo de calor do estudo de Liu e Lu (2009) - Seção do condensador

As menores dimensões utilizadas na malha computacional foram fixadas na ordem de 5 centésimos de milímetro (correspondente a 25\% da menor ordem de grandeza obtida no modelo) para obter a precisão desejada. Uma precisão maior tornaria os elementos da matriz porosa pequenos demais na direção radial do tubo de calor em relação ao comprimento radial do modelo, podendo causar problemas de convergência, Assim, as regiões correspondentes à parede do tubo de cobre foram divididas em 5 partes iguais, as regiões correspondentes à matriz porosa foram divididas em 4 partes iguais e a região correspondente à câmara de vapor foi dividida em 32 partes iguais. As 
seções do evaporador e adiabática foram divididas em 200 partes iguais e a seção do condensador foi dividida em 300 partes iguais. A região correspondente a matriz porosa foi dividida em três partes iguais, de forma a separar as partes da matriz porosa contidas em cada uma das três seções existentes no tubo de calor (evaporador, condensador e adiabática). Todos os elementos receberam 100\% na avaliação de qualidade realizada pelo ICEM CFD. A malha resultante para este caso contem 28700 elementos. Parte da seção do condensador da malha computacional resultante pode ser observada na Fig. 32, utilizando a mesma configuração de cores mencionada anteriormente.

Por fim, a terceira malha computacional foi elaborada de forma a representar o tubo de calor contendo etilenoglicol apresentado nos estudos de Putra et al. (2012). As dimensões do tubo de calor utilizado neste estudo foram apresentadas na Tabela 6.

A geometria correspondente a estas dimensões foi novamente elaborada no ICEM CFD e a malha correspondente a esta geometria foi elaborada através da rotina automática de construção de malha computacional baseada na geometria do problema, contida no ICEM CFD.

As menores dimensões utilizadas na malha computacional foram fixadas na ordem de 5 centésimos de milímetro (correspondente a 25\% da menor ordem de grandeza obtida no modelo) para obter a precisão desejada. Uma precisão maior tornaria os elementos da matriz porosa pequenos demais na direção radial do tubo de calor em relação ao comprimento radial do modelo, podendo causar problemas de convergência. Assim, as regiões correspondentes à parede do tubo de cobre foram divididas em 4 partes iguais, as regiões correspondentes à matriz porosa foram divididas em 6 partes iguais e a região correspondente à câmara de vapor foi dividida em 70 partes iguais. As seções do evaporador e do condensador foram divididas em 300 partes iguais e a seção adiabática foi dividida em 400 partes iguais. Todos os elementos receberem $100 \%$ na avaliação de qualidade realizada pelo ICEM CFD. A malha resultante para este caso contem 80000 elementos. A região correspondente a matriz porosa foi dividida em três partes iguais, de forma a separar as partes da matriz porosa contidas em cada uma das três seções existentes no tubo de calor (evaporador, condensador e adiabática). Parte da seção do condensador da malha computacional resultante (que se repete ao longo de todo o comprimento do tubo de calor) pode ser observada na Fig. 33, utilizando a mesma configuração de cores mencionada anteriormente. 


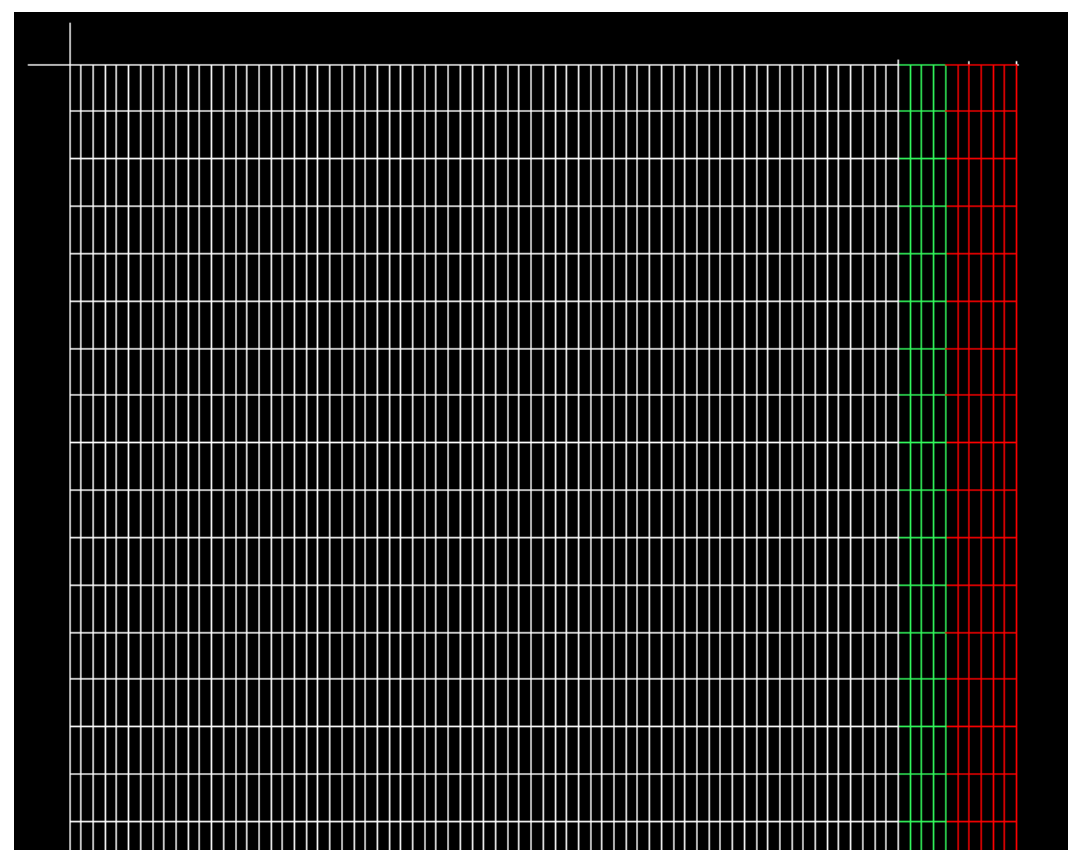

Figura 33. Trecho da malha computacional construída para a avaliação do tubo de calor do estudo de Putra et al. (2012)

\subsubsection{Materiais e suas propriedades físicas}

É possível dividir os materiais utilizados na construção de um tubo de calor em três categorias, de acordo com sua aplicação. Estas categorias são: parede do tubo de calor, matriz porosa e fluido de trabalho.

Na parede do tubo de calor, é necessário que o material utilizado seja capaz de conter o fluido de trabalho sob pressão no interior do tubo de calor sem sofrer alterações do ponto de vista estrutural, tais como corrosão ou deformação mecânica. Ao mesmo tempo, o material utilizado deve ter uma condutividade térmica suficientemente alta para que o calor recebido pelo tubo de calor seja transmitido ao fluido de trabalho de forma eficiente. Em todos os modelos estudados, um único material foi utilizado com esta finalidade, que é o cobre.

O cobre é um material utilizado amplamente em aplicações de engenharia pelas suas propriedades físicas atrativas, tais como a condutividade elétrica e condutividade térmica. A $300 \mathrm{~K}$, o cobre apresenta calor específico de 0,385 kJ/kg.K, massa específica de $8930 \mathrm{~kg} / \mathrm{m}^{3}$ e condutividade térmica de $401 \mathrm{~W} / \mathrm{m} . \mathrm{K}$.

Para a matriz porosa, são utilizadas diversas configurações estruturais contendo materiais sólidos dispostos de maneira a formarem uma estrutura porosa capaz de 
transportar o fluido de trabalho da seção do condensador para a seção do evaporador. Esta matriz porosa é considerada em todos os estudos levantados como sendo uma estrutura constante, não sofrendo desta forma nenhuma alteração em suas propriedades referentes ao meio poroso (porosidade e permeabilidade) ao longo do processo de operação do tubo de calor. Nos três tubos de calor estudados, foram utilizadas duas estruturas diferentes para a construção da matriz porosa.

No trabalho de Zerbini (1984), foram utilizadas telas de malha feitas de bronze. 0 bronze é uma liga metálica composta por diversas proporções de cobre e um segundo material (geralmente zinco), sendo que a mais utilizada delas consiste em uma proporção de 60/40 dos materiais mencionados. É também um material sólido bastante utilizado na fabricação de telas contendo diferentes aberturas, e possui boas propriedades térmicas, tais como uma massa específica de $8520 \mathrm{~kg} / \mathrm{m}^{3}$, um calor específico de 0,377 kJ/kg.K e uma condutividade térmica de $109 \mathrm{~W} / \mathrm{m} . \mathrm{K}$.

A matriz porosa foi obtida a partir de telas de malha quadrada enroladas e pressionadas sobre a superfície interna do vaso contensor. Para a formação destas telas, utilizou-se uma composição entre duas malhas: a primeira delas contendo aberturas de 0,140 mm e fios com diâmetro de 0,114 $\mathrm{mm}$ e a segunda contendo aberturas de 0,065 mm e fios com diâmetro de 0,062 mm. Utilizou-se a malha de menor abertura na porção externa da região da matriz porosa, de forma a aumentar a pressão de bombeamento capilar ao longo do tubo de calor.

Para essa matriz porosa, Zerbini (1984) determinou que o raio de curvatura mínimo do menisco é igual a 6,35.10-5 $\mathrm{m}$. Dadas as dimensões do tubo de calor, o valor médio da permeabilidade do meio poroso foi definido como sendo igual a 2,38.10-10 $\mathrm{m}^{2}$, utilizando a equação modificada de Blake-Kozeny definida em Chi (1976) para matrizes porosas compostas por telas. Esta equação possui a seguinte forma:

$$
K=\frac{d_{f}^{2} \varepsilon^{3}}{122(1-\varepsilon)^{2}}
$$

Onde $d_{f}$ corresponde ao diâmetro do fio utilizado na composição da tela e $\varepsilon$ corresponde a porosidade total da matriz porosa.

Utilizando os valores dados para a permeabilidade da matriz porosa e um diâmetro médio de fio correspondente a 0,088mm, a Equação [65] pode ser resolvida 
para a porosidade, sendo possível obter assim um valor médio efetivo de 0,699 para a porosidade da matriz porosa utilizada.

No estudo de Liu e Lu (2009), a matriz porosa foi obtida por meio de uma série de sulcos retangulares introduzidos na parede interna do tubo de calor. Desta forma, o material utilizado como base para a matriz porosa é o mesmo cobre que compõe a parede do tubo de calor. Para a determinação da porosidade desta estrutura, utilizou-se a definição de porosidade, que é a fração entre o volume de espaços vazios existentes em um material e o volume total deste mesmo material. Sabendo que o tubo de calor apresentava 60 aberturas retangulares ao longo de seu perímetro com dimensões definidas pela Tab. 5, o volume de espaços vazios foi determinado como sendo 1050 $\mathrm{mm}^{3}$. Considerando que o volume total da região correspondente a matriz porosa é de $1451,4 \mathrm{~mm}^{3}$, o valor da porosidade foi definido como sendo 0,723 .

Para a determinação da permeabilidade das passagens retangulares, é necessário adotar a hipótese de que o escoamento permanece no regime laminar ao longo de todo o comprimento das aberturas retangulares. Com isso, a permeabilidade ao longo das aberturas retangulares pode ser expressa pela seguinte equação, extraída de Chi (1976):

$$
K=\frac{2 \varepsilon R_{h}{ }^{2}}{\left(f_{l} R e_{l}\right)}
$$

Onde $R_{h}$ corresponde ao raio hidráulico das aberturas retangulares de profundidade $\delta$ e largura $w$, e pode ser representado pela seguinte equação:

$$
R_{h}=\frac{2 w \delta}{w+2 \delta}
$$

Para as aberturas retangulares existentes no tubo de calor do estudo de Liu e Lu (2009), o valor deste raio hidráulico é de aproximadamente 0,154 mm.

Para a determinação do valor de $\left(f_{l} R_{l}\right)$ é necessário determinar o valor da razão de aspecto das aberturas retangulares como sendo:

$$
A R=\frac{w}{2 \delta}
$$


Para as aberturas retangulares existentes no tubo de calor do estudo de Liu e Lu (2009), o valor desta razão de aspecto é de 0,625. Com esse valor, é possível obter o valor de $\left(f_{l} R e_{l}\right)$ a partir da Fig. 34, extraída e adaptada de Chi (1976).

Para a razão de aspecto definida, o valor de $\left(f_{l} R e_{l}\right)$ é de aproximadamente 15. Assim, o valor da permeabilidade para a matriz porosa do tubo de calor do estudo de Liu e Lu (2009) pode ser calculado pela Equação [66] e possui valor igual a 2,283.10-9 $\mathrm{m}^{2}$.

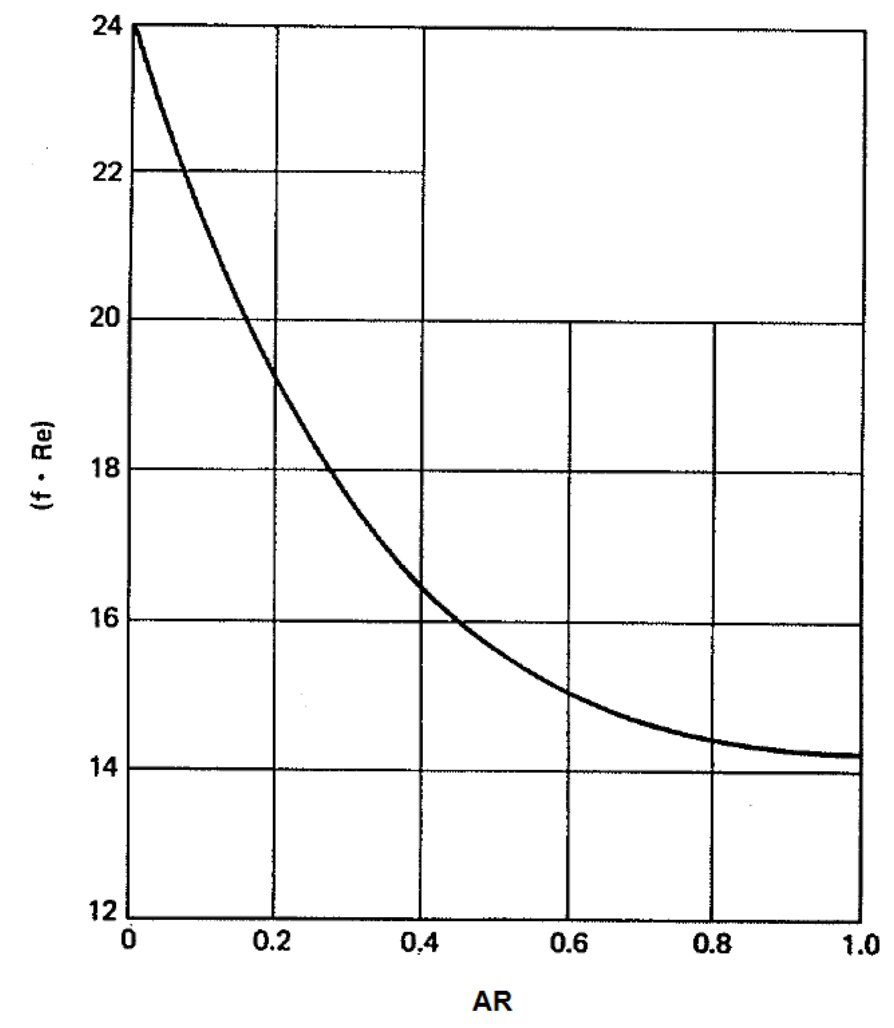

Figura 34. Valor da função de Reynolds utilizada para a determinação da permeabilidade de matrizes porosas contendo aberturas retangulares (adaptada de Chi, 1976)

Por fim, a matriz porosa utilizada nos tubos de calor do trabalho de Putra et al. (2012) consiste em telas de malha enroladas, feitas a partir de um único entrançamento de aço inoxidável. 0 aço inoxidável é uma variante do aço composta por ferro e diversas proporções de cromo, sendo este responsável por tornar o aço inoxidável quando presente em proporções acima de 12\%. Isto ocorre devido a formação de uma película ao redor do material que impede o transporte de oxigênio da atmosfera para o metal. Por sua resistência a corrosão, pode ser utilizado em aplicações em contato direto com 
fluidos oxidantes, como em um tubo de calor. Suas propriedades físicas podem variar de acordo com a proporção de cromo utilizada. Como referência, podemos tomar como propriedades médias uma massa específica de $7955 \mathrm{~kg} / \mathrm{m}^{3}$, um calor específico de 0,510 kJ/kg.K e uma condutividade térmica de 15,5 W/m.K.

O estudo de Putra et al. (2012) fornece como parâmetros da tela utilizada para a construção da matriz porosa o diâmetro do fio utilizado como sendo igual a 56,5 $\mu \mathrm{m}$, e o número de malha $(N)$, correspondente a quantidade de entrançamentos existentes por unidade de comprimento, como sendo igual a 6,742 entrançados de fios por milímetro. Para a determinação da porosidade de matrizes porosas compostas por telas, é possível utilizar a equação fornecida por Chi (1976), que relaciona a porosidade com o diâmetro do fio utilizado e com o número de malha. Esta equação possui a seguinte forma:

$$
\varepsilon=1-\frac{1,05 N \pi d_{f}}{4}
$$

Assim, o valor da porosidade da matriz porosa utilizada no tubo de calor destes estudos é de 0,686.

Com este valor da porosidade, é possível determinar o valor da permeabilidade utilizando a equação modificada de Blake-Kozeny (Equação [65]). Aplicando as propriedades, o valor obtido para a permeabilidade é de 8,558.10-11 $\mathrm{m}^{2}$.

O fluido de trabalho utilizado possui grande importância no desempenho térmico do tubo de calor, e consiste no principal objeto de estudo do presente trabalho. É desejável que o fluido de trabalho apresente uma condutividade térmica alta, para que o valor dos coeficientes de transferência de calor sejam altos, e ao mesmo tempo, o valor da viscosidade do fluido de trabalho deve ser baixo, de forma que as perdas de carga obtidas no escoamento que ocorre ao longo da matriz porosa sejam baixas.

Para a validação dos modelos computacionais elaborados para representar o comportamento dos tubos de calor de todas as aplicações experimentalmente estudadas (Zerbini, 1984; Liu e Lu, 2009; Putra et al., 2012) foi possível realizar um teste preliminar do comportamento térmico do tubo de calor contendo somente água, uma vez que todos os estudos selecionados apresentaram resultados para este tipo de situação. As propriedades físicas da água são amplamente conhecidas na literatura. 
Foram utilizadas como referência as propriedades da água líquida a $25{ }^{\circ} \mathrm{C}$ na pressão de $1 \mathrm{~atm}$. Estas propriedades são:

- Água líquida:

- $\rho_{\mathrm{H} 20, \mathrm{l}}=997 \mathrm{~kg} / \mathrm{m}^{3}$;

$-c_{\mathrm{p}, \mathrm{H} 2 \mathrm{O}, \mathrm{l}}=4181,7 \mathrm{~J} / \mathrm{kg} . \mathrm{K}$;

$-\mu_{\mathrm{H} 20, \mathrm{l}}=8,899.10^{-4} \mathrm{~kg} / \mathrm{m} . \mathrm{s}$;

$-k_{\mathrm{H} 2 \mathrm{O}, \mathrm{l}}=0,6069 \mathrm{~W} / \mathrm{m} \cdot \mathrm{K}$.

No trabalho de Liu e Lu (2009), são utilizados nanofluidos contendo nanotubos de carbono em substituição à água pura. 0 artigo utiliza nanofluidos contendo água como fluido-base e nanotubos de carbono como nanopartículas, em concentrações volumétricas entre $0,25 \%$ e $0,8 \%$, de diâmetro médio de $15 \mathrm{~nm}$ e comprimento médio de $10 \mu \mathrm{m}$. Neste artigo, não são utilizados modelos para a previsão das propriedades físicas dos nanofluidos utilizados.

Assim, os modelos indicados ao longo da revisão bibliográfica serão utilizados para avaliar possíveis valores das principais propriedades físicas dos nanofluidos contendo nanotubos de carbono. Estas propriedades são: massa específica, calor específico, viscosidade e condutividade térmica.

Para a determinação da massa específica, um único modelo foi utilizado em todos os artigos pesquisados envolvendo nanofluidos contendo nanotubos de carbono. Este modelo é a regra das misturas, Equação [25], a qual considera que a massa específica resultante do nanofluido consiste na soma ponderada simples das massas específicas do fluido-base e da nanopartícula. Este modelo será adotado em todos os casos envolvendo nanofluidos contendo nanotubos de carbono.

Para o calor específico, é possível utilizar os dois modelos propostos no estudo de O’Hanley et al. (2012), indicados pelas Equações [37] e [38] do presente estudo. No entanto, como o próprio estudo de O’Hanley et al. (2012) mostra que a concordância obtida pelo modelo da Equação [37] com os resultados experimentais é baixa, e como o modelo da Equação [38] também se encontra adaptado e reproduzido nos trabalhos de Xuan e Roetzel (2000) e Rashmi et al. (2013), o enfoque do presente estudo será direcionado ao modelo indicado pela Equação [38], e desta forma, o modelo indicado pela Equação [37] será desprezado nas análises posteriores.

Em relação aos modelos apresentados na revisão bibliográfica para as demais propriedades, foram selecionados os seguintes modelos, considerando as condições de 
concentração volumétrica, tamanho de nanopartículas e ausência de aglomerados nos nanofluidos estudados no experimento de Liu e Lu (2009):

- Para a viscosidade absoluta:

- $\quad$ modelo de Einstein (Equação [26]);

- $\quad$ modelo de Nielsen (Equação [27]);

- $\quad$ modelo de Batchelor (Equação [28]);

- $\quad$ modelo de Brinkman (Equação [29]);

- $\quad$ modelo de Nguyen (Equação [30]);

- $\quad$ modelo de Pak e Cho (Equação [31]);

- $\quad$ modelo de Krieger e Dougherty (Equação [32]);

- $\quad$ modelo de Maron e Pierce (Equação [33]);

- modelo de Brenner e Condiff (Equações [34] e [35]).

- Para a condutividade térmica:

- modelo de Hamilton e Crosser (Equações [39] e [40]);

- modelo de Nan (Equações [41] a [46]);

- $\quad$ modelo de Xue (Equação [47]);

- $\quad$ modelo de Jeffrey (Equação [48] a [50]);

- $\quad$ modelo de Yu e Choi (Equação [59]).

Para a utilização correta destes modelos, é necessário avaliar três propriedades das nanopartículas de nanotubos de carbono utilizadas: massa específica, calor específico e condutividade térmica. A partir do trabalho de Yang et al. (2002), as propriedades dos nanotubos de carbono utilizadas neste trabalho são:

- $\rho$ CNT $=1,34 \mathrm{~g} / \mathrm{cm}^{3}$;

$-c_{\mathrm{p}, \mathrm{CNT}}=470 \mathrm{~J} / \mathrm{kg} \cdot \mathrm{K}$;

$-k_{\mathrm{CNT}}=200 \mathrm{~W} / \mathrm{m} \cdot \mathrm{K}$.

Já nos trabalhos de Putra et al. (2012), são utilizados água, etilenoglicol e nanofluidos contendo etilenoglicol como fluido-base. As propriedades do etilenoglicol no estado líquido são conhecidas amplamente e correspondem aos seguintes valores, para o fluido a $20^{\circ} \mathrm{C}$ e $1 \mathrm{~atm}^{1}$ :

$$
\begin{aligned}
& -\rho_{\mathrm{EG}, \mathrm{l}}=1115,6 \mathrm{~kg} / \mathrm{m}^{3} ; \\
& -c_{\mathrm{p}, \mathrm{EG}, \mathrm{l}}=2386,5 \mathrm{~J} / \mathrm{kg} . \mathrm{K} ;
\end{aligned}
$$

\footnotetext{
${ }_{1}^{1}$ Disponível em "Ethylene Glycol - Product Guide"
} 
$-\mu \mathrm{EG}, \mathrm{l}=0,0213 \mathrm{~kg} / \mathrm{m} . \mathrm{s}$;

- $k_{\mathrm{EG}, \mathrm{l}}=0,25 \mathrm{~W} / \mathrm{m} . \mathrm{K}$.

No estado de vapor a $100 \mathrm{kPa}$ e a $471 \mathrm{~K}$, as propriedades do etilenoglicol correspondem $\mathrm{a}^{2}$ :

- $\rho_{E G, v}=2,573 \mathrm{~kg} / \mathrm{m}^{3}$

$-C_{p, E G, v}=1410 \mathrm{~J} / \mathrm{kg} . \mathrm{K}$.

Para a estimativa das propriedades de transporte, utilizaremos o método de Reichenberg e a as equações de Misic e Thodos para gases puros, contendo moléculas não lineares, não-hidrocarbonetos e polares, a qualquer temperatura. Esses métodos podem ser encontrados em Green e Perry (2007), e são descritos a seguir.

0 método de Reichenberg permite a estimativa da viscosidade dinâmica para gases puros contendo moléculas de não-hidrocarbonetos, polares, e a pressões abaixo da pressão atmosférica:

$$
\mu=\frac{A^{\prime} T_{r}}{\left[1+0,36 T_{r}\left(T_{r}-1\right)\right]^{1 / 6}}
$$

Onde $A^{\prime}$ pode ser definido para gases orgânicos como:

$$
A^{\prime}=\frac{M^{1 / 2} T_{c r i t}}{\sum n_{j} C_{j}}
$$

0 valor de $M$ corresponde à massa molecular do etilenoglicol $(62,07 \mathrm{~g} / \mathrm{mol})$, e as temperaturas $T_{c r i t}$ e $T_{r}$ são as temperaturas crítica e reduzida do etilenoglicol. Considerando a temperatura de ebulição do etilenoglicol (471 K) como o estado de referência, temos que:

$$
\begin{aligned}
& -T_{c}=720 \mathrm{~K} \\
& -T_{r}=T_{r e f} / T_{c}=471 / 720=0,654
\end{aligned}
$$

O valor de $C_{j}$ pode ser obtido somando as contribuições de cada grupo existente dentro da molécula de etilenoglicol. Como a molécula de etilenoglicol possui duas moléculas de carbono duplamente ligadas e dois grupos - $\mathrm{OH}$ (álcoois), e utilizando uma

2 Disponível em Martinez (http://webserver.dmt.upm.es/ isidoro/dat1/eGAS.pdf) 
tabela correspondente destes valores de Green e Perry (2007), o valor de $\sum n_{i} C_{i}$ corresponde a $2,886.10^{8}$.

Assim, os seguintes valores foram obtidos utilizando as equações [81] e [82]:

- $A^{\prime}=1,966.10^{-5}$ Pa.s;

$-\mu_{E G, v}=1,304.10^{-5}$ Pa.s.

Em sequência, pode-se utilizar as equações de Misic e Thodos, para gases contendo não-hidrocarbonetos puros, em pressões abaixo da pressão atmosférica e contendo moléculas não lineares:

$$
k=\frac{\mu}{M}\left(1,15 c_{v}+16903,36\right)
$$

O valor de $c_{v}$ pode ser calculado subtraindo a constante universal dos gases (8314 $\mathrm{J} / \mathrm{kmol.K})$ do calor específico a pressão constante $\left(c_{p}\right)$. Assim temos que:

- $C_{v, E G, v}=79205 \mathrm{~J} / \mathrm{kmol} . \mathrm{K}$;

$-k_{E G, v}=0,0227 \mathrm{~W} / \mathrm{m} . \mathrm{K}$.

As nanopartículas utilizadas neste estudo são o óxido de alumínio $\left(\mathrm{Al}_{2} \mathrm{O}_{3}\right)$, o dióxido de titânio $\left(\mathrm{TiO}_{2}\right)$ e o óxido de zinco ( $\left.\mathrm{ZnO}\right)$. No presente estudo, serão avaliados os nanofluidos contendo somente nanopartículas de ZnO. No estudo de Putra et al. (2012), foram utilizadas soluções contendo etilenoglicol e nanopartículas de ZnO presentes em concentrações volumétricas entre 1\% e 5\%.

Assim, para o levantamento das propriedades físicas destes nanofluidos, foram novamente utilizados os modelos apresentados na revisão bibliográfica. Os modelos utilizados para o levantamento da massa específica (modelo de Pak e Cho (1998), Equação [25]) e do calor específico (modelo de O’Hanley (2012), Equação [38]) serão utilizados novamente para a avaliação destas propriedades nestes nanofluidos contendo etilenoglicol, uma vez que são modelos utilizados amplamente na literatura para diferentes tipos de nanofluidos.

O levantamento das demais propriedades é feito por meio de uma avaliação dos estudos da literatura que buscam determinar a viscosidade absoluta e a condutividade térmica de nanofluidos contendo etilenoglicol. Considerando as propriedades e as características dos nanofluidos utilizados no estudo de Putra et al. (2012), foram selecionados os seguintes modelos: 
- Para a viscosidade absoluta:

- $\quad$ modelo de Einstein (Equação [26]);

- $\quad$ modelo de Nielsen (Equação [27]);

- $\quad$ modelo de Batchelor (Equação [28]);

- modelo de Brinkman (Equação [29]);

- $\quad$ modelo de Pak e Cho (Equação [31]);

- $\quad$ modelo de Chow (Equação [51]);

- modelo de Krieger e Dougherty (Equações [32] e [52]).

- Para a condutividade térmica:

- $\quad$ modelo de Hamilton e Crosser (Equações [39] e [40]);

- $\quad$ modelo de Wasp (Equação [53]);

- $\quad$ modelo de Jeffrey (Equação [48] a [50]);

- $\quad$ modelo de Chen et al. (Equações [54] a [56]);

- modelo de Murshed (Equações [57] e [58]);

- $\quad$ modelo de Yu e Choi (Equação [59]);

- $\quad$ modelo de Turian (Equação [60]).

Para a utilização correta destes modelos, é necessário levantar três propriedades das nanopartículas de ZnO utilizadas: massa específica, calor específico e condutividade térmica. Morkoç e Özgür (2009) e Pastoriza-Gallego et. al (2014) fornecem estas propriedades, de forma que as propriedades utilizadas das nanopartículas de óxido de zinco neste trabalho são:

$$
\begin{aligned}
& -\rho_{Z n O}=5607 \mathrm{~kg} / \mathrm{m}^{3} ; \\
& -c_{p, Z n O}=495,2 \mathrm{~J} / \mathrm{kg} . \mathrm{K} ; \\
& -k_{Z n O}=49 \mathrm{~W} / \mathrm{m} . \mathrm{K} .
\end{aligned}
$$

\subsubsection{Configuração dos modelos computacionais}

Inicialmente, foram definidos os controles de execução do problema, inserindo a opção de precisão dupla (double precision), para que o problema possa ser resolvido utilizando variáveis de ponto flutuante contendo 8 bytes. Como o programa CFX é voltado para a simulação de modelos tridimensionais, as malhas computacionais elaboradas tiveram que ser representadas por meio de uma grade tridimensional 
contendo uma espessura na direção $\mathrm{z}$ de valor diminuto (1 milímetro) e condições de simetria aplicadas em ambas as faces localizadas nos planos $\mathrm{x}-\mathrm{y}$ ao serem exportadas para o programa CFX. Adicionalmente, foi aplicada uma condição de contorno de simetria na face do plano y-z correspondente ao eixo central do problema, de forma a considerar a axissimetria existente em um tubo de calor.

Foram definidos três domínios principais ao longo de todas as malhas utilizadas, de forma que fosse possível definir as regiões correspondentes a parede do tubo de calor, a câmara de vapor e a matriz porosa, esta última subdividida em três subdomínios referentes a cada região do tubo de calor (adiabática, evaporador e condensador). Estes domínios foram configurados da seguinte forma:

- $\quad$ Região COPPER (parede do tubo de calor)

- domínio do tipo sólido, contínuo e estacionário;

- material definido como cobre (Copper);

- transferência de calor definida pelo método da energia térmica (desconsidera os efeitos decorrentes da compressibilidade);

- temperatura inicial definida como a temperatura em regime permanente do tubo de calor;

- $\quad$ Região STEAM (câmara de vapor)

- domínio do tipo fluido, contínuo e estacionário;

- temperatura inicial definida como a temperatura em regime permanente do tubo de calor;

- $\quad$ pressão de referência definida como sendo a pressão de saturação da água nesta temperatura inicial, localizada na extremidade do tubo de calor adjacente a seção do condensador;

- transferência de calor definida pelo método da energia térmica (desconsidera os efeitos decorrentes da compressibilidade);

- $\quad$ regime de escoamento pertencente a região laminar (devido as baixas velocidades e baixas dimensões características), contendo efeitos de dissipação viscosa;

- coordenadas definidas como cilíndricas;

- $\quad$ Região WICK (matriz porosa) - subdividida em WICKAD (matriz porosa contida na seção adiabática), WICKCOND (matriz porosa contida na seção 
do condensador) e WICKEVAP (matriz porosa contida na seção do evaporador);

- domínio do tipo fluido, contínuo e estacionário;

- condutividade térmica definida através da Equação [8];

- massa específica, viscosidade absoluta e calor específico definidos neste domínio como sendo iguais as propriedades do fluido de trabalho no estado líquido ${ }^{3}$;

- $\quad$ modelo de perdas definido como isotrópico (simplificação);

- permeabilidade definida por meio de um termo fonte negativo volumétrico associado a quantidade de movimento tal como definido nas equações [5] e [6];

- temperatura inicial definida como a temperatura em regime permanente do tubo de calor;

- pressão de referência definida como a pressão de saturação da água nesta temperatura inicial, localizada na extremidade do tubo de calor adjacente a seção do condensador;

- transferência de calor definida pelo método da energia térmica (desconsidera os efeitos decorrentes da compressibilidade);

- regime de escoamento pertencente a região laminar para o fluido (devido as baixas velocidades e baixas dimensões características), contendo efeitos de dissipação viscosa;

- coordenadas definidas como cilíndricas.

Com o domínio definido, torna-se necessário aplicar as condições de contorno do problema de forma a representar as condições de operação e os fenômenos de evaporação e condensação no interior do tubo de calor. Para isso, foram definidas fronteiras específicas e subdomínios ao longo da malha do problema de forma a introduzir computacionalmente as condições definidas em Mahjoub e Matabroshan

3 Nos domínios porosos, o valor da condutividade térmica efetiva no modelo de Mahjoub e Matabroshan (2008) depende da porosidade na equação da conservação da energia (Eq. [7]), e por isso foi calculado através da Eq. [8]. Os demais valores de propriedades que são utilizados nas equações de conservação são as próprias propriedades do fluido contido neste domínio, e por isso, estas propriedades são inseridas nestes domínios sem quaisquer alterações. 
(2008). As Figuras 35 e 36 mostram parte destas fronteiras e subdomínios nas regiões de transição entre as seções do evaporador e do condensador, respectivamente, e a seção adiabática, utilizando cores para representar as condições de contorno aplicadas de maneira descrita a seguir.

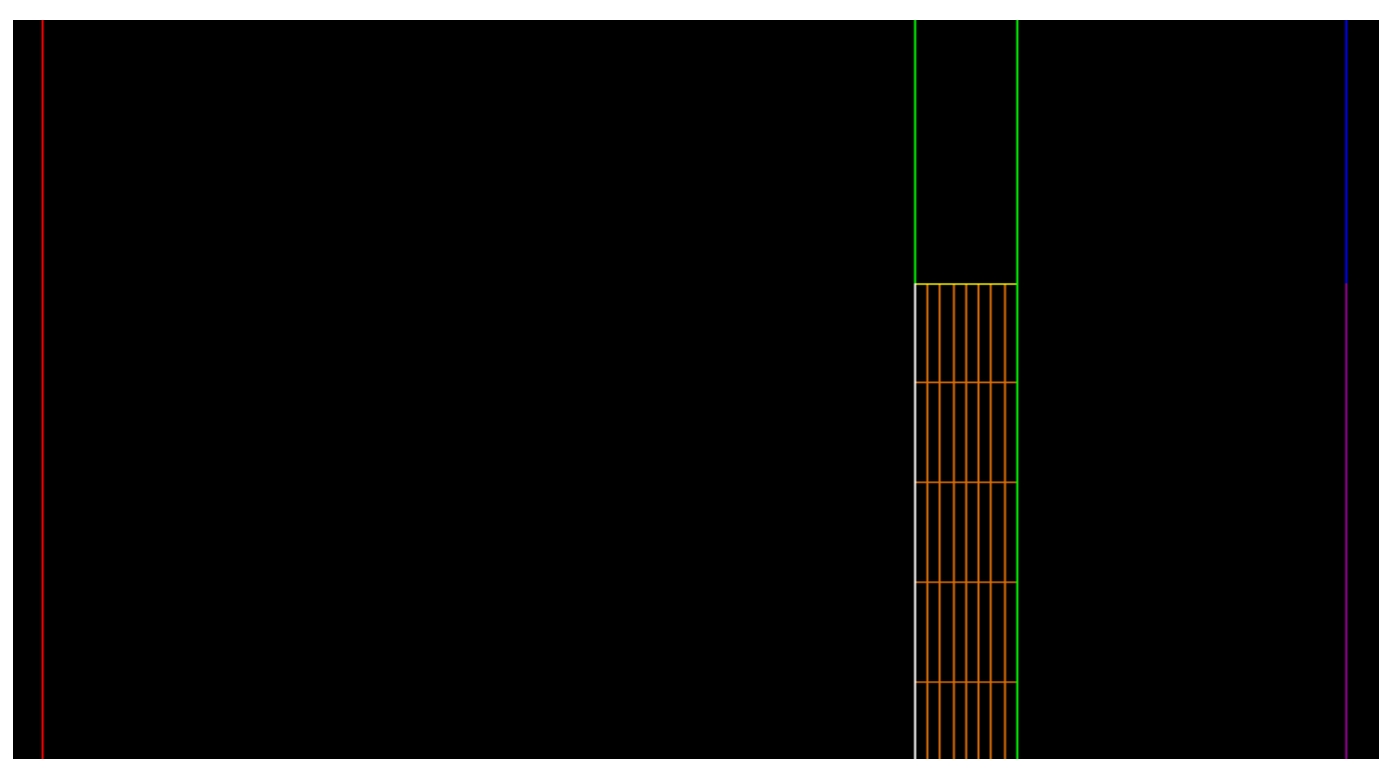

Figura 35. Representação das condições de contorno aplicadas na transição entre a seção do evaporador e a seção adiabática ${ }^{4}$

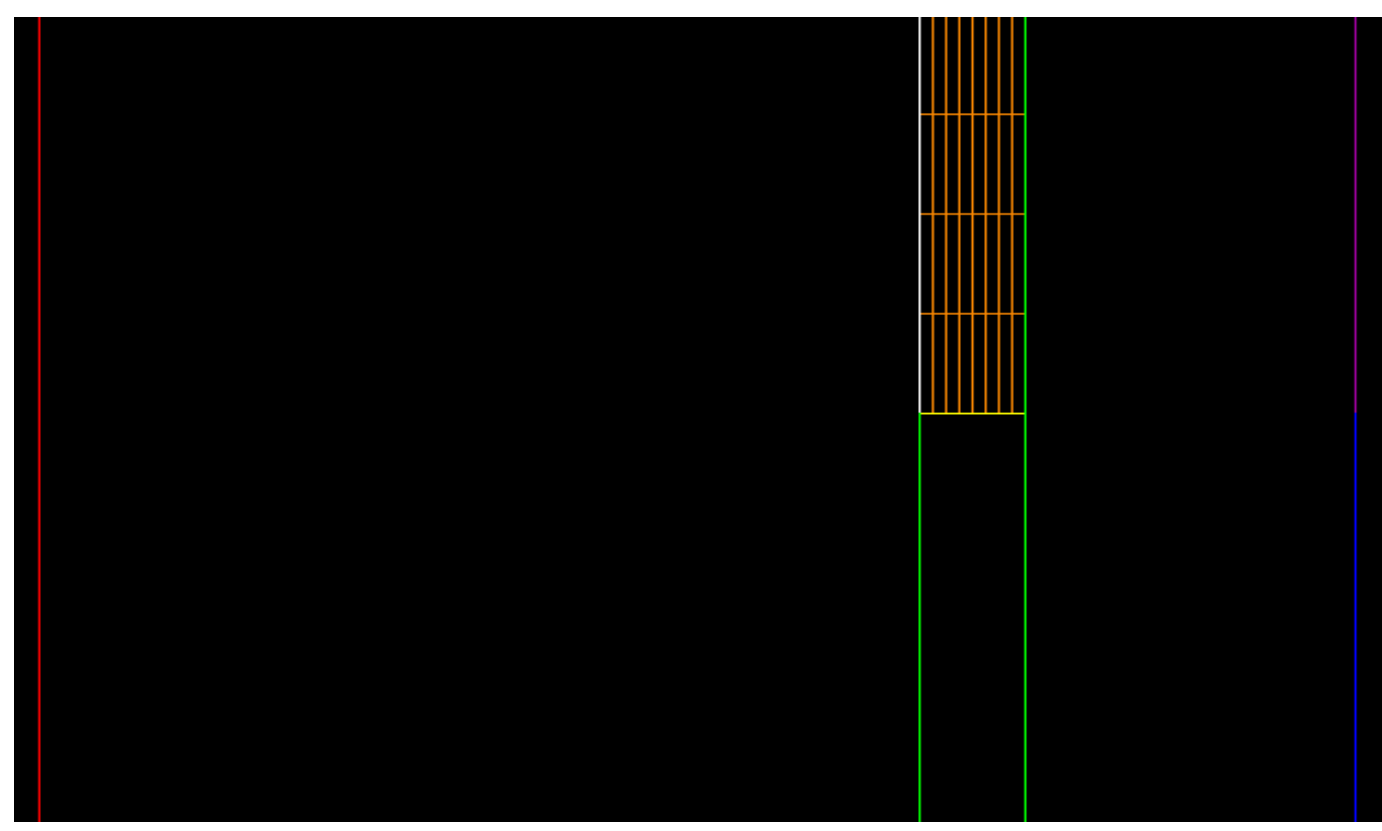

Figura 36. Representação das condições de contorno aplicadas na transição entre a seção do condensador e a seção adiabática ${ }^{4}$

\footnotetext{
${ }^{4}$ Obs.: Ainda que as Figuras 35 e 36 sejam referentes à malha utilizada para a representação do tubo de calor de Zerbini (1984), estas características são idênticas em todos os três tubos de calor estudados.
} 
As fronteiras de cor roxa são definidas como fronteiras do tipo parede e representam a introdução de calor na seção do evaporador e a extração de calor na seção do condensador (referente a uma quantidade de calor inserida com sinal negativo). Um fluxo de calor fixo é definido nestas fronteiras e corresponde a quantidade de calor proporcional ao volume do modelo computacional, dividido pela área externa equivalente destas seções, e pode ser calculado da através da Equação [73].

$$
\dot{Q}_{s}=\frac{\dot{Q}_{m o d}}{\mathrm{~A}_{m o d, s}}=\frac{\left(\dot{Q}_{\text {exp }} \frac{0,001 \cdot R_{o} L_{t}}{\pi R_{o}^{2} L_{t}}\right)}{0,001 \cdot L_{s}}=\frac{\dot{Q}_{\text {exp }}}{\pi R_{o} L_{s}}
$$

Onde $\dot{Q}$ corresponde a potência térmica que atravessa o tubo de calor, $\mathrm{L}$ corresponde ao comprimento da seção de interesse e os subscritos mod e exp correspondem respectivamente às quantidades referentes ao modelo computacional e ao experimento, $t$ corresponde a totalidade do tubo de calor e $s$ corresponde a seção de interesse (evaporador ou condensador). É possível observar que as simplificações na Equação [73] resultam em uma forma análoga das equações [20] e [22] para uma situação contendo meio tubo de calor, tal como esperado das condições de simetria adotadas para a construção do modelo.

Assim, é possível reescrever a Equação [73] referente às seções do evaporador e do condensador:

$$
\begin{gathered}
\dot{Q}_{e}=\frac{\dot{Q}_{\text {exp }}}{\pi R_{o} L_{e}} \\
\dot{Q}_{c}=-\frac{\dot{Q}_{\text {exp }}}{\pi R_{o} L_{c}}
\end{gathered}
$$

Para a representação da conversão da energia térmica em energia interna decorrente do processo de evaporação, e do fenômeno inverso decorrente do processo de condensação, foram utilizados termos fonte de energia representativos. Estes termos fonte são análogos aos termos volumétricos apresentados nas equações [16] a [18] e são aplicados nos elementos de cor laranja nas Figuras 35 e 36. No entanto, estes termos 
foram modificados de forma a refletirem as condições artificiais de bidimensionalidade adotadas no modelo computacional. Desta forma, os termos representados nas equações [16] a [18] assumem a seguinte forma geral:

$$
S_{\text {mod }}= \pm \frac{\dot{Q}_{\text {mod }}}{\text { 0,001.t. } L_{s}}
$$

Onde $\mathrm{t}$ corresponde a espessura da matriz porosa. Assim, para as seções do evaporador e do condensador, as equações podem ser escritas como:

$$
\begin{gathered}
S_{e}=-\frac{\dot{Q}_{m o d}}{0,001 \cdot t \cdot L_{e}} \\
S_{c}=+\frac{\dot{Q}_{m o d}}{0,001 \cdot t \cdot L_{c}}
\end{gathered}
$$

No entanto, a aplicação de $100 \%$ do calor recebido pela seção do evaporador para a evaporação do fluido de trabalho negligencia a existência de condução de calor na parede do tubo de calor. Esta simplificação mostrou-se inadequada nas simulações computacionais preliminares, visto que um pequeno fluxo de calor sempre é conduzido através da parede do tubo de calor, e, mesmo sendo pequeno, este fluxo de calor provoca alterações significativas nos campos de temperatura ao final das simulações. Além disso, é possível observar nos estudos de Kempers et al. (2008) e Wong (2014) a presença de um fluxo de calor sendo conduzido ao longo da parede do tubo de calor, cujos valores variam desde menos de $2 \%$ do fluxo total inserido no evaporador para um tubo de calor contendo água (Kempers et al., 2008) até entre 1,1-6\% deste mesmo fluxo para água ou 5-10\% deste mesmo fluxo para metanol e acetona (Wong, 2014).

Desta forma, uma análise de conservação de energia foi realizada na parede do tubo de calor de forma a determinar a parcela do fluxo de calor que é conduzido pela parede do tubo de calor e não contribui para a evaporação do fluido de trabalho. Esta análise é demonstrada no Apêndice 1, e comprova que é necessário introduzir um parâmetro $\eta$ referente à fração do fluxo de calor que efetivamente é utilizado para a 
mudança de fase no interior do tubo de calor. Assim, as equações [77] e [78] passam a assumir a seguinte forma:

$$
\begin{aligned}
& S_{e}=-\eta \frac{\dot{Q}_{\text {mod }}}{0,001 \cdot t \cdot L_{e}} \\
& S_{c}=+\eta \frac{\dot{Q}_{\text {mod }}}{0,001 \cdot t \cdot L_{c}}
\end{aligned}
$$

De acordo com a análise do Apêndice, verifica-se que o parâmetro $\eta$ assume valores entre 0,96 e 0,995 , e apresenta comportamento inversamente proporcional ao fluxo de calor inserido no tubo de calor.

As fronteiras de cor branca são definidas como fronteiras do tipo interface e representam a interface entre a matriz porosa e a câmara de vapor nas seções do evaporador e do condensador. Nestas interfaces, são inseridos termos fonte referentes à introdução e remoção da quantidade de movimento decorrentes dos processos de evaporação e condensação que ocorrem no interior do tubo de calor, responsáveis pela movimentação do fluido no interior do modelo.

Para a representação destes termos fonte de quantidade de movimento, são utilizadas formas modificadas das equações [10] a [15], sendo que por conta das opções do CFX optou-se por inserir esta quantidade de movimento na forma de um fluxo mássico equivalente por unidade de área ao invés de utilizar velocidades. Este procedimento visa facilitar a solução dos balanços de massa.

Assim, para a região da câmara de vapor, é possível escrever estes termos fonte utilizando a seguinte equação genérica:

$$
\dot{m}_{v, \text { mod }}= \pm\left(\frac{\dot{Q}_{m o d} / h_{l v}}{\mathrm{~A}_{m o d, s}}\right)=\frac{\dot{Q}_{m o d}}{0,001 \cdot L_{s} \cdot h_{l v}}
$$

No entanto, uma vez que este fluxo mássico é dependente do fluxo de calor utilizado para a mudança de fase, também é necessário introduzir nesta equação o parâmetro $\eta$ de forma a considerar que somente o fluxo de calor utilizado para a 
mudança de fase é responsável pela introdução ou remoção de quantidade de movimento no tubo de calor. Desta forma, a Equação [81] assume a seguinte forma:

$$
\dot{m}_{v, \text { mod }}= \pm \eta \frac{\dot{Q}_{\text {mod }}}{0,001 \cdot L_{s} \cdot h_{l v}}
$$

Assim, podemos escrever os termos fonte referentes à introdução e remoção de fluxo mássico por unidade de área na câmara de vapor para as seções do evaporador e do condensador da seguinte forma:

$$
\begin{gathered}
\dot{m}_{v, e}=+\eta \frac{\dot{Q}_{m o d}}{0,001 \cdot L_{e} \cdot h_{l v}} \\
\dot{m}_{v, c}=-\eta \frac{\dot{Q}_{m o d}}{0,001 \cdot L_{c} \cdot h_{l v}}
\end{gathered}
$$

Analogamente, a partir da conservação da massa, é possível escrever os termos fonte referentes a região da matriz porosa da seguinte forma:

$$
\begin{gathered}
\dot{m}_{l, e}=-\eta \frac{\dot{Q}_{m o d}}{0,001 \cdot L_{e} \cdot h_{l v}} \\
\dot{m}_{l, c}=+\eta \frac{\dot{Q}_{m o d}}{0,001 \cdot L_{c} \cdot h_{l v}}
\end{gathered}
$$

É definido também que não existe fluxo de quantidade de movimento atravessando estas interfaces, de forma a manter os fluidos escoando separadamente, e que a transferência de calor entre os dois lados da interface respeita os princípios de conservação da energia, transferindo todo o calor que recebe em uma face para a face adjacente.

As fronteiras representadas pelas cores azul e verde correspondem a fronteiras do tipo "parede" (isto é, não existe fluxo de quantidade de movimento atravessando elas). As paredes de cor azul são do tipo "adiabático" (isto é, não existe fluxo de calor atravessando elas), enquanto as paredes de cor verde correspondem a paredes nas 
quais é respeitada a conservação de energia entre seus dois lados. 0 topo e a base do tubo de calor também são representados por fronteiras de cor azul, ainda que não estejam ilustrados.

As fronteiras de cor amarela correspondem a pseudo-fronteiras criadas somente para separar os subdomínios localizados no interior da matriz porosa (WICKAD, WICKCOND e WICKEVAP). Assim, estas fronteiras respeitam as condições de conservação de energia e de quantidade de movimento na matriz porosa sem exercerem qualquer influência sobre elas.

Por fim, a fronteira de cor vermelha corresponde a condição de simetria adotada de forma a representar a axissimetria existente no problema, permitindo assim que a simulação de meia malha seja equivalente a simulação de um tubo de calor completo.

Em seguida, é necessário especificar os controles de solução do problema, de forma que a solução numérica das equações de conservação possa ser realizada de forma robusta, sem divergências. Para isso, é necessário definir quatro configurações principais: Esquema de advecção, controle de convergência residual, número máximo de iterações e escala de tempo numérica.

A seleção do esquema de advecção permite que sejam determinados os coeficientes usados para a integração numérica das equações de conservação. Assim, de acordo com o esquema utilizado, é possível obter uma convergência melhor do problema e representar os gradientes de maneira mais semelhante ao problema real. A versão utilizada do programa computacional CFX permite a utilização de três esquemas prontos para a solução do problema: Upwind, High Resolution e Specified Blend Factor.

Dos esquemas apresentados, o esquema que se mostrou mais apropriado para a solução do problema de um tubo de calor consiste no esquema de segunda ordem representado pela introdução de um fator de combinação igual a 1 (Esquema Specified Blend Factor). Este esquema permite a obtenção de uma solução bastante representativa, sem tantos erros de discretização como os obtidos pelo esquema Upwind, e contendo baixo resíduo, uma vez que o problema não apresenta oscilações bruscas. 0 esquema de advecção High Resolution utiliza fatores de combinação nãolineares, cujo tratamento pode levar a divergências no processo de solução, e por isso não foi utilizado neste problema.

O controle de convergência residual corresponde a um valor máximo definido para a soma (RMS) das variações realizadas no último passo de iteração das equações de 
conservação, de forma que a simulação é interrompida e tratada como convergente uma vez que esta soma atinge este valor de máximo. 0 valor padrão definido pelo programa CFX para este controle de convergência é $10^{-4}$. No entanto, este valor encontra-se próximo a ordem de grandeza máxima das variáveis utilizadas neste problema. Assim, em todas as simulações, este valor foi redefinido como sendo $10^{-7}$.

O número máximo de iterações compreende a quantidade de iterações que o sistema irá realizar caso o controle de convergência residual não seja atingido. Em todas as simulações, este valor foi definido como sendo igual a 2000 iterações. Entretanto, este valor não foi atingido para nenhum dos casos estudados.

A escala de tempo numérica corresponde a cada subdivisão criada pela simulação de forma a diferenciar os passos numéricos (iterações) realizados ao longo do domínio para cada equação de conservação. Uma escala de tempo menor corresponde a uma variação menor das propriedades em cada iteração, e a uma necessidade de um maior número de iterações de forma a atingir a solução convergida desejada. Após a realização de alguns testes, foi possível perceber que a escala de tempo automática na configuração conservativa adotada como padrão pelo CFX é adequada para a solução do problema de um tubo de calor, e por isso, esta configuração permaneceu como sendo automática.

\subsubsection{Zerbini (1984)}

Para avaliar o comportamento preliminar da simulação computacional de um tubo de calor, utilizou-se o tubo de calor do trabalho de Zerbini (1984) para a construção de um modelo computacional de um tubo de calor contendo somente água.

A malha computacional utilizada para a construção deste modelo consiste na malha representada na Figura 31. As condições iniciais definidas especificamente para este modelo são: 
- $\quad$ Região STEAM

- Material definido como vapor d'agua, tratado como um gás real representado pelo modelo padrão de Redlich-Kwong como vapor seco nas condições de saturação (H2ORK5).

- $\quad$ Região WICK

- Material definido como líquido e customizado por meio da alteração das propriedades físicas;

- Condutividade térmica definida através da Equação [8], considerando o material líquido como sendo água, o material sólido como sendo bronze e a porosidade definida como 0,699 , assumindo valor final igual a $1,604 \mathrm{~W} / \mathrm{m} . \mathrm{K}$;

- Massa específica, viscosidade absoluta e calor específico definidos neste domínio como sendo as propriedades definidas para a água no estado líquido (Water);

- Permeabilidade aplicada ao termo fonte definida como 2,38.10-10 $\mathrm{m}^{2}$.

Em sequência, os valores definidos para as condições de contorno, associados às equações [77] e [78] e as dimensões da Tab. 2, referentes às interações do meio externo com o tubo de calor podem ser observados na Tabela 9.

Tabela 9. Condições de contorno térmicas adotadas para as interações com meio externo para o trabalho de Zerbini (1984)

\begin{tabular}{ccc}
\hline \multirow{2}{*}{ Potência térmica } & \multicolumn{2}{c}{ Potência equivalente } \\
\cline { 2 - 3 } & Seção do evaporador & Seção do condensador \\
\hline $24 \mathrm{~W}$ & $6015,3 \mathrm{~W} / \mathrm{m}^{2}$ & $-6015,3 \mathrm{~W} / \mathrm{m}^{2}$ \\
\hline $37 \mathrm{~W}$ & $9273,6 \mathrm{~W} / \mathrm{m}^{2}$ & $-9273,6 \mathrm{~W} / \mathrm{m}^{2}$ \\
\hline $49 \mathrm{~W}$ & $12281 \mathrm{~W} / \mathrm{m}^{2}$ & $-12281 \mathrm{~W} / \mathrm{m}^{2}$ \\
\hline
\end{tabular}

\footnotetext{
${ }^{5} \mathrm{O}$ modelo padrão de Redlich-Kwong foi utilizado porque não existe proximidade do ponto crítico da água, nem tampouco interação entre líquido e vapor conforme hipótese adotada no modelo de Mahjoub e Matabroshan (2008), que admite que os fluidos escoam separadamente no tubo de calor (página 20). 0 modelo padrão de Redlich-Kwong estima o valor da massa específica e do calor específico do material por meio de polinomiais dependentes da temperatura crítica, da pressão crítica e do fator de acentricidade do material (ANSYS CFX-Solver Theory Guide, 2013)
} 
Em seguida, por meio da análise indicada no Apêndice 1, foram determinados os valores do coeficiente $\eta$ indicados na Tab. 10 para os três casos estudados do trabalho de Zerbini (1984).

Tabela 10. Parâmetros $\eta$ provenientes da análise de balanço de energia adotados para o trabalho de Zerbini (1984)

\begin{tabular}{cc}
\hline Potência térmica & Parâmetro $\eta$ \\
\hline $24 \mathrm{~W}$ & 0,99 \\
\hline $37 \mathrm{~W}$ & 0,985 \\
\hline $49 \mathrm{~W}$ & 0,985 \\
\hline
\end{tabular}

Assim, torna-se possível determinar os valores correspondentes às condições de contorno referentes aos processos de evaporação e condensação definidas pelas equações [79] e [80] para a parte térmica e pelas equações [83] a [86] para a parte hidrodinâmica. Utilizando as mesmas dimensões fixadas na Tab. 2, estas condições de contorno assumem os valores representados nas Tabs. 11 e 12:

Tabela 11. Condições de contorno térmicas adotadas para os processos de evaporação e condensação para o trabalho de Zerbini (1984)

\begin{tabular}{ccc}
\hline Potência térmica & Seção & Termo fonte inserido \\
\hline \multirow{2}{*}{$24 \mathrm{~W}$} & Evaporador & $-5,95.10^{6} \mathrm{~W} / \mathrm{m}^{3}$ \\
\cline { 2 - 3 } & Condensador & $5,95.10^{6} \mathrm{~W} / \mathrm{m}^{3}$ \\
\hline \multirow{2}{*}{$37 \mathrm{~W}$} & Evaporador & $-9,13.10^{6} \mathrm{~W} / \mathrm{m}^{3}$ \\
\cline { 2 - 3 } & Condensador & $9,13.10^{6} \mathrm{~W} / \mathrm{m}^{3}$ \\
\hline \multirow{2}{*}{$49 \mathrm{~W}$} & Evaporador & $-1,21.10^{7} \mathrm{~W} / \mathrm{m}^{3}$ \\
\cline { 2 - 3 } & Condensador & $1,21.10^{7} \mathrm{~W} / \mathrm{m}^{3}$ \\
\hline
\end{tabular}


Tabela 12. Condições de contorno hidrodinâmicas adotadas para os processos de evaporação e condensação para o trabalho de Zerbini (1984)

\begin{tabular}{|c|c|c|c|}
\hline Potência térmica & Região & Seção & Termo fonte inserido \\
\hline \multirow{4}{*}{$24 \mathrm{~W}$} & \multirow{2}{*}{ Câmara de Vapor } & Evaporador & $0,0027 \mathrm{~kg} /\left(\mathrm{m}^{2} \mathrm{~s}\right)$ \\
\hline & & Condensador & $-0,0027 \mathrm{~kg} /\left(\mathrm{m}^{2} \mathrm{~s}\right)$ \\
\hline & \multirow{2}{*}{ Matriz Porosa } & Evaporador & $-0,0027 \mathrm{~kg} /\left(\mathrm{m}^{2} \mathrm{~s}\right)$ \\
\hline & & Condensador & $0,0027 \mathrm{~kg} /\left(\mathrm{m}^{2} \mathrm{~s}\right)$ \\
\hline \multirow{4}{*}{$37 \mathrm{~W}$} & \multirow{2}{*}{ Câmara de Vapor } & Evaporador & $0,0045 \mathrm{~kg} /\left(\mathrm{m}^{2} \mathrm{~s}\right)$ \\
\hline & & Condensador & $-0,0045 \mathrm{~kg} /\left(\mathrm{m}^{2} \mathrm{~s}\right)$ \\
\hline & \multirow{2}{*}{ Matriz Porosa } & Evaporador & $-0,0045 \mathrm{~kg} /\left(\mathrm{m}^{2} \mathrm{~s}\right)$ \\
\hline & & Condensador & $0,0045 \mathrm{~kg} /\left(\mathrm{m}^{2} \mathrm{~s}\right)$ \\
\hline \multirow{4}{*}{$49 \mathrm{~W}$} & \multirow{2}{*}{ Câmara de Vapor } & Evaporador & $0,0064 \mathrm{~kg} /\left(\mathrm{m}^{2} \mathrm{~s}\right)$ \\
\hline & & Condensador & $-0,0064 \mathrm{~kg} /\left(\mathrm{m}^{2} \mathrm{~s}\right)$ \\
\hline & \multirow{2}{*}{ Matriz Porosa } & Evaporador & $-0,0064 \mathrm{~kg} /\left(\mathrm{m}^{2} \mathrm{~s}\right)$ \\
\hline & & Condensador & $0,0064 \mathrm{~kg} /\left(\mathrm{m}^{2} \mathrm{~s}\right)$ \\
\hline
\end{tabular}

\subsubsection{Liu e Lu (2009)}

Para a análise do comportamento dos nanofluidos contendo nanopartículas de nanotubos de carbono no interior de um tubo de calor, utilizou-se o tubo de calor do trabalho de Liu e Lu (2009). Esta modelagem é comparada diretamente com os resultados presentes em Liu e Lu (2009) para este mesmo tubo de calor contendo somente água.

A malha computacional utilizada para a construção deste modelo está representada na Figura 32. As condições iniciais adotadas especificamente para este modelo são:

- $\quad$ Região STEAM

- Material definido como vapor d'agua, tratado como um gás real representado pelo modelo padrão de Redlich-Kwong como vapor seco nas condições de saturação $(H 2 O R K)$. 
- $\quad$ Região WICK

- Material definido como líquido e customizado por meio da alteração das propriedades físicas;

- Permeabilidade aplicada ao termo fonte definida como $2,28.10^{-9} \mathrm{~m}^{2}$.

Adicionalmente, o valor da condutividade térmica da região WICK é definido pela da Equação [8], e considera-se que o material sólido que compõe a matriz porosa é o mesmo cobre utilizado para a construção das paredes do tubo de calor, devido ao tipo de matriz porosa adotado neste caso (sulcos retangulares), e que a porosidade possui valor igual a 0,699, tal como definido anteriormente. No entanto, a Equação [8] requer o valor da condutividade térmica do nanofluido contendo nanotubos de carbono, cujo valor varia de acordo com a correlação utilizada para sua determinação.

Assim, para a avaliação do valor desta propriedade, consideraremos nanofluidos idênticos aos utilizados no estudo de Liu e Lu (2009). Estes nanofluidos contém água como fluido-base e nanotubos de carbono com diâmetro médio de $15 \mathrm{~nm}$ e comprimento médio de $10 \mu \mathrm{m}$. 0 valor da concentração mássica estudado é de $2 \%$, o que corresponde a uma concentração volumétrica de $0,62 \%$.

A Tabela 13 mostra os valores obtidos para a condutividade térmica em um nanofluido com as características citadas por meio das correlações levantadas especificamente para a determinação da condutividade térmica de nanofluidos contendo nanopartículas de nanotubos de carbono na revisão bibliográfica, em comparação com a condutividade térmica da água pura:

Tabela 13. Condutividade térmica do nanofluido contendo nanotubos de carbono do estudo de Liu e Lu (2009) e de fluido comparativo

\begin{tabular}{|c|c|c|c|}
\hline Fluido & Correlação & Equações & Condutividade $(\mathrm{W} / \mathrm{m} . \mathrm{K})$ \\
\hline Água pura & & & 0,63 \\
\hline \multirow{5}{*}{ Nanofluido } & Hamilton - Crosser & [39] e [40] & 0,70 \\
\hline & Nan & [41] a [46] & 0,73 \\
\hline & Xue & {$[47]$} & 0,67 \\
\hline & Jeffrey & [48] a [50] & 0,64 \\
\hline & Yu e Choi & [59] & 0,64 \\
\hline
\end{tabular}


A partir dos dados da Tabela 13, foram levantados os valores que correspondem aos limites do intervalo de condutividades térmicas do nanofluido definido pelo conjunto de modelos apresentados. Estes valores correspondem a um limite inferior definido pelos modelos de Jeffrey e Yu e Choi de 0,64 W/m.K e a um limite superior definido pelo modelo de Nan de $0,73 \mathrm{~W} / \mathrm{m} . \mathrm{K}$.

Estes valores de condutividade térmica foram utilizados para o cálculo da condutividade térmica equivalente aplicando a Equação [8]. Assim, obteve-se um intervalo correspondente entre $1,70 \mathrm{~W} / \mathrm{m} . \mathrm{K}$ e 1,94 W/m.K para a condutividade térmica efetivamente aplicada à região WICK. Estes valores são avaliados em comparação com a condutividade térmica efetiva deste mesmo tubo de calor contendo somente água, cujo valor definido pela Equação [8] é de 1,67 W/m.K

De forma semelhante, os valores da viscosidade absoluta deste nanofluido foram definidos através dos modelos apresentados na revisão bibliográfica e podem ser observados na Tab. 14 em comparação com a viscosidade absoluta da água pura.

Tabela 14. Viscosidade absoluta do nanofluido contendo nanotubos de carbono do estudo de Liu e Lu (2009) e de fluido comparativo

\begin{tabular}{cccc}
\hline Fluido & Correlação & Equação & Viscosidade (Pa.s) \\
\hline Água pura & & & $8,90 \mathrm{E}-04$ \\
\hline & Einstein & {$[26]$} & $9,04 \mathrm{E}-04$ \\
\cline { 2 - 4 } & Nielsen & {$[27]$} & $9,04 \mathrm{E}-04$ \\
\cline { 2 - 4 } & Batchelor & {$[28]$} & $9,04 \mathrm{E}-04$ \\
\cline { 2 - 4 } Nanofluido & Brinkman & {$[29]$} & $9,04 \mathrm{E}-04$ \\
\cline { 2 - 4 } & Nguyen & {$[30]$} & $1,52 \mathrm{E}-03$ \\
\cline { 2 - 4 } & Pak e Cho & {$[31]$} & $1,12 \mathrm{E}-03$ \\
\cline { 2 - 4 } & Krieger e Dougherty & {$[32]$} & $9,05 \mathrm{E}-04$ \\
\cline { 2 - 4 } & Maron e Pierce & {$[33]$} & $1,30 \mathrm{E}-03$ \\
\cline { 2 - 4 } & Brenner e Condiff & {$[34] \mathrm{e} \mathrm{[35]}$} & $1,10 \mathrm{E}-03$ \\
\hline
\end{tabular}

A partir dos dados da Tabela 14, foram levantados os valores que correspondem aos limites do intervalo de viscosidades absolutas do nanofluido definido pelo conjunto de modelos apresentados. Estes valores correspondem a um limite inferior definido pelos modelos de Einstein, Nielsen, Batchelor e Brinkman de 9,04.10-4 Pa.s e a um limite 
superior definido pelo modelo de Nguyen de 1,52.10-3 Pa.s. Estes valores são avaliados em comparação com a viscosidade absoluta da água.

Por fim, os valores da massa específica e calor específico são definidos neste domínio através das equações [25] e [38], referentes aos modelos de Pak e Cho (1998) e O’Hanley(2012), e assumem os seguintes valores:

$$
\begin{aligned}
& -\rho_{n f}=999,13 \mathrm{~kg} / \mathrm{m}^{3} \\
& -c_{p, n f}=4159,69 \mathrm{~J} / \mathrm{kg} . \mathrm{K}
\end{aligned}
$$

Estes valores são avaliados em comparação com a densidade e o calor específico da água, cujos valores são:

$$
\begin{aligned}
& -\rho_{H 2 O}=997 \mathrm{~kg} / \mathrm{m}^{3} ; \\
& -c_{p, H 2 O}=4181,7 \mathrm{~J} / \mathrm{kg} . \mathrm{K} .
\end{aligned}
$$

Em seguida, de forma análoga à realizada no modelo computacional do tubo de calor de Zerbini (1984), a definição dos valores referentes às condições de contorno aplicadas ao modelo definidos pelas Tabs. 9 a 12 pode ser realizada utilizando os parâmetros definidos para o tubo de calor de Liu e Lu (2009) e as dimensões da Tab. 5. Assim, os valores das condições de contorno aplicadas ao modelo computacional do tubo de calor de Liu e Lu (2009) podem ser observados nas tabelas 15 a 18.

Tabela 15. Condições de contorno térmicas adotadas para as interações com meio externo adotadas para o trabalho de Liu e Lu (2009)

\begin{tabular}{ccc}
\hline \multirow{2}{*}{ Potência térmica } & \multicolumn{2}{c}{ Potência equivalente } \\
\cline { 2 - 3 } & Seção do evaporador & Seção do condensador \\
\hline $10 \mathrm{~W}$ & $7957,7 \mathrm{~W} / \mathrm{m}^{2}$ & $-5305,2 \mathrm{~W} / \mathrm{m}^{2}$ \\
\hline $40 \mathrm{~W}$ & $31831 \mathrm{~W} / \mathrm{m}^{2}$ & $-21221 \mathrm{~W} / \mathrm{m}^{2}$ \\
\hline $70 \mathrm{~W}$ & $55704 \mathrm{~W} / \mathrm{m}^{2}$ & $-37136 \mathrm{~W} / \mathrm{m}^{2}$ \\
\hline $80 \mathrm{~W}$ & $63662 \mathrm{~W} / \mathrm{m}^{2}$ & $-42441 \mathrm{~W} / \mathrm{m}^{2}$ \\
\hline
\end{tabular}


Tabela 16. Parâmetros $\eta$ provenientes da análise de balanço de energia adotados para o trabalho de Liu e Lu (2009)

\begin{tabular}{cc}
\hline Potência térmica & Parâmetro $\eta$ \\
\hline $10 \mathrm{~W}$ & 0,99 \\
\hline $40 \mathrm{~W}$ & 0,985 \\
\hline $70 \mathrm{~W}$ & 0,979 \\
\hline $80 \mathrm{~W}$ & 0,968 \\
\hline
\end{tabular}

Tabela 17. Condições de contorno térmicas adotadas para os processos de evaporação e condensação para o trabalho de Liu e Lu (2009)

\begin{tabular}{ccc}
\hline Potência térmica & Seção & Termo fonte inserido \\
\hline \multirow{2}{*}{$10 \mathrm{~W}$} & Evaporador & $-3,94.10^{7} \mathrm{~W} / \mathrm{m}^{3}$ \\
\cline { 2 - 3 } & Condensador & $2,63.10^{7} \mathrm{~W} / \mathrm{m}^{3}$ \\
\hline \multirow{2}{*}{$40 \mathrm{~W}$} & Evaporador & $-1,57.10^{8} \mathrm{~W} / \mathrm{m}^{3}$ \\
\cline { 2 - 3 } & Condensador & $1,05.10^{8} \mathrm{~W} / \mathrm{m}^{3}$ \\
\hline \multirow{2}{*}{$70 \mathrm{~W}$} & Evaporador & $-2,73.10^{8} \mathrm{~W} / \mathrm{m}^{3}$ \\
\hline \multirow{2}{*}{$80 \mathrm{~W}$} & Condensador & $1,82.10^{8} \mathrm{~W} / \mathrm{m}^{3}$ \\
\hline & Evaporador & $-3,08.10^{8} \mathrm{~W} / \mathrm{m}^{3}$ \\
\hline & Condensador & $2,05.10^{8} \mathrm{~W} / \mathrm{m}^{3}$ \\
\hline
\end{tabular}


Tabela 18. Condições de contorno hidrodinâmicas adotadas para os processos de evaporação e condensação para o trabalho de Liu e Lu (2009)

\begin{tabular}{|c|c|c|c|}
\hline Potência térmica & Região & Seção & Termo fonte inserido \\
\hline \multirow{4}{*}{$10 \mathrm{~W}$} & \multirow{2}{*}{ Câmara de Vapor } & Evaporador & $0,0027 \mathrm{~kg} /\left(\mathrm{m}^{2} \mathrm{~s}\right)$ \\
\hline & & Condensador & $-0,0033 \mathrm{~kg} /\left(\mathrm{m}^{2} \mathrm{~s}\right)$ \\
\hline & \multirow{2}{*}{ Matriz Porosa } & Evaporador & $-0,0027 \mathrm{~kg} /\left(\mathrm{m}^{2} \mathrm{~s}\right)$ \\
\hline & & Condensador & $0,0033 \mathrm{~kg} /\left(\mathrm{m}^{2} \mathrm{~s}\right)$ \\
\hline \multirow{4}{*}{$40 \mathrm{~W}$} & \multirow{2}{*}{ Câmara de Vapor } & Evaporador & $0,0130 \mathrm{~kg} /\left(\mathrm{m}^{2} \mathrm{~s}\right)$ \\
\hline & & Condensador & $-0,0087 \mathrm{~kg} /\left(\mathrm{m}^{2} \mathrm{~s}\right)$ \\
\hline & \multirow{2}{*}{ Matriz Porosa } & Evaporador & $-0,0130 \mathrm{~kg} /\left(\mathrm{m}^{2} \mathrm{~s}\right)$ \\
\hline & & Condensador & $0,0087 \mathrm{~kg} /\left(\mathrm{m}^{2} \mathrm{~s}\right)$ \\
\hline \multirow{4}{*}{$70 \mathrm{~W}$} & \multirow{2}{*}{ Câmara de Vapor } & Evaporador & $0,0227 \mathrm{~kg} /\left(\mathrm{m}^{2} \mathrm{~s}\right)$ \\
\hline & & Condensador & $-0,0151 \mathrm{~kg} /\left(\mathrm{m}^{2} \mathrm{~s}\right)$ \\
\hline & \multirow{2}{*}{ Matriz Porosa } & Evaporador & $-0,0227 \mathrm{~kg} /\left(\mathrm{m}^{2} \mathrm{~s}\right)$ \\
\hline & & Condensador & $0,0151 \mathrm{~kg} /\left(\mathrm{m}^{2} \mathrm{~s}\right)$ \\
\hline \multirow{4}{*}{$80 \mathrm{~W}$} & \multirow{2}{*}{ Câmara de Vapor } & Evaporador & $0,0256 \mathrm{~kg} /\left(\mathrm{m}^{2} \mathrm{~s}\right)$ \\
\hline & & Condensador & $-0,0171 \mathrm{~kg} /\left(\mathrm{m}^{2} \mathrm{~s}\right)$ \\
\hline & \multirow{2}{*}{ Matriz Porosa } & Evaporador & $-0,0256 \mathrm{~kg} /\left(\mathrm{m}^{2} \mathrm{~s}\right)$ \\
\hline & & Condensador & $0,0171 \mathrm{~kg} /\left(\mathrm{m}^{2} \mathrm{~s}\right)$ \\
\hline
\end{tabular}

\subsubsection{Putra et al. (2012)}

Por fim, o último caso estudado compreende um tubo de calor contendo um nanofluido composto por etilenoglicol e nanopartículas de óxido de zinco ( $\mathrm{ZnO}$ ). Neste caso, utilizou-se o tubo de calor do trabalho de Putra et al. (2012). Esta modelagem é comparada diretamente com os resultados presentes em Putra et al. (2012) para este mesmo tubo de calor contendo somente água e somente etilenoglicol.

A malha computacional utilizada para a construção deste modelo consiste na malha representada na Figura 33. As condições iniciais adotadas especificamente para este modelo são:

- $\quad$ Região STEAM

- Nesta região, o material é definido de acordo com o fluido de trabalho utilizado: 
- Para água, este material é definido como vapor d'agua, tratado como um gás real representado pelo modelo padrão de Redlich-Kwong como vapor seco nas condições de saturação (H2ORK);

- Para etilenoglicol ou nanofluidos contendo etilenoglicol como fluidobase, este material é definido como sendo vapor de etilenoglicol, cujas características são inseridas em um material customizado do tipo gás contendo as seguintes propriedades:

$$
\begin{array}{ll}
\circ & \rho_{E G, v}=2,573 \mathrm{~kg} / \mathrm{m}^{3} \\
\circ & c_{p, E G, v}=1410 \mathrm{~J} / \mathrm{kg} \cdot \mathrm{K} \\
\circ & \mu_{E G, v}=1,304.10^{-5} \mathrm{~Pa} \cdot \mathrm{S} \\
\circ & k_{E G, v}=0,0227 \mathrm{~W} / \mathrm{m} \cdot \mathrm{K} \\
\circ & T_{r e f}=471 \mathrm{~K} \\
\circ & P_{r e f}=100 \mathrm{kPa}
\end{array}
$$

- $\quad$ Região WICK

- Material definido como líquido e customizado por meio da alteração das propriedades físicas;

- $\quad$ Permeabilidade aplicada ao termo fonte definida como 8,558.10-11 $\mathrm{m}^{2}$.

Adicionalmente, o valor da condutividade térmica da região WICK é definido através da Equação [8], e considera-se que o material sólido que compõe a matriz porosa é o aço inoxidável, cujas propriedades já foram definidas, e que a porosidade possui valor igual a 0,686, tal como definido anteriormente. No entanto, a Equação [8] requer a definição do valor específico da condutividade térmica deste nanofluido contendo etilenoglicol, cujo valor varia de acordo com a correlação utilizada para sua determinação.

O nanofluido avaliado do estudo de Putra et. al (2012) consiste em um nanofluido contendo etilenoglicol e nanopartículas de óxido de zinco a uma concentração volumétrica de 5\%. A Tabela 19 mostra os valores da condutividade térmica obtidos para esta configuração através das correlações levantadas na revisão bibliográfica, em comparação com as condutividades térmicas da água e do etilenoglicol puros: 
Tabela 19. Condutividade térmica do nanofluido contendo etilenoglicol e $\mathrm{ZnO}$ do estudo de Putra et al. (2012) e de fluidos comparativos

\begin{tabular}{|c|c|c|c|}
\hline Fluido & Correlação & Equações & Condutividade $(\mathrm{W} / \mathrm{m} . \mathrm{K})$ \\
\hline Água pura & & & 0,63 \\
\hline Etilenoglicol & & & 0,26 \\
\hline \multirow{7}{*}{ Nanofluido } & Hamilton - Crosser & [39] e [40] & 0,33 \\
\hline & Wasp & {$[53]$} & 0,30 \\
\hline & Jeffrey & [48] a [50] & 0,30 \\
\hline & Chen et al. & [54] a [56] & 0,49 \\
\hline & Murshed & [57] e [58] & 0,31 \\
\hline & Yu e Choi & [59] & 0,28 \\
\hline & Turian & {$[60]$} & 0,34 \\
\hline
\end{tabular}

A partir dos dados da Tab. 19, foram levantados os valores que correspondem aos limites do intervalo de condutividades térmicas do nanofluido definido pelo conjunto de correlações apresentado. Estes valores correspondem a um limite inferior definido pelo modelo de $\mathrm{Yu}$ e Choi de $0,28 \mathrm{~W} / \mathrm{m} . \mathrm{K}$ e a um limite superior definido pelo modelo de Chen et al. de $0,49 \mathrm{~W} / \mathrm{m} . \mathrm{K}$.

Estes valores de condutividade térmica foram utilizados para o cálculo da condutividade térmica equivalente aplicando a Equação [8]. Assim, obteve-se um intervalo correspondente entre $0,76 \mathrm{~W} / \mathrm{m} . \mathrm{K}$ e $1,30 \mathrm{~W} / \mathrm{m} . \mathrm{K}$ para a condutividade térmica efetivamente aplicada à região WICK. Estes valores são avaliados em comparação com a condutividade térmica efetiva deste mesmo tubo de calor contendo somente água, cujo valor definido pela Equação [8] é de 1,67 W/m.K, e em comparação com a condutividade térmica efetiva deste mesmo tubo de calor contendo somente etilenoglicol, cujo valor definido pela Equação [8] é de 0,71 W/m.K.

De forma semelhante, os valores da viscosidade absoluta deste nanofluido foram definidos através das correlações apresentadas na revisão bibliográfica e podem ser observados na Tab. 20 em comparação com a viscosidade absoluta da água e com a viscosidade absoluta do etilenoglicol. 
Tabela 20. Viscosidade absoluta do nanofluido contendo etilenoglicol e ZnO do estudo de Putra et. al (2012) e de fluidos comparativos

\begin{tabular}{|c|c|c|c|}
\hline Fluido & Correlação & Equação & Viscosidade (Pa.s) \\
\hline Água pura & & & $8,90 \mathrm{E}-04$ \\
\hline Etilenoglicol & & & $3,68 \mathrm{E}-03$ \\
\hline \multirow{7}{*}{ Nanofluido } & Einstein & {$[26]$} & $4,14 \mathrm{E}-03$ \\
\hline & Nielsen & [27] & 4,39E-03 \\
\hline & Batchelor & [28] & $4,20 \mathrm{E}-03$ \\
\hline & Brinkman & [29] & $4,16 \mathrm{E}-03$ \\
\hline & Pak e Cho & [31] & $1,58 \mathrm{E}-02$ \\
\hline & Chow & {$[51]$} & $6,20 \mathrm{E}-03$ \\
\hline & Krieger e Dougherty & [32] e [52] & $7,43 \mathrm{E}-03$ \\
\hline
\end{tabular}

A partir dos dados da Tabela 20, foram levantados os valores que correspondem aos limites do intervalo de viscosidades absolutas do nanofluido definido pelo conjunto de correlações apresentado. Estes valores correspondem a um limite inferior definido pelo modelo de Einstein de 4,14.10-3 Pa.s e a um limite superior definido pelo modelo de Pak e Cho de 1,58.10-2 Pa.s. Estes valores são avaliados em comparação com a viscosidade absoluta da água e com a viscosidade absoluta do etilenoglicol.

Por fim, os valores da massa específica e calor específico são definidos neste domínio através das equações [25] e [38], referentes aos modelos de Pak e Cho (1998) e O’Hanley(2012), e assumem os seguintes valores:

$$
\begin{aligned}
& -\rho_{n f}=1302,65 \mathrm{~kg} / \mathrm{m}^{3} \\
& -c_{p, n f}=2355,72 \mathrm{~J} / \mathrm{kg} . \mathrm{K}
\end{aligned}
$$

Estes valores são avaliados em comparação com a densidade e o calor específico da água e do etilenoglicol, cujos valores são:

$$
\begin{aligned}
& -\rho_{H 2 O}=997 \mathrm{~kg} / \mathrm{m}^{3} \\
& -c_{p, H 2 O}=4181,7 \mathrm{~J} / \mathrm{kg} \cdot \mathrm{K} \\
& -\rho_{E G, l}=1115,6 \mathrm{~kg} / \mathrm{m}^{3} \\
& -c_{p, E G, l}=2386,5 \mathrm{~J} / \mathrm{kg} \cdot \mathrm{K}
\end{aligned}
$$

Em seguida, de forma análoga à realizada no modelo computacional do tubo de calor de Zerbini (1984), a definição dos valores referentes às condições de contorno 
aplicadas ao modelo definidos pelas tabelas 9 a 12 pode ser realizada utilizando os parâmetros definidos para o tubo de calor de Putra et al. (2012) e as dimensões da Tab. 6. Entretanto, é importante observar que existe uma diferença importante entre o tubo de calor estudado em Putra et al. e os demais tubos de calor.

Esta diferença corresponde à temperatura da extremidade do tubo de calor localizada no final da seção do condensador. No tubo de calor do estudo de Putra et al. (2012), é possível observar que todos os casos estudados apresentam uma convergência nesta posição para uma temperatura de aproximadamente $25{ }^{\circ} \mathrm{C}$.

Este comportamento indica que o experimento foi configurado de tal forma que esta extremidade permaneceu a temperatura de $25{ }^{\circ} \mathrm{C}$, independente da configuração adotada. Desta forma, como não é possível saber com certeza qual condição de contorno corresponde a este comportamento, o presente estudo adotou uma condição de contorno adicional nesta extremidade somente na parede do tubo de calor, de forma a fixar a temperatura desta posição em $25{ }^{\circ} \mathrm{C}$. Isto fez com que um novo balanço de energia tivesse que ser realizado nesta extremidade do tubo de calor, e esta análise foi incluída no apêndice 2 .

Observou-se através desta análise que esta temperatura fixa provoca a extração de cerca de 3,5\% do calor que atinge a seção do condensador. Assim, a condição de contorno referente à extração de calor da seção do condensador para o meio externo for aplicada contendo somente 96,5\% do calor inserido na seção do evaporador (com sinal negativo) de forma a garantir a conservação da energia.

Levando estes fatores em consideração, os valores das condições de contorno aplicadas ao modelo computacional do tubo de calor de Putra et al. (2012) podem ser observados nas Tabelas 21 a 24. É importante destacar que, como a potência térmica aplicada a este tubo de calor é constante em todos os casos estudados deste tubo de calor, a distinção entre os modelos estudados nestas tabelas é feita através do fluido de trabalho. 
Tabela 21. Condições de contorno térmicas adotadas para as interações com meio externo para o trabalho de Putra et al. (2012)

\begin{tabular}{ccc}
\hline \multirow{2}{*}{ Fluido de trabalho } & \multicolumn{2}{c}{ Potência equivalente } \\
\cline { 2 - 3 } & Seção do evaporador & Seção do condensador \\
\hline Água & $38396 \mathrm{~W} / \mathrm{m}^{2}$ & $-39789 \mathrm{~W} / \mathrm{m}^{2}$ \\
\hline Etilenoglicol (EG) & $38396 \mathrm{~W} / \mathrm{m}^{2}$ & $-39789 \mathrm{~W} / \mathrm{m}^{2}$ \\
\hline Nanofluido EG + ZnO & $38396 \mathrm{~W} / \mathrm{m}^{2}$ & $-39789 \mathrm{~W} / \mathrm{m}^{2}$ \\
\hline
\end{tabular}

Tabela 22. Parâmetros $\eta$ provenientes da análise de balanço de energia adotados para o trabalho de Putra et al. (2012)

\begin{tabular}{cc}
\hline Fluido de trabalho & Parâmetro $\eta$ \\
\hline Água & 0,995 \\
\hline Etilenoglicol (EG) & 0,995 \\
\hline Nanofluido EG + ZnO & 0,995 \\
\hline
\end{tabular}

Tabela 23. Condições de contorno térmicas adotadas para os processos de evaporação e condensação no trabalho de Putra et al. (2012)

\begin{tabular}{ccc}
\hline Fluido de trabalho & Seção & Termo fonte inserido \\
\hline \multirow{2}{*}{ Água } & Evaporador & $-1,98.10^{8} \mathrm{~W} / \mathrm{m}^{3}$ \\
\cline { 2 - 3 } & Condensador & $1,98.10^{8} \mathrm{~W} / \mathrm{m}^{3}$ \\
\hline \multirow{2}{*}{ Etilenoglicol (EG) } & Evaporador & $-1,98.10^{8} \mathrm{~W} / \mathrm{m}^{3}$ \\
\cline { 2 - 3 } & Condensador & $1,98.10^{8} \mathrm{~W} / \mathrm{m}^{3}$ \\
\hline \multirow{2}{*}{ Nanofluido EG $+\mathrm{ZnO}$} & Evaporador & $-1,98.10^{8} \mathrm{~W} / \mathrm{m}^{3}$ \\
\cline { 2 - 3 } & Condensador & $1,98.10^{8} \mathrm{~W} / \mathrm{m}^{3}$ \\
\hline
\end{tabular}


Tabela 24. Condições de contorno hidrodinâmicas adotadas nos processos de evaporação e condensação para o trabalho de Putra et al. (2012)

\begin{tabular}{|c|c|c|c|}
\hline Fluido de trabalho & Região & Seção & Termo fonte inserido \\
\hline \multirow{4}{*}{ Água } & \multirow{2}{*}{ Câmara de Vapor } & Evaporador & $0,0097 \mathrm{~kg} /\left(\mathrm{m}^{2} \mathrm{~s}\right)$ \\
\hline & & Condensador & $-0,0097 \mathrm{~kg} /\left(\mathrm{m}^{2} \mathrm{~s}\right)$ \\
\hline & \multirow{2}{*}{ Matriz Porosa } & Evaporador & $-0,0097 \mathrm{~kg} /\left(\mathrm{m}^{2} \mathrm{~s}\right)$ \\
\hline & & Condensador & $0,0097 \mathrm{~kg} /\left(\mathrm{m}^{2} \mathrm{~s}\right)$ \\
\hline \multirow{4}{*}{ Etilenoglicol (EG) } & \multirow{2}{*}{ Câmara de Vapor } & Evaporador & $0,0278 \mathrm{~kg} /\left(\mathrm{m}^{2} \mathrm{~s}\right)$ \\
\hline & & Condensador & $-0,0278 \mathrm{~kg} /\left(\mathrm{m}^{2} \mathrm{~s}\right)$ \\
\hline & \multirow{2}{*}{ Matriz Porosa } & Evaporador & $-0,0278 \mathrm{~kg} /\left(\mathrm{m}^{2} \mathrm{~s}\right)$ \\
\hline & & Condensador & $0,0278 \mathrm{~kg} /\left(\mathrm{m}^{2} \mathrm{~s}\right)$ \\
\hline \multirow{4}{*}{ Nanofluido EG + ZnO } & \multirow{2}{*}{ Câmara de Vapor } & Evaporador & $0,0278 \mathrm{~kg} /\left(\mathrm{m}^{2} \mathrm{~s}\right)$ \\
\hline & & Condensador & $-0,0278 \mathrm{~kg} /\left(\mathrm{m}^{2} \mathrm{~s}\right)$ \\
\hline & \multirow{2}{*}{ Matriz Porosa } & Evaporador & $-0,0278 \mathrm{~kg} /\left(\mathrm{m}^{2} \mathrm{~s}\right)$ \\
\hline & & Condensador & $0,0278 \mathrm{~kg} /\left(\mathrm{m}^{2} \mathrm{~s}\right)$ \\
\hline
\end{tabular}




\section{RESULTADOS}

\subsection{Validação preliminar do modelo computacional para água e etilenoglicol como fluidos de trabalho}

\subsubsection{Zerbini (1984)}

Para o tubo de calor de Zerbini, os perfis de temperaturas obtidos através das simulações computacionais na parede deste tubo de calor podem ser observados em comparação com os resultados experimentais de Zerbini (1984) nas Figuras 37 a 39. Nesses perfis a posição Y no tubo de calor parte do zero na extremidade da seção do evaporador

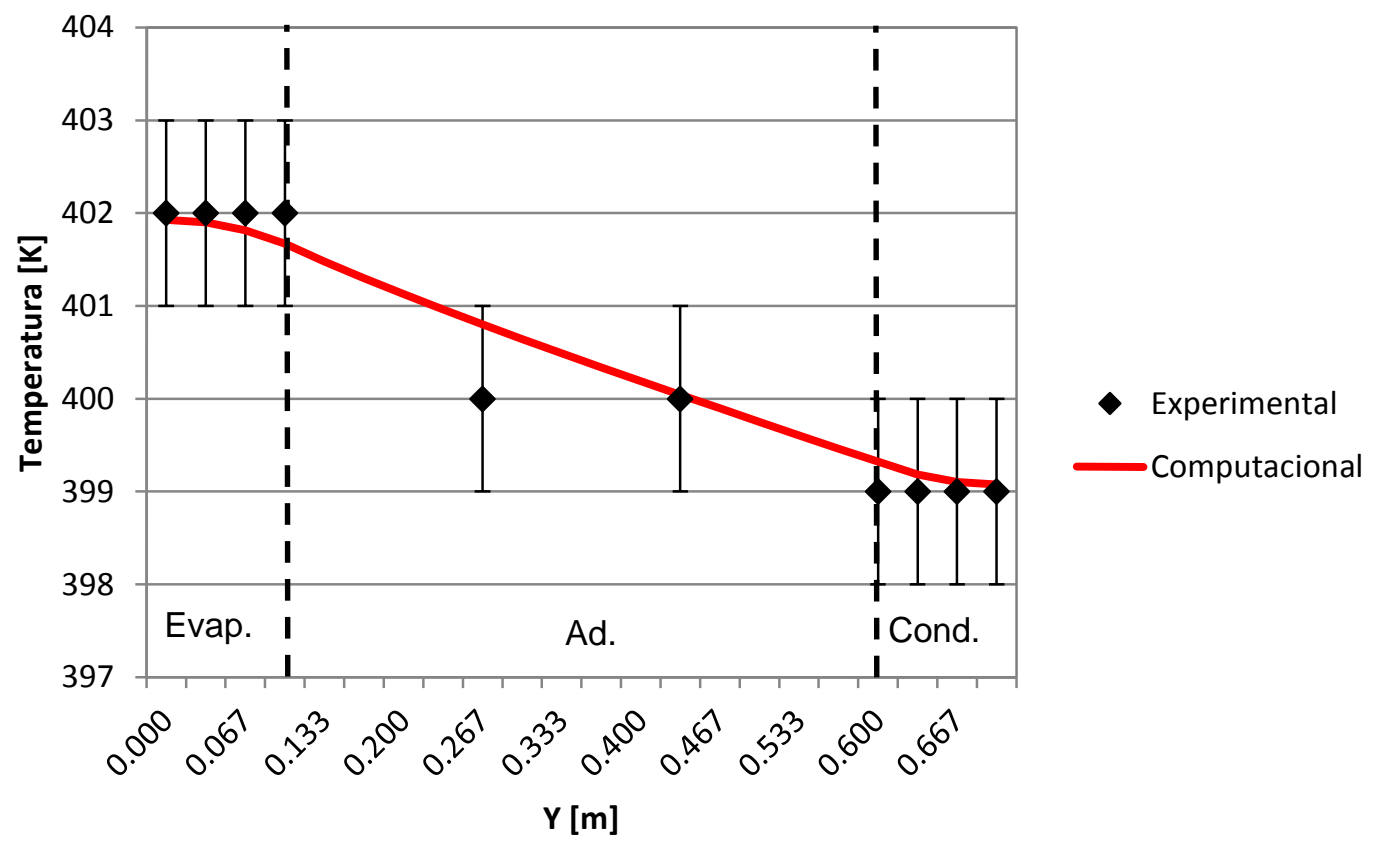

Figura 37. Comparação entre o perfil de temperaturas obtido experimentalmente no trabalho de Zerbini (1984) e o perfil de temperaturas obtido computacionalmente pelo CFX para $\dot{Q}=24 \mathrm{~W}$ 


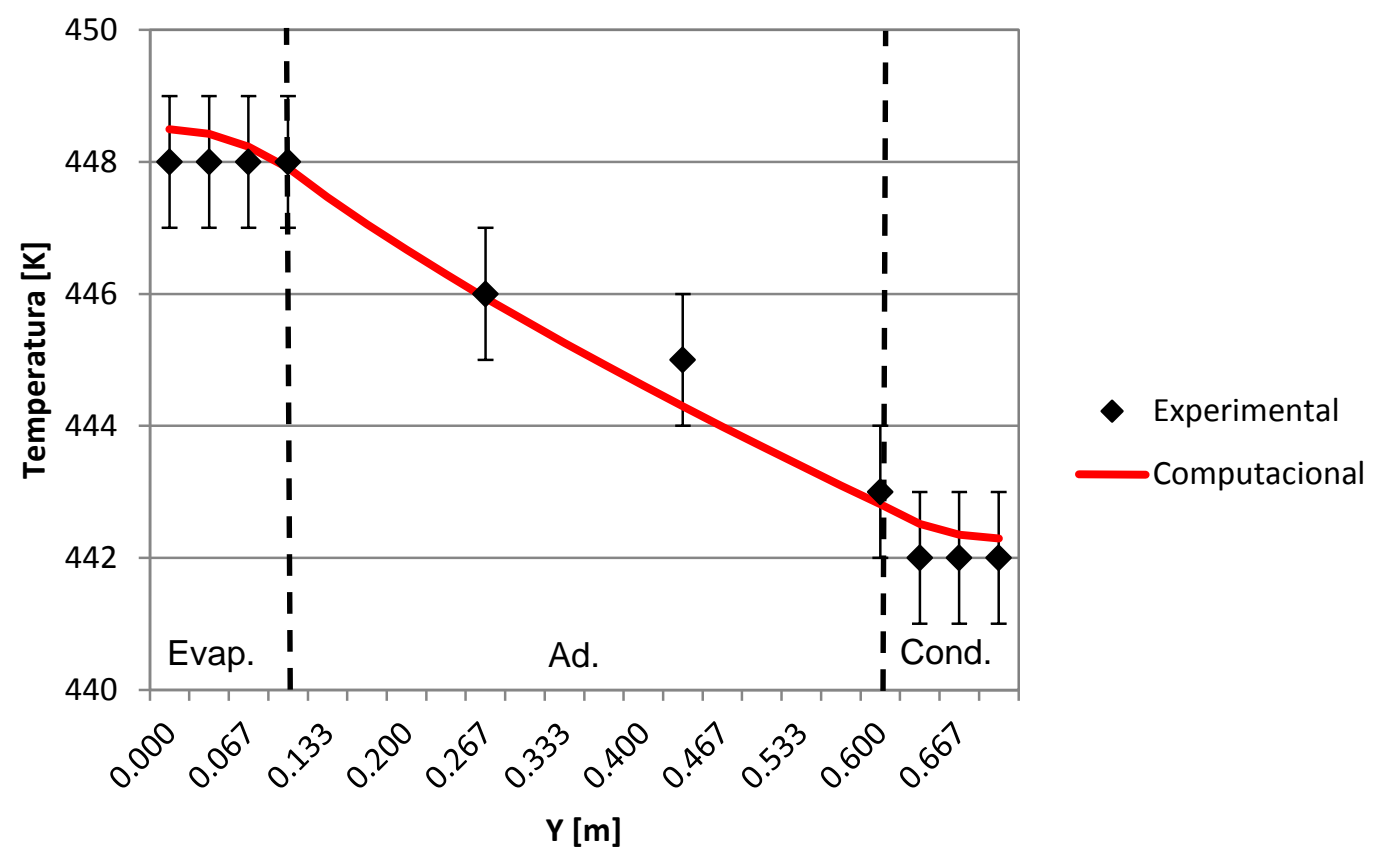

Figura 38. Comparação entre o perfil de temperaturas obtido experimentalmente no trabalho de Zerbini (1984) e o perfil de temperaturas obtido computacionalmente pelo CFX para $\dot{Q}=37 W$

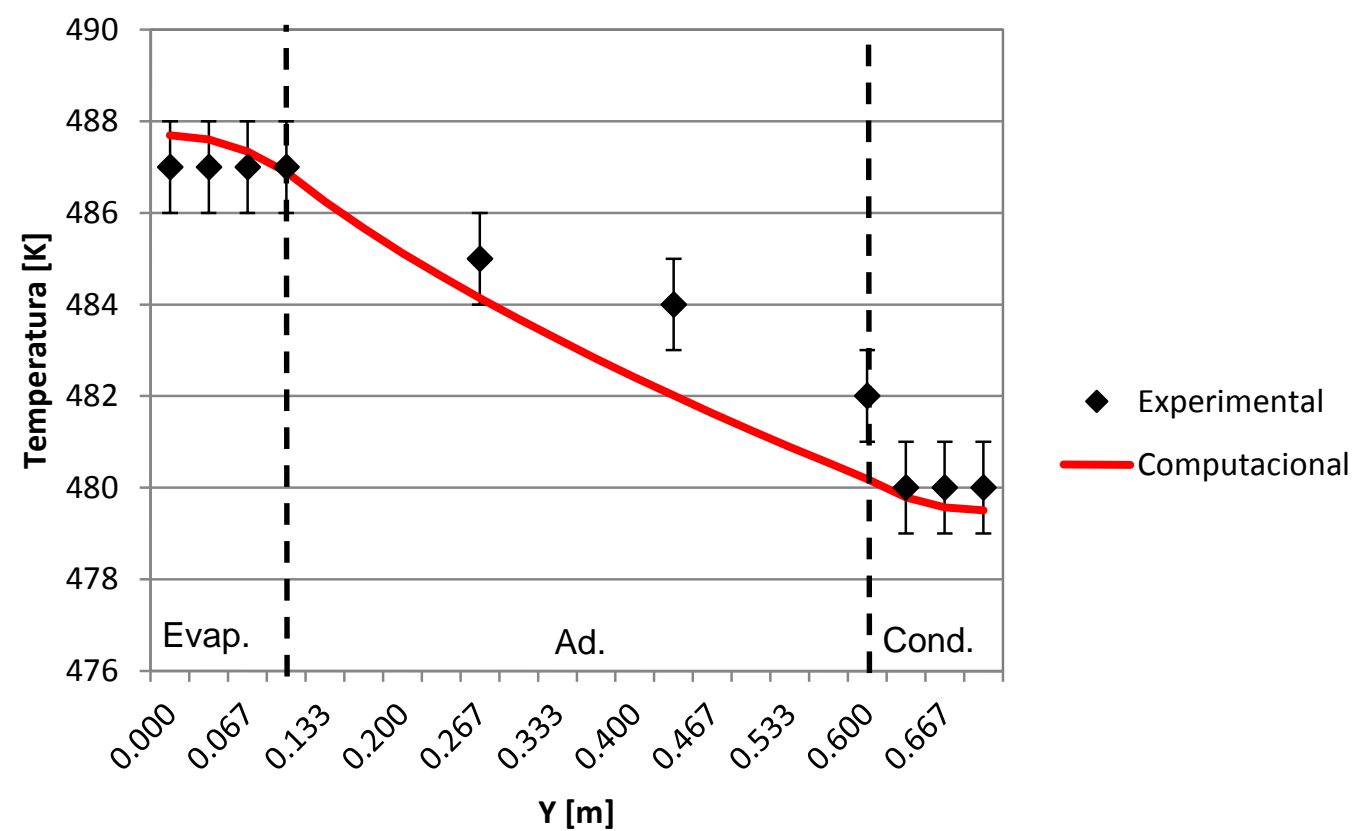

Figura 39. Comparação entre o perfil de temperaturas obtido experimentalmente no trabalho de Zerbini (1984) e o perfil de temperaturas obtido computacionalmente pelo CFX para $\dot{Q}=49 \mathrm{~W}$ 
Pode-se observar que, com exceção de dois pontos pertencentes ao caso contendo uma potência térmica inserida de $49 \mathrm{~W}$, todos os pontos encontrados na simulação computacional encontram-se dentro da faixa de erros estabelecida pelo autor. Além disso, todos os perfis obtidos computacionalmente apresentam uma compatibilidade muito alta nas extremidades das seções do evaporador e do condensador, distanciando-se no máximo em $0,7 \mathrm{~K}$ da temperatura obtida experimentalmente nestas seções.

Observa-se também que o aumento da potência térmica inserida no tubo de calor tem por consequência o aumento da temperatura média do tubo de calor em cerca de 40 $\mathrm{K}$ para cada aumento de 12-13 W realizado na potência térmica.

Adicionalmente, pode-se calcular os valores da resistência térmica deste tubo de calor para cada um dos casos indicados utilizando a Equação [61]. Estes valores podem ser observados na Tabela 25.

Tabela 25. Resistências térmicas obtidas experimentalmente e computacionalmente para o tubo de calor de Zerbini (1984)

\begin{tabular}{cccc}
\hline & \multicolumn{3}{c}{ Resistência térmica (K/W) } \\
\hline Potência térmica & Experimental & Computacional & Erro percentual \\
\hline $24 \mathrm{~W}$ & 0,125 & 0,111 & $-11,2 \%$ \\
\hline $37 \mathrm{~W}$ & 0,155 & 0,156 & $+0,7 \%$ \\
\hline $49 \mathrm{~W}$ & 0,133 & 0,156 & $+17,3 \%$ \\
\hline
\end{tabular}

Os resultados apresentam boa concordância entre si em termos absolutos, com valores nas mesmas ordens de grandeza e variando a resistência térmica de um mesmo tubo de calor nas mesmas condições em, no máximo, 0,023 K/W, o que corresponde a aproximadamente uma ordem de grandeza abaixo dos valores determinados experimentalmente para estas resistências. Além disso, observa-se que o erro percentual absoluto é menos significativo para uma potência intermediária do que nas extremidades do intervalo de potências térmicas estudado. 


\subsubsection{Liu e Lu (2009)}

De forma análoga, os perfis de temperaturas na parede do tubo de calor de Liu e Lu (2009) contendo somente água, obtidos através das simulações computacionais, podem ser observados em comparação com os resultados experimentais de Liu e Lu (2009) na Figura 40. Os valores das incertezas associadas às temperaturas medidas experimentalmente reportados pelos autores $\left(0,2{ }^{\circ} \mathrm{C}\right)$ não foram introduzidos nesta figura por serem pouco significativos quando comparados ao fundo de escala da figura.

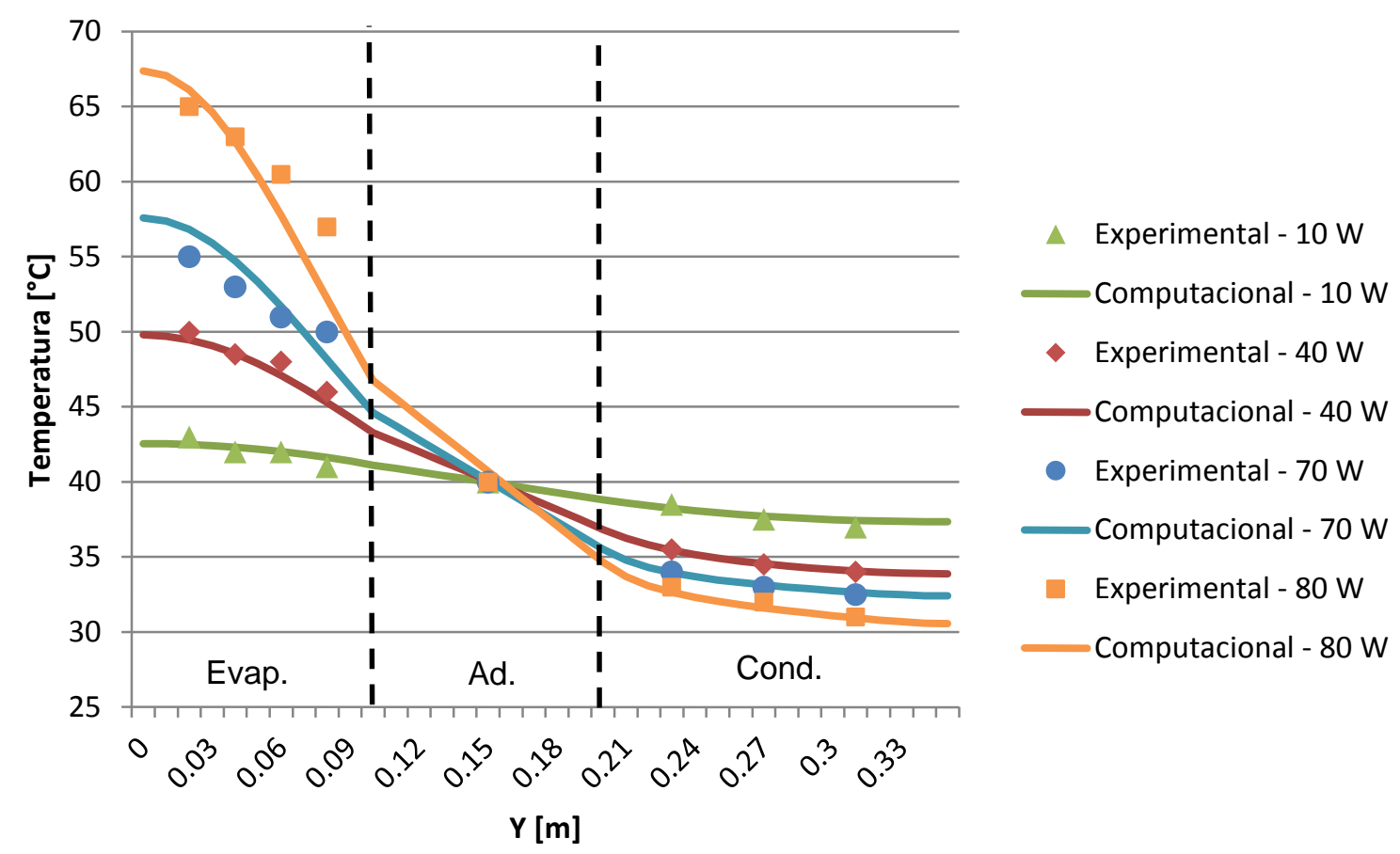

Figura 40. Comparação entre os perfis de temperaturas obtidos experimentalmente no trabalho de Liu e Lu (2009) e os perfis de temperaturas obtidos computacionalmente pelo CFX para diferentes potências térmicas inseridas na seção do evaporador

A figura 40 mostra que o comportamento térmico obtido nas simulações computacionais para a parede do tubo de calor apresenta boa concordância visualmente com os dados experimentais em todas as seções, exceto na transição entre a seção do evaporador e a seção adiabática.

Adicionalmente, é possível observar comparativamente na Tabela 26 os valores computacionais obtidos nos mesmos pontos investigados experimentalmente por Liu e Lu (2009). 
Tabela 26. Comparação entre os perfis de temperaturas do tubo de calor de Liu e Lu (2009) contendo água para diferentes potências térmicas inseridas

\begin{tabular}{|c|c|c|c|c|c|c|}
\hline & \multicolumn{6}{|c|}{ Temperatura $\left({ }^{\circ} \mathrm{C}\right)$} \\
\hline & \multicolumn{3}{|c|}{$10 \mathrm{~W}$} & \multicolumn{3}{|c|}{$40 W$} \\
\hline $\mathrm{Y}(\mathrm{m})$ & Exp. & Comp. & $\Delta \mathrm{T}$ & Exp. & Comp. & $\Delta \mathrm{T}$ \\
\hline 0,02 & $43,0 \pm 0,2$ & 42,5 & $+0,5$ & $50,0 \pm 0,2$ & 49,5 & $-0,5$ \\
\hline 0,04 & $42,0 \pm 0,2$ & 42,3 & $+0,3$ & $48,5 \pm 0,2$ & 48,5 & 0,0 \\
\hline 0,06 & $42,0 \pm 0,2$ & 42,0 & 0,0 & $48,0 \pm 0,2$ & 47,1 & $-0,9$ \\
\hline 0,08 & $41,0 \pm 0,2$ & 41,6 & $+0,6$ & $46,0 \pm 0,2$ & 45,3 & $-0,7$ \\
\hline 0,15 & $40,0 \pm 0,2$ & 40,0 & 0,0 & $40,0 \pm 0,2$ & 40,1 & $+0,1$ \\
\hline 0,23 & $38,5 \pm 0,2$ & 38,2 & $-0,3$ & $35,5 \pm 0,2$ & 35,5 & 0,0 \\
\hline 0,27 & $37,5 \pm 0,2$ & 37,7 & $+0,2$ & $34,5 \pm 0,2$ & 34,5 & 0,0 \\
\hline \multirow[t]{3}{*}{0,31} & $37,0 \pm 0,2$ & 37,4 & $+0,4$ & $34,0 \pm 0,2$ & 34,1 & $+0,1$ \\
\hline & \multicolumn{3}{|c|}{$70 \mathrm{~W}$} & \multicolumn{3}{|c|}{$80 \mathrm{~W}$} \\
\hline & Exp. & Comp. & $\Delta \mathrm{T}$ & Exp. & Comp. & $\Delta \mathrm{T}$ \\
\hline 0,02 & $55,0 \pm 0,2$ & 56,8 & $+1,8$ & $65,0 \pm 0,2$ & 66,1 & $+1,1$ \\
\hline 0,04 & $53,0 \pm 0,2$ & 54,7 & $+1,7$ & $63,0 \pm 0,2$ & 62,7 & $-0,3$ \\
\hline 0,06 & $51,0 \pm 0,2$ & 51,7 & $+0,7$ & $60,5 \pm 0,2$ & 57,7 & $-2,8$ \\
\hline 0,08 & $50,0 \pm 0,2$ & 48,2 & $-1,8$ & $57,0 \pm 0,2$ & 52,2 & $-4,8$ \\
\hline 0,15 & $40,0 \pm 0,2$ & 40,1 & $+0,1$ & $40,0 \pm 0,2$ & 40,7 & $+0,7$ \\
\hline 0,23 & $34,0 \pm 0,2$ & 33,9 & $-0,1$ & $33,0 \pm 0,2$ & 32,6 & $-0,4$ \\
\hline 0,27 & $33,0 \pm 0,2$ & 33,1 & $+0,1$ & $32,0 \pm 0,2$ & 31,6 & $-0,4$ \\
\hline 0,31 & $32,5 \pm 0,2$ & 32,6 & $+0,1$ & $31,0 \pm 0,2$ & 30,9 & $-0,1$ \\
\hline
\end{tabular}

Os resultados obtidos mostram uma razoável adequação dos valores computacionais com os resultados experimentais tanto do ponto de vista qualitativo quanto quantitativo, visto que os perfis de temperatura apresentam comportamentos tais como esperado e que a média do valor absoluto das diferenças obtidas entre os resultados computacionais e os dados experimentais varia entre $0,3{ }^{\circ} \mathrm{C}$ para o melhor 
caso $(10 \mathrm{~W})$ e $1,3^{\circ} \mathrm{C}$ para o pior caso $(80 \mathrm{~W})$. Pode-se observar também que o nível de concordância obtido entre os dados experimentais e os resultados computacionais cai com o aumento da potência térmica inserida no condensador.

Adicionalmente, é possível calcular os valores da resistência térmica deste tubo de calor para cada um dos casos indicados utilizando a Equação [61]. Estes valores podem ser observados na Tabela 27.

Tabela 27. Resistências térmicas obtidas experimentalmente e computacionalmente para o tubo de calor de Liu e Lu (2009) contendo água

\begin{tabular}{cccc}
\hline \multirow{2}{*}{ Potência térmica } & \multicolumn{3}{c}{ Resistência térmica $\left({ }^{\circ} \mathrm{C} / \mathrm{W}\right)$} \\
\cline { 2 - 4 } & Experimental & Computacional & Erro Percentual \\
\hline $10 \mathrm{~W}$ & 0,433 & 0,422 & $-2,5 \%$ \\
\hline $40 \mathrm{~W}$ & 0,336 & 0,314 & $-6,5 \%$ \\
\hline $70 \mathrm{~W}$ & 0,273 & 0,273 & 0 \\
\hline $80 \mathrm{~W}$ & 0,367 & 0,340 & $-7,4 \%$ \\
\hline
\end{tabular}

Os resultados apresentam boa concordância em termos absolutos, com valores nas mesmas ordens de grandeza e variando a resistência térmica de um mesmo tubo de calor nas mesmas condições em, no máximo, $0,027{ }^{\circ} \mathrm{C} / \mathrm{W}$, o que corresponde a aproximadamente uma ordem de grandeza abaixo dos valores determinados experimentalmente para estas resistências. Além disso, observa-se que o comportamento obtido para a resistência térmica do tubo de calor contendo água corresponde ao comportamento determinado para a resistência térmica deste mesmo tubo de calor por Liu e Lu (2009) na Figura 14, e que novamente o erro percentual absoluto é menos significativo para uma potência intermediária do que nas extremidades do intervalo de potências térmicas estudado.

\subsubsection{Putra et al. (2012)}

Por fim, o perfil de temperaturas na parede do tubo de calor de Putra et al. (2012) contendo somente água, obtido através das simulações computacionais, pode ser 
observado em comparação com os resultados experimentais de Putra et al. (2012) na Fig. 41, para uma potência equivalente a $30 \mathrm{~W}$ sendo inserida na seção do evaporador.

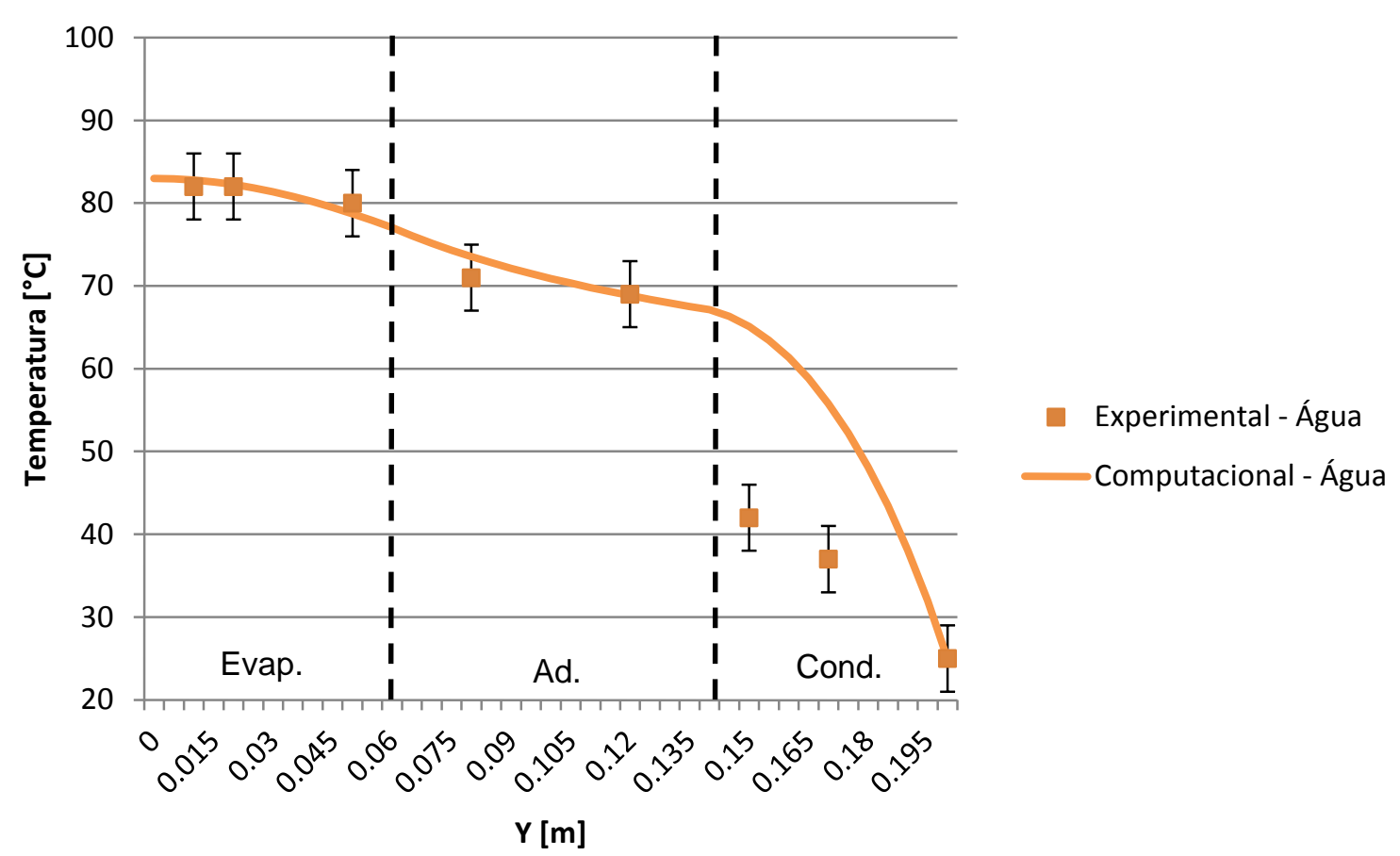

Figura 41. Comparação entre o perfil de temperaturas obtido experimentalmente no trabalho de Putra et al. (2012) e o perfil de temperaturas obtido computacionalmente pelo CFX para água como fluido de trabalho

A partir da Fig. 41, pode-se perceber nitidamente que existe uma diferença significativa entre os dados experimentais e a solução numérica na região do condensador. Isto deve estar ligado à condição de contorno adotada nesta região (temperatura fixa de $25{ }^{\circ} \mathrm{C}$ na extremidade do tubo de calor). Esta condição de contorno não se mostra adequada para a representação do comportamento experimental da seção do condensador do tubo de calor de Putra et al. (2012). Um fato que tende a comprovar isso é que, como se pode observar na figura, as seções remanescentes apresentaram exatidão e precisão significativas, apresentando um comportamento qualitativamente adequado e dentro das faixas de incerteza. Este comportamento pode ser observado com mais detalhes na Figura 42. 


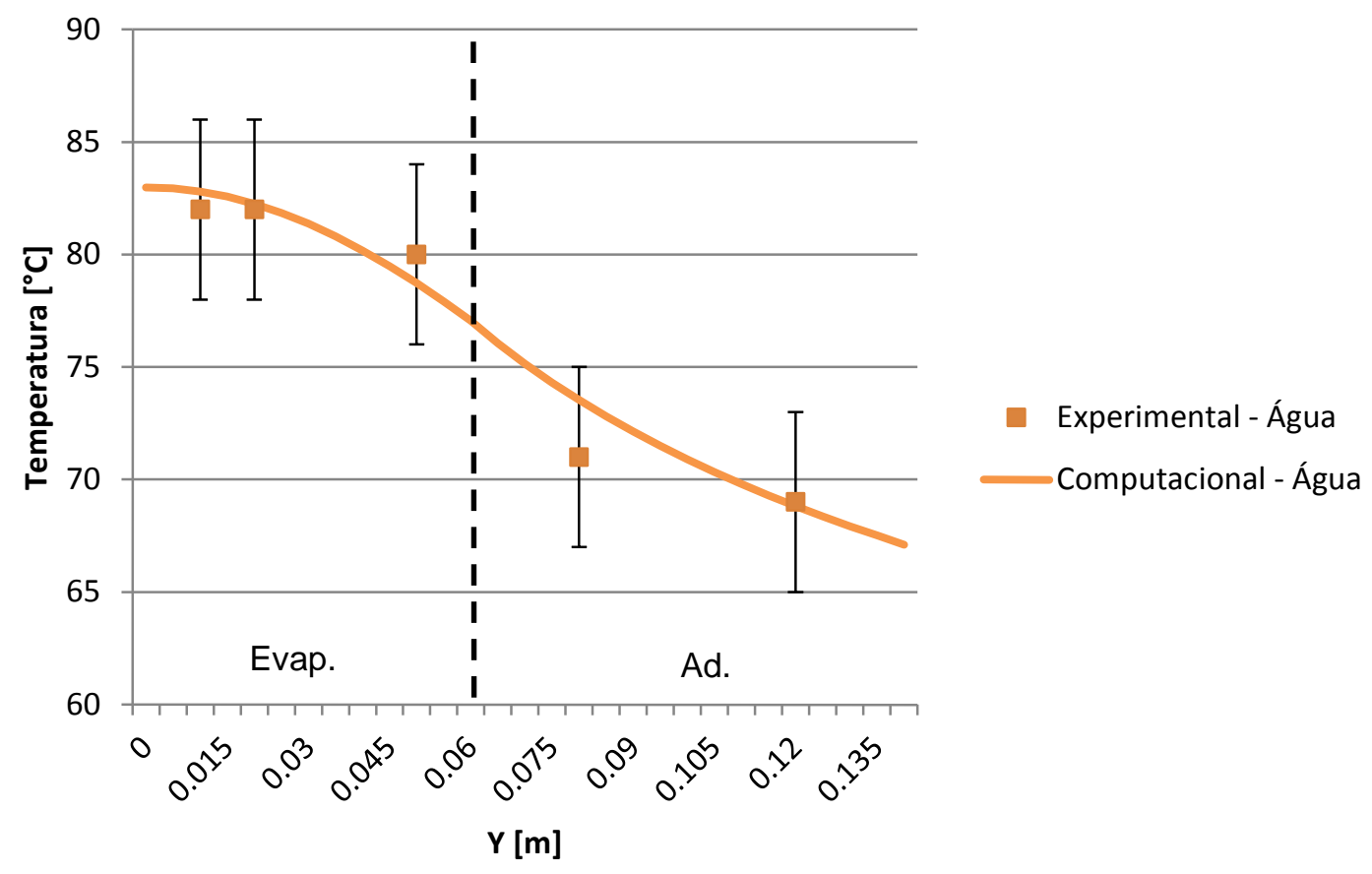

Figura 42. Comparação entre o perfil de temperaturas obtido experimentalmente no trabalho de Putra et al. (2012) e o perfil de temperaturas obtido computacionalmente pelo CFX para água como fluido de trabalho - detalhe da seção do evaporador e seção adiabática

Da Fig. 42, nota-se que a curva levantada permanece dentro das margens de erro em todo o intervalo estudado, e que a diferença máxima de temperatura entre a simulação computacional e os dados experimentais nestas regiões é de $2,12{ }^{\circ} \mathrm{C}$, ou $7 \%$. Assim, deste trecho em diante, somente estas regiões do tubo de calor serão levadas em consideração para a análise dos resultados computacionais obtidos para este tubo de calor.

Com isso, pode-se calcular os valores da resistência térmica utilizando a Equação [62], específica para o tubo de calor de Putra et. al (2012). Estes valores podem ser observados na Tabela 28.

Os resultados apresentam uma concordância razoável entre si em termos absolutos, visto que os valores se encontram na mesma ordem de grandeza e a resistência térmica de um mesmo tubo de calor nas mesmas condições varia em 0,061 ${ }^{\circ} \mathrm{C} / \mathrm{W}$, o que corresponde a aproximadamente ao dobro de uma ordem de grandeza abaixo dos valores determinados para estas resistências. 
Tabela 28. Resistências térmicas obtidas experimentalmente e computacionalmente para o tubo de calor de Putra et al. (2012) contendo água

\begin{tabular}{cccc}
\hline \multirow{2}{*}{ Fluido de trabalho } & \multicolumn{3}{c}{ Resistência térmica $\left({ }^{\circ} \mathrm{C} / \mathrm{W}\right)$} \\
\cline { 2 - 4 } & Experimental & Computacional & Erro Percentual \\
\hline Água & 0,378 & 0,317 & $-16,1 \%$ \\
\hline
\end{tabular}

Pode-se também obter o perfil de temperaturas na parede deste mesmo tubo de calor utilizando etilenoglicol (EG) como fluido de trabalho. A Figura 43 mostra os resultados computacionais deste tubo de calor contendo etilenoglicol em comparação com os resultados experimentais de Putra et al. (2012) para uma potência equivalente a $30 \mathrm{~W}$ sendo inserida na seção do evaporador e levando em consideração que somente as seções do evaporador e adiabática apresentam um comportamento satisfatório nesta modelagem.

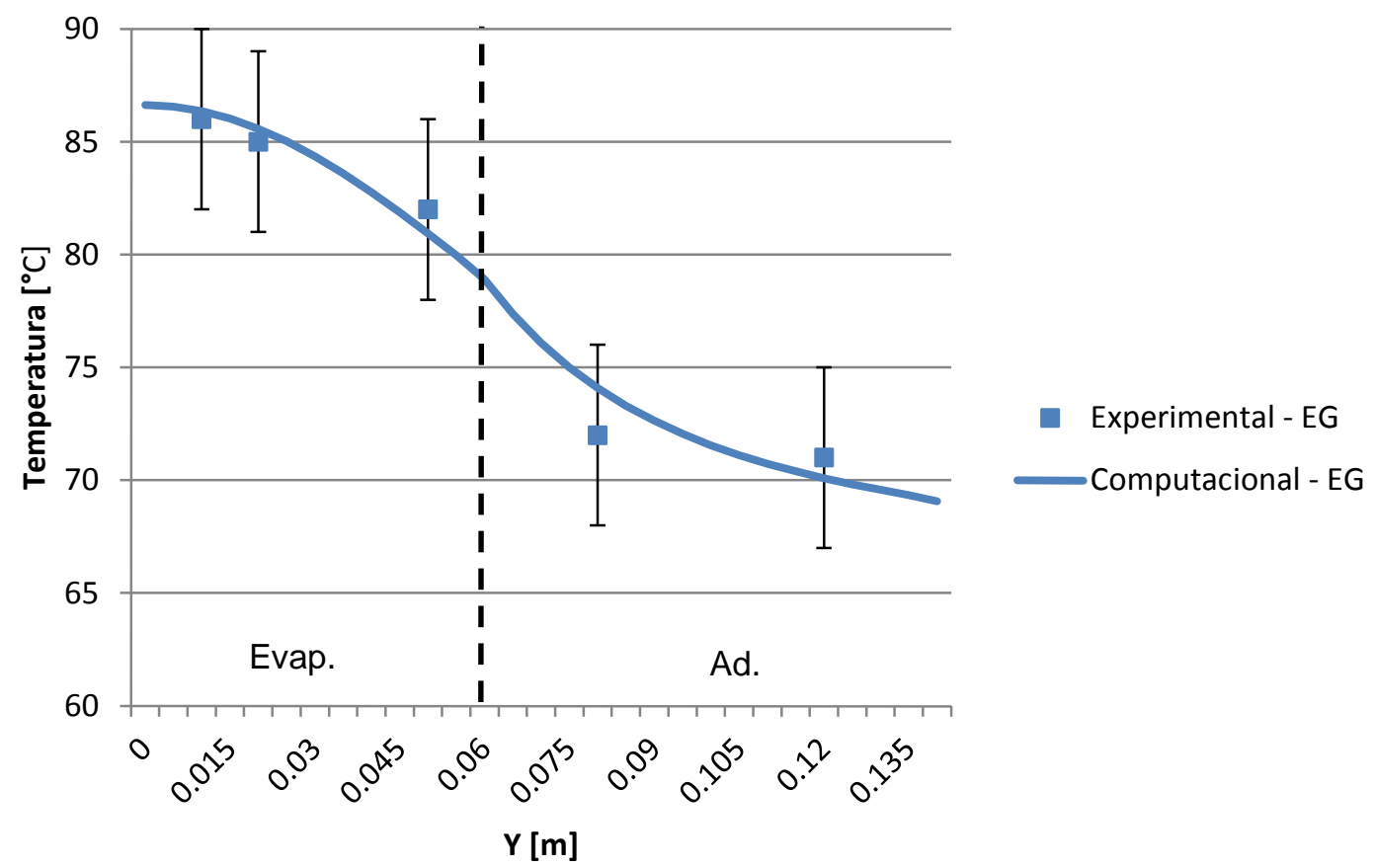

Figura 43. Comparação entre o perfil de temperaturas obtido experimentalmente no trabalho de Putra et al. (2012) e o perfil de temperaturas obtido computacionalmente pelo CFX para etilenoglicol como fluido de trabalho - detalhe da seção do evaporador e seção adiabática 
Da Figura 43, nota-se que a curva levantada permanece dentro das margens de erro em todo o intervalo estudado, e que a diferença máxima de temperatura entre a simulação computacional e os dados experimentais nesta região é de $2,08{ }^{\circ} \mathrm{C}$, ou $2,9 \%$, o que indica que estas seções apresentam um comportamento quantitativamente adequado.

Com isso, pode-se calcular os valores da resistência térmica utilizando a Equação [62], específica para o tubo de calor de Putra et. al (2012). Estes valores podem ser observados na Tabela 29.

Tabela 29. Resistências térmicas obtidas experimentalmente e computacionalmente para o tubo de calor de Putra et al. (2012) contendo etilenoglicol

\begin{tabular}{cccc}
\hline \multirow{2}{*}{ Fluido de Trabalho } & \multicolumn{3}{c}{ Resistência térmica $\left({ }^{\circ} \mathrm{C} / \mathrm{W}\right)$} \\
\cline { 2 - 4 } & Experimental & Computacional & Erro Percentual \\
\hline Etilenoglicol & 0,428 & 0,377 & $-11,9 \%$ \\
\hline
\end{tabular}

Os resultados apresentam concordância razoável entre si em valores absolutos, com valores aproximadamente na mesma ordem de grandeza e variando a resistência térmica de um mesmo tubo de calor nas mesmas condições em $0,051{ }^{\circ} \mathrm{C} / \mathrm{W}$, o que corresponde a aproximadamente uma ordem de grandeza abaixo dos valores determinados experimentalmente para estas resistências. Pode-se perceber também que o erro percentual foi menor para o etilenoglicol do que para a água.

\subsection{Aplicação dos nanofluidos no modelo computacional}

\subsubsection{Nanofluidos contendo nanotubos de carbono (Liu e Lu, 2009)}

A princípio, é necessário definir os dados que foram inseridos no modelo computacional para representar os intervalos correspondentes de propriedades avaliados nos nanofluidos contendo nanotubos de carbono ao longo das seções anteriores.

Para isso, dois casos distintos foram definidos de forma a revelarem as configurações cujos resultados correspondem às situações nas quais o desempenho 
térmico atinge um valor de máximo (utilizando as correlações nas quais a viscosidade absoluta é mínima e a condutividade térmica é máxima) ou um valor de mínimo (utilizando as correlações nas quais a viscosidade absoluta é máxima e a condutividade térmica é mínima). Para o nanofluido utilizado no tubo de calor de Liu e Lu (2009) contendo água e nanotubos de carbono, estes casos correspondem a:

- $\quad$ Desempenho térmico máximo:

○ Viscosidade absoluta

- Correlações de Einstein / Nielsen / Batchelor / Brinkman

- $\mu=9,04.10^{-4}$ Pa.s

○ Condutividade térmica

- Correlação de Nan

- $\mathrm{k}=0,73 \mathrm{~W} / \mathrm{m} . \mathrm{K}$

- Desempenho térmico mínimo:

○ Viscosidade absoluta

- Correlação de Nguyen

- $\mu=1,52.10^{-3}$ Pa.s

○ Condutividade térmica

- Correlações de Jeffrey / Yu e Choi

- $\mathrm{k}=0,64 \mathrm{~W} / \mathrm{m} \cdot \mathrm{K}$

De forma a simplificar a nomenclatura, os casos definidos como desempenho térmico máximo e mínimo para todos os tubos de calor serão referidos respectivamente como "DTMax" e "DTMin" a partir deste ponto.

Os perfis de temperaturas da parede do tubo de calor obtido nas simulações do tubo de calor de Liu e Lu (2009) contendo os conjuntos de propriedades DTMax e DTMin em comparação com este mesmo perfil de temperaturas obtido com as propriedades da água podem ser observados para as diferentes potências térmicas inseridas na seção do evaporador deste tubo de calor nas Figuras 44 a 47. 


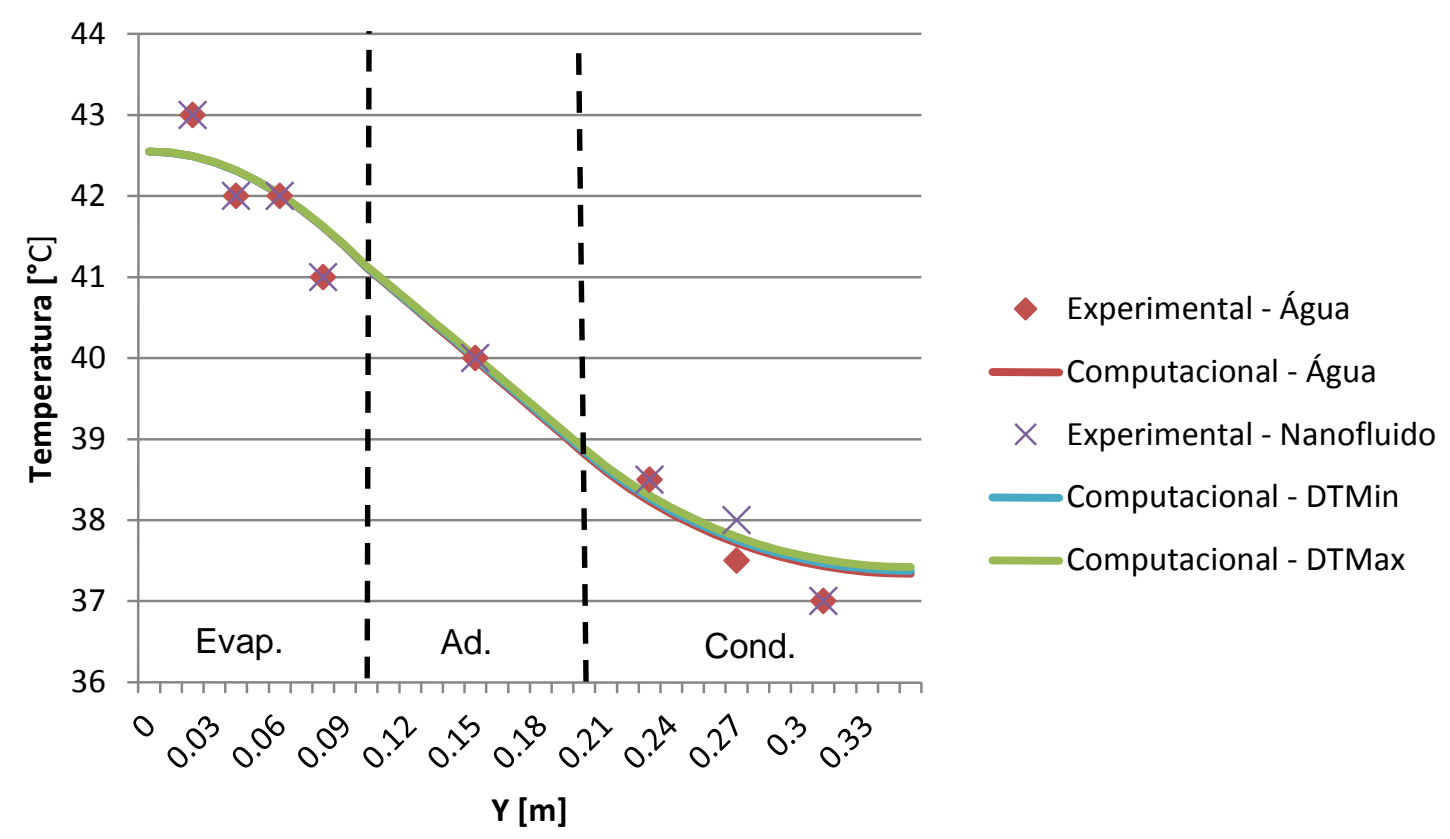

Figura 44. Comparação entre os perfis de temperaturas experimentais e computacionais do tubo de calor de Liu e Lu (2009) contendo água e um nanofluido composto por água e nanotubos de carbono $-\dot{Q}=10 \mathrm{~W}$

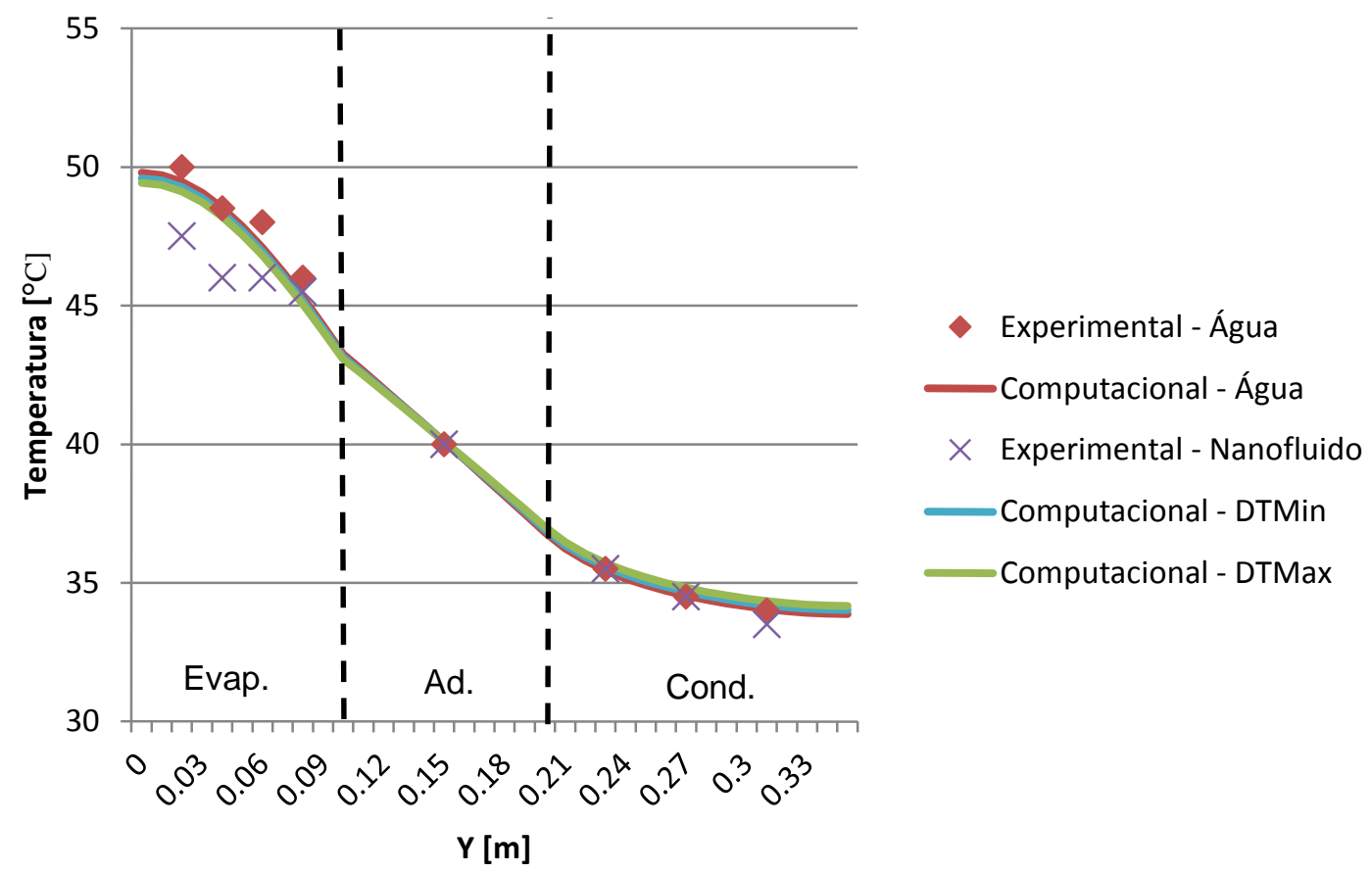

Figura 45. Comparação entre os perfis de temperaturas experimentais e computacionais do tubo de calor de Liu e Lu (2009) contendo água e um nanofluido composto por água e nanotubos de carbono - $\dot{Q}=40 \mathrm{~W}$ 


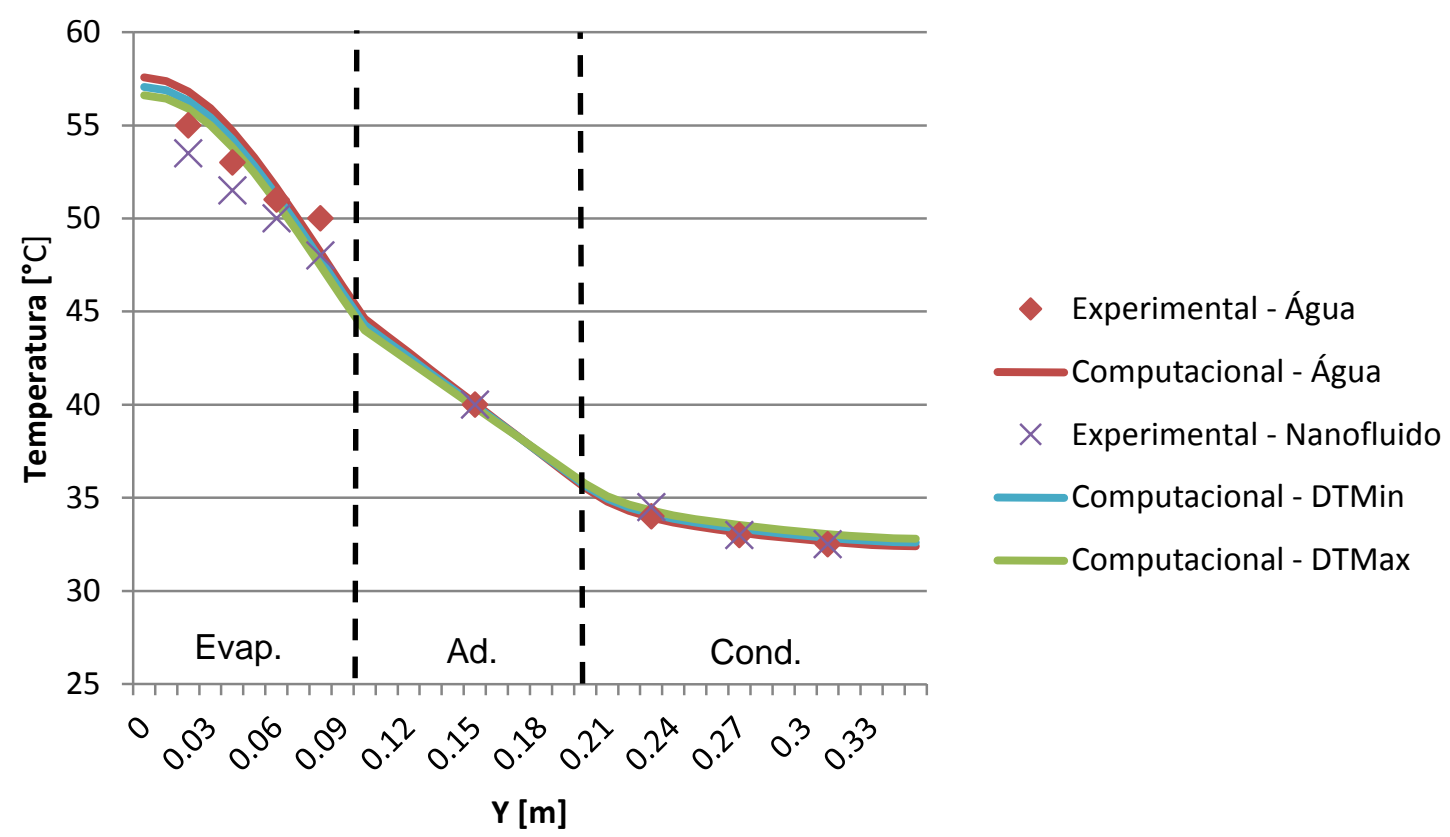

Figura 46. Comparação entre os perfis de temperaturas experimentais e computacionais do tubo de calor de Liu e Lu (2009) contendo água e um nanofluido composto por água e nanotubos de carbono - $\dot{Q}=70 \mathrm{~W}$

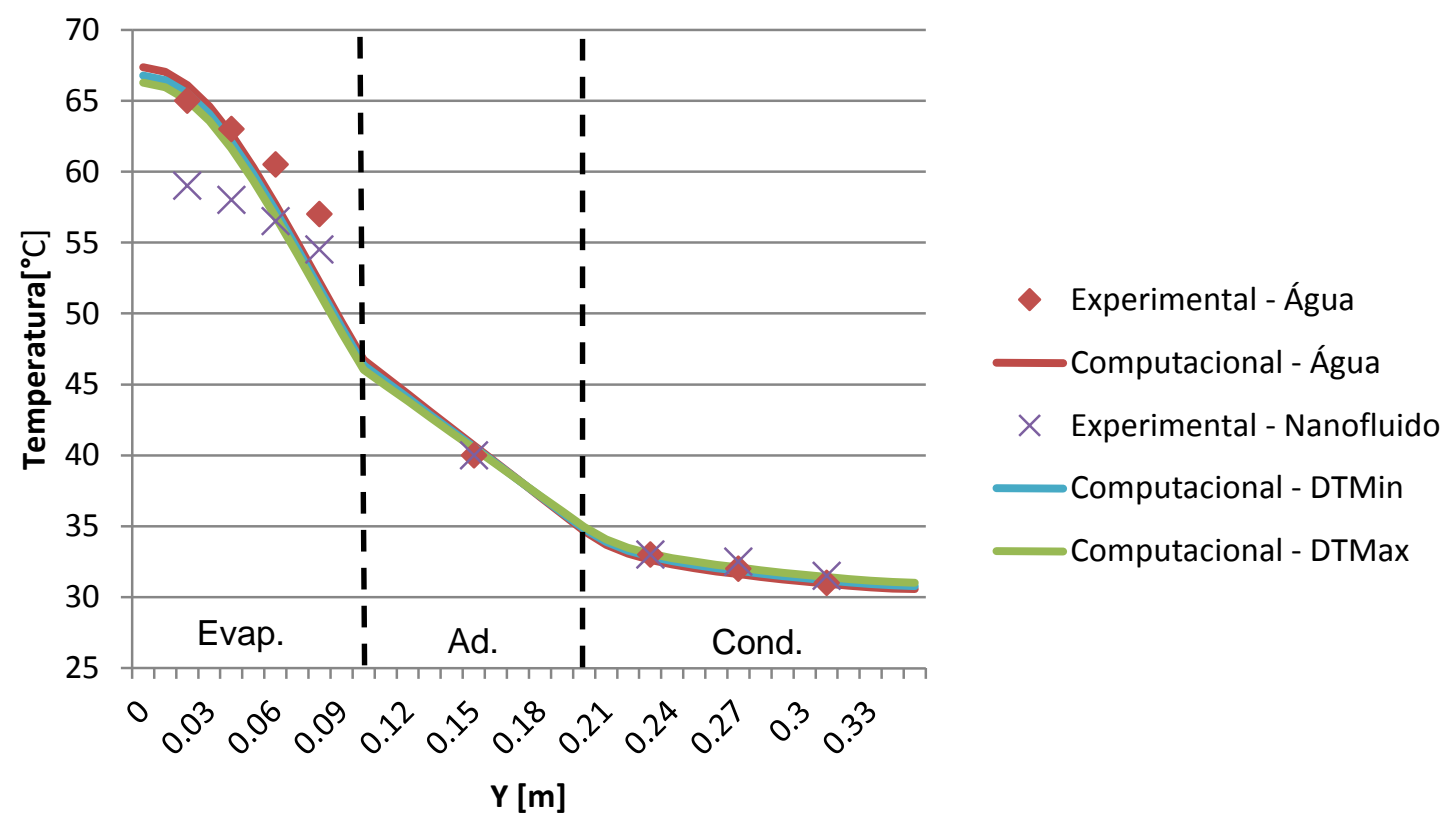

Figura 47. Comparação entre os perfis de temperaturas experimentais e computacionais do tubo de calor de Liu e Lu (2009) contendo água e um nanofluido composto por água e nanotubos de carbono $-\dot{Q}=80 \mathrm{~W}$ 
Das Figuras 44 a 47, é possível perceber que, utilizando nanofluidos, somente no caso contendo uma potência térmica inserida de $10 \mathrm{~W}$ existe uma concordância significativa entre o perfil de temperaturas obtido experimentalmente por Liu e $\mathrm{Lu}$ (2009) e o perfil de temperaturas obtido computacionalmente utilizando nanofluidos em ambos os casos estudados (DTMin e DTMax). Para esta potência térmica em específico, a diferença máxima de temperaturas observada entre estes perfis de temperatura corresponde a $0,63{ }^{\circ} \mathrm{C}$, ou $1,54 \%$ do valor experimental. Entretanto, é importante observar que neste caso, as variações de temperaturas são bastante pequenas, o que justifica a alta precisão obtida. Nos demais casos, esta diferença máxima atingiu valores relativos tais como 5,13\% para $40 \mathrm{~W}, 4,55 \%$ para $70 \mathrm{~W}$ e $11,11 \%$ para $80 \mathrm{~W}$.

De forma mais geral, é possível observar que, quantitativamente, a alteração das propriedades do fluido de forma a representar as propriedades do nanofluido contendo nanotubos de carbono não surtiu o efeito esperado, e existe uma diferença significativa entre o comportamento térmico computacional e o comportamento térmico experimental da seção do evaporador. Nesta seção ocorrem as mudanças mais drásticas causadas pela inserção das nanopartículas no fluido, e desta forma, as diferenças obtidas mostram que existem aspectos na modelagem da ebulição de um nanofluido cujo efeito tem sido negligenciado na modelagem existente na literatura.

Adicionalmente, é possível calcular os valores da resistência térmica do tubo de calor para cada um dos casos apresentados utilizando a Equação [61]. Estes valores podem ser observados na Tabela 30.

Da Tab. 30, é possível observar que a alteração das propriedades do fluido surtiu um efeito qualitativamente adequado, uma vez que o caso DTMax sempre apresentou uma redução na resistência térmica em relação ao caso DTMin, o que indica que sempre houve uma melhora no desempenho térmico do tubo de calor com a introdução de correlações que proporcionavam propriedades térmicas melhores.

Além disso, observa-se que os resultados para as resistências térmicas apresentam boa concordância entre si, tanto em valores absolutos como em valores relativos, com valores nas mesmas ordens de grandeza e variando a resistência térmica de um mesmo tubo de calor nas mesmas condições em, no máximo, $0,023^{\circ} \mathrm{C} / \mathrm{W}$ para o caso DTMin e $0,015{ }^{\circ} \mathrm{C} / \mathrm{W}$ para o DTMax, o que corresponde a aproximadamente uma ordem de grandeza abaixo dos valores determinados experimentalmente para estas 
resistências. Isto ocorre devido à obtenção de um gradiente de temperaturas alto na seção do evaporador, fazendo o valor médio das temperaturas obtidas computacionalmente na seção do evaporador se aproximar do valor médio das temperaturas obtidas experimentalmente nesta mesma seção. Além disso, é possível observar valores de erro percentual comparáveis aos obtidos somente utilizando fluido base.

Tabela 30. Resistências térmicas obtidas experimentalmente e computacionalmente para o tubo de calor de Liu e Lu (2009) contendo um nanofluido composto por água e nanotubos de carbono

\begin{tabular}{ccccc}
\hline \multirow{2}{*}{$\begin{array}{c}\text { Conjunto de } \\
\text { Propriedades }\end{array}$} & \multirow{2}{*}{ Potência } & \multicolumn{3}{c}{ Resistência térmica $\left({ }^{\circ} \mathrm{C} / \mathrm{W}\right)$} \\
\cline { 3 - 5 } & & Experimental & Computacional & Erro Percentual \\
\hline \multirow{3}{*}{ DTMax } & $10 \mathrm{~W}$ & 0,417 & 0,415 & $-0,5 \%$ \\
\cline { 2 - 5 } & $40 \mathrm{~W}$ & 0,294 & 0,300 & $+2,0 \%$ \\
\cline { 2 - 5 } & $70 \mathrm{~W}$ & 0,249 & 0,255 & $+2,4 \%$ \\
\cline { 2 - 5 } & $80 \mathrm{~W}$ & 0,308 & 0,323 & $+4,9 \%$ \\
\hline \multirow{3}{*}{ DTMin } & $10 \mathrm{~W}$ & 0,417 & 0,418 & $+0,2 \%$ \\
\cline { 2 - 5 } & $40 \mathrm{~W}$ & 0,294 & 0,307 & $+4,4 \%$ \\
\cline { 2 - 5 } & $70 \mathrm{~W}$ & 0,249 & 0,264 & $+6,0 \%$ \\
\hline & $80 \mathrm{~W}$ & 0,308 & 0,331 & $+7,5 \%$ \\
\hline
\end{tabular}

Por fim, é importante observar também que o comportamento obtido para a resistência térmica do tubo de calor contendo o nanofluido corresponde ao comportamento relativo da resistência térmica deste mesmo tubo de calor por Liu e $\mathrm{Lu}$ (2009) na Figura 14.

\subsubsection{Nanofluidos contendo etilenoglicol (Putra et al., 2012)}

Inicialmente, é possível elaborar um gráfico a partir dos valores obtidos para a condutividade térmica utilizando cada uma das correlações selecionadas para a análise da condutividade térmica de nanofluidos contendo etilenoglicol e comparar estes valores com os valores da condutividade térmica do nanofluido contendo etilenoglicol e 
óxido de zinco, fornecidos por Putra et al. (2012) e representados na Figura 15. Este gráfico pode ser observado na Figura 48.

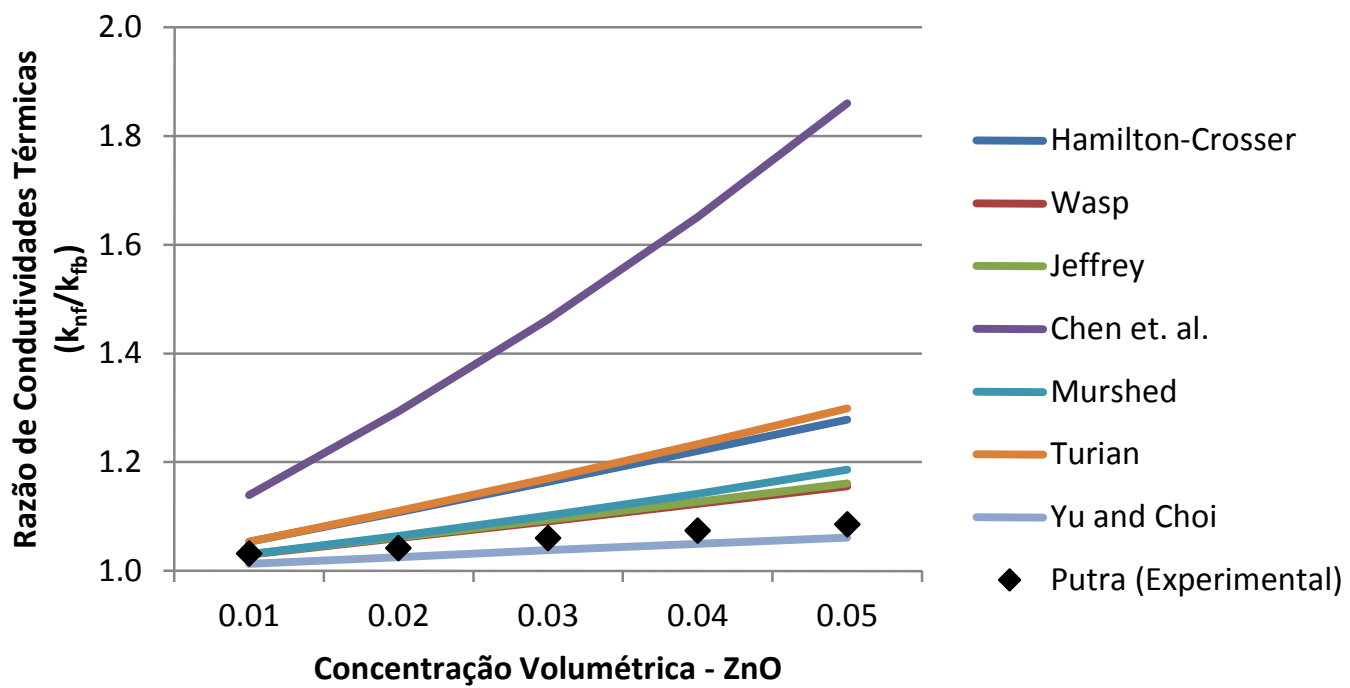

Figura 48. Comparação entre os as condutividades térmicas obtidas utilizando correlações da literatura e os dados fornecidos por Putra et. al (2012) para o nanofluido composto por etilenoglicol e óxido de zinco

Da Figura 48, observa-se que o comportamento da condutividade térmica do nanofluido medido experimentalmente aproxima-se mais do comportamento obtido por meio da correlação de Yu e Choi do que do comportamento definido pelas demais correlações.

Em seguida, é necessário definir novamente os dados a serem inseridos no modelo computacional de forma a representar os intervalos correspondentes de propriedades avaliados nos nanofluidos contendo etilenoglicol e óxido de zinco ao longo das seções anteriores.

Para tanto, os casos DTMax e DTMin serão redefinidos para os nanofluidos contendo etilenoglicol e óxido de zinco do estudo de Putra et al.(2012):

- DTMax:

○ Viscosidade absoluta

- Correlação de Einstein

- $\mu=4,14.10^{-3}$ Pa.s

- Condutividade térmica

- Correlação Chen et al. 
- $\mathrm{k}=0,49 \mathrm{~W} / \mathrm{m} \cdot \mathrm{K}$

- DTMin:

- Viscosidade absoluta

- Correlação de Pak e Cho

- $\mu=1,58.10^{-2}$ Pa.s

- Condutividade térmica

- Correlação de Yu e Choi

- $\mathrm{k}=0,28 \mathrm{~W} / \mathrm{m} \cdot \mathrm{K}$

Os perfis de temperaturas da parede do tubo de calor obtidos nas seções do evaporador e adiabática das simulações do tubo de calor de Putra et al. (2012) contendo os conjuntos de propriedades DTMax e DTMin em comparação com este mesmo perfil de temperaturas obtido com as propriedades da água e do etilenoglicol podem ser observados em comparação com os dados experimentais de Putra et al. (2012) a partir das Figura 49.

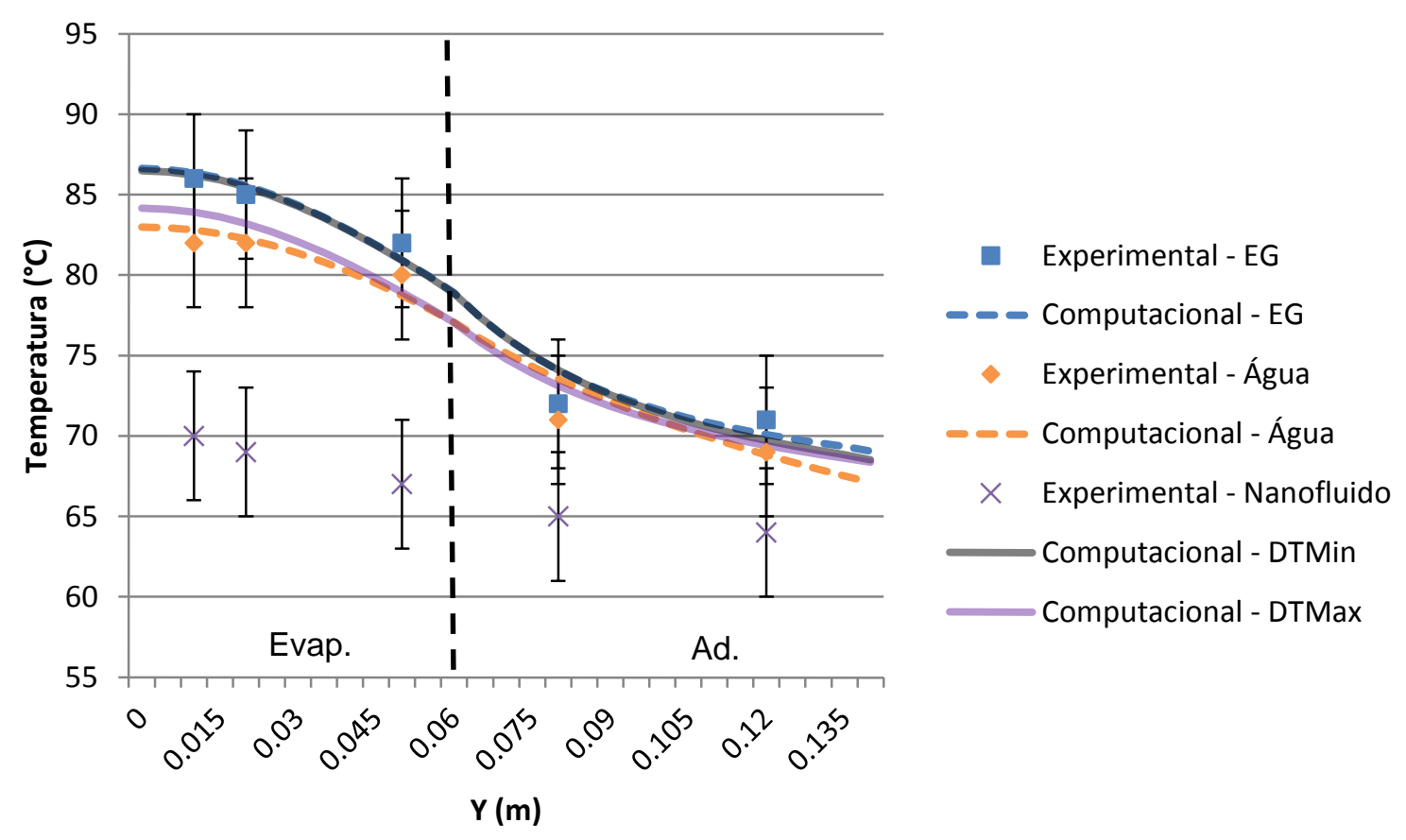

Figura 49. Comparação entre os perfis de temperaturas experimentais e computacionais do tubo de calor de Putra et. al (2012) contendo água, etilenoglicol e um nanofluido composto por etilenoglicol e óxido de zinco 
À primeira vista, é importante destacar que o mesmo comportamento observado na simulação do tubo de calor de Liu e Lu (2009) contendo nanofluidos se repete aqui. Neste caso, mesmo havendo uma alteração mais significativa do perfil de temperaturas para o caso DTMax, os perfis de temperaturas obtidos computacionalmente para o nanofluido se encontram ainda mais distantes daquele obtido experimentalmente, revelando diferenças máximas de 23,9\% para DTMin e de 20,6\% para DTMax.

No entanto, é possível identificar da Fig. 49 que o comportamento térmico dos perfis de temperaturas obtidos com a alteração das propriedades físicas é qualitativamente similar ao perfil de temperaturas esperado.

Para quantificar esta relação, calculou-se o fator de correlação linear obtido entre os dados experimentais e os casos definidos como DTMax e DTMin. Obteve-se desta forma fatores de correlação lineares iguais a 0,99 para DTMax e 0,98 para DTMin, oferecendo assim suporte a esta afirmação.

Adicionalmente, pode-se perceber claramente que o desempenho térmico obtido computacionalmente para o tubo de calor contendo o nanofluido utilizando o caso DTMax encontra-se posicionado entre o desempenho térmico do tubo de calor contendo água e o desempenho térmico do tubo de calor contendo etilenoglicol. Este comportamento coincide com o comportamento da condutividade térmica definido para estes fluidos. Isto leva a crer na hipótese de que o simples aumento da condutividade térmica utilizando correlações de propriedades nunca teria como consequência um aumento do desempenho térmico de um nanofluido com a mesma ordem de grandeza que os experimentos apresentam. Esta ordem de grandeza pode ser observada mais claramente a partir dos valores das resistências térmicas do tubo de calor para cada um dos casos apresentados por Putra et al. (2012), calculadas utilizando a Equação [62]. Estes valores podem ser observados na Tabela 31.

Percebe-se que não existe uma concordância adequada entre a resistência térmica obtida experimentalmente para o tubo de calor utilizando nanofluidos e os modelos computacionais adotados, variando a resistência térmica de um mesmo tubo de calor nas mesmas condições em $0,242{ }^{\circ} \mathrm{C} / \mathrm{W}$ para o caso DTMin e em 0,194 para o caso DTMax , o que corresponde a mesma ordem de grandeza dos valores determinados experimentalmente para estas resistências. 
Tabela 31. Resistências térmicas obtidas experimentalmente e computacionalmente para o tubo de calor de Putra et al. (2012) contendo água, etilenoglicol e um nanofluido composto por etilenoglicol e óxido de zinco

\begin{tabular}{cccc}
\hline \multirow{2}{*}{ Fluido de Trabalho } & \multicolumn{3}{c}{ Resistência térmica $\left({ }^{\circ} \mathrm{C} / \mathrm{W}\right)$} \\
\cline { 2 - 4 } & Experimental & Computacional & Erro Percentual \\
\hline Água & 0,378 & 0,317 & $-16,1 \%$ \\
\hline Etilenoglicol & 0,428 & 0,377 & $-11,9 \%$ \\
\hline Nanofluido - DTMax & 0,139 & 0,333 & $+139,6 \%$ \\
\hline Nanofluido - DTMin & 0,139 & 0,381 & $+174,1 \%$ \\
\hline
\end{tabular}

\subsection{Análises de sensibilidade}

\subsubsection{Potência térmica inserida - Água}

A fim de analisar a influência das margens de erro nos valores da potência térmica introduzidos na seção do condensador, pode-se realizar uma análise de sensibilidade no valor desta potência observando o efeito da adição ou subtração da margem de erro nos valores da potência térmica inserida.

Para isso, é necessário definir os valores da margem de erro para cada um dos tubos de calor estudados. Para o tubo de calor de Zerbini (1984), é adotado como margem de erro o valor propagado da incerteza relativa fornecida para os valores da tensão e da corrente elétrica fornecidos à resistência elétrica utilizada para o aquecimento do tubo de calor. Estes valores foram definidos como 1\% para a tensão e $5 \%$ para a corrente.

Como o valor da potência térmica dissipada consiste em um produto simples entre o valor da tensão e o valor da corrente, é possível escrever o valor da margem de erro para esta potência como:

$$
\% E r r_{Q}=\sqrt{\% E r r_{V}^{2}+\% E r r_{I}^{2}}
$$


Para os demais tubos de calor, os valores referentes à incerteza das potências térmicas inseridas foram fornecidos diretamente. Os valores desta incerteza para cada tubo podem ser observados na Tabela 32.

Tabela 32. Valores das incertezas associadas a potência térmica de cada tubo de calor

\begin{tabular}{cc}
\hline & Incerteza (\%) \\
\hline Zerbini (1984) & $5,1 \%$ \\
\hline Liu e Lu (2009) & $4 \%$ \\
\hline Putra et al. (2012) & $2 \%$ \\
\hline
\end{tabular}

Com isso, pode-se observar nas Figuras 50 a 53 o efeito da adição ou subtração destas porcentagens nas potências térmicas inseridas (cuja variação também é propagada para todas as condições derivadas destas potências) por meio da variação obtida nos perfis de temperatura dos seguintes casos:

- $\quad$ Zerbini (1984)

○ $\quad \dot{Q}=37 W$

- $\quad$ Liu e Lu (2009)

○ $\dot{Q}=40 \mathrm{~W}$

○ $\dot{Q}=70 \mathrm{~W}$

- $\quad$ Putra et al. (2012)

- Tubo de calor contendo água

Pode-se perceber na Fig. 50 que o aumento na potência térmica fornecida ao evaporador aproxima o valor do perfil de temperatura na seção do condensador dos valores obtidos experimentalmente, enquanto que na seção do evaporador, ocorre o contrário. Para uma diminuição na potência térmica fornecida ao evaporador, o comportamento inverso ocorre e a aproximação se torna melhor na seção do evaporador e pior na seção do condensador.

Para estes casos, o valor da diferença média obtida entre as temperaturas obtidas experimentalmente e computacionalmente varia de $0,075 \%$ para o caso base para $0,08 \%$ com um aumento de $5,1 \%$ e para $0,074 \%$ com uma diminuição de $5,1 \%$. 


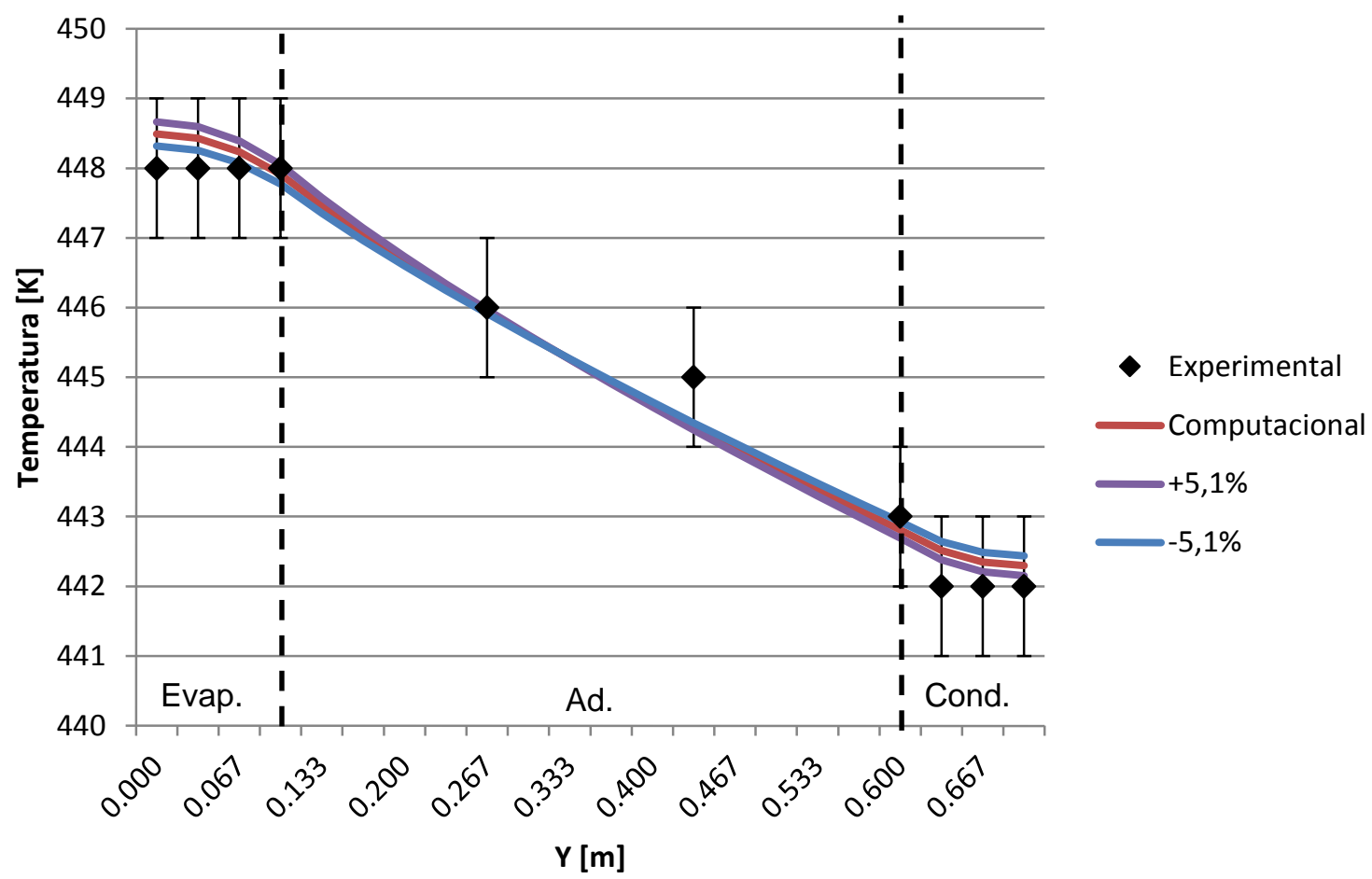

Figura 50. Análise de sensibilidade da potência térmica do tubo de calor de Zerbini (1984) contendo água para $\dot{Q}=37 W \pm 5,1 \%$

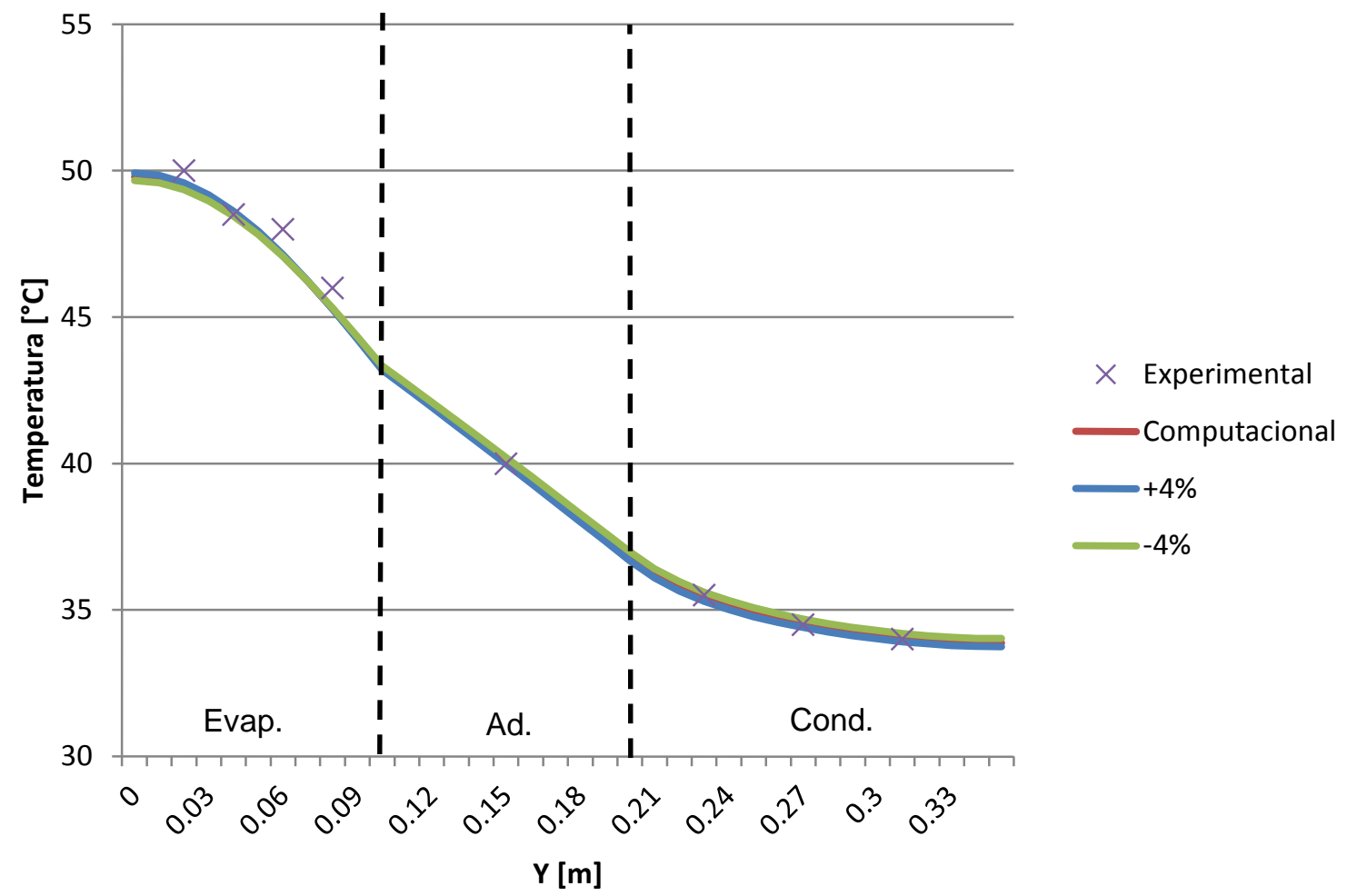

Figura 51. Análise de sensibilidade da potência térmica do tubo de calor de Liu e Lu (2009) contendo água para $\dot{Q}=40 W \pm 4 \%$ 
Da Figura 51, observa-se que a alteração de 4\% na potência térmica fornecida ao evaporador representa uma diferença quase imperceptível no perfil de temperaturas para o caso base de $\dot{Q}=40 \mathrm{~W}$. De fato, o valor da diferença média obtida entre as temperaturas obtidas experimentalmente e computacionalmente varia de $0,66 \%$ para o caso base para $0,71 \%$ com um aumento de $4 \%$ e para $0,86 \%$ com uma diminuição de $4 \%$.

Pode-se perceber na Fig. 52 que a diminuição na potência térmica fornecida ao evaporador aproxima o valor do perfil de temperatura na seção do evaporador dos valores obtidos experimentalmente e para um aumento na potência térmica fornecida ao evaporador, o comportamento inverso ocorre, e a aproximação se torna pior na seção do evaporador. Não são observadas alterações visualmente perceptíveis na seção do condensador.

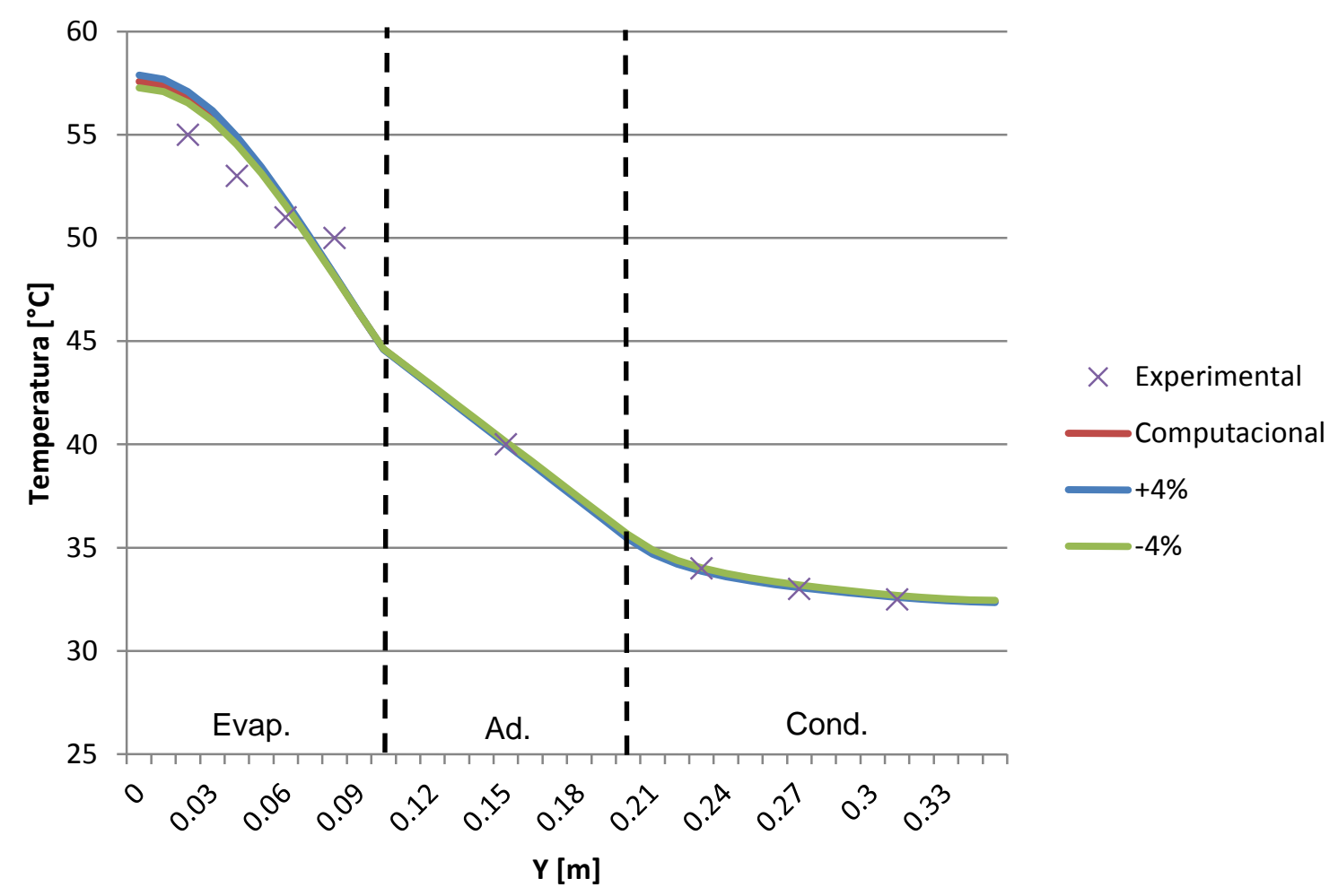

Figura 52. Análise de sensibilidade da potência térmica do tubo de calor de Liu e Lu (2009) contendo água para $\dot{Q}=70 \mathrm{~W} \pm 4 \%$ 
Para estes casos, o valor da diferença média obtida entre as temperaturas obtidas experimentalmente e computacionalmente varia de 1,59\% para o caso base para 1,69\% com um aumento de 4\% e 1,51\% com uma diminuição de 4\%.

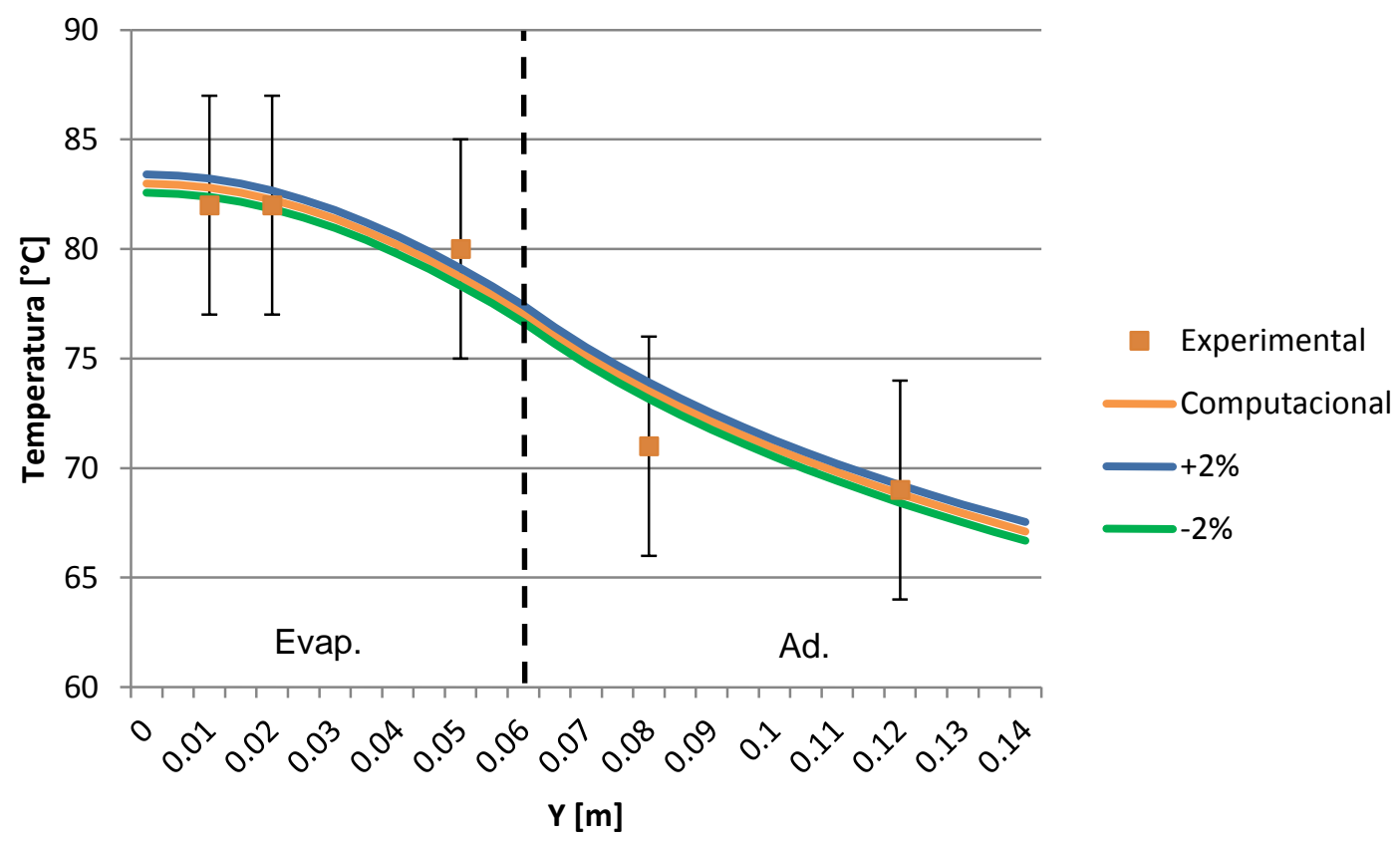

Figura 53. Análise de sensibilidade da potência térmica do tubo de calor de Putra et al. (2012) contendo água para $\dot{Q}=30 W \pm 2 \%$

Por fim, na Fig. 53, observa-se que o aumento da potência térmica causa um aumento global na temperatura média do tubo de calor nas seções do evaporador e adiabática, enquanto que o contrário ocorre com a diminuição da potência térmica, reduzindo a temperatura média do tubo de calor nestas mesmas seções.

Para estes casos, o valor da diferença média obtida entre as temperaturas obtidas experimentalmente e computacionalmente varia de 1,34\% para o caso base para 1,56\% com um aumento de $2 \%$ e 1,33\% com uma diminuição de $2 \%$.

É importante destacar, a partir da observação das Figuras 50 e 53, que a variação na potência térmica não foi significativa a ponto de remover as temperaturas obtidas computacionalmente das margens de erro definidas para as leituras experimentais das temperaturas.

Em todos os casos, as pequenas diferenças de temperatura obtidas nesta análise de sensibilidade em relação aos casos base não justificam a análise dos valores das 
resistências térmicas, pois as alterações obtidas são muito pequenas (entre $0,001{ }^{\circ} \mathrm{C} / \mathrm{W}$ e $\left.0,008^{\circ} \mathrm{C} / \mathrm{W}\right)$.

\subsubsection{Concentração volumétrica de nanopartículas nos nanofluidos}

Para observar o efeito da alteração da concentração volumétrica de nanopartículas do nanofluido no desempenho térmico dos tubos de calor estudados, é possível aplicar valores arbitrários para esta concentração volumétrica e observar a faixa de resultados obtidos.

Neste estudo, foram utilizadas seis diferentes concentrações volumétricas de nanopartículas, de forma a representar resultados na ordem de grandeza percentual entre $1 \%$ e $10 \%$. Isso se deve à observação de que variações nesta ordem de grandeza de concentrações volumétricas permitem a obtenção de mudanças significativas no perfil de temperaturas, e ao mesmo tempo representam nanofluidos com concentrações similares à maioria dos casos estudados.

Assim, foram selecionadas como concentrações volumétricas de interesse os valores referentes às extremidades deste intervalo (1\% e 10\%) e mais quatro concentrações volumétricas posicionadas de forma simétrica em relação ao ponto médio deste intervalo (5,5\%), abrangendo também a concentração volumétrica de $5 \%$ utilizada no trabalho de Putra et al. (2012). Estas concentrações são: 2\%, 5\%, 6\% e 9\%.

Desta forma, foram levantados os conjuntos de propriedades correspondentes a estas concentrações para o nanofluido contendo água e nanotubos de carbono do estudo de Liu e Lu (2009) e para o nanofluido contendo etilenoglicol e óxido de zinco do trabalho de Putra et al. (2012). Os valores destas propriedades podem ser observados nas tabelas 34 e 35 .

É importante destacar que os casos DTMax e DTMin são definidos por correlações de propriedades diferentes para as concentrações volumétricas de nanopartículas iguais a $6 \%, 9 \%$ e 10\%, por conta dos limites de validade das correlações propostas na literatura. Como as correlações Einstein e de Maron e Pierce são limitadas para nanofluidos contendo baixa concentração volumétrica de nanopartículas, foram utilizadas as correlações de Nielsen e de Pak e Cho em substituição a estas correlações nestas simulações. Estas novas correlações continuam correspondendo aos intervalos de propriedades para os quais os desempenhos térmicos atingem valores máximos e 
mínimos, de forma que o intervalo de resultados obtido utilizando os conjuntos de propriedades nestas concentrações mais altas é definido da mesma forma do que nas concentrações mais baixas.

Tabela 33. Conjunto de propriedades dos nanofluidos contendo água e nanotubos de carbono para diferentes concentrações volumétricas de nanopartículas

\begin{tabular}{|c|c|c|c|c|c|}
\hline $\begin{array}{l}\text { Concentração } \\
\text { volumétrica }\end{array}$ & Configuração adotada & $\begin{array}{c}\text { Massa } \\
\text { específica } \\
\left(\mathrm{kg} / \mathrm{m}^{3}\right)\end{array}$ & $\begin{array}{c}\text { Calor } \\
\text { Específico } \\
(\mathrm{J} / \mathrm{kgK})\end{array}$ & $\begin{array}{c}\text { Viscosidade } \\
\text { Absoluta (Pa.s) }\end{array}$ & $\begin{array}{l}\text { Condutividade } \\
\text { Térmica } \\
(\mathrm{W} / \mathrm{m} . \mathrm{K})\end{array}$ \\
\hline $1 \%$ & $\begin{array}{c}\text { DTMax } \\
\text { (Einstein - Nan) }\end{array}$ & 1000,43 & 4143,34 & $9,12.10^{-4}$ & 0,80 \\
\hline $1 \%$ & $\begin{array}{c}\text { DTMin } \\
\text { (Yu e Choi - Maron e } \\
\text { Pierce) }\end{array}$ & 1000,43 & 4143,34 & $1,70.10^{-3}$ & 0,64 \\
\hline $2 \%$ & $\begin{array}{c}\text { DTMax } \\
\text { (Einstein - Nan) }\end{array}$ & 1003,86 & 4107,90 & $9,34.10^{-4}$ & 0,96 \\
\hline $2 \%$ & $\begin{array}{c}\text { DTMin } \\
\text { (Yu e Choi - Maron e } \\
\text { Pierce) }\end{array}$ & 1003,86 & 4107,90 & $4,47.10^{-3}$ & 0,65 \\
\hline $5 \%$ & $\begin{array}{c}\text { DTMax } \\
\text { (Einstein - Nan) }\end{array}$ & 1014,15 & 4001,58 & $1,00.10^{-3}$ & 1,48 \\
\hline $5 \%$ & $\begin{array}{c}\text { DTMin } \\
\text { (Yu e Choi - Maron e } \\
\text { Pierce) }\end{array}$ & 1014,15 & 4001,58 & $6,00.10^{-3}$ & 0,67 \\
\hline $6 \%$ & $\begin{array}{c}\text { DTMax } \\
\text { (Nielsen - Nan) }\end{array}$ & 1017,58 & 3965,95 & $1,03.10^{-3}$ & 1,66 \\
\hline $6 \%$ & $\begin{array}{c}\text { DTMin } \\
\text { (Yu e Choi - Pak e Cho) }\end{array}$ & 1017,58 & 3965,95 & $4,69.10^{-3}$ & 0,68 \\
\hline $9 \%$ & $\begin{array}{c}\text { DTMax } \\
\text { (Nielsen - Nan) }\end{array}$ & 1027,87 & 3859,54 & $1,11.10^{-3}$ & 2,21 \\
\hline $9 \%$ & $\begin{array}{c}\text { DTMin } \\
\text { (Yu e Choi - Pak e Cho) }\end{array}$ & 1027,87 & 3859,54 & $7,87 \cdot 10^{-3}$ & 0,70 \\
\hline $10 \%$ & $\begin{array}{c}\text { DTMax } \\
\text { (Nielsen - Nan) }\end{array}$ & 1031,30 & 3824,38 & $1,14.10^{-3}$ & 2,40 \\
\hline $10 \%$ & $\begin{array}{c}\text { DTMin } \\
\text { (Yu e Choi - Pak e Cho) }\end{array}$ & 1031,30 & 3824,38 & $9,12.10^{-3}$ & 0,70 \\
\hline
\end{tabular}


Tabela 34. Conjunto de propriedades dos nanofluidos contendo etilenoglicol e óxido de zinco para diferentes concentrações volumétricas de nanopartículas

\begin{tabular}{|c|c|c|c|c|c|}
\hline $\begin{array}{l}\text { Concentração } \\
\text { volumétrica }\end{array}$ & $\begin{array}{l}\text { Configuração } \\
\text { adotada }\end{array}$ & $\begin{array}{c}\text { Massa } \\
\text { específica } \\
\left(\mathrm{kg} / \mathrm{m}^{3}\right)\end{array}$ & $\begin{array}{c}\text { Calor } \\
\text { Específico } \\
(\mathrm{J} / \mathrm{kgK})\end{array}$ & $\begin{array}{c}\text { Viscosidade } \\
\text { Absoluta (Pa.s) }\end{array}$ & $\begin{array}{l}\text { Condutividade } \\
\text { Térmica } \\
(\mathrm{W} / \mathrm{m} . \mathrm{K})\end{array}$ \\
\hline $1 \%$ & $\begin{array}{c}\text { DTMax } \\
\text { (Einstein - Chen et al.) }\end{array}$ & 1121,41 & 2346,26 & $3,77.10^{-3}$ & 0,30 \\
\hline $1 \%$ & $\begin{array}{c}\text { DTMin } \\
\text { (Yu e Choi - Pak e Cho) }\end{array}$ & 1121,41 & 2346,26 & $5,32 \cdot 10^{-3}$ & 0,27 \\
\hline $2 \%$ & $\begin{array}{c}\text { DTMax } \\
\text { (Einstein - Chen et al.) }\end{array}$ & 1116,72 & 2348,63 & $3,86.10^{-3}$ & 0,34 \\
\hline $2 \%$ & $\begin{array}{c}\text { DTMin } \\
\text { (Yu e Choi - Pak e Cho) }\end{array}$ & 1116,72 & 2348,63 & $7,34.10^{-3}$ & 0,27 \\
\hline $5 \%$ & $\begin{array}{c}\text { DTMax } \\
\text { (Einstein - Chen et al.) }\end{array}$ & 1302,65 & 2355,72 & $4,14.10^{-3}$ & 0,49 \\
\hline $5 \%$ & $\begin{array}{c}\text { DTMin } \\
\text { (Yu e Choi - Pak e Cho) }\end{array}$ & 1302,65 & 2355,72 & $1,58.10^{-2}$ & 0,28 \\
\hline $6 \%$ & $\begin{array}{c}\text { DTMax } \\
\text { (Nielsen - Chen et al.) }\end{array}$ & 1347,95 & 2358,08 & $4,54.10^{-3}$ & 0,55 \\
\hline $6 \%$ & $\begin{array}{c}\text { DTMin } \\
\text { (Yu e Choi - Pak e Cho) }\end{array}$ & 1347,95 & 2358,08 & $1,94.10^{-2}$ & 0,28 \\
\hline $9 \%$ & $\begin{array}{c}\text { DTMax } \\
\text { (Nielsen - Chen et al.) }\end{array}$ & 1483,88 & 2365,17 & $5,03 \cdot 10^{-3}$ & 0,79 \\
\hline $9 \%$ & $\begin{array}{c}\text { DTMin } \\
\text { (Yu e Choi - Pak e Cho) }\end{array}$ & 1483,88 & 2365,17 & $3,25.10^{-2}$ & 0,29 \\
\hline $10 \%$ & $\begin{array}{c}\text { DTMax } \\
\text { (Nielsen - Chen et al.) }\end{array}$ & 1529,19 & 2367,53 & $5,21 \cdot 10^{-3}$ & 0,89 \\
\hline $10 \%$ & $\begin{array}{c}\text { DTMin } \\
\text { (Yu e Choi - Pak e Cho) }\end{array}$ & 1529,19 & 2367,53 & $3,77.10^{-2}$ & 0,29 \\
\hline
\end{tabular}

Das Tabelas 34 e 35, ainda pode-se levantar um gráfico avaliando a intensificação proporcional da condutividade térmica dos nanofluidos utilizados em relação a condutividade térmica de seus respectivos fluidos-base para cada concentração volumétrica de nanopartículas estudada. Este gráfico pode ser observado na Figura 54. 


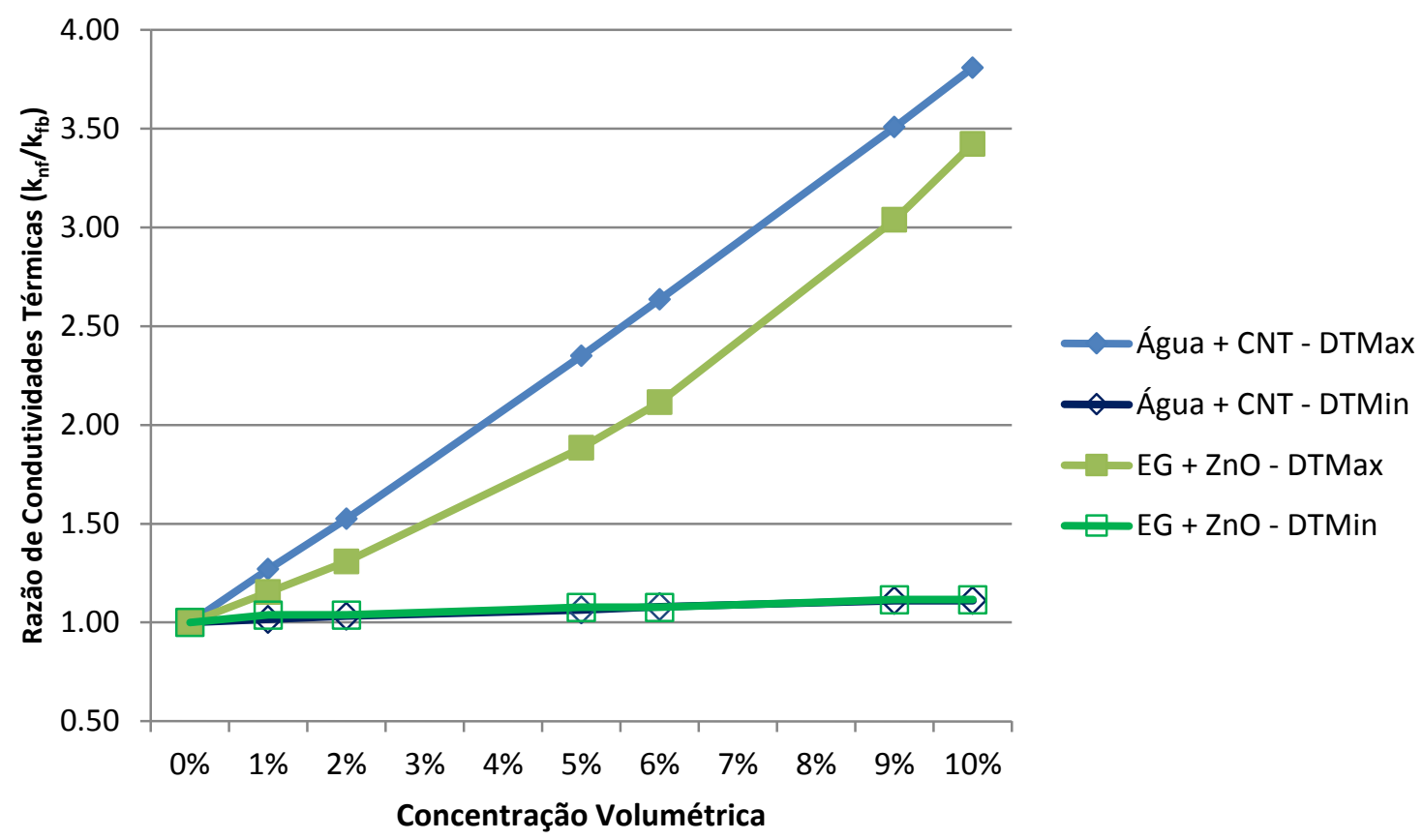

Figura 54. Intensificação proporcional obtida para a condutividade térmica dos nanofluidos estudados

Observa-se na Figura 54 que ambos os nanofluidos apresentam um comportamento qualitativamente semelhante no que se refere à intensificação proporcional da condutividade térmica. Entretanto, é importante observar que as nanopartículas de nanotubos de carbono introduzidas na água possuem uma condutividade térmica aproximadamente 4 vezes maior do que as nanopartículas de óxido de zinco introduzidas no etilenoglicol. Esta observação traz suporte à consideração de que a intensificação proporcional da condutividade térmica obtida por meio da introdução de nanopartículas em fluidos com menor condutividade térmica é proporcionalmente mais intensa do que a obtida em nanofluidos compostos por fluidosbase com maior condutividade térmica.

Em seguida, com as propriedades das Tabs. 34 e 35 e os valores da condutividade térmica efetiva determinados por meio destas mesmas tabelas em conjunto com a Equação [8], podemos obter os resultados referentes ao desempenho térmico obtido com a introdução de nanofluidos nos tubos de calor estudados contendo estas concentrações volumétricas de nanopartículas. Para isso, são abordados os seguintes casos:

- $\quad$ Liu e Lu (2009)

$$
\circ \quad \dot{Q}=40 W
$$


○ $\quad \dot{Q}=70 W$

- $\quad$ Putra et. al (2012)

As Figuras 55 a 60 mostram variações nos valores de temperatura obtidas para diferentes concentrações volumétricas de partículas no tubo de calor do estudo de Liu e Lu (2009).

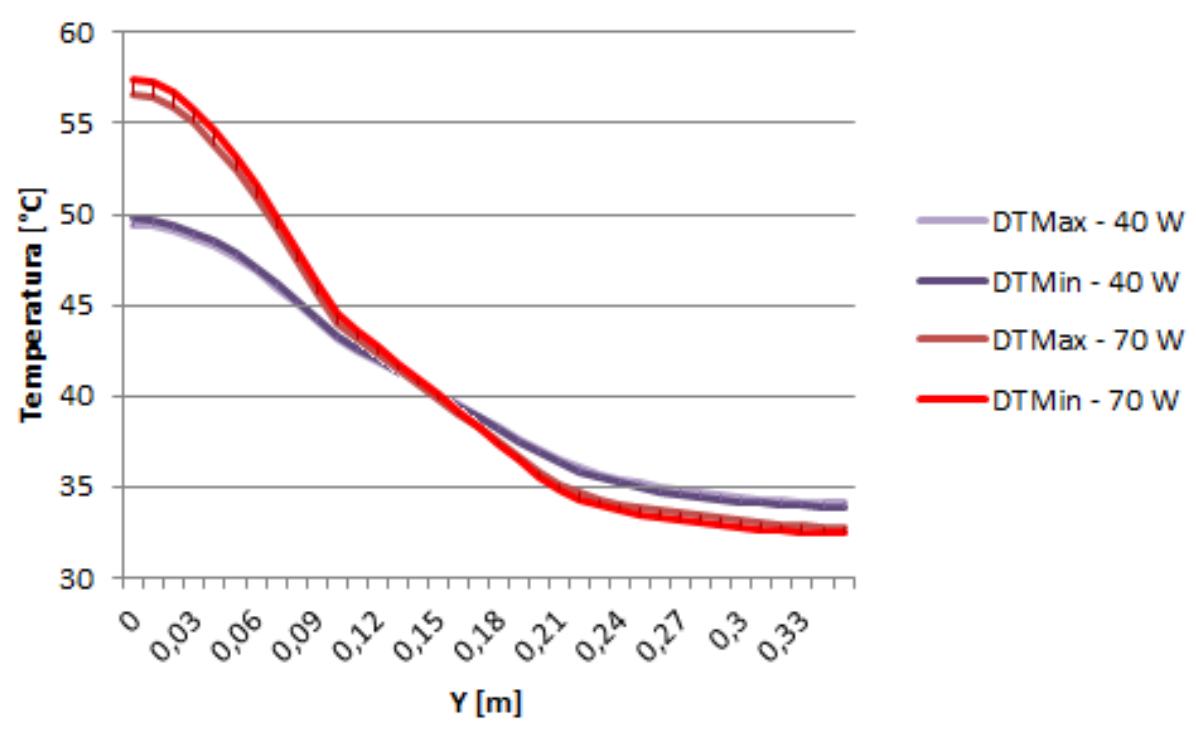

Figura 55. Análise de sensibilidade da concentração volumétrica de nanopartículas do nanofluido do tubo de calor de Liu e Lu (2009) contendo um nanofluido composto por água e nanotubos de carbono para $\varphi=1 \%$

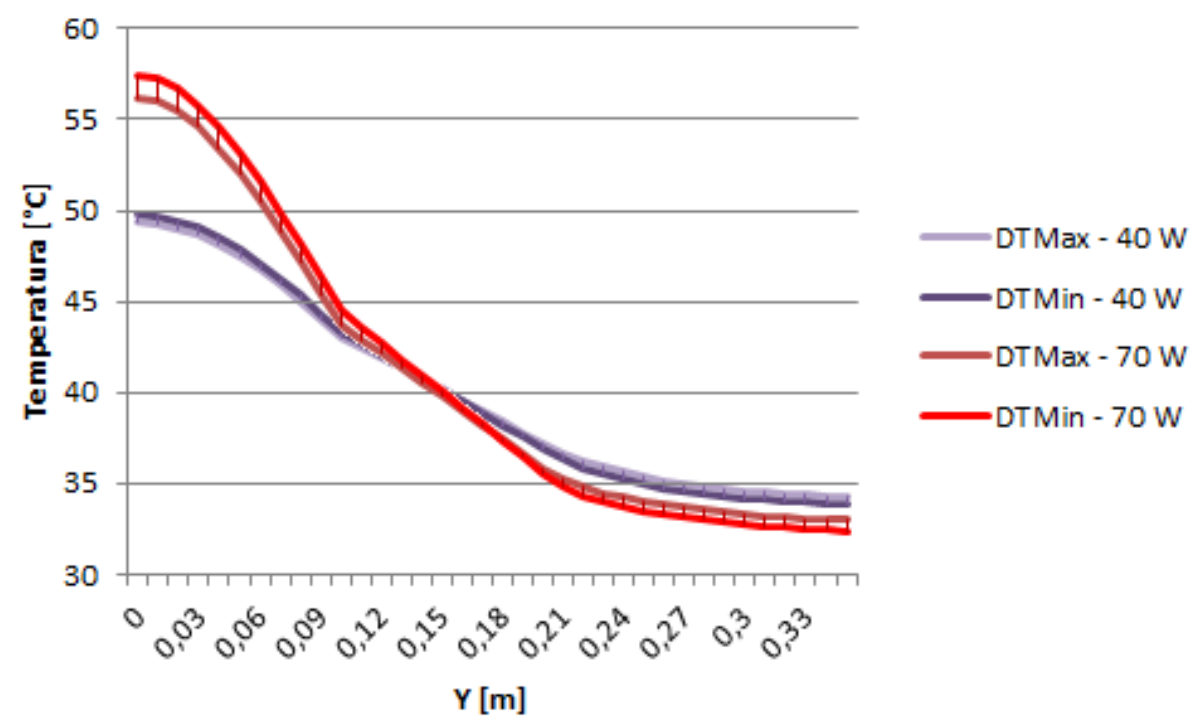

Figura 56. Análise de sensibilidade da concentração volumétrica de nanopartículas do nanofluido do tubo de calor de Liu e Lu (2009) contendo um nanofluido composto por água e nanotubos de carbono para $\varphi=2 \%$ 


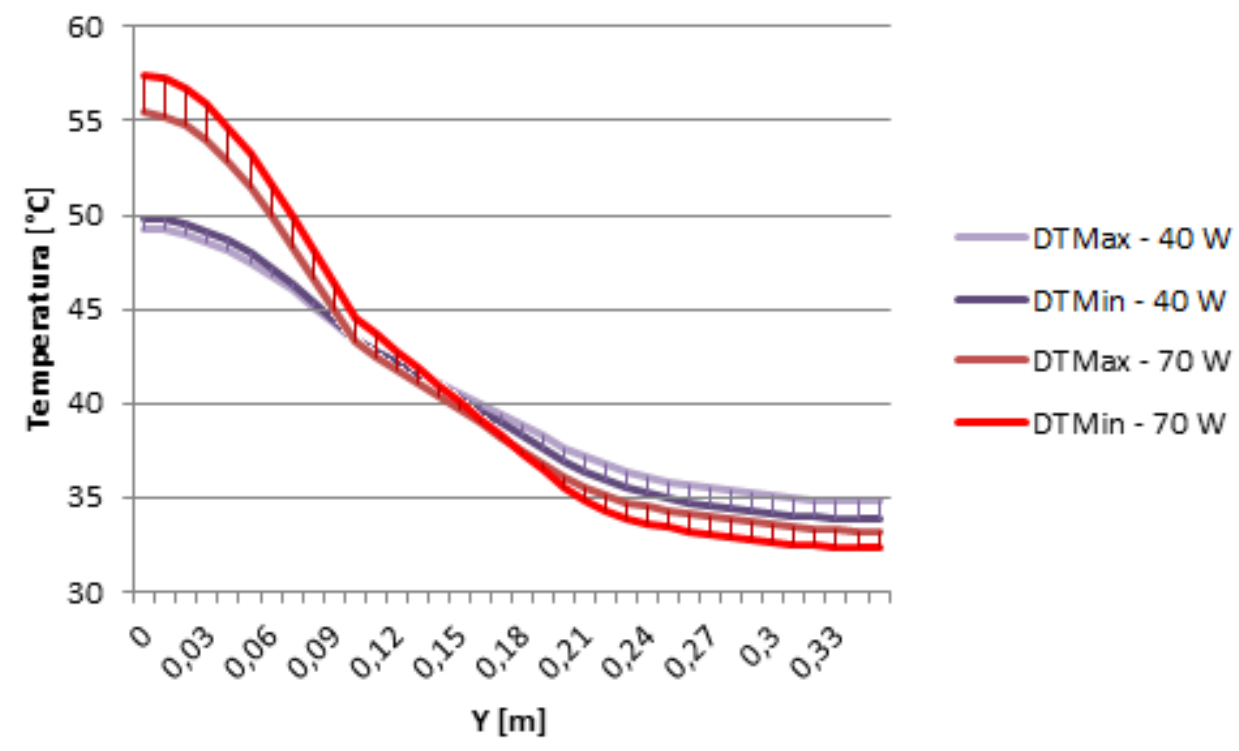

Figura 57. Análise de sensibilidade da concentração volumétrica de nanopartículas do nanofluido do tubo de calor de Liu e Lu (2009) contendo um nanofluido composto por água e nanotubos de carbono para $\varphi=5 \%$

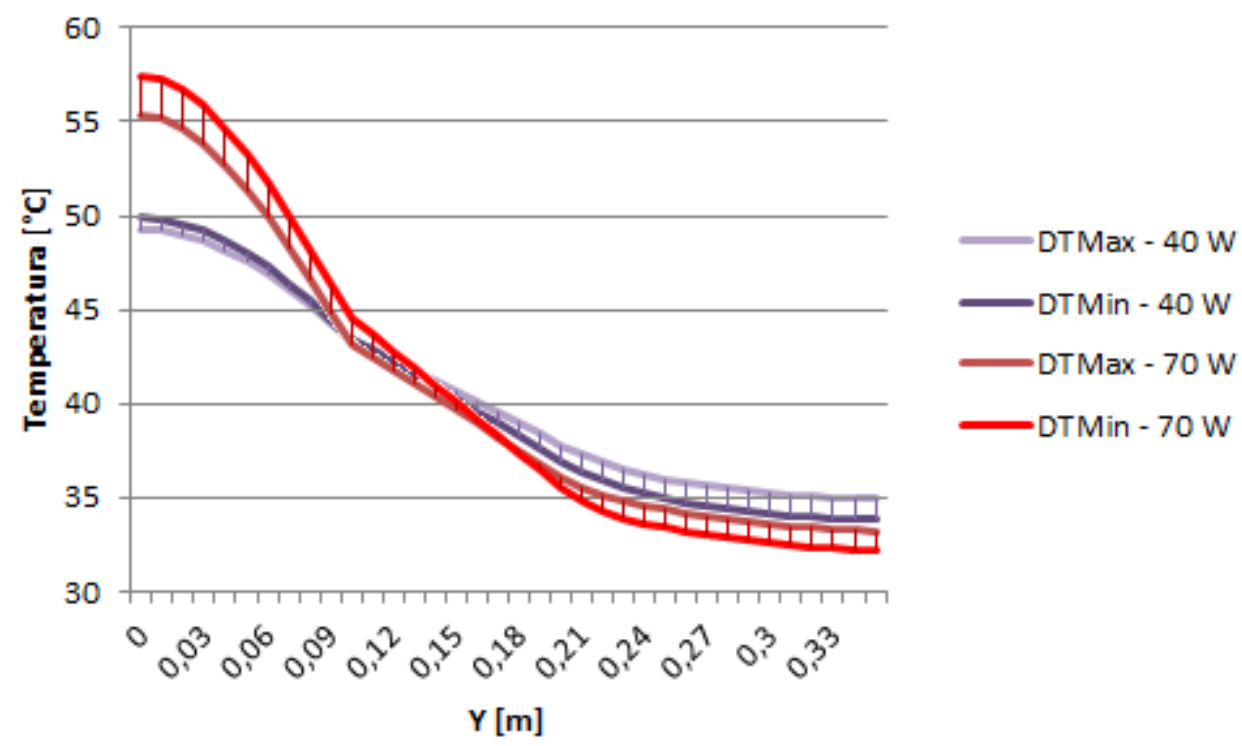

Figura 58. Análise de sensibilidade da concentração volumétrica de nanopartículas do nanofluido do tubo de calor de Liu e Lu (2009) contendo um nanofluido composto por água e nanotubos de carbono para $\varphi=6 \%$ 


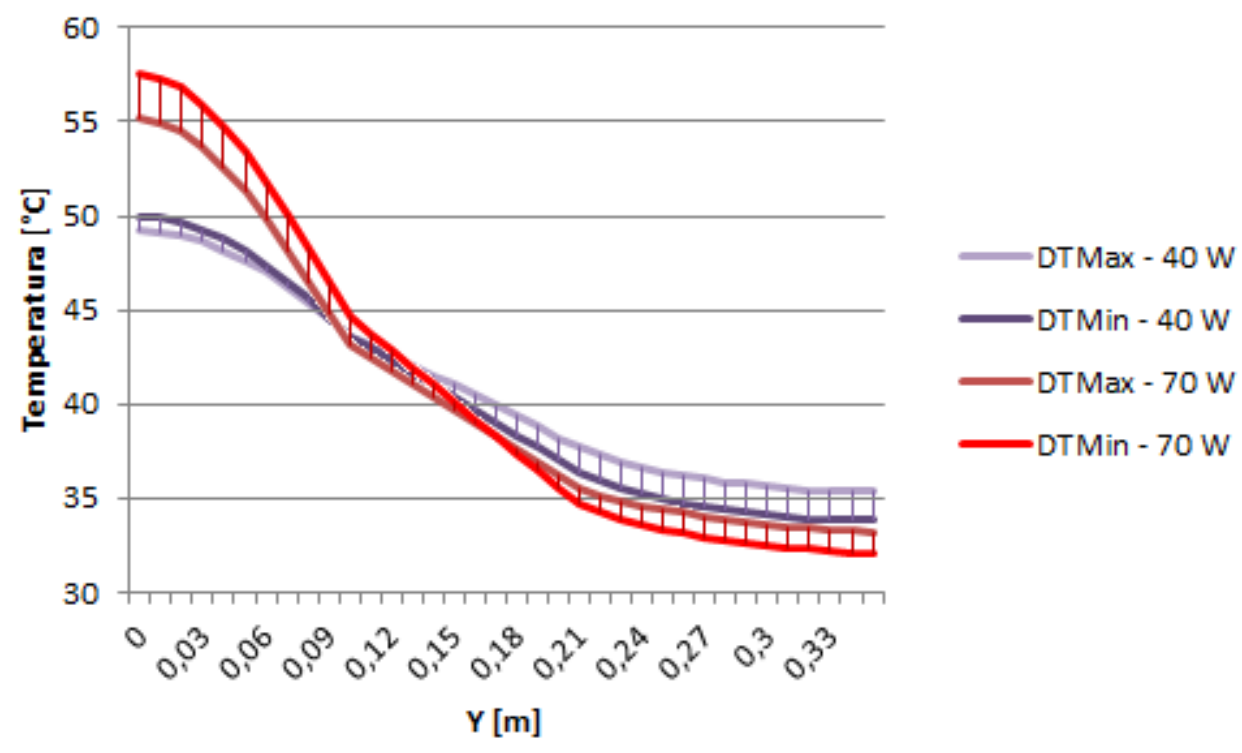

Figura 59. Análise de sensibilidade da concentração volumétrica de nanopartículas do nanofluido do tubo de calor de Liu e Lu (2009) contendo um nanofluido composto por água e nanotubos de carbono para $\varphi=9 \%$

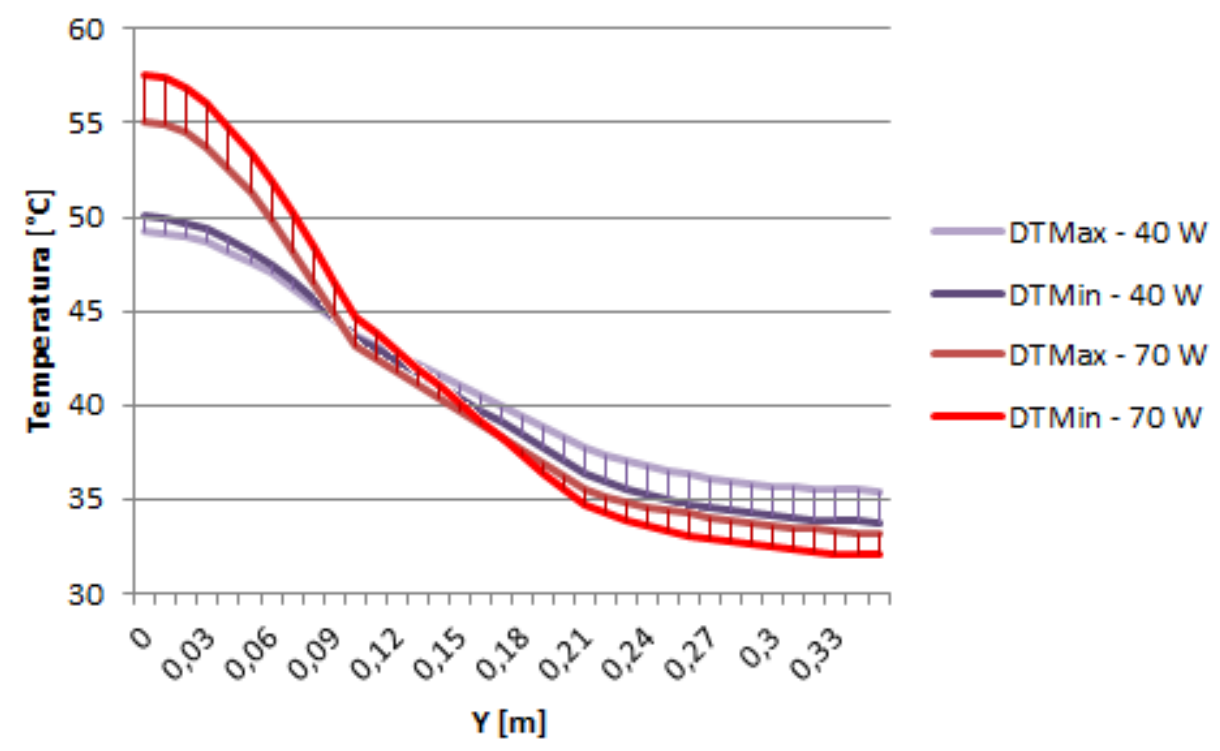

Figura 60. Análise de sensibilidade da concentração volumétrica de nanopartículas do nanofluido do tubo de calor de Liu e Lu (2009) contendo um nanofluido composto por água e nanotubos de carbono para $\varphi=10 \%$

Como uma primeira análise visual, é possível observar que os resultados obtidos nos casos referentes a uma potência térmica inserida de $40 \mathrm{~W}$ mostram um impacto 
maior da variação da concentração volumétrica de partículas na variação das temperaturas da seção do condensador do que na seção do evaporador, enquanto os casos referentes a uma potência térmica inserida de $70 \mathrm{~W}$ apresentam impacto semelhante em ambas as seções (evaporador e condensador). Este comportamento indica que a potência térmica inserida possui influência direta no processo de ebulição de um nanofluido, e supõe-se que este comportamento seja relacionado a uma maior agitação das partículas na seção do evaporador, enquanto que o processo de condensação de nanofluidos permanece praticamente inalterado com a variação da potência térmica inserida.

Posteriormente, é possível observar também que, para o caso DTMax, houve uma redução significativa da resistência térmica do tubo de calor com o aumento da concentração volumétrica de nanopartículas em ambas as potências térmicas estudadas, enquanto que para o caso DTMin, houve um pequeno aumento da resistência térmica com o aumento desta concentração. Este comportamento é esperado, uma vez que as correlações utilizadas para o cálculo da viscosidade absoluta e da condutividade térmica são funções da concentração volumétrica de nanopartículas do nanofluido.

Na Tabela 35, pode-se observar numericamente o valor obtido para a variação destas resistências térmicas através da Equação [61].

Assim, em DTMax o aumento da condutividade térmica foi capaz de compensar o efeito do aumento da viscosidade, melhorando o desempenho térmico do tubo de calor, e em DTMin a viscosidade foi elevada de tal forma que o aumento da condutividade térmica foi insuficiente para compensar os efeitos de perda de pressão, causando assim uma deterioração no desempenho do tubo de calor.

Observa-se da Tab. 35 também que o aumento de 1\% para 10\% na concentração volumétrica de nanopartículas pode causar uma redução máxima na resistência térmica de $12,16 \%$ ou um aumento máximo na resistência térmica de 2,49\%.

Não são observados neste intervalo quaisquer pontos de inflexão para os quais as tendências de aumento ou redução da resistência térmica sejam revertidas nos casos DTMax e DTMin. Entretanto, observa-se que, com o aumento da concentração volumétrica de nanopartículas, a razão de redução da resistência térmica em DTMax diminui e a razão de aumento da resistência térmica em DTMin aumenta, o que leva a crer que, em um hipotético caso contendo nanofluidos configurados utilizando modelos 
de propriedades intermediários, serão observados pontos para os quais a resistência térmica é mínima.

Tabela 35. Resistências térmicas do tubo de calor de Liu e Lu (2009) contendo nanofluidos compostos por água e nanotubos de carbono em diferentes concentrações volumétricas

\begin{tabular}{|c|c|c|c|}
\hline \multirow{2}{*}{$\begin{array}{l}\text { Conjunto de } \\
\text { Propriedades }\end{array}$} & \multirow{2}{*}{$\begin{array}{l}\text { Concentração } \\
\text { Volumétrica }\end{array}$} & \multicolumn{2}{|c|}{ Resistência térmica $\left({ }^{\circ} \mathrm{C} / \mathrm{W}\right)$} \\
\hline & & $40 \mathrm{~W}$ & $70 \mathrm{~W}$ \\
\hline \multirow{6}{*}{ DTMax } & $1 \%$ & 0,300 & 0,256 \\
\hline & $2 \%$ & 0,294 & 0,248 \\
\hline & $5 \%$ & 0,283 & 0,235 \\
\hline & $6 \%$ & 0,280 & 0,234 \\
\hline & $9 \%$ & 0,273 & 0,232 \\
\hline & $10 \%$ & 0,270 & 0,232 \\
\hline \multirow{6}{*}{ DTMin } & $1 \%$ & 0,312 & 0,270 \\
\hline & $2 \%$ & 0,313 & 0,270 \\
\hline & $5 \%$ & 0,316 & 0,273 \\
\hline & $6 \%$ & 0,317 & 0,273 \\
\hline & $9 \%$ & 0,320 & 0,276 \\
\hline & $10 \%$ & 0,321 & 0,278 \\
\hline
\end{tabular}

Para uma melhor visualização desta afirmação, a figura 59 mostra o efeito obtido com a introdução de 10 aproximações linearmente posicionadas entre os casos DTMin e DTMax da resistência térmica obtida com uma potência térmica inserida de 70W. Estas aproximações lineares representam tubos de calor contendo nanofluidos hipoteticamente representados por correlações de propriedades que fornecem condutividades térmicas menores do que a de DTMax e viscosidades absolutas menores do que a de DTMin.

Observa-se da Fig. 61 que as aproximações lineares de números 5 a 10, são casos onde ocorrem valores de mínimo para a resistência térmica, e consequentemente, pontos de máximo para o desempenho térmico do tubo de calor contendo nanofluidos, tais como previstos na literatura. 


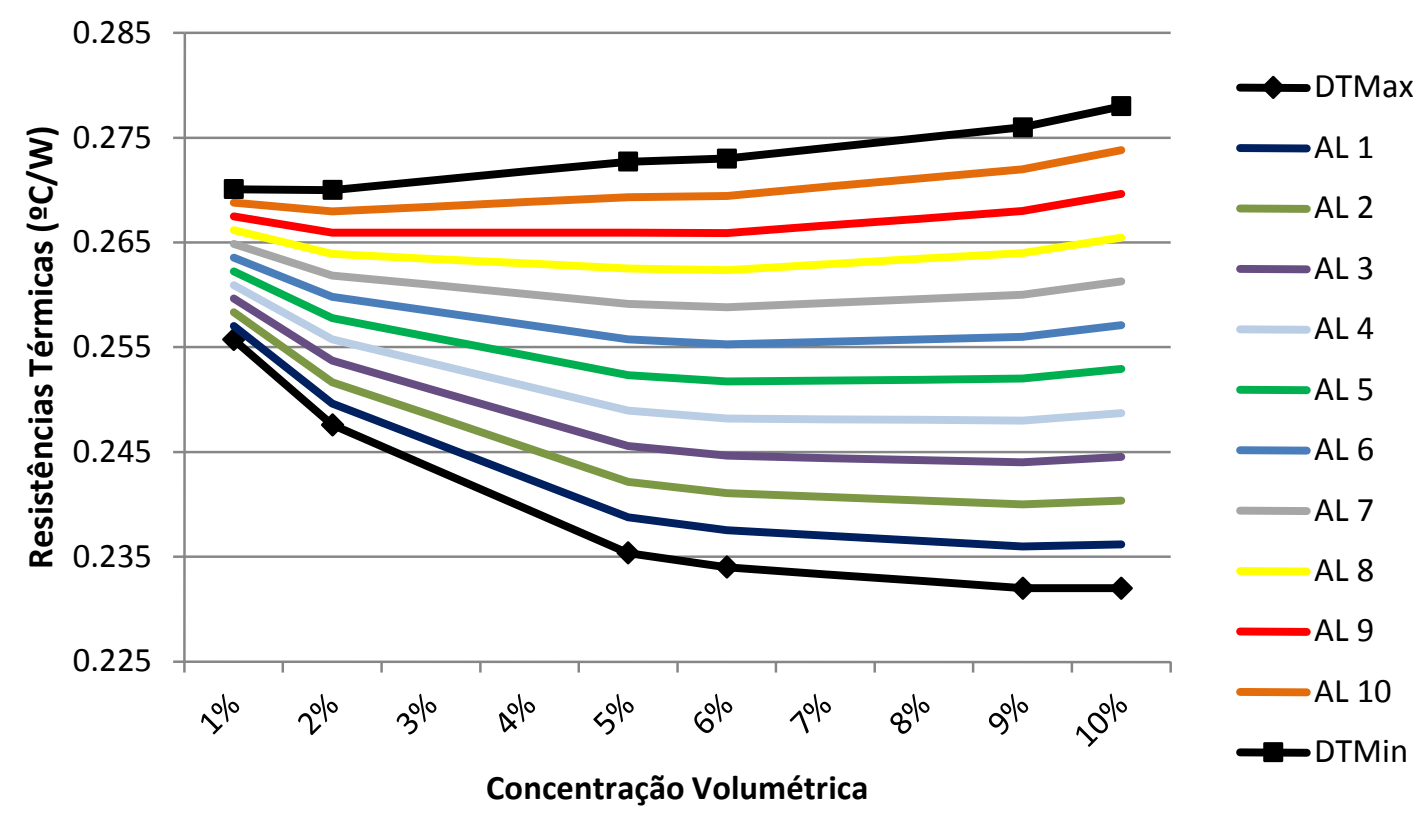

Figura 61. Resistências térmicas obtidas por meio de 10 aproximações lineares inseridas entre as resistências térmicas obtidas para os casos DTMax e DTMin no tubo de calor de Liu e Lu (2009) para $\dot{Q}=70 \mathrm{~W}$

Em seguida, as Figuras 62 a 67 mostram os intervalos de temperaturas nas seções do evaporador e adiabática, obtidos com a variação da concentração volumétrica do nanofluido do tubo de calor do estudo de Putra et al. (2012).

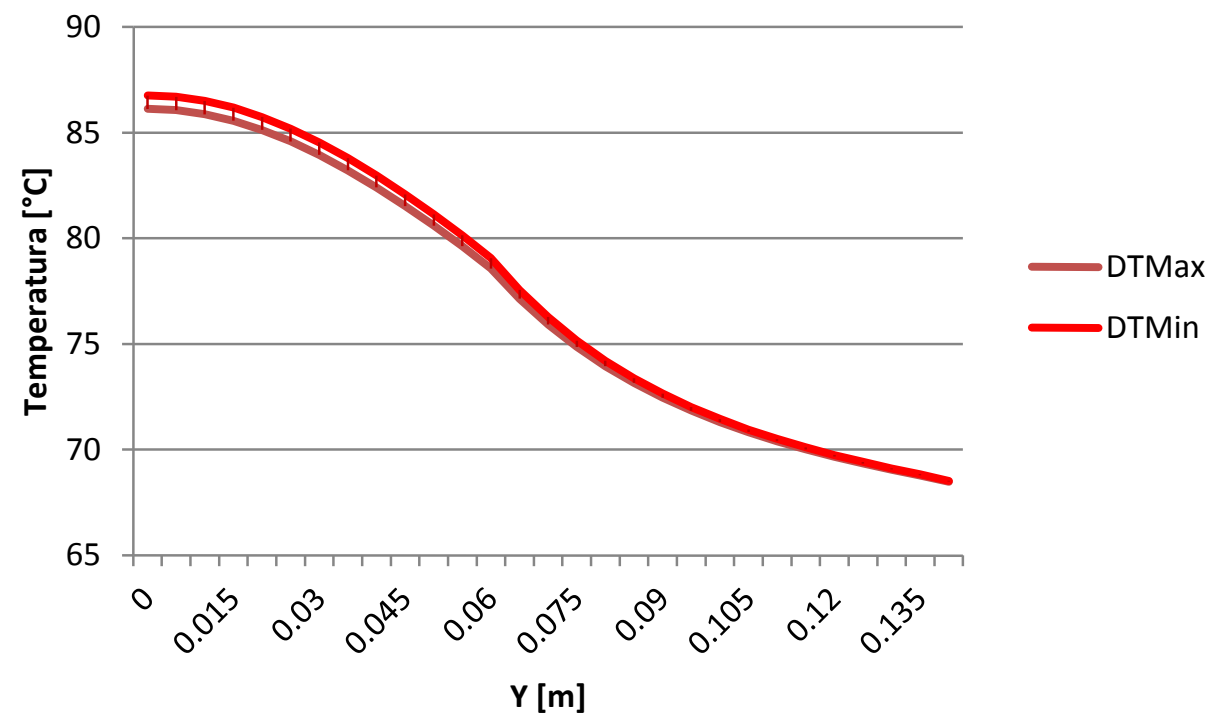

Figura 62. Análise de sensibilidade da concentração volumétrica de nanopartículas do nanofluido do tubo de calor de Putra et al. (2012) contendo um nanofluido composto por etilenoglicol e óxido de zinco para $\varphi=1 \%$ 


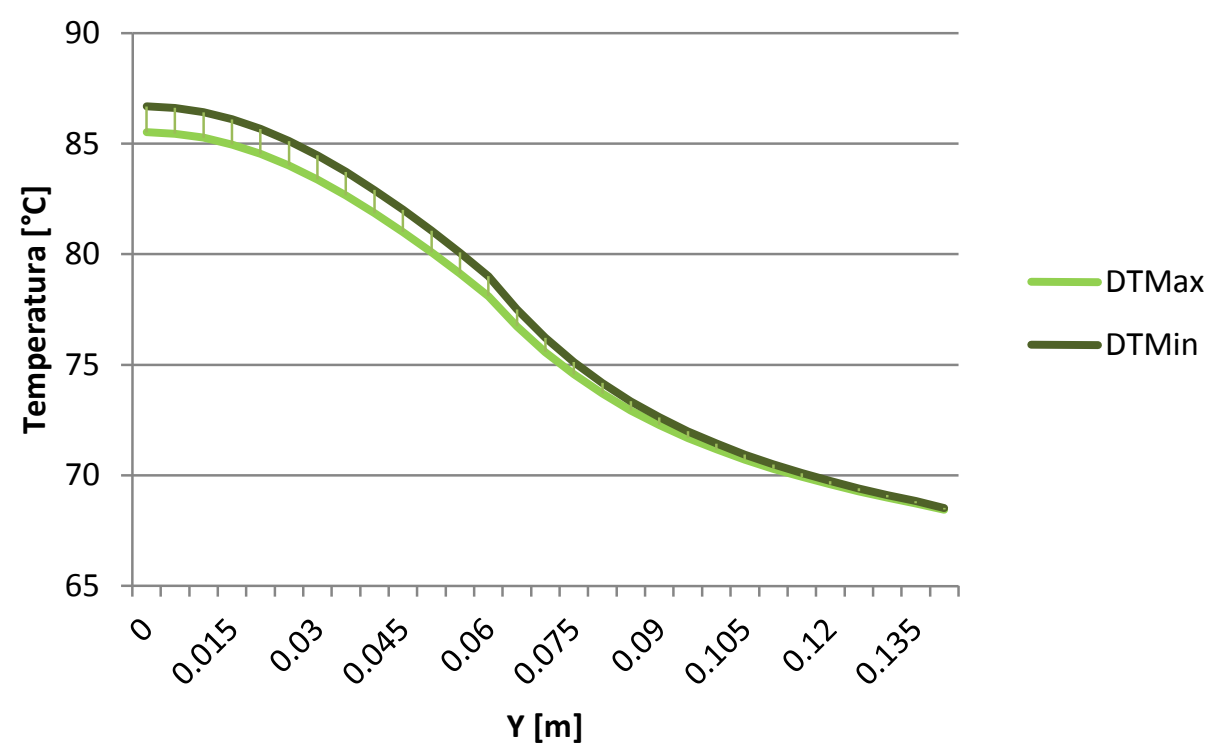

Figura 63. Análise de sensibilidade da concentração volumétrica de nanopartículas do nanofluido do tubo de calor de Putra et al. (2012) contendo um nanofluido composto por etilenoglicol e óxido de zinco para $\varphi=2 \%$

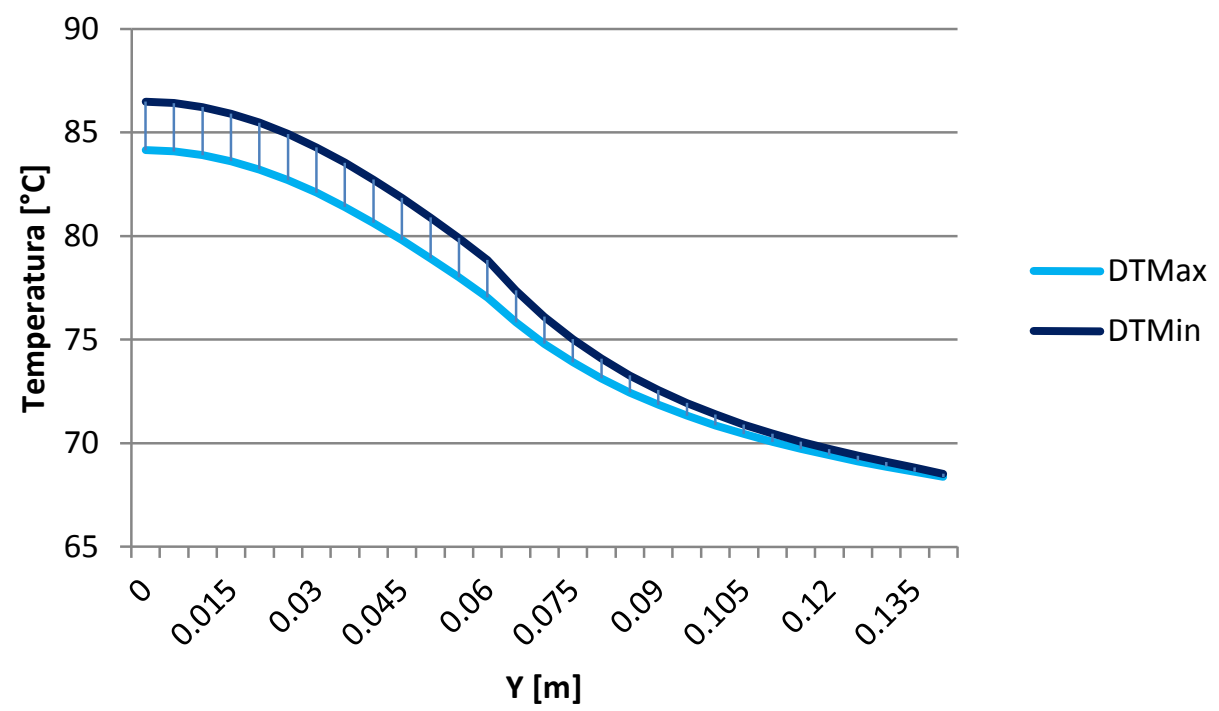

Figura 64. Análise de sensibilidade da concentração volumétrica de nanopartículas do nanofluido do tubo de calor de Putra et al. (2012) contendo um nanofluido composto por etilenoglicol e óxido de zinco para $\varphi=5 \%$ 


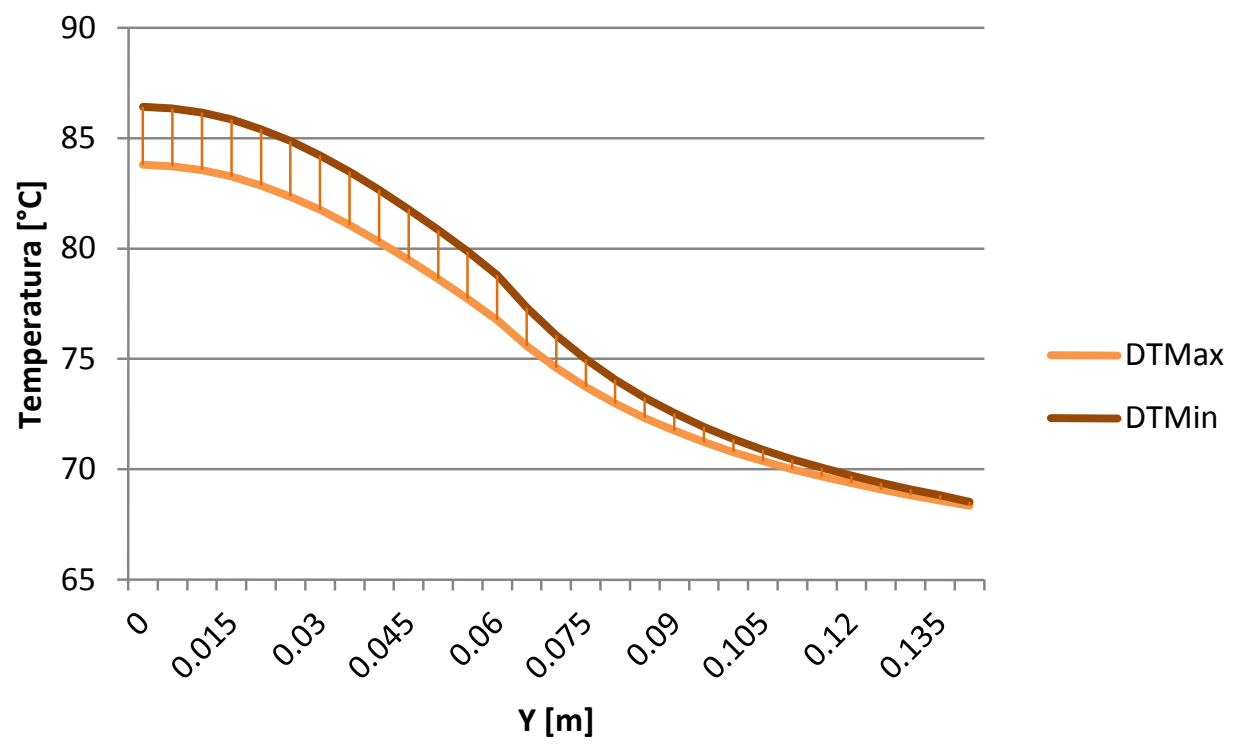

Figura 65. Análise de sensibilidade da concentração volumétrica de nanopartículas do nanofluido do tubo de calor de Putra et al. (2012) contendo um nanofluido composto por etilenoglicol e óxido de zinco para $\varphi=6 \%$

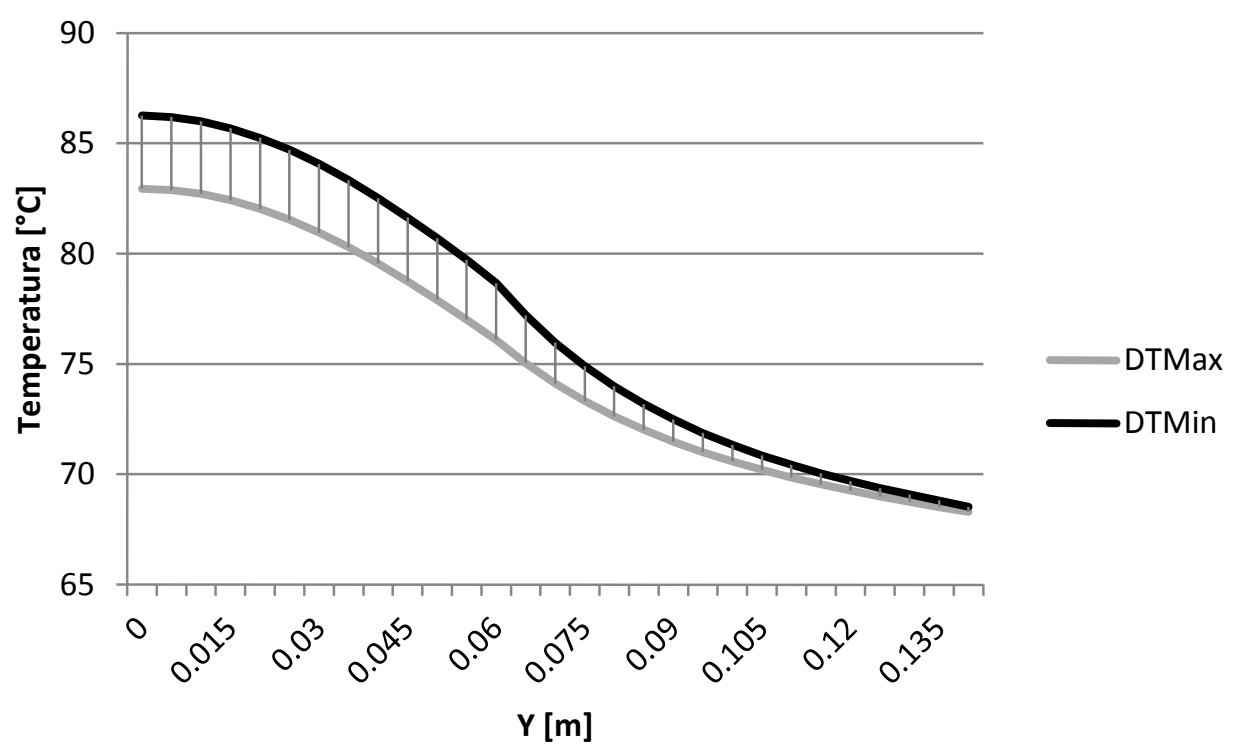

Figura 66. Análise de sensibilidade da concentração volumétrica de nanopartículas do nanofluido do tubo de calor de Putra et al. (2012) contendo um nanofluido composto por etilenoglicol e óxido de zinco para $\varphi=9 \%$ 


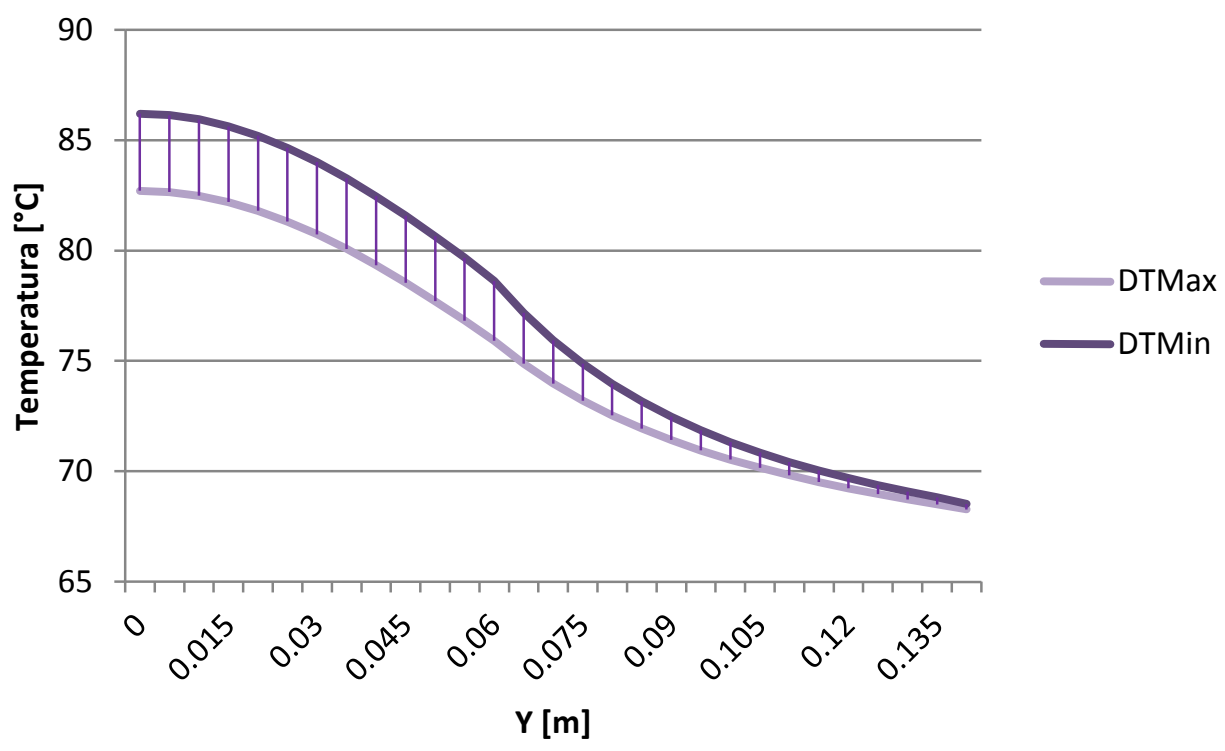

Figura 67. Análise de sensibilidade da concentração volumétrica de nanopartículas do nanofluido do tubo de calor de Putra et al. (2012) contendo um nanofluido composto por etilenoglicol e óxido de zinco para $\varphi=10 \%$

Observa-se neste caso um comportamento similar ao obtido nas Figs. 55 a 60 para a potência térmica de $70 \mathrm{~W}$, com a variação de temperatura sendo mais intensa na seção do evaporador e para a concentração volumétrica de nanopartículas de 10\%. Além disso, os valores das resistências térmicas assumem o mesmo comportamento de proporcionalidade com a concentração volumétrica para DTMax, sendo calculados pela Equação [62], específica para o tubo de calor de Putra et al. (2012). Estes valores podem ser observados na Tab. 36.

Neste caso, o aumento da concentração volumétrica de nanopartículas no caso DTMin também obteve uma redução na resistência térmica do tubo de calor de Putra et al. (2012). Este resultado sugere que, mesmo utilizando as condições para as quais o desempenho térmico do tubo de calor é modelado utilizando o conjunto de propriedades mais prejudicial ao desempenho térmico possível, ocorre intensificação do desempenho térmico por meio do aumento da concentração de nanopartículas neste caso. 
Tabela 36. Resistências térmicas do tubo de calor de Putra et al. (2012) contendo nanofluidos compostos por etilenoglicol e óxido de zinco em diferentes concentrações volumétricas

\begin{tabular}{ccc}
\hline \multirow{2}{*}{$\begin{array}{c}\text { Conjunto de } \\
\text { Propriedades }\end{array}$} & $\begin{array}{c}\text { Concentração } \\
\text { Volumétrica }\end{array}$ & Resistência térmica $\left({ }^{\circ} \mathrm{C} / \mathrm{W}\right)$ \\
\hline \multirow{3}{*}{ DTMax } & $1 \%$ & 0,374 \\
\cline { 2 - 3 } & $2 \%$ & 0,361 \\
\cline { 2 - 3 } & $5 \%$ & 0,333 \\
\hline & $6 \%$ & 0,326 \\
\hline & $9 \%$ & 0,308 \\
\hline \multirow{2}{*}{ DTMin } & $10 \%$ & 0,303 \\
\hline & $2 \%$ & 0,387 \\
\cline { 2 - 3 } & $5 \%$ & 0,386 \\
\hline & $6 \%$ & 0,381 \\
\hline & $10 \%$ & 0,380 \\
\hline
\end{tabular}

Não são observados neste intervalo quaisquer pontos de inflexão para os quais a tendência de aumento da resistência térmica seja revertida, nem possibilidades de inflexões em casos intermediários. Colocando esta tendência em perspectiva com os valores das resistências térmicas obtidas para o nanofluido contendo água e nanotubos de carbono, é possível observar que existe uma diferença no comportamento destes nanofluidos. Supõe-se que a variação da massa específica e do calor específico seja responsável por esta diferença, uma vez que a massa específica é muito mais intensificada no nanofluido contendo etilenoglicol e óxido de zinco, e que o calor específico neste nanofluido aumenta com a concentração volumétrica de nanopartículas, ao contrário do que ocorre no nanofluido contendo água e nanotubos de carbono. 


\section{DISCUSSÃO E CONCLUSÕES}

\subsection{Discussão}

Os resultados obtidos com a utilização do modelo proposto por Mahjoub e Matabroshan (2008) e utilizado por Gavtash et al. (2012) para a construção de um tubo de calor podem levar a uma série de considerações envolvendo as diferentes situações avaliadas neste estudo.

A partir dos resultados das simulações de tubos de calor contendo somente os fluidos-base sem a presença de nanopartículas, os seguintes aspectos podem ser considerados:

- a adoção da existência de condução de calor na parede do tubo de calor é uma alteração introduzida neste trabalho que aproxima os resultados computacionais dos resultados experimentais; a análise feita no apêndice 1, associada aos trabalhos experimentais de Kempers et al. (2008) e Wong (2014) leva a crer que uma abordagem similar a esta deva ser adotada em trabalhos futuros, se possível incorporando a quantidade de calor conduzida pela parede do tubo de calor ao modelo computacional automaticamente;

- a consideração feita pelo modelo de Mahjoub e Matabroshan (2008) de que a evaporação no interior de um tubo de calor pode ser representada de forma simplificada por um termo fonte constante ao longo do comprimento desta seção pode ser um fator responsável por parte das distorções obtidas entre os resultados computacionais e os dados experimentais nas regiões de transição do tubo de calor, visto que na literatura, os coeficientes de transferência de calor em situações de ebulição convectiva são dependentes de parâmetros que variam ao longo do comprimento da seção do evaporador (Kandlikar, 1990; Cabral, 2012); isto abre espaço para a adoção de condições de contorno mais complexas, cujo comportamento também pode ser estudado em trabalhos futuros;

- a análise de sensibilidade em relação à potência térmica da água indica que a incerteza nesse parâmetro não pode ser responsável pelas distorções observadas, mantendo as curvas calculadas para os perfis de temperatura da 
parede dos tubos de calor dos trabalhos de Zerbini (1984) e Putra et al. (2012) dentro das margens de erro definidas nos trabalhos experimentais.

- a adaptação do modelo computacional de forma a reproduzir uma simulação computacional bidimensional por meio de um modelo tridimensional de espessura reduzida não introduziu erros significativos, dado que os níveis de temperatura obtidos são compatíveis com os perfis experimentais e poucos pontos obtidos se encontraram realmente distantes das margens de erro definidas experimentalmente utilizando somente fluidos-base;

- a condição de contorno adotada nas simulações para tentar reproduzir a condição física utilizada nos levantamentos experimentais do tubo de calor de Putra et al. (2012) a partir da análise de balanço de energia do apêndice 2 levou a resultados insatisfatórios das simulações nesse trecho; isto indica que uma modelagem mais complexa desta região deste tubo de calor é necessária de forma a representar corretamente o comportamento de um tubo de calor nestas condições; ainda assim, esta discrepância não afetou de forma significativa os resultados obtidos para as demais seções do tubo de calor, tornando as análises dos perfis de temperatura destas seções e da resistência térmica possíveis.

- em todos os tubos de calor simulados contendo somente fluidos-base, os valores absolutos das resistências térmicas apresentaram aproximações dos valores experimentais contendo aproximadamente uma ordem de grandeza de diferença dos valores definidos experimentalmente. Isto indica que esta modelagem é potencialmente adequada para a definição destes valores nestes casos; entretanto, é importante destacar que, em termos relativos, estes valores representam diferenças absolutas entre 0 e 17,9\% de acordo com a potência térmica inserida, de forma que somente em determinados valores de potência térmica inserida a simulação computacional fornece uma aproximação suficientemente adequada para a estimativa da resistência térmica.

Já para a simulação de tubos de calor contendo nanofluidos, as considerações podem ser feitas: 
- observa-se dos resultados obtidos que a simples alteração das propriedades do fluido utilizando correlações diferentes não foi suficiente para representar o comportamento térmico da seção do evaporador de um tubo de calor contendo um nanofluido, pois ambos os trabalhos experimentais estudados mostram reduções mais significativas da temperatura máxima do tubo de calor nesta seção do que os perfis de temperatura obtidos computacionalmente neste trabalho revelam.

- as correlações de propriedades utilizadas para a modelagem das propriedades dos nanofluidos levaram em consideração diversos fenômenos que ocorrem em nanofluidos cuja importância se mostra significativa na literatura (tais como o efeito do movimento browniano de partículas, o efeito de aglomeração de nanopartículas, o efeito da temperatura média de mistura, o efeito da concentração volumétrica de nanopartículas, entre outros); isto leva a crer que a simples consideração destes fenômenos por meio de termos adicionais nas correlações utilizadas para o cálculo das propriedades abordadas neste trabalho não é suficiente para modelar o processo de ebulição que ocorre na seção do evaporador de um tubo de calor, subestimando o efeito causado pela introdução das nanopartículas neste processo.

- os resultados obtidos a partir das simulações utilizando o tubo de calor de Liu e Lu (2009) também levam a crer que a modelagem negligencia algum parâmetro importante somente na seção do evaporador, devido à discrepância obtida ter sido claramente observada somente nesta seção; na seção do condensador, a variação é pequena a ponto de poder ser justificada através dos efeitos de variação de propriedades.

- comparando o trabalho de Gavtash et al. (2012) com os resultados computacionais obtidos, observa-se que os perfis de temperatura obtidos com a aplicação de nanofluidos no tubo de calor deste trabalho (Figura 25) apresentam uma variação pequena na temperatura da parede mesmo para concentrações volumétricas de $20 \%$ e estes perfis não são comparados diretamente com nenhum dado experimental; esta variação pequena também é observada nos resultados obtidos pelo presente estudo, mas não condizem 
com o comportamento experimental observado nos tubos de calor estudados contendo nanofluidos.

- ainda a respeito de Gavtash et al. (2012), a redução da resistência térmica obtida pelos autores de fato foi justificada por meio do aumento da condutividade térmica causado pela introdução de nanofluidos, e este efeito também ocorreu no presente estudo; no entanto, este efeito isoladamente não reproduz o comportamento observado das resistências térmicas associadas aos perfis de temperatura dos tubos de calor estudados.

- ainda a respeito de Gavtash et al. (2012), nenhum comentário foi feito a respeito dos valores do calor específico e da entalpia de vaporização do nanofluido utilizado pelos autores; isso leva a crer que os valores utilizados são as propriedades do fluido-base sem nanopartículas, o que pode ter causado algumas das discrepâncias observadas; além disso, nenhuma informação é dada a respeito das características da matriz porosa utilizada, o que não permite reproduzir os resultados por eles obtidos.

- a respeito dos aspectos que podem ser responsáveis pelas diferenças observadas, os estudos de Ding et al. (2006) e Suganthi et al. (2014) enumeraram fatores que influenciam a transferência de calor em um nanofluido, cujos efeitos não foram introduzidos nos modelos computacionais do presente estudo e que podem ser considerados em trabalhos experimentais e de simulação futuros:

- o rearranjo das nanopartículas ao longo do nanofluido, causado pelas taxas de cisalhamento não uniformes ao longo da secção transversal do escoamento;

○ a redução da camada limite térmica ao longo do escoamento, causada pela presença de nanopartículas;

- a indução de microconvecção causada pelo Browniano de partículas e o transporte de calor causado pela mecânica molecular de partículas;

- adicionalmente, um fator importante é mencionado nos trabalhos de Liu e Lu (2009) e Putra et al. (2012), que consiste na influência do nanofluido na interação existente entre o fluido de trabalho e a superfície de aquecimento no processo de ebulição; o trabalho de Liu e Lu refere-se à diminuição do ângulo de contato entre o fluido e a superfície sólida obtido com a introdução dos 
nanofluidos como sendo responsável por um aumento na pressão capilar de bombeamento no interior do tubo de calor, modificando assim o desempenho do tubo de calor, enquanto Putra et al. (2012) conclui que a utilização de nanofluidos no interior de um tubo de calor causa a formação de uma camada fina na superfície da matriz porosa, e que esta camada possibilita uma melhora do transporte capilar ao longo do tubo de calor, permitindo a obtenção de uma transferência de calor ainda mais intensa do que a esperada pela simples intensificação da condutividade térmica;

- é possível identificar na literatura referente à ebulição de nanofluidos uma série de trabalhos indicando a modificação da superfície de aquecimento causada pela introdução das nanopartículas no fluido-base como sendo o principal fator responsável pela intensificação da transferência de calor por ebulição, tais como Narayan et al. (2007), Li et al. (2014), Kim et al. (2007), Taylor e Phelan (2009), You et al. (2003) e diversos outros; esta modificação não é quantificada em nenhum trabalho computacional contendo tubos de calor e pode ser o fator responsável pela alteração causada por um nanofluido no comportamento térmico de um tubo de calor observado experimentalmente;

- esta modificação pode ser responsável pela alteração de parâmetros cuja influência é sentida diretamente no desempenho térmico do tubo de calor, como por exemplo, a temperatura de regime permanente, a entalpia de vaporização, a área de contato sólido-líquido, o comportamento dos termos fonte utilizados na modelagem do fenômeno de ebulição, entre outros; no entanto, a quantificação da influência destes parâmetros apresenta uma série de dificuldades, uma vez que boa parte deles ainda depende fortemente das condições empíricas aplicadas a cada tubo de calor, e por isso, não pode ser analisada mais a fundo neste estudo;

- adicionalmente, pode-se observar que não foram encontrados trabalhos na literatura associando ebulição sob convecção de nanofluidos e meios porosos, e que este pode ser mais um campo a ser explorado em futuras pesquisas;

A respeito dos modelos de propriedades dos nanofluidos estudados, pode-se afirmar o seguinte: 
- observa-se que os casos definidos como DTMax e DTMin de fato correspondem às situações nas quais são observadas os desempenhos máximo e mínimo para os modelos de propriedades adotados; assim, uma vez que se corrijam as discrepâncias observadas na modelagem, esta análise será capaz de explicitar os modelos mais adequados para a avaliação das propriedades do nanofluido em um tubo de calor;

- uma comparação entre os resultados obtidos computacionalmente para o tubo de calor de Putra et al. (2012) com água, etilenoglicol e o nanofluido contendo etilenoglicol e óxido de zinco avaliado para os casos DTMin e DTMax, indica que existe uma relação inversamente proporcional entre o valor da resistência térmica do tubo de calor e a condutividade térmica do fluido de trabalho utilizado, ou seja, uma maior condutividade térmica resulta em uma menor resistência térmica, e vice-versa; isto leva a crer que, utilizando um fluido de trabalho com uma condutividade térmica menor do que a da água (como ocorre em DTMin e DTMax), seria impossível obter uma resistência térmica menor do que a da água utilizando o modelo de Mahjoub e Matabroshan (2008) sem quaisquer modificações e, consequentemente, impossível de reproduzir a resistência térmica obtida experimentalmente no trabalho de Putra et al. (2012) com a adição de nanofluidos;

- observa-se que o comportamento da condutividade térmica do nanofluido contendo etilenoglicol e óxido de zinco medido experimentalmente por Putra et al. (2012) aproxima-se mais do comportamento obtido através da correlação de Yu e Choi do que do comportamento definido pelas demais correlações; esta observação fortalece a consideração de que a modificação da condutividade térmica isoladamente não é capaz de proporcionar uma alteração no desempenho térmico tão significativa como a alteração observada experimentalmente nos trabalhos de Liu e Lu (2009) e Putra et al. (2012).

Por fim, as seguintes considerações podem ser feitas a respeito do efeito da variação da concentração volumétrica de nanopartículas do nanofluido no desempenho térmico do tubo de calor:

- a variação proporcional do valor da condutividade térmica obtida com a variação da concentração volumétrica de nanopartículas para o nanofluido 
contendo água e etilenoglicol é comparável à variação proporcional obtida para o nanofluido contendo etilenoglicol e óxido de zinco; no entanto, como a condutividade térmica do óxido de zinco é cerca de 4 vezes menor do que a condutividade térmica do nanotubo de carbono, pode-se observar que os modelos de propriedades utilizados para o cálculo da condutividade térmica de nanofluidos contendo etilenoglicol preveem uma variação proporcionalmente maior da condutividade térmica do que os modelos utilizados para o cálculo da condutividade térmica de nanofluidos contendo água, e isso fornece base teórica para corroborar a afirmação de que a intensificação proporcional da condutividade térmica obtida por meio da introdução de nanopartículas em fluidos com menor condutividade térmica é proporcionalmente mais intensa do que a obtida em nanofluidos compostos por fluidos-base com maior condutividade térmica;

- as variações obtidas com a alteração da concentração volumétrica de nanopartículas foram proporcionalmente menores no calor específico do que na massa específica; indicando que a escolha do estudo de Gavtash et al. (2012) de negligenciar o cálculo do calor específico do nanofluido utilizado provavelmente não teve consequências significativas; já a alteração obtida com a variação da concentração do nanofluido de $1 \%$ para $10 \%$ correspondeu ao aumento de aproximadamente uma ordem de grandeza na viscosidade do caso DTMin e ao aumento de três vezes na condutividade térmica do caso DTMax;

- para concentrações volumétricas mais altas nota-se uma variação maior de desempenho entre DTMax e DTMin, e isso indica uma dependência maior do modelo das alterações sofridas pela condutividade térmica com a variação da concentração volumétrica do que das alterações sofridas pela viscosidade absoluta;

- não são observados quaisquer pontos de inflexão para os quais as tendências de aumento ou redução da resistência térmica sejam revertidas nos casos definidos como DTMax ou DTMin para ambos os tubos de calor contendo nanofluidos; entretanto, das resistências térmicas obtidas da análise de sensibilidade tubo de calor de Liu e Lu (2009), observa-se que com o aumento da concentração volumétrica de nanopartículas ocorre redução da resistência térmica em DTMax e aumento da resistência térmica em DTMin, e que com 
este aumento da concentração volumétrica de nanopartículas, a razão de redução da resistência térmica em DTMax diminui e a razão de aumento da resistência térmica em DTMin aumenta;

- da avaliação do comportamento destas resistências térmicas no tubo de calor de Liu e Lu (2009) por meio de aproximações lineares, observa-se que em alguns casos hipotéticos correspondentes a tubos de calor contendo nanofluidos cujas propriedades são semelhantes às propriedades do caso DTMin, serão observados pontos de máximo tais como previstos na literatura;

- por fim, o aumento do valor obtido para as resistências térmicas do tubo de calor de Liu e Lu (2009), proporcional à concentração volumétrica de nanopartículas estudada para o caso DTMin, indica que o modelo computacional utilizado permite representar situações para as quais ocorre deterioração do desempenho térmico do tubo de calor tal como observado em alguns casos experimentais, desde que sejam utilizadas correlações de propriedades adequadas.

\subsection{Conclusões}

0 presente trabalho permite considerar que o modelo proposto por Mahjoub e Matabroshan (2008) e utilizado por Gavtash et al. (2012) tem seus méritos na avaliação do comportamento térmico de um tubo de calor contendo um fluido comum sem nanopartículas e na avaliação do comportamento da seção do condensador de um tubo de calor contendo nanofluidos, mas que falha em descrever o comportamento da seção do evaporador de um tubo de calor contendo nanofluidos.

Esta discrepância foi observada em uma série de situações, de forma que é seguro afirmar que existem efeitos que ocorrem na seção do evaporador de um tubo de calor contendo nanofluidos cuja influência não foi levada em consideração neste modelo. Ao que tudo indica, estes efeitos estão relacionados com a influência das nanopartículas na interação existente entre o fluido de trabalho e a superfície de aquecimento no processo de ebulição. Esta modificação foi observada nas conclusões dos trabalhos experimentais envolvendo nanofluidos em tubos de calor utilizados como base para o presente trabalho, e tem sido apontada como causa para a intensificação da transferência de calor por ebulição de nanofluidos por uma série de trabalhos da literatura. Assim, acredita-se 
que estudos posteriores devam ser realizados de forma a avaliarem novas formas de modelar o comportamento desta seção em uma simulação computacional.

Em sequência, pode-se afirmar a respeito da avaliação dos modelos de propriedades dos nanofluidos que a simples alteração da condutividade térmica do nanofluido não é capaz de causar uma alteração tão significativa no desempenho térmico de um tubo de calor contendo este nanofluido de forma a representar o comportamento experimental. Ao compararmos a alteração no valor da condutividade térmica obtida experimentalmente no trabalho de Putra et al. (2012) com a alteração obtida neste trabalho através da utilização dos modelos de propriedade estudados, e tendo em vista os resultados obtidos para cada trabalho com estas alterações, é possível facilmente corroborar esta afirmação.

Além disso, observou-se que a aplicação dos modelos de propriedades em casos extremos permite a obtenção de uma faixa de resultados, na qual será possível avaliar corretamente a validade dos modelos de propriedades uma vez que as condições de modelagem tenham sido estabelecidas corretamente para a seção do evaporador.

Observa-se também que a avaliação dos efeitos da variação da concentração volumétrica de nanopartículas mostra que a modelagem computacional pode ser configurada de forma a refletir corretamente o comportamento observado na literatura, uma vez que o desempenho do sistema pode atingir um valor de máximo em uma determinada concentração volumétrica de nanopartículas em algumas configurações específicas de modelagem das propriedades dos nanofluidos.

Além disso, observa-se que a análise de sensibilidade desta concentração volumétrica fornece base para corroborar a afirmação de que a intensificação proporcional da condutividade térmica obtida por meio da introdução de nanopartículas em fluidos com menor condutividade térmica é proporcionalmente mais intensa do que a obtida em nanofluidos compostos por fluidos-base com maior condutividade térmica, e também fornece base para afirmar que é possível representar computacionalmente situações nas quais ocorre deterioração do desempenho térmico do tubo de calor, tal como ocorre em alguns casos experimentais.

Por fim, é importante destacar como principais aspectos a serem desenvolvidos em futuros estudos a incorporação de condições de contorno considerando automaticamente a condução de calor ao longo da parede do tubo de calor no modelo computacional, a utilização de termos fonte mais complexos para a representação dos 
fenômenos de mudança de fase (capazes de representarem corretamente o fenômeno de ebulição sob convecção em um meio poroso anular) e a introdução de condições de contorno adicionais representando os fenômenos negligenciados que ocorrem no escoamento de um nanofluido em um meio poroso no modelo computacional. 


\section{REFERÊNCIAS}

ANDERSON, J.H.; WATERS, E.D. Permafrost stabilizing heat pipe assembly, United States Patent US 4,036,286, 22 de abril de 1974, 19 de julho de 1977.

ANSYS CFX-Solver Theory Guide, Vol. 15.0, Novembro de 2013. Disponível em: http://148.204.81.206/Ansys/150/ANSYS\%20CFX-solver\%20Theory\%20Guide.pdf. ASMAIE, L.; HAGHSHENASFARD, M.; MEHRABANI-ZEINABAD, A.; NASR ESFAHANY, M. Thermal performance analysis of nanofluids in a thermosyphon heat pipe using CFD modeling, Heat and Mass Transfer, vol. 49, no. 5, pp. 667-678, Maio de 2013.

BUSCHMANN, M.H Nanofluids in thermosyphons and heat pipes: Overview of recent experiments and modelling approaches, International Journal of Thermal Sciences, vol. 72, pp. 1-17, Outubro de 2013.

CABRAL, F.P. Estudo da ebulição convectiva de nanofluidos no interior de microcanais. São Carlos: USP, 2012, 143 p., Dissertação de Mestrado - Programa de Pós Graduação em Engenharia Mecânica e Área de Concentração em Térmica e Fluidos, Escola de Engenharia de São Carlos da Universidade de São Paulo, São Carlos, 2012.

CHI, S.W. Heat pipe theory and practice: A sourcebook. Nova York, Hemisphere Publishing Corporation, 1976.

DING, Y.; ALIAS, H.; WEN, D.; WILLLIAMS, R.A. Heat transfer of aqueous suspensions of carbon nanotubes (CNT nanofluids), International Journal of Heat and Mass Transfer, vol. 49, nos. 1-2, pp. 240-250, Janeiro de 2006.

EASTMAN, J.A.; CHOI, S.U.S.; LI, S.; YU, W.; THOMPSON, L.J. Anomalously increased effective thermal conductivities of ethylene glycol-based nanofluids containing copper nanoparticles, Applied Physics Letters, vol. 78, no. 6, pp. 718720, Fevereiro de 2001.

Ethylene Glycol - Product Guide, The MEGlobal Group of Companies, 2008. Disponível em: $\quad$ http://www.meglobal.biz/media/product guides/MEGlobal MEG.pdf

FAGHRI, A. Heat Pipe Science and Technology. Taylor \& Francis Publishing, 1995.

FASULA, C. Oscillating heat pipes (OHP), Dissertação (Mestrado) - University of Rhode Island, Estados Unidos, maio de 2009. 
GAVTASH, B.; HUSSAIN, K.; LAYEGHI, M.; SADEGHI LAFMEJANI, S. Numerical simulation of the effects of nanofluid on a heat pipe thermal performance, World Academy of Science, Engineering \& Technology, no. 68, pp. 549-555, 2012.

GARG, J.; POUDEL, B.; CHIESA, M.; GORDON, J.B.; MA, J.J.; WANG, J.B.; REN, Z.F.; KANG, Y.T.; OHTANI, H.; NANDA, J.; MCKINLEY, G.H.; CHEN, G. Enhanced thermal conductivity and viscosity of copper nanoparticles in ethylene glycol nanofluid, Journal of Applied Physics, vol. 103, no. 7, artigo 074301, 2008.

GAUGLER, R.S. Heat transfer devices, United States Patent US 2,350,348, 21 de dezembro de 1942, 6 de junho de 1944.

GREEN, D.; PERRY, R. Perry's Chemical Engineers' Handbook. McGraw-Hill Professional, 8ª edição, 2007.

GROVER, G.; COTTER, T.P.; ERICKSON, G.F. Structures of very high thermal conductance, Journal of Applied Physics, vol. 35, no. 6, pp.1990-1991, Junho de 1964.

HALELFADL, S.; ESTELLÉ, P.; ALADAG, B.; DONER, N.; MARÉ, T. Viscosity of carbon nanotubes water based nanofluids - Influence of concentration and temperature, International Journal of Thermal Sciences, vol. 71, pp. 111-117, 2013. HUMINIC, G.; HUMINIC, A. Study on Thermal Performances of the Heat Pipes with Water - Nanoparticles Mixture, SAE Technical Paper 2010-01-0183, In: SAE 2010 World Congress \& Exhibition, Detroit, Michigan, Estados Unidos, 2010.

JEFFREY, D.J. Conduction through a random suspension of spheres, Proceedings of the Royal Society A: Mathematical, Physical and Engineering Science, vol. 335, no. 1602, pp. 355-367, Novembro de 1973.

KAKAÇ, S; PRAMUANJAROENKIJ, A. Review of convective heat transfer enhancement with nanofluids, International Journal of Heat and Mass Transfer , Turquia, vol 52, pp. 3187-3196, 2009.

KANDLIKAR, S.G. A General Correlation for Two-Phase Flow Boiling Heat Transfer Coefficient Inside Horizontal and Vertical Tubes, ASME Journal of Heat Transfer, vol. 112, pp. 219-228, 1990.

KEMPERS, R.; ROBINSON, A.J.; EWING, D.; CHING, C.Y. Characterization of evaporator and condenser thermal resistances of a screen mesh wicked heat pipe, International Journal of Heat and Mass Transfer, vol. 51, nos. 25-26, pp. 6039-6046, Dezembro de 2008. 
KIM, S.J.; BANG, I.C.; BUONGIORNO, J.; HU, L.W. Surface wettability change during pool boiling of nanofluids and its effect on critical heat flux, International Journal of Heat and Mass Transfer, vol. 50, pp. 4105-4116, 2007.

KWAK, K.; KIM, C. Viscosity and thermal conductivity of copper oxide nanofluid dispersed in ethylene glycol, Korea-Australia Rheology Journal, vol. 17, no. 2, pp. 35-40, Junho de 2005.

LAMAS, B.; ABREU, B.;FONSECA, A.;MARTINS, N.; OLIVEIRA, M. Critical analysis of the thermal conductivity models for CNT based properties, International Journal of Thermal Sciences, vol. 78, pp. 65-76, Abril de 2014.

LEE, S.; CHOI, S. U. S.; LI, S.; EASTMAN, J. A. Measuring Thermal Conductivity of Fluids Containing Oxide Nanoparticles, Journal of Heat Transfer, vol. 121, no. 2, pp. 280 289, Maio de 1999.

LEE, J.H.; LEE, S.H.; CHOI, C.J.; JANG, S.P.; CHOI, S.U.S. A Review of Thermal Conductivity Data, Mechanisms and Models for Nanofluids, International Journal of Micro-Nano Scale Transport, vol.1, no. 4, pp. 269-322, 2010.

LI, X.; CHEUNG, S.C.P.; TU, J. Nucleate boiling of dilute nanofluids e Mechanism exploring and modeling, International Journal of Thermal Sciences, vol. 84, pp. 323-334, 2014.

LIU, M.S.; LIN, M.C.C.; HUANG, I.T.;WANG, C.C. Enhancement of thermal conductivity with carbon nanotube for nanofluids, International Communications in Heat and Mass Transfer, vol. 32, no. 9, pp. 1202-1210, Outubro de 2005.

LIU, Z.H.; LI, Y.Y. A new frontier of nanofluid research - Application of nanofluids in heat pipes, International Journal of Heat and Mass Transfer, China, vol. 55, no. 2324, pp. 6786-6797, Novembro de 2012.

LIU, Z.H.; LI, Y.Y.; BAO, R. Thermal performance of inclined grooved heat pipes using nanofluids. International Journal of Thermal Sciences, vol. 49, no. 9, pp. 16801687, Setembro de 2010a.

LIU, Z.H.; LU, L. Thermal performance of an axially microgrooved heat pipe using carbon nanotube suspensions, Journal of Thermophysics and Heat Transfer, vol. 23 , no. 1, pp. $170-175,2009$.

LIU, Z.H.; YANG, X.F.; WANG, G.S.; GUO, G.L. Influence of carbon nanotube suspension on the thermal performance of a miniature thermosyphon, International 
Journal of Heat and Mass Transfer, vol. 53, nos. 9-10, pp. 1914-1920, Abril de 2010b.

MORKOÇ, H.; ÖZGÜR, Ü. Zinc Oxide: Fundamentals, Materials and Device Technology. Wiley-VCH, 2009.

MAHJOUB, S.; MATABROSHAN, A. Numerical simulation of a conventional heat pipe, World Academy of Science, Engineering and Technology, no 39, pp. 117 - 122, 2008. MARTINEZ, I. Properties of gases, 1995-2015. Disponível em: http://webserver.dmt.upm.es/ isidoro/dat1/eGAS.pdf.

MAXWELL, J.C. A Treatise on Electricity and Magnetism, 3르 ed., Clarendon Press, Oxford, 1873.

MISHRA, P.C.; MUKHERJEE, S.; NAYAK, S.K.; PANDA, A. A brief review on viscosity of nanofluids, International Nano Letters, vol. 4, no. 4, pp. 109-120, Dezembro de 2014.

NARAYAN, G.P.; ANOOP, K.B.; DAS, S.K. Mechanism of enhancement/deterioration of boiling heat transfer using stable nanoparticle suspensions over vertical tubes, Journal of Applied Physics, vol. 102, no. 7, artigo 074317, 2007.

O'HANLEY, H.; BUONGIORNO, J.; MCKRELL, T.; HU, L.W. Measurement and model validation of nanofluid specific heat capacity with differential scanning calorimetry, Advances in Mechanical Engineering, vol. 2012, artigo 181079, 6 páginas, 2012.

ONG, S.S.; WALWEKAR, R. Heat transfer enhancement using CNT nanofluids in a turbulent flow heat exchanger - an experimental study, In: EURECA 2013 conference, 1-2 de Julho, 2013, Taylors University, Malásia.

PAK, B.C.; CHO, Y.I. Hydrodynamic and heat transfer study of dispersed fluids with submicron metallic oxide particles, Experimental Heat Transfer: A Journal of Thermal Energy Generation, Transport, Storage, and Conversion, vol. 11, no. 2, pp.151-170, 1998.

PASTORIZA-GALLEGO, M.J.; LUGO, L.; CABALEIRO, D.; LEGIDO, J.L.; PIÑEIRO, M.M. Thermophysical profile of ethylene glycol-based ZnO nanofluids, Applied Energy, vol. 135,pp. 548-559, Dezembro de 2014.

PEYGHAMBARZADEH, S.M.; HASHEMABADI, S.H.; HOSEINI, S.M.; SEIFI JAMNANI, M. Experimental study of heat transfer enhancement using water/ethylene glycol based nanofluids as a new coolant for car radiators, International 
Communications in Heat and Mass Transfer, vol. 38, no. 9, pp. 1283-1290, Novembro de 2011.

PRASHER, R.; SONG, D.; WANG, J.; PHELAN, P. Measurements of nanofluid viscosity and its implications for thermal applications, Applied Physics Letters, vol. 89, artigo 133108, 2006.

PUTRA, N.; SEPTIADI, W.N.; RAHMAN, H.; IRWANSYAH, R. Thermal performance of screen mesh wick heat pipes with nanofluids, Experimental Thermal and Fluid Science, vol. 40, pp. 10-17, Julho de 2012.

RASHIDI, F.; NEZAMABAD, N.M. Experimental investigation of convective heat transfer coefficient of CNTs nanofluid under constant heat flux. In: Proceedings of the World Congress on Engineering 201, Vol III WCE 2011, 6 - 8 de Julho, 2011, Londres, Reino Unido.

RASHMI, W.; KHALID, M.; ISMAIL, A.F.; SAIDUR, R.; RASHID, A.K. Experimental and numerical investigation of heat transfer in CNT nanofluids, Journal of Experimental Nanoscience, vol. 10, no. 7, pp. 545-563, 2013.

SAIDUR, R.; LEONG, K.Y.; MOHAMMAD, H.A. A review on applications and challenges of nanofluids, Renewable and Sustainable Energy Reviews, vol. 15, no.3, pp. 16461668, Abril de 2011.

SHAFAHI, M.; BIANCO, V.; VAFAI, K.; MANCA, O. An investigation of the thermal performance of cylindrical heat pipes using nanofluids, vol. 53, nos. 1-3, pp. 376 - 383, Janeiro de 2010.

SHANBEDI, M.; HERIS, S.Z.; BANJADAM, M.; AMIRI, M.; MAGHREBI, M. Investigation of heat-transfer characterization of EDA-MWCNT/DI-Water nanofluid in a twophase closed thermosyphon, Industrial and Engineering Chemistry Research, vol. 51, no. 3, pp. 1423-1428, 2012.

SUGANTHI, K.S.; LEELA VINODHAN, V.; RAJAN, K.S. Heat transfer performance and transport properties of ZnO-ethylene glycol and $\mathrm{ZnO}$-ethylene glycol-water nanofluid coolants, Applied Energy, vol. 135, pp. 548-559, Dezembro de 2014.

SUNDAR, L.S.; RAMANA, E.V.; SINGH, M.K.; SOUSA, A.C.M. Thermal conductivity and viscosity of stabilized ethylene glycol and water mixture Al203 nanofluids for heat transfer applications: An experimental study, International Communications in Heat and Mass Transfer, vol. 56, pp. 86-95, Agosto de 2014. 
SURESHKUMAR, R.; MOHIDEEN, S.T.; NETHAJI, N. Heat transfer characteristics of nanofluids in heat pipes: A review, Renewable and Sustainable Energy Reviews, vol. 20, pp. 397-410, Abril de 2013.

TAYLOR, R.A.; PHELAN, P.E. Pool boiling of nanofluids: Comprehensive review of existing data and limited new data, International Journal of Heat and Mass Transfer, no. 52, pp. 5339-5347, 2009.

Thermal-Fluids Central - Free Online Resource for Heat and Mass Transfer, Thermodynamics, Fluid Mechanics, Combustion, and Multiphase Systems, 2010-2011. Disponível em: https://www.thermalfluidscentral.org/.

WALLIN, P. Heat pipe, selection of working fluid, Project Report , MVk 160 Heat and Mass Transfer, Lund, Suécia, 2012.

WEN, D.; DING, Y. Effective thermal conductivity of aqueous suspensions of carbon nanotubes (carbon nanotube nanofluids), Journal of Thermophysics and Heat Transfer, vol. 18, no. 4 pp. 481-485, 2004.

WONG, S. C. The Evaporation Mechanism in the Wick of Copper Heat Pipes. Springer, 2014, ISBN 978-3-319-04495-8.

XIE, H.; LEE, H.; YOU, W.; CHOI, M. Nanofluids containing multiwalled carbon nanotubes and their enhanced thermal properties, Journal of Applied Physics, vol. 94, no. 8, pp. 4967-4971, 2003.

XIE, H.; YU, W.; LI, Y.; CHEN, L. Discussion on the thermal conductivity enhancement of nanofluids, Nanoscale Research Letters, vol. 6, no. 1, artigo 124, 2011.

XUAN, Y.; ROETZEL, W. Conceptions for heat transfer correlation of nanofluids, International Journal of Heat and Mass Transfer, vol. 43, pp. 3701-3707, 2000.

XUE, H.; FAN, J.; HU, Y.; HONG, R.; CEN, K. The interface effect of carbon nanotube suspension on the thermal performance of a two-phase closed thermosyphon, Journal of Applied Physics, vol. 10, no. 10, artigo 104909, 2006.

YANG, D.J.; ZHANG, Q.; CHEN, G.; YOON, S.F.; AHN, J.; WANG, S.G.; ZHOU, Q.; WANG, Q.; LI, J.Q. Thermal conductivity of multiwalled carbon nanotubes, Physical Review B, vol. 66, artigo 165440, Outubro de 2002.

YOU, S.M.; KIM, J.H.; KIM, K.M. Effect of nanoparticles on critical heat flux of water in pool boiling of heat transfer, Applied Physics Letters, no. 83. pp. 3374-3376, 2003. 
YU, W.; XIE, H.; CHEN, L.; LI, Y. Investigation of thermal conductivity and viscosity of ethylene glycol based ZnO nanofluid, Thermochimica Acta, vol. 491, nos. 1-2, pp. 92-96, Julho de 2009.

ZERBINI, E.J.G. J. Um estudo analítico - experimental de um "heat pipe" de temperatura moderada. São Paulo: USP, 1984, 97 p., Dissertação de Mestrado Programa de Pós Graduação em Engenharia Mecânica, Escola Politécnica, Universidade de São Paulo, São Paulo, 1984.

ZHU, N.; VAFAI, K. Analysis of cylindrical heat pipes incorporating the effects of liquid-vapor coupling and non-Darcian transport - a closed form solution, International Journal of Heat and Mass Transfer, vol. 42, no. 18, pp. 3405-3418, Setembro de 1999. 


\section{APÊNDICE A - ANÁLISE DA CONSERVAÇÃO DA ENERGIA NA PAREDE DO TUBO DE CALOR}

O objetivo desta análise complementar consiste em determinar valores aproximados para a fração da potência térmica inserida nos tubos de calor estudados que é conduzida pela parede da seção do evaporador destes tubos de calor em direção à seção adiabática e, desta forma, não contribui para a evaporação do fluido de trabalho no interior destes tubos de calor. Deseja-se obter como resultado final a quantidade complementar a esta fração de potência térmica, ou seja, a quantidade de calor efetivamente responsável pela evaporação do fluido na matriz porosa, sendo esta fração de interesse definida por meio de um parâmetro $\eta$.

Para isso, os efeitos desta condução de calor são avaliados por meio dos perfis de temperatura obtidos das simulações computacionais do tubo de calor de Zerbini (1984) sob condições de potência térmica inserida de 24 W, 37 W e 49 W.

Para a realização desta análise, foi feito um balanço de energia ao redor da parede localizada na seção do evaporador deste tubo de calor. A representação esquemática da Fig. 68 mostra como foi definido o volume de controle pelo qual se realizou este balanço de energia.

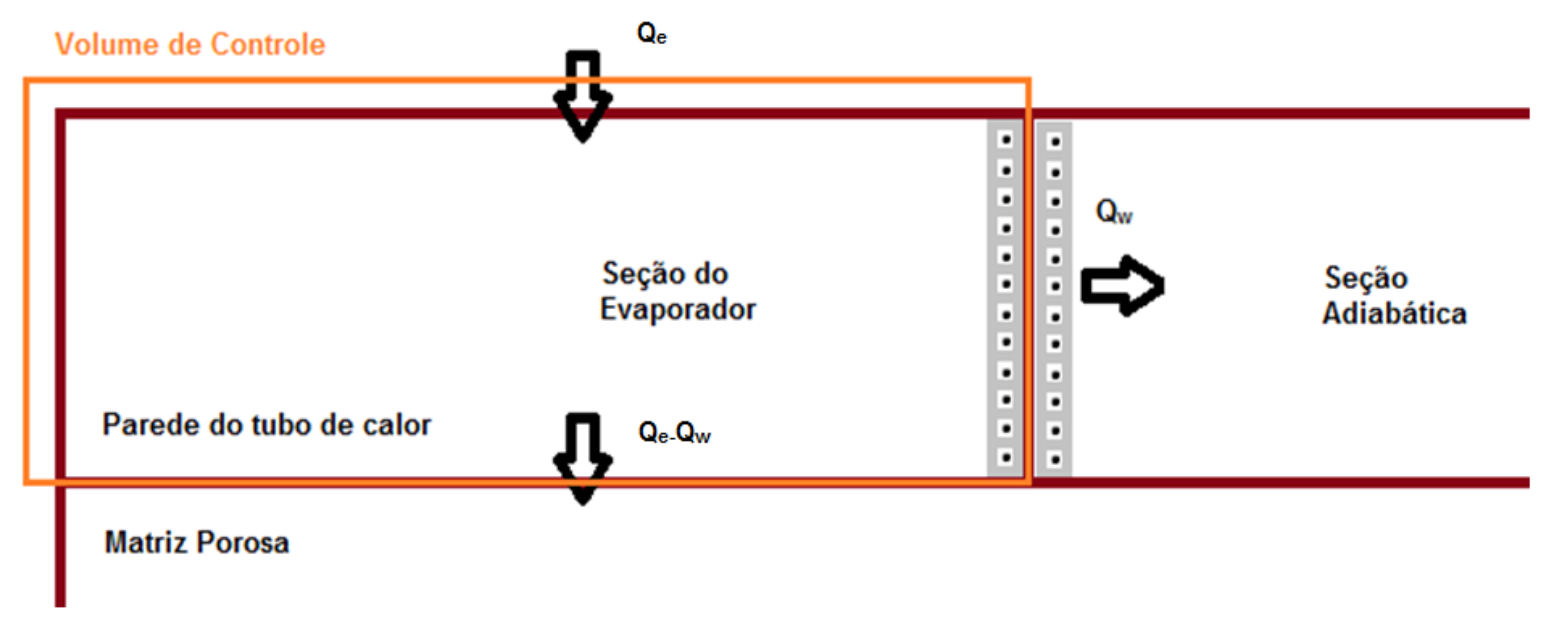

Figura 68. Representação esquemática do balanço de energia feito na parede da seção do evaporador do tubo de calor de Zerbini (1984)

Observa-se da Figura 68 que uma quantidade de calor $Q_{e}$ é introduzida neste volume de controle na seção do evaporador e que uma quantidade de calor $Q_{w}$ é extraída 
da seção do evaporador por meio da condução de calor, restando uma quantidade de calor $\left(Q_{e}-Q_{w}\right)$ para a evaporação do fluido de trabalho.

Com a determinação deste volume de controle envolvendo a parede do tubo de calor presente na seção do evaporador, foi possível realizar o cálculo da quantidade de calor que é transferida da seção do evaporador para a seção adiabática por meio de condução ao longo desta parede.

Este cálculo é feito assumindo a hipótese de que a condução de calor ocorre de forma aproximadamente unidimensional ao longo da parede do tubo de calor. Esta hipótese pode ser verificada observando que a diferença de temperatura entre as faces interna e externa da parede do tubo de calor é praticamente desprezível (na ordem de $0,05 \mathrm{~K})$.

Desta forma, uma vez que o programa CFX fornece o valor das temperaturas no centro dos volumes que compõem a fronteira entre a seção do evaporador e a seção adiabática, pode-se utilizar a equação de condução unidimensional entre os volumes adjacentes da parede do tubo de calor que formam a fronteira entre a seção do evaporador e a seção adiabática, considerando que as dimensões são pequenas o suficiente para que a derivada da temperatura em relação ao espaço possa ser aproximada para a variação linear de temperatura entre os volumes que compõem esta fronteira, dividida pela distância entre eles, da seguinte forma:

$$
Q_{w}=k_{w} \mathrm{~A}_{v o l} \frac{\Delta T}{\Delta y}
$$

Para o tubo de calor de Zerbini (1984), os valores da condutividade térmica, da distância entre o centro dos volumes e da área de contato entre os volumes, de acordo com as características do modelo elaborado, correspondem a $401 \mathrm{~W} / \mathrm{m} . \mathrm{K}, 1,25 \mathrm{~mm}$ e 0,2 $\mathrm{mm}^{2}$. As temperaturas utilizadas nesta análise são determinadas no centro dos volumes que compõem a fronteira entre a seção do evaporador e a seção adiabática (pontos de cor preta no centro dos volumes de cor cinza).

Com esta modelagem em mente, foram levantados os perfis de temperatura destes pontos para o cálculo de $Q_{w}$ utilizando diferentes quantidades de calor transmitidas para a matriz porosa $\left(Q_{e}-Q_{w}\right)$. Inicialmente, utilizou-se uma quantidade de aproximadamente $100 \%$ do calor recebido pela seção do evaporador para $\left(Q_{e}-Q_{w}\right)$ para a 
obtenção de um primeiro perfil de temperaturas. A partir deste perfil de temperaturas, tornou-se possível realizar um processo recursivo de redução desta porcentagem utilizada, alocando $0,5 \%$ de $Q_{e}$ para $Q_{w}$ sucessivamente. Como condição de parada desta recursão, definiu-se que no momento que a diferença entre o valor obtido do balanço de energia para $\left(Q_{e}-Q_{w}\right)$ e o valor adotado inicialmente para $\left(Q_{e}-Q_{w}\right)$ atingisse um valor menor ou igual a estes mesmos $0,5 \%$ de $Q_{e}$, o valor adotado para $\left(Q_{e}-Q_{w}\right)$ seria definido como a porcentagem adequada.

Os resultados finais desta análise para cada potência térmica inserida no tubo de calor de Zerbini (1984) podem ser observados na Tabela 37.

Os valores encontrados estão dentro das faixas definidas por Kempers et al. (2008) e Wong (2014) para um tubo de calor contendo água. Análises semelhantes foram realizadas nos tubos de calor de Liu e Lu (2009) e Putra et al. (2012) de forma a definir os valores dos parâmetros $\eta$ nestes tubos de calor, e os valores das porcentagens obtidas podem ser observados nas Tabs. 16 e 22 do presente estudo.

Tabela 37. Resultados obtidos para a análise da porcentagem de calor conduzido pela parede do tubo de calor da seção do evaporador para a seção adiabática

\begin{tabular}{cccccc}
\hline Caso & $Q_{e}$ & $\begin{array}{c}\text { Porcentagem } \\
\text { adotada }(\eta)\end{array}$ & $Q_{\mathrm{w}}$ & $\frac{Q_{e}-Q_{w}}{Q_{e}}$ & Diferença \\
\hline $24 \mathrm{~W}$ & 0,602 & $99,0 \%$ & 0,008 & $98,7 \%$ & $0,3 \%$ \\
\hline $37 \mathrm{~W}$ & 0,927 & $98,5 \%$ & 0,017 & $98,2 \%$ & $0,3 \%$ \\
\hline $49 \mathrm{~W}$ & 1,228 & $98,5 \%$ & 0,025 & $98,0 \%$ & $0,5 \%$ \\
\hline
\end{tabular}




\section{APÊNDICE B - ANÁLISE DA CONSERVAÇÃO DA ENERGIA NO TUBO DE} CALOR DE PUTRA ET AL. (2012)

O objetivo desta análise complementar consiste em fornecer uma estimativa apropriada para a quantidade de calor que é retirada do tubo de calor de Putra et al. (2012) pela seção do condensador, levando em consideração a condição de contorno adicional aplicada na extremidade desta seção do tubo de calor, de forma a fixar a temperatura desta posição em $25{ }^{\circ} \mathrm{C}$.

Para isso, os efeitos causados por esta condição de contorno são avaliados por meio dos perfis de temperatura obtidos das simulações computacionais do tubo de calor de Putra et al. (2012) contendo água e etilenoglicol puros.

Para a realização desta análise, foi feito um balanço de energia ao redor da parede localizada na seção do condensador deste tubo de calor. A representação esquemática da Fig. 69 mostra como foi definido o volume de controle pelo qual se realizou este balanço de energia.

A Figura 69 mostra que na seção do condensador do tubo de calor de Putra et al. (2012), ocorrem dois fluxos de entrada e dois fluxos de saída de calor.

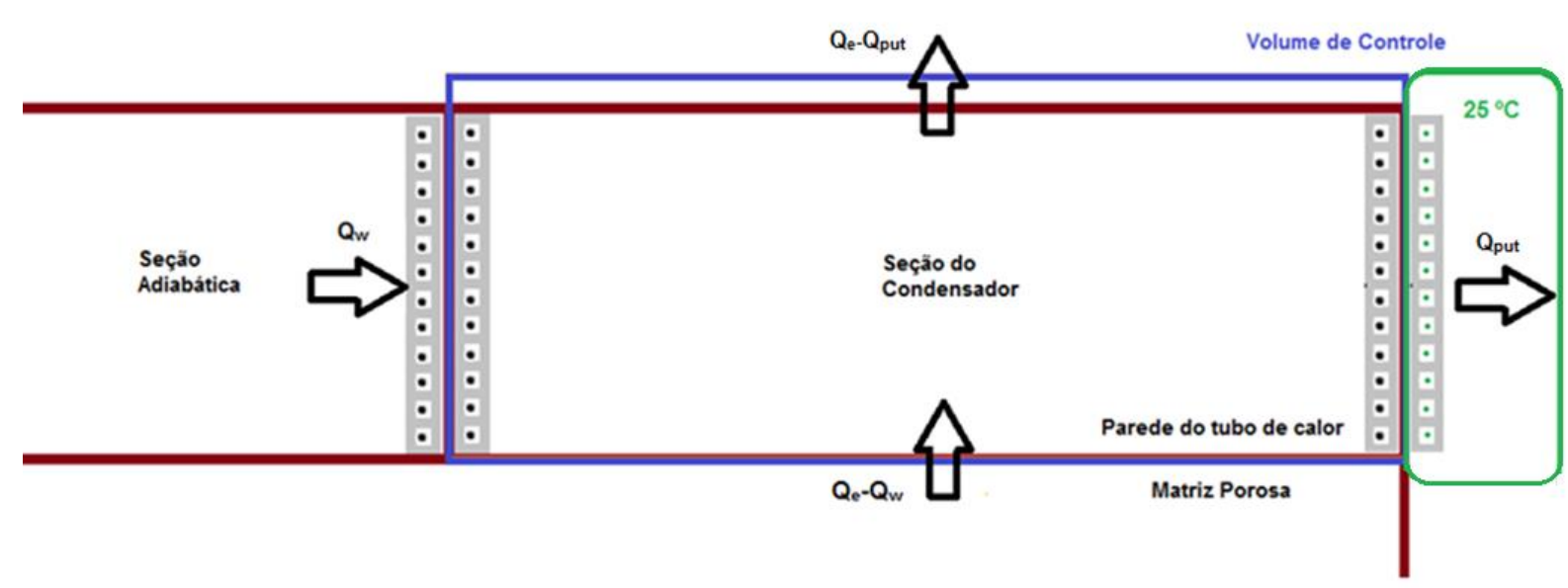

Figura 69. Representação esquemática do balanço de energia feito na parede da seção do condensador do tubo de calor de Putra et al. (2012)

Os fluxos de entrada correspondem a quantidade de calor conduzida por meio da parede do tubo de calor, cuja forma de determinação já foi definida por meio do balanço 
de energia realizado para este tubo de calor no apêndice 1 , e será novamente denominada $Q_{w}$, e a quantidade de calor obtida através do processo de condensação que ocorre na matriz porosa, cujo valor já foi definido por meio do balanço de energia realizado para este tubo de calor no apêndice 1 , e será novamente denominada $\left(Q_{e}-Q_{w}\right)$. Assim, pela conservação da energia, existe um fluxo de calor igual a $Q_{e}$ entrando na seção do condensador do tubo de calor de Putra et al. (2012).

Entretanto, o fluxo de saída da seção do condensador possui duas partes, sendo uma delas correspondente a quantidade de calor extraída pela condição de contorno referente à temperatura fixa de $25{ }^{\circ} \mathrm{C}$ adotada na posição indicada em verde na Figura 65. Para a avaliação desta quantidade $Q_{p u t}$, considerou-se a existência de pseudovolumes de temperatura fixa igual a $25{ }^{\circ} \mathrm{C}$ (volumes contendo pontos de cor verde) posicionados adjacentes aos volumes localizados nesta extremidade do tubo de calor, permitindo assim o cálculo de um fluxo de calor equivalente utilizando a Equação [88] do apêndice 1. Neste caso, para o tubo de calor de Putra et al. (2012), os valores da condutividade térmica, da distância entre o centro dos volumes e da área de contato entre os volumes, de acordo com as características do modelo elaborado, correspondem a $401 \mathrm{~W} / \mathrm{m} . \mathrm{K}, 0,2 \mathrm{~mm}$ e $0,05 \mu \mathrm{m}^{2}$.

Por fim, para a determinação do fluxo de calor remanescente, correspondente a quantidade de calor de interesse desta análise, deve-se subtrair o valor de $Q_{p u t}$ do fluxo de entrada $Q_{e}$. Com isto em mente, foram levantados os perfis de temperatura dos pontos posicionados nas fronteiras deste volume de controle para diferentes valores de $Q_{p u t}$. Inicialmente, considerou-se $Q_{p u t}=0$ para a obtenção de um primeiro perfil de temperaturas. A partir deste perfil de temperaturas, tornou-se possível realizar um processo recursivo de incremento do valor de $Q_{p u t}$, acrescentando 0,5\% de $Q_{e}$ por vez. Como condição de parada desta recursão, definiu-se que no momento que a diferença obtida entre o balanço de energia e a porcentagem utilizada atingisse um valor menor ou igual a estes mesmos $0,5 \%$ de $Q_{e}$, o valor utilizado como $\left(Q_{e}-Q_{p u t}\right)$ seria definido como a porcentagem adequada.

Este processo recursivo teve como resultado os valores indicados na Tab. 38 para cada fluido aplicado no tubo de calor de Putra et al. (2012). 
Tabela 38. Resultados obtidos para a análise da porcentagem de calor retirado pela condição de contorno da seção do condensador do tubo de calor de Putra et al. (2012)

\begin{tabular}{cccccccc}
\hline Caso & $\begin{array}{c}\text { Porcentagem } \\
\text { utilizada }\end{array}$ & $\mathrm{Q}_{\mathrm{w}}$ & $\mathrm{Q}_{\mathrm{e}}-\mathrm{Q}_{\mathrm{w}}$ & $\mathrm{Q}_{\text {put }}$ & $\mathrm{Q}_{\mathrm{e}}-\mathrm{Q}_{\text {put }}$ & $\frac{Q_{p u t}}{Q_{e}}$ & Diferença \\
\hline Água & $3,5 \%$ & 0,012 & 2,381 & 0,092 & 2,301 & $3,6 \%$ & $0,1 \%$ \\
\hline Etilenoglicol & $3,5 \%$ & 0,021 & 2,375 & 0,103 & 2,293 & $4,0 \%$ & $0,5 \%$ \\
\hline
\end{tabular}

Observou-se através desta análise que esta temperatura fixa provoca a extração de cerca de 3,5\% do calor que atinge a seção do condensador. Assim, o valor de $\left(Q_{e}-Q_{p u t}\right)$ aplicado nas simulações computacionais do tubo de calor de Putra et al. (2012) foi considerado como sendo sempre igual a 96,5\% de $Q_{e}$. 